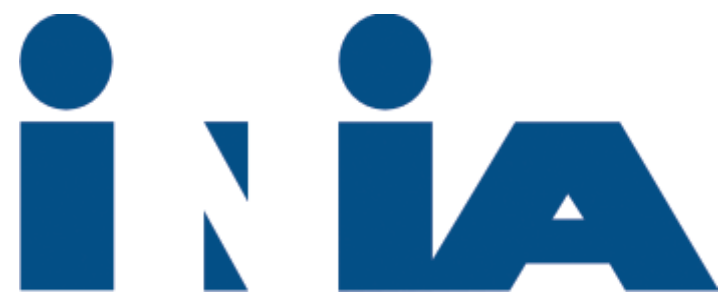

INSTITUTO NACIONAL DE INVESTIGACIÓN AGROPECUARIA

URUGUAY
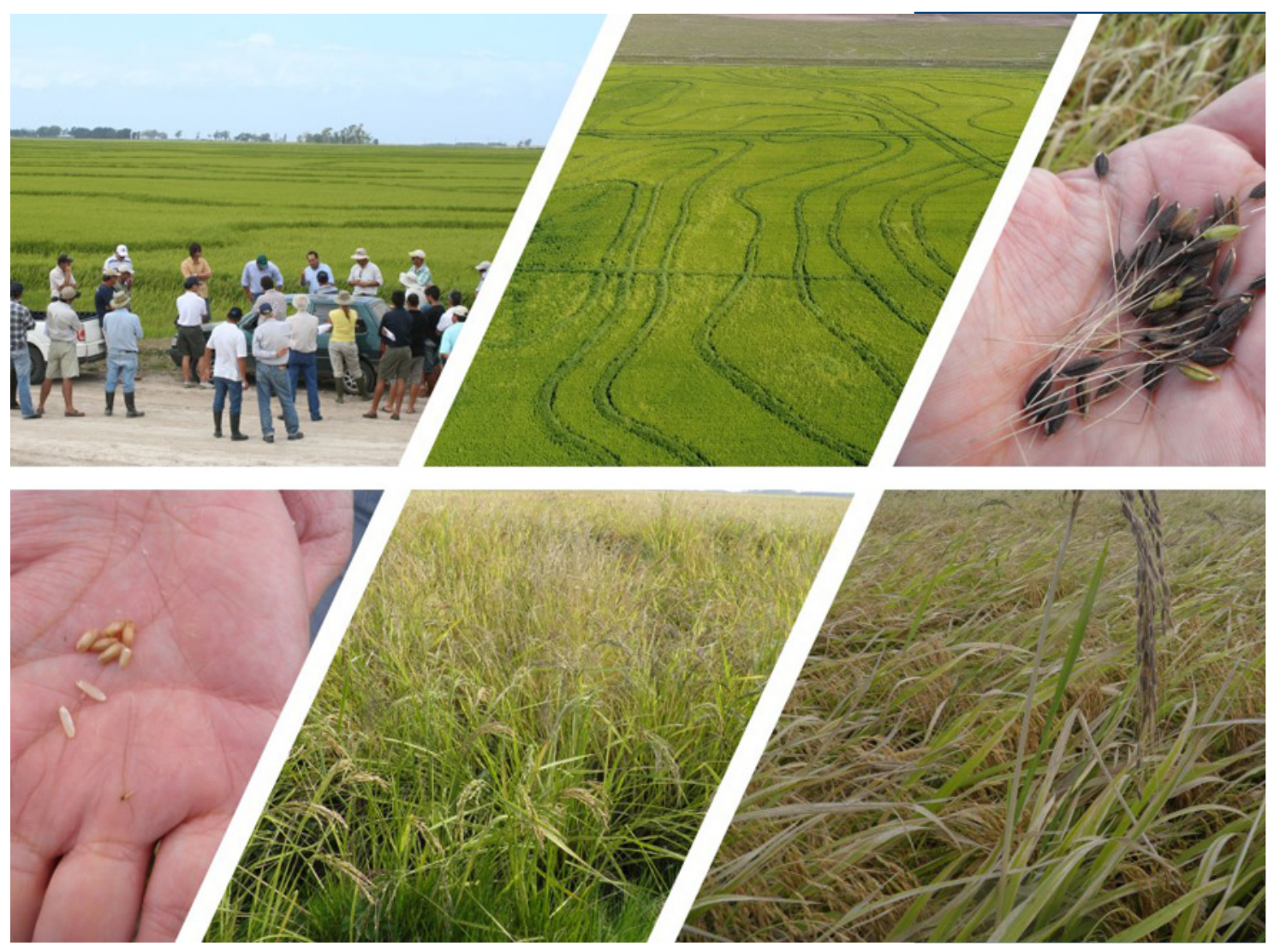

MANEJO

SUSTENTABLE

DEL ARROZ

RESISTENTE A LAS

IMIDAZOLINONAS

Diciembre, 2021

SERIE TÉCNICA

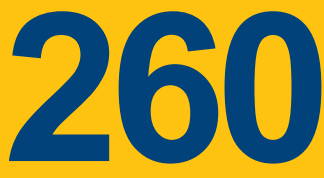

INIA 


\title{
MANEJO SUSTENTABLE DEL ARROZ RESISTENTE A LAS IMIDAZOLINONAS
}

\author{
Autores: Néstor Saldain * \\ Claudia Marchesi ** \\ Juan E. Rosas *** \\ Ana Laura Pereira **** \\ Editores: Horacio Saravia ***** \\ Belky Mesones ${ }^{* * * * * *}$
}

* Ing. Agr. M.Sc. INIA. Programa Nacional de Investigación en Producción de Arroz.

** Ing. Agr. M. Sc. PhD. INIA. Programa Nacional de Investigación en Producción de Arroz.

*** Lic. M. Sc. Dr. INIA. Programa Nacional de Investigación en Producción de Arroz.

**** D. Sc. INIA. Unidad de Semillas.

***** Ing. Agr. M. Sc. INIA. Unidad de Comunicación y Transferencia de Tecnología.

***** Lic. Bibliotecología, Biblioteca INIA Treinta y Tres. 
Título: MANEJO SUSTENTABLE DEL ARROZ RESISTENTE A LAS IMIDAZOLINONAS

Autores: Néstor Saldain

Claudia Marchesi

Juan E. Rosas

Ana Laura Pereira

Editores: Horacio Saravia

Belky Mesones

Serie Técnica $\mathrm{N}^{\circ} 260$

(C) 2021, INIA

doi: http://doi.org/10.35676/INIA/ST.260

e-ISBN: 978-9974-38-463-7

Editado por la Unidad de Comunicación y Transferencia de Tecnología del INIA

Avda. Italia 6201, Edificio Los Guayabos, Parque Tecnológico del LATU, Montevideo, Uruguay.

http://www.inia.uy

Quedan reservados todos los derechos de la presente edición. Esta publicación no se podrá reproducir total o parcialmente sin expreso consentimiento del INIA. 


\section{Instituto Nacional de Investigación Agropecuaria}

\section{Integración de la Junta Directiva}

Ing. Agr. José Bónica - Presidente

Ing. Agr. Walter Baethgen - Vicepresidente

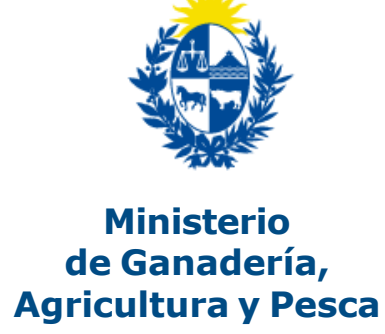

Ing. Agr. Rafael Secco

Ing. Agr. Martín Gortari
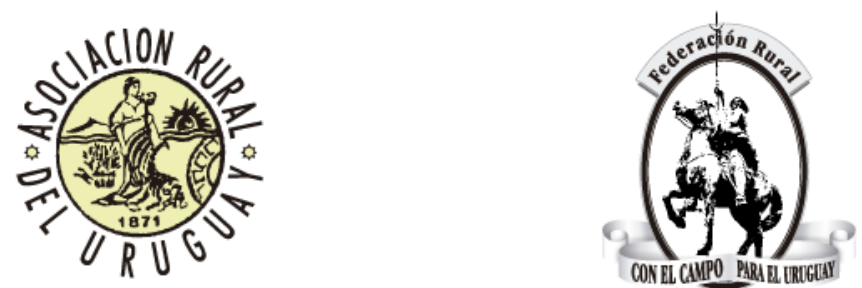

Ing. Agr. Alberto Bozzo

Ing. Agr. Alejandro Henry
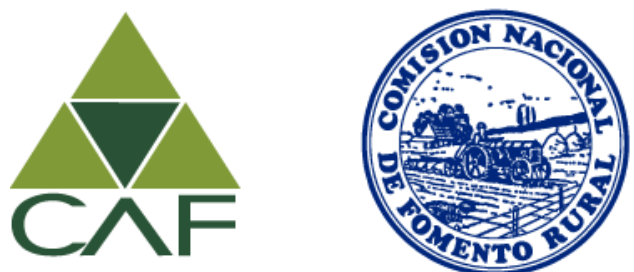


\section{CONTENIDO}

INTRODUCCIÓN

Página

1 - LA PROBLEMÁTICA DEL ARROZ MALEZA Y SU CONTROL CON EL ARROZ RESISTENTE A LAS IMIDAZOLINONAS

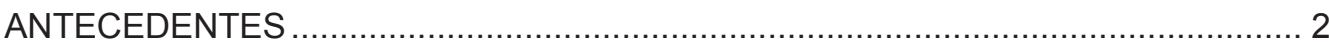

Evolución del arroz maleza en el país ..................................................................... 2

Control del arroz maleza previo a la nueva tecnología ............................................ 3

Evolución del área sembrada con arroz resistente a las imidazolinonas ................. 4

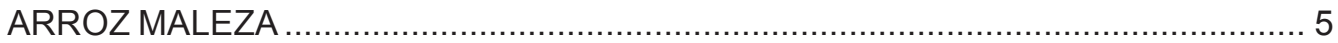

Origen del arroz maleza (arroz rojo o arroz macho) ........................................... 5

Características que facilitan su persistencia en el agroecosistema del arroz .......... 7

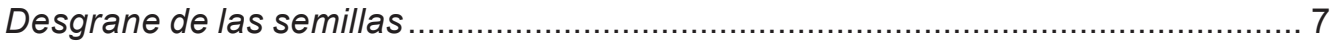

Color del pericarpio/dormancia de las semillas ..................................................... 7

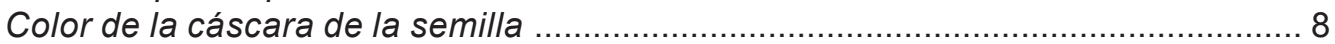

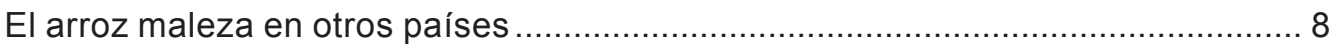

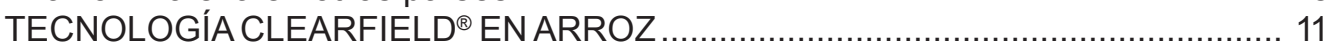

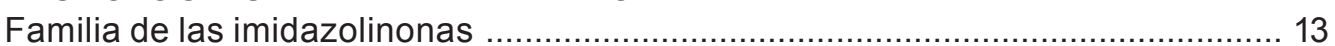

Estructura esquelética de las imidazolinonas asociadas al arroz resistente ......... 13

Modo de acción de las imidazolinonas .............................................................. 13

Comportamiento de las imidazolinonas en el agua y suelo ................................. 14

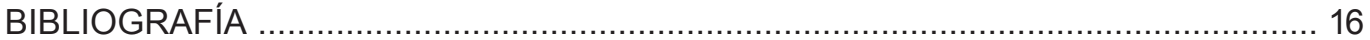

2 - RECOMENDACIONES PARA UN MANEJO SUSTENTABLE DEL ARROZ RESISTENTE A IMIDAZOLINONAS Y HERRAMIENTAS DE APOYO DISPONIBLES ... 19

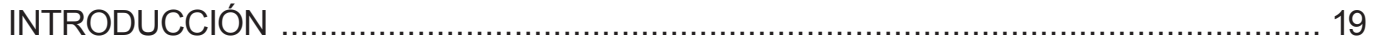

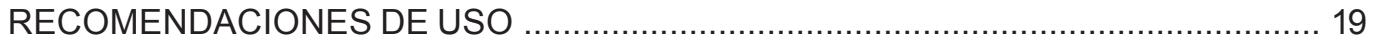

¿QUÉ OTROS CULTIVOS PUEDO INCORPORAR AL SISTEMA? ........................... 20

HERRAMIENTAS DE APOYO DISPONIBLES .................................................... 22

3 - IMPORTANCIA DE LA SEMILLA CERTIFICADA EN LA CONTENCIÓN DEL

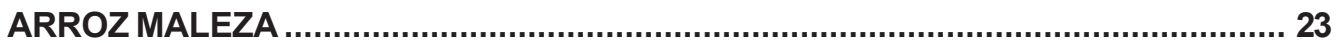

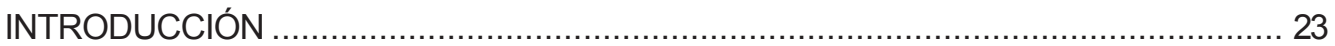

SISTEMA NACIONAL PARA PRODUCCIÓN DE SEMILLA DE ARROZ ........................ 23

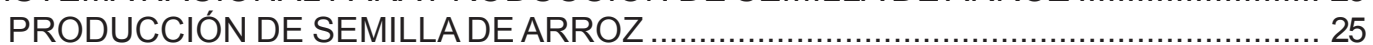

RESULTADOS DE LA CREACIÓN Y MANTENIMIENTO DEL PROGRAMA DE CERTIFICACIÓN DE SEMILLAS DE ARROZ ................................................... 26

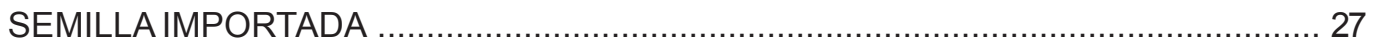

LAS FORTALEZAS DEL SISTEMA EN EL USO Y ADOPCIÓN DE SEMILLAS

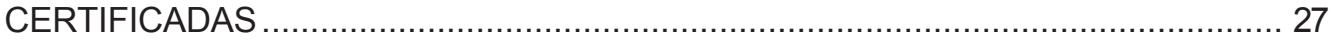

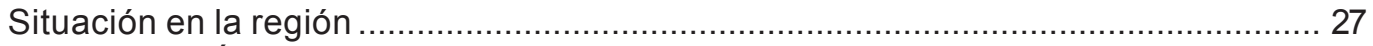

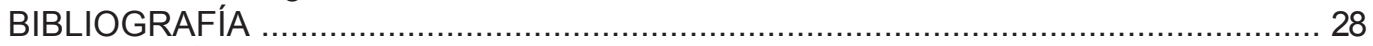

4 - FLUJO GÉNICO DEL ARROZ CLEARFIELD ${ }^{\circledR}$ AL ARROZ MALEZA: ESTUDIO

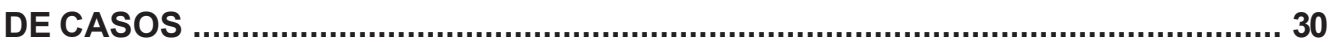

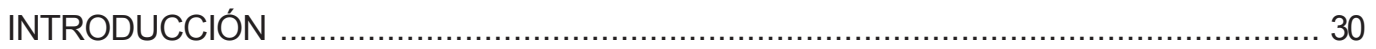

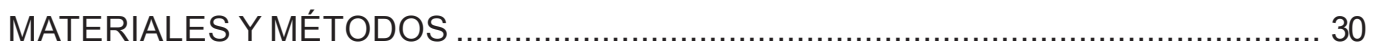

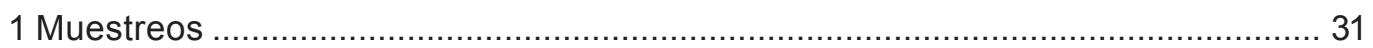

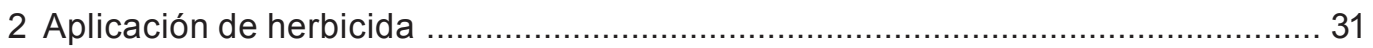

3 Detección molecular de mutaciones de resistencia ............................................... 32

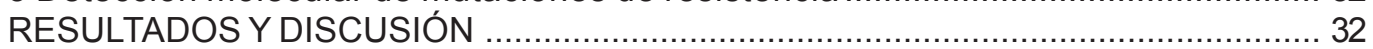

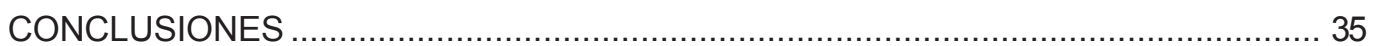

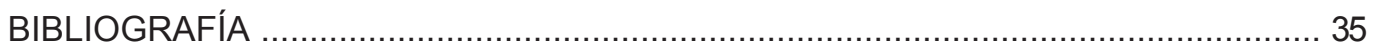


5 - MONITOREO DE MUTACIONES DE RESISTENCIA A IMIDAZOLINONAS EN

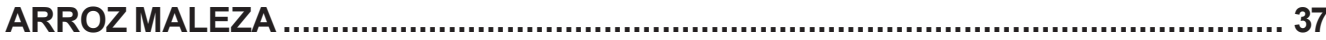

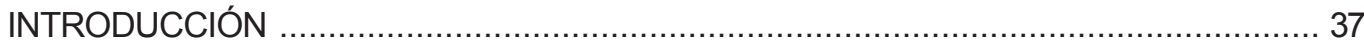

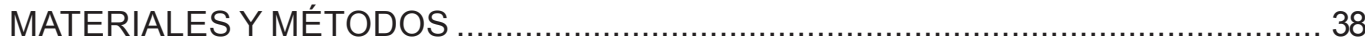

Muestras analizadas en el SDRI y conjuntos de datos para análisis estadísticos .... 38

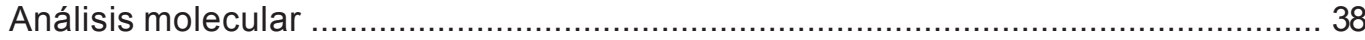

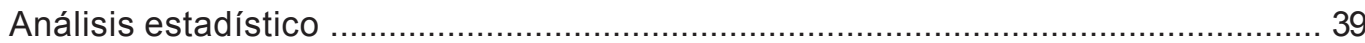

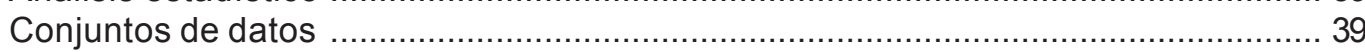

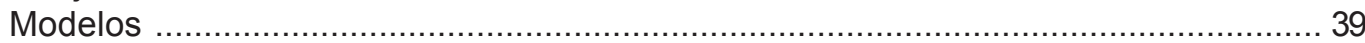

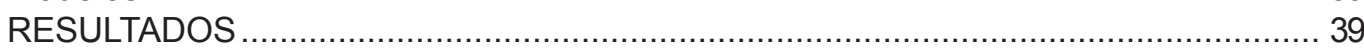

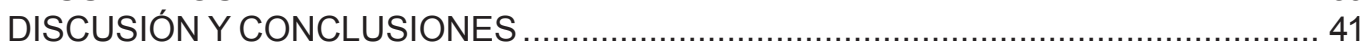

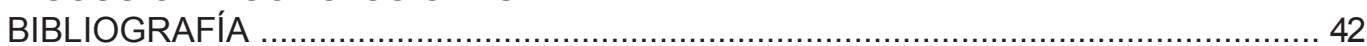

6 - RESISTENCIA DE CAPINES A HERBICIDAS EN SISTEMAS DE PRODUCCIÓN

DE ARROZ.

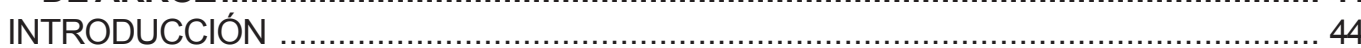

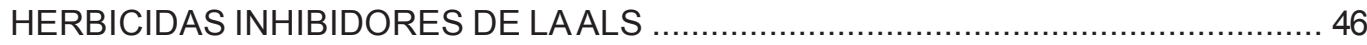

MALEZAS PROBLEMA EN SISTEMAS ARROCEROS ....................................... 48

MALEZAS RESISTENTES EN SISTEMAS ARROCEROS DE URUGUAY ................. 50

ESTRATEGIAS PARA REDUCIR EL RIESGO DE EVOLUCIÓN A BIOTIPOS

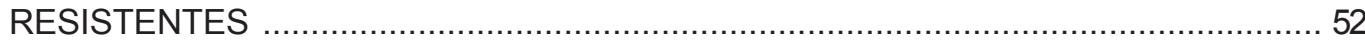

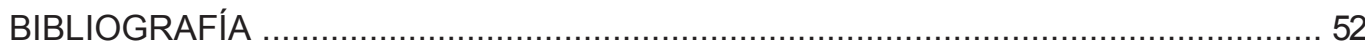

7 - DISIPACIÓN DE LOS RESIDUOS REMANENTES DE LAS IMIDAZOLINONAS

Y SU INCIDENCIA EN LOS CULTIVOS SIGUIENTES ....................................... 56

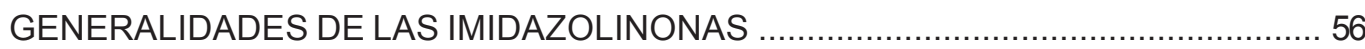

DINÁMICA DEL PH EN EL SUELO BAJO INUNDACIÓN ...................................... 58

¿CÓMO SE COMPORTAN LOS RESIDUOS DE LAS IMIDAZOLINONAS EN EL PERFIL

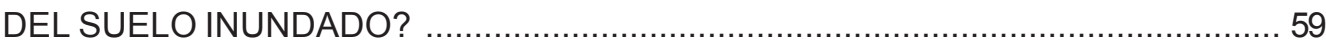

Disipación de los residuos de las imidazolinonas en el agua de riego .....................6. 62

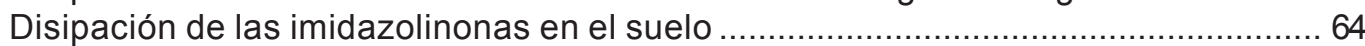

Efecto de las imidazolinonas en los cultivos siguientes ....................................... 67

Susceptibilidad de las especies forrajeras a los residuos remanentes del imazapir

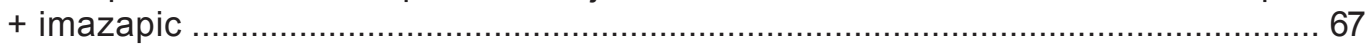

Efecto de los residuos del imazapir + imazapic sobre la productividad inicial de la pastura . 69

Efecto de los residuos del imazapir + imazapic en la secuencia arroz CL, raigrás,

arroz no CL y/o sorgo forrajero bajo siembra directa ......................................... 72

Efecto de los residuos remanentes del imazapir + imazapic en arroz no CL bajo

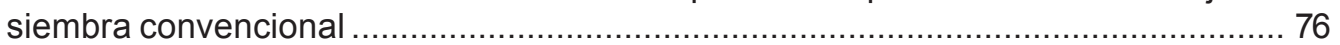

Efecto de los residuos remanentes del imazapir + imazapic sobre la soja siguiente ... 77

¿CÓMO MITIGAR LOS EFECTOS NO DESEADOS DE LOS RESIDUOS REMANENTES

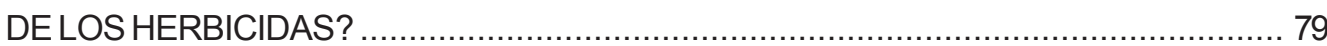

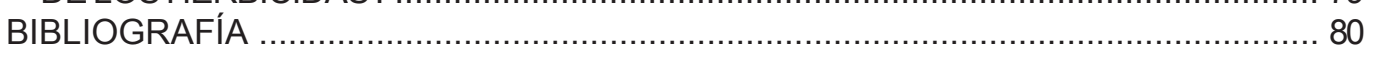

8 - EL USO SOSTENIBLE DEL ARROZ RESISTENTE A IMIDAZOLINONAS

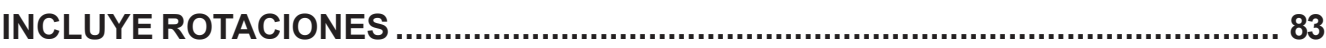

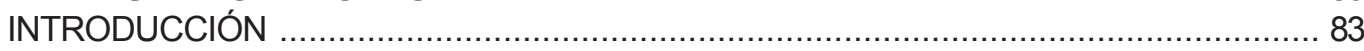

¿Qué pasó con las poblaciones del arroz maleza? ................................................ 83

¿Qué pasó con las poblaciones de capín? ............................................................ 84

¿Qué pasó con la acumulación de los residuos de imazapir + imazapic? ................. 84

¿Qué pasó con la deriva de los herbicidas? ....................................................... 85

¿Qué pasó cuando en el apuro no se leen las etiquetas de los herbicidas a utilizar? .. 86

¿Qué estrategias se deben de usar para minimizar los efectos no deseados? ......... 87

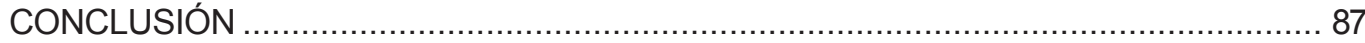

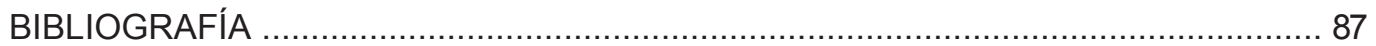




\section{ÍNDICE DE FIGURAS}

\section{Capítulo 1.}

Figura 1. Evolución del área sembrada con arroz y y con arroz resistentes a las imidazolinonas, y de la productividad del arroz en el período 1991- 2019.

Página

Figura 2. Díptico de difusión de COOPAR SA destinado a promover distintas prácticas culturales para reducir las poblaciones de plantas de arroz maleza de las chacras con infestación.

Figura 3. Esquema esquelético básico de los herbicidas usados en el arroz Clearfield ${ }^{\bullet} . . . .13$

\section{Capítulo 3.}

Figura 1. Esquema explicativo del Sistema Nacional para Producción de Semillas de Arroz en Uruguay, sus categorías de multiplicación y actores involucrados 24

Figura 2. Evolución de la proporción de semilla de arroz certificada, comercial y sin categoría en Uruguay.

\section{Capítulo 4.}

Figura 1. Marcación de puntos y protección de la semilla para su colecta

Figura 2. Ejemplos de variabilidad fenotípica observada en AM de sectores $C$ y D, indicadora de poblaciones segregantes

Figura 3. Distribución espacial de puntos muestreados y resultados de la aplicación de imidazolinonas en plantas de AM colectadas de los cuatro sectores del Caso I

Figura 4. Resultados del análisis molecular de plantas seleccionadas de progenies con más del $50 \%$ de sobrevivientes tras la aplicación de dosis letales de imidazolinonas, en los cuatro sectores del Caso I.....

\section{Capítulo 5.}

Figura 1. Evolución de la probabilidad de resistencia en plantas de AM a lo largo de las últimas 8 zafras en chacras con intensidad de uso de CL baja (menor a 2 años), media ( 2 años) y alta (más de 2 años)

Figura 2. Probabilidades de resistencia en plantas de AM colectadas al primer año de uso de CL 40 Capítulo 6.

Figura 1. Evolución de resistencia a herbicidas en una población de malezas, bajo presión de selección impartida por el uso de herbicidas

Figura 2. Principales factores de riesgo para la evolución de resistencia, y sus componentes

Figura 3. Distribución de los biotipos de Echinochloa crus-galli con resistencia a los diferentes herbicidas en uso en arroz. Se incluye la información de la intensidad de uso arrocero del área en cuestión (color más oscuro, mayor intensidad)....

Capítulo 7.

Figura 1. Distintas formas químicas de las imidazolinonas en la solución acuosa .............56

Figura 2. Efecto del pH de la solución acuosa en la composición de distintas formas químicas ... 57

Figura 3. Efecto del pH en el coeficiente de distribución (Kd) entre la matriz coloidal del suelo y el agua

Figura 4. Distribución de la concentración de imazetapir $(\mu \mathrm{g} / \mathrm{kg})$ en los distintos horizontes en el perfil del suelo muestreado después de haber cultivado dos años seguidos arroz $\mathrm{CL}$ y un año arroz no $\mathrm{CL}$ bajo siembra convencional con laboreo y en siembra directa 59 
Figura 5. Altura de la planta del sorgo forrajero $(\mathrm{cm})$ a las 4 SDS de los tratamientos sin imazapir + imazapic y (O) con $110+37 \mathrm{~g}$ a.e./ha de imazapir + imazapic correspondiente a los muestreos en el horizonte de 0-10 cm estudiados en función del sitio y del año de recolección.

Figura 6. Altura de la planta del sorgo forrajero $(\mathrm{cm})$ a las 5 SDS de los tratamientos (•) sin imazapir + imazapic y (O) con $110+37 \mathrm{~g}$ a.e./ha de imazapir + imazapic correspondiente a los muestreos de $10-20 \mathrm{~cm}$ estudiados en función del sitio y año de recolección.

Figura 7. Materia seca producida ( $\mathrm{kg} / \mathrm{ha}$ ) por cada especie forrajera a los 180 días después de la siembra sobre el rastrojo del arroz Clearfield con dosis crecientes de imazapir + imazapic en postemergencia aplicadas en el cultivo

Figura 8. Rendimiento de arroz (kg/ha) frente a dosis crecientes de la premezcla de imazapir + imazapic aplicadas en postemergencia al arroz CL el año anterior en la Unidad Experimental Paso de La Laguna

Figura 9. Respuesta en el rendimiento de la soja $(\mathrm{kg} / \mathrm{ha})$ siguiente a los residuos remanentes dejados por el uso de dosis crecientes de imazapir + imazapic aplicadas en postemergencia en el arroz CL en 2014-2015. Santa María, 2015-2016 78

\section{Capítulo 8.}

Figura 1. Susceptibilidad del AM a la mezcla preformulada de imazapir + imazapic, y mutaciones de resistencia en dos chacras con historia contrastante. Río Branco, 2017-2018.

Figura 2. Escapes de capín al control de la aplicación de la mezcla preformulada de imazapir + imazapic en dos situaciones distintas

Figura 3. Sorgo forrajero afectado por los residuos de la mezcla de imazapir + Imazapic. Este de Cerro Largo, 2016-2017 


\section{ÍNDICE DE CUADROS}

\section{Capítulo 1.}

Página

Tabla 1. Algunos materiales resistentes a las imidazolinonas que estuvieron o están disponibles en el Mercosur

Tabla 2. Coeficientes obtenidos del ajuste del modelo log-logística de cuatro parámetros para las variedades e híbridos portadores de la mutación $\operatorname{Ser}_{653}$ Asp para cada herbicida considerado

Tabla 3. Coeficientes obtenidos del ajuste del modelo log-logística de cuatro parámetros para las variedades e híbridos portadores de la mutación Ala $_{122}$ Thr para cada herbicida considerado

Tabla 4. Algunas propiedades químicas de los herbicidas usados en el arroz Clearfield ${ }^{\circledR} 14$

Tabla 5. Vida media de las imidazolinonas y otros herbicidas usados en arroz Clearfield ${ }^{\circledR}$

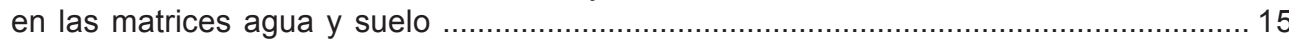

\section{Capítulo 4}

Tabla 1. Detalle de características de cada sector estudiado en el Caso I

\section{Capítulo 6.}

Tabla 1. Moléculas de inhibidores de la ALS clasificadas según su química (grupo) y patrones de resistencia cruzada más comunes

\section{Capítulo 7.}

Tabla 1. Evolución de la concentración ( $\mu \mathrm{g} / \mathrm{l}, \mathrm{ppb})$ del imazapir e imazapic en el agua de inundación del arroz Clearfield ${ }^{\circledR}$. Río Branco, 2008-2009 y 2009-2010

Tabla 2. Evolución de la concentración ( $\mu \mathrm{g} / \mathrm{L}, \mathrm{ppb})$ de los principios activos imazapir e imazapic en el agua de inundación del arroz Clearfield ${ }^{\circledR}$. UEPL, 2007-2008, 2008-2009 y 2009-2010

Tabla 3. Cinética de la foto degradación del imazapir, imazetapir e imazaquín tanto en agua como en la superficie del suelo $(n=3)$

Tabla 4. Características del suelo utilizado en Río Branco y en la UEPL para la evaluación de la susceptibilidad de las distintas especies a los residuos de imazapir + imazapic en el suelo

Tabla 5. Materia seca producida a los 180 días después de la siembra (DDS) sobre el rastrojo de arroz Clearfield por especies forrajeras seleccionadas en un suelo de Río Branco, 2008-2009

Tabla 6. Características fisicoquímicas y textura del solod melánico en los distintos sitios de la Unidad Experimental Paso de La Laguna (UEPL).

Tabla 7. Materia seca producida por la pradera a los 180 días después de la siembra debido a la interacción año por tratamiento herbicida en la U E Paso de La Laguna ... 70

Tabla 8. Materia seca producida por las malezas a los 180 días después de la siembra debido a la interacción año por tratamiento herbicida en la U E del Paso de La Laguna .. 70

Tabla 9. Materia seca producida por la pradera a los 180 días después de la siembra debido a la interacción año por manejo del riego en la $U$ E del Paso de La Laguna ..... 71

Tabla 10. Materia seca producida por las especies a los 180 días después de la siembra (DDS) promedio de siembra a 1 y 5 SDC de la pradera con dosis de imazapir + imazapic. Río Branco, 2008-2009

Tabla 11. Características de los suelos usados para los estudios de secuencia de cultivos 72 


\section{Página}

Tabla 12. Resultados promedios obtenidos para densidad y crecimiento inicial de las plantas a los 90 días después de la siembra (DDS) y altura de la planta al corte del raigrás cV. LE 284 respecto a las dosis de imazapir + imazapic en ambos sitios evaluados

Tabla 13. Productividad del raigrás cv. LE 284 a los 180 después de la siembra debido a la interacción entre las dosis de imazapir + imazapic y el año de siembra arroz CL/sitio .... 73

Tabla 14. Resultados obtenidos con El Paso 144 en la Unidad Experimental Paso de La Laguna (UEPL) y con INIA Olimar en Río Branco.

Tabla 15. Efecto de la mezcla de imazetapir + imazapic asperjada en IRGA 422 CL en el año 2004-2005 en el cultivo siguiente de IRGA 417 sembrado a los 371 días después de la aplicación. Santa María, 2005-2006.

Tabla 16. Efecto de la mezcla de imazetapir + imazapic asperjada en IRGA 422 CL en el año 2004-2005 en el cultivo siguiente de IRGA 417 sembrado a los 705 días después de la aplicación. Santa María, 2006-2007.

Tabla 17. Efecto del imazetapir + imazapic aplicado en postemergencia de IRGA 422 CL en 2006-2007 sobre el arroz no CL siguiente sembrado a los 335 DDA en 2007-2008 y a los 710 DDA en 2008-2009. Capao de Leao, RS

Tabla 18. Efecto del imazetapir + imazapic aplicado en postemergencia de BRS Señuelo CL en 2007-2008 sobre el arroz no CL siguiente sembrado a los 339 DDA en 20082009 y a los 702 DDA en 2009-2010. Capao de Leao, RS

Tabla 19. Resultados obtenidos frente a los residuos remanentes de imazapir + imazapic generados en el suelo con el sorgo forrajero (cv. Talisman en 2009 y cv. ACA 764 en 2010) en Río Branco*

Tabla 20. Efecto de la aplicación de imazetapir + imazapic en IRGA 422 CL (2006-2007) en el sorgo forrajero sembrado en dos momentos. Santa María, 2007-2008 y 2008-2009 .... 76

Tabla 21. Características de la soja en estado vegetativo y reproductivo afectadas por la presencia de cobertura en el barbecho para el nivel de humedad del suelo mayor a $70 \%$ de la capacidad de campo. Santa María, 2016-2017......

Tabla 22. Efecto de la cobertura y la humedad del suelo en el barbecho el rendimiento de soja. Santa María, 2016-2017 
En la siguiente publicación se consolida el conocimiento generado en el marco de la ejecución de varios proyectos relacionados con la utilización de los arroces resistentes a las imidazolinonas, más la experiencia de campo obtenida por los usuarios y las medidas de cuidado de la tecnología recomendada por la empresa BASF. Entre los proyectos, se destacan el FTG 0608 «Impacto ambiental de la adopción de los arroces resistentes a las imidazolinonas en sistemas productivos contrastantes de América Latina» financiado parcialmente por el Fondo Regional de Tecnología Agropecuaria (FONTAGRO) a partir de 2007, el SCT_X_2010_1_14 sobre el «Servicio de detección molecular de arroz maleza resistente a herbicida» financiado por la Agencia Nacional de Investigación e Innovación (ANII) en el marco del Ilamado Fortalecimiento de Servicios Científico-Tecnológicos 2010 y finalmente, el proyecto $A z \_25 \_0 \_00$ «Manejo de las poblaciones de capín resistentes a los herbicidas usados en arroz», financiado por el Instituto Nacional de Investigación Agropecuaria (INIA), también iniciado en el mismo año.

Se recibió apoyo de BASF en el financiamiento de actividades específicas de los proyectos, suministro de los estándares analíticos del imazapir e imazapic y del herbicida usado asociado a la tecnología.

El objetivo de esta publicación es exponer lo aprendido respecto a esta tecnología y ahondar en la elaboración de pautas claras para promover un manejo sustentable de la misma. La publicación está estructurada en ocho capítulos independientes, tratando diferentes aspectos relevantes para cumplir con ese objetivo. Se incluye una introducción, una revisión bibliográfica sobre el origen del arroz maleza en el mundo, cómo se generó la resistencia a las imidazolinonas en el arroz cultivado y las características más relevantes de los herbicidas asociados (Capítulo 1), las recomendaciones de uso de la tecnología (Capítulo 2), la descripción del vital proceso de producción de semilla certificada (Capítulo 3), la adquisición de las mutaciones por el arroz maleza que portan las variedades de arroz resistentes (Capítulo 4), el servicio de detección de mutaciones en el arroz maleza (Capítulo 5), las implicancias de la resistencia inducida por el uso de los herbicidas asociados a la tecnología (Capítulo 6), la disipación de los residuos de los herbicidas en el agua y suelo y cómo afectan a los cultivos siguientes (Capítulo 7) y finalmente, el manejo agronómico de la tecnología inmersa en el sistema de producción (Capítulo 8). 


\section{1 - LA PROBLEMÁTICA DEL ARROZ MALEZA Y SU CONTROL CON EL ARROZ RESISTENTE A LAS IMIDAZOLINONAS}

PALABRAS CLAVE: de-domesticación, imazapir e imazapic, mutaciones inducidas arroz

\section{ANTECEDENTES}

\section{Evolución del arroz maleza en el país}

El cultivo de arroz en Uruguay comenzó a tener un área de siembra establecida en el este, a partir de 1930. La producción fue creciendo hasta satisfacer el consumo nacional, iniciándose posteriormente una corriente exportadora firme del cereal. En aquel entonces predominaba el uso de semilla importada con presencia de malezas contaminantes, lo que motivó la introducción de las dos malezas principales asociadas al cultivo: el arroz maleza (Oryza sp.) y el capín (Echinochloa crusgalli) (Topolansky, 1975).

El arroz maleza es una planta anual, exótica, autofecunda, diploide, emparentada con el arroz cultivado, conocida popularmente como arroz rojo debido a que su pericarpio es color rojo a amarronado y muy asociada al sistema de siembra del arroz en suelo seco con posterior inundación. Tiene gran capacidad de macollaje y tiende a ser más alta que las variedades de arroz actualmente cultivadas, lo que le otorga la capacidad de interferir con el cultivo y originar pérdidas productivas muy significativas. Además, presenta fácil y elevado desgrane de las semillas, pericarpio rojo y semillas con dormancia, lo que la hace una maleza muy persistente en las chacras de arroz (Delouche et al., 2007).

En la etapa vegetativa las hojas son largas y angostas de color verde claro y hábito decumbente. En nuestro país han sido identificados dos biotipos característicos: a) el arroz maleza común, cuyas semillas están cubiertas con cáscara de color paja (lema y pálea), generalmente aristas ausentes en aquellas espiguillas ubicadas en las raquillas medias y superiores, y aristas cortas o ausentes en gran parte de las semillas ubicadas en las raquillas inferiores de la panoja; no presenta coloración púrpura en la base de las vainas;

b) arroz maleza denominado arroz negro, con semillas con las envolturas de color negro donde todas tienen aristas muy largas. Presenta la base de las vainas con coloraciones púrpura y a veces se expresan en el borde de las láminas, así como en el apículo de las espiguillas.

En ambos biotipos cuando se remueven las cubiertas de las semillas, queda al descubierto un pericarpio frecuentemente de color rojo y/o amarronado (Zorrilla, 1992).

Se estima que cuando esta maleza interfiere durante todo el ciclo del arroz, puede reducir la productividad en un $80 \%$ (Smith, 1988). La interferencia de 35 plantas $/ \mathrm{m}^{2}$ en una variedad de arroz pre$\operatorname{coz}$ y de baja estatura redujo en un $90 \%$ su rendimiento, mientras que 40 plantas/ $\mathrm{m}^{2}$ en una variedad de ciclo largo y alta produjo un $67 \%$ menos. Los componentes que se ven más afectados son la densidad de panojas y el número de granos/panoja (Kwon et al., 1992).

A nivel de chacra, como la distribución espacial de la maleza problema no es uniforme sino más bien agregada, la mayor 
pérdida de productividad se presenta en esos sectores. Cuando se cosecha el arroz en esas áreas, se colecta un $30 \%$ de las semillas del arroz maleza, dispersándose el restante en el suelo (Diarra et al., 1985). Las semillas colectadas contaminan las cargas del arroz cáscara enviadas al recibo, determinándose deducciones del $0,25 \%$ por $1 \%$ o fracción por encima de la base de comercialización (1\%). En casos extremos los envíos pueden ser rechazadas cuando el contenido de granos rojos excede la tolerancia de recibo de $5 \%$ de acuerdo con el decreto $321 / 988$ (MGAP, 1988). Para la industria manejar los granos rojos resulta en mayores costos debido a que implica mayor tiempo de pulido para eliminar los restos del pericarpio rojo del grano dado que el consumidor prefiere la ausencia de estos granos rojos. Además, implicó mayores inversiones en incorporar clasificadoras por color para eliminar granos con defectos. Entre ellos los granos rojos en el arroz precocido dado el contraste que generan o los granos de la maleza, además, al ser más cortos y anchos, y presentar un porcentaje alto de yeso se hacen muy visibles en el arroz elaborado que debe tener una gran uniformidad en la apariencia de los granos.

El arroz maleza común era el tipo más frecuentemente observado en el cultivo durante muchos años, coincidiendo con la predominancia en el área de cultivo de la variedad Bluebelle, perteneciente al subgrupo japónica tropical y de ciclo corto. A mediados de la década de los ochenta se liberó el cultivar EI Paso 144, perteneciente al subgrupo índica y ciclo más largo, que sustituyó rápidamente a Bluebelle. A partir de ese cambio abrupto, los técnicos comenzaron a observar más frecuentemente la presencia del arroz negro, atribuyéndolo a que el ciclo más largo del cultivo le permitía al arroz negro finalizar el llenado de sus semillas, desgranándose las mismas apenas alcanzaban la madurez fisiológica previo a la cosecha del arroz (Com. pers. Varela, J., Etcheverry, A., Platero, A., 1997).

\section{Control del arroz maleza previo a la nueva tecnología}

El área sembrada con arroz alcanzó $220 \mathrm{mil}$ ha en 1998, variando entre 180 y 166 mil ha durante varios años, reduciéndose en las últimas zafras hasta alcanzar 143 mil ha (Figura 1). En la fase expansiva del área, se promovió por parte de la Asociación de Cultivadores de Arroz (ACA), la Gremial de Molinos más COOPAR, Instituto Nacional de Semillas (INASE, ex DIGRA-MGAP) y el Instituto Nacional de Investigación Agropecuaria (INIA, ex CIAAB) el uso de semilla certificada libre de malezas. Esta se constituyó en una medida altamente eficaz para evitar que se propagara el arroz maleza a las áreas de campos vírgenes que se iban colonizando (Zorrilla, 1992). En la actualidad, tener la mayor parte del área libre de esta maleza es una ventaja competitiva del sector. En la zafra 2008-2009, se cuantificó que alrededor del $31 \%$ del área sembrada correspondió a chacras en las cuales los productores realizaron algún manejo diferencial debido a la presencia del arroz maleza (DIEA/MGAP, 2009).

En situaciones de chacras con infestaciones de baja densidad de arroz maleza, se retiraban las plantas por medio de cuadrillas de personal entrenado y contratadas para esa tarea específica. Se destaca el caso particular de COOPAR que llegó a promover esta práctica financiándola a la cosecha hasta fines de la primera década de este siglo procesando en la actualidad muy pocos casos (Figura $2)$. Se embolsaban las plantas colectadas y se las quemaba o enterraban para su disposición final. En algunos otoños lluviosos, las plantas removidas de la chacra se depositaban afuera del arrozal y al no llegar a destruirlas a tiempo, las mismas arraigaban y dieron semillas, estableciéndose la infestación en el borde la chacra (traslado físico). En otros casos similares se usaba un equipo de barras llevado por dos operarios, con cuerdas que se humedecían desde un depósito y liberaban una solución con glifosato al $50 \%$. Cuando tocaba la hoja bandera y la 
panoja del arroz maleza que sobresalía sobre el cultivo, se absorbía suficiente para evitar que formasen semillas viables.

En otras chacras se presentaban infestaciones en manchones bien diferenciados, donde no era posible obtener arroz, se le aplicaba glifosato directamente para evitar la producción de semillas viables. En situaciones de chacras muy grandes con infestaciones variables en densidad y distribución espacial no eran prácticos ni eficientes los métodos antes mencionados. Aunque no fue una práctica adoptada en general, en chacras con el escenario descripto anteriormente, se asperjaba hidracida maleica por medio de un avión agrícola cuando la panoja de arroz maleza finalizaba la floración y el arroz comercial estaba en estado pastoso. Consecuentemente, la semilla de arroz maleza no germinaba (Com. pers. Varela, J., 2003) debido a la mal formación del embrión (Gigena y Moreira, 2002), disminuyendo las entradas de semillas viables al banco de semillas del suelo.

\section{Evolución del área sembrada con arroz resistente a las imidazolinonas}

La creación de los arroces resistentes a las imidazolinonas permitió el control selectivo del arroz maleza, dado que, anteriormente era imposible realizar un control químico selectivo debido a su similitud fisiológica (Crougham et al., 1996). Los herbicidas asociados a esta tecnología obtienen un control eficaz de malezas gramíneas anuales, como el arroz maleza, capín, pasto blanco, malezas de hojas anchas como yerba del bicho, gamba rusa, gramíneas perennes como gramilla y del género Paspalum, y ciperáceas, con el manejo de la inundación adecuado (Anónimo, BASF, 2017).

A partir de la zafra 2005-2006, se inició la siembra de los primeros materiales de arroz resistentes en el país. Entre ellos, se destacan la variedad CL161 siendo introducida de Luisiana, y Avaxí CL un híbrido de Rice-Tec sustituido posteriormente por INOV CL a partir del 2010. De los materiales generados por el INTA, primero se introdujo la variedad INTA Puitá CL siendo sustituida por Gurí INTA CL en 2011. La variedad IRGA 422CL fue liberada en Río Grande del Sur en el 2003, descartándose el uso de esa mutación en los materiales de INIA por no expresar un nivel de tolerancia adecuada al ambiente local (Com. pers. Deambrosi, E., 2002).

En los últimos años, el área sembrada con estos materiales resistentes aumentó en términos absolutos y relativos hasta la zafra 2017-2018, no obstante la reducción en el área sembrada (Figura 1). Básicamente, esto ocurre porque se sigue

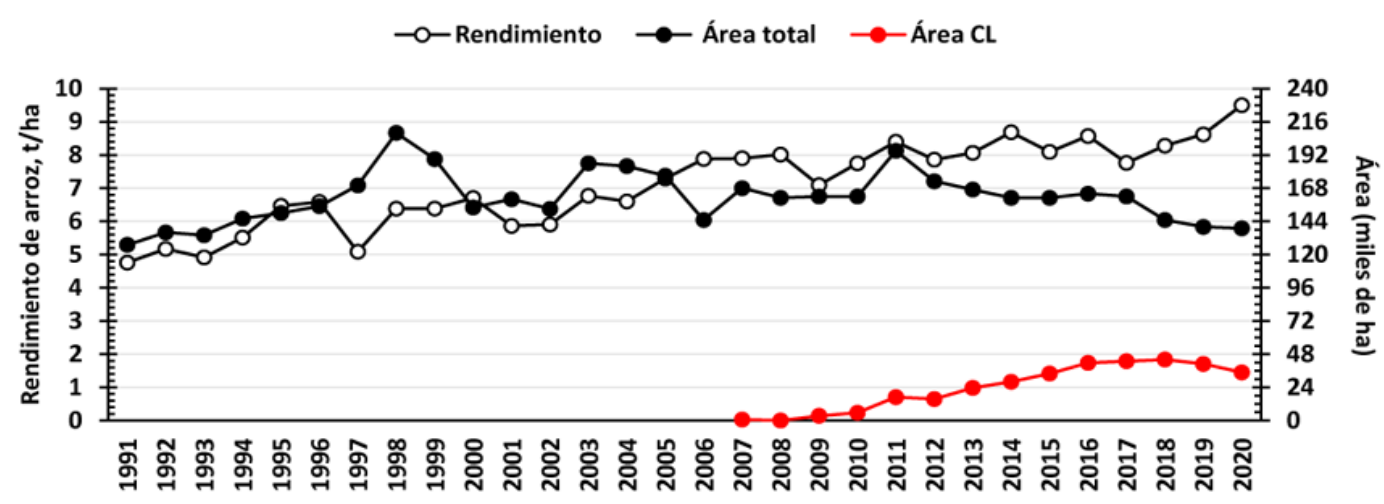

Año de siembra

Figura 1. Evolución de las áreas sembradas con arroz y con arroz resistente a las imidazolinonas, y de la productividad del arroz en el período 1991-2019. Elaborado con datos del Boletín de Estadísticas Agropecuaria y Encuesta arrocera (DIEA-MGAP) e Informe final de zafra de la Comisión Sectorial del Arroz (CSA-OPP). 
cultivando los campos que tenían arroz maleza en el pasado y que motivaron el uso de los arroces resistentes a las imidazolinonas. En esos sitios los sistemas de riego dominan un área con suelos de fácil preparación, con menor contenido de materia orgánica y de la fracción arcilla y mayor contenido de la fracción arena en el horizonte superficial. La infraestructura para riego y la caminería interna ha sido largamente amortizada, con suministro de agua abundante y confiable de los ríos como el Yaguarón, Tacuarí y Cebollatí, además de la laguna Merín en el este y en el río Tacuarembó junto a áreas regadas por represas en la zona centro. Sobre suelos más fértiles existen sistemas de riego que toman agua de los ríos Uruguay y Cuareim en el norte del país, donde la infestación de arroz maleza perdura. En menor medida y contrariamente a lo recomendado, los materiales resistentes se han usado en áreas sin problemas de arroz maleza, con suelos de mayor pendiente, fertilidad, y regados por gravedad desde represas, básicamente por practicidad para controlar otras malezas como Digitaria spp., aunque existe un menú con disponibilidad de opciones para el control eficaz de dichas malezas.

En su cartilla de divulgación para el seguimiento y cuidado de la tecnología,
BASF recomienda sembrar hasta dos años consecutivos con arroz Clearfield ${ }^{\circledR}$. El sistema Clearfield ${ }^{\circledR}$ es una de las tecnologías de arroz resistente a las imidazolinonas, con el uso una mezcla preformulada de imazapir e imazapic. Además, se agregan a los híbridos resistentes disponibles de Rice Tec una nueva generación conocida como FullPage. Como todos los sistemas que involucren el uso de arroz resistente a herbicidas, su uso debe acompañarse por un seguimiento minucioso de las chacras para mantener la eficacia de control de la tecnología en las mismas (Anónimo a, BASF).

\section{ARROZ MALEZA \\ Origen del arroz maleza (arroz rojo o arroz macho)}

El proceso de domesticación del arroz cultivado (Oryza sativa L.) comenzó hace unos 8000 años atrás, probablemente en distintos lugares al mismo tiempo, sobre diferentes poblaciones de arroz salvaje (O. rufipogon). Esta es una especie perenne con semillas de cubiertas de color negro u oscuros, aristas largas, pericarpio rojo con dormancia secundaria y dehiscentes. El rango de distribución de esta especie era más al norte de la actual de-
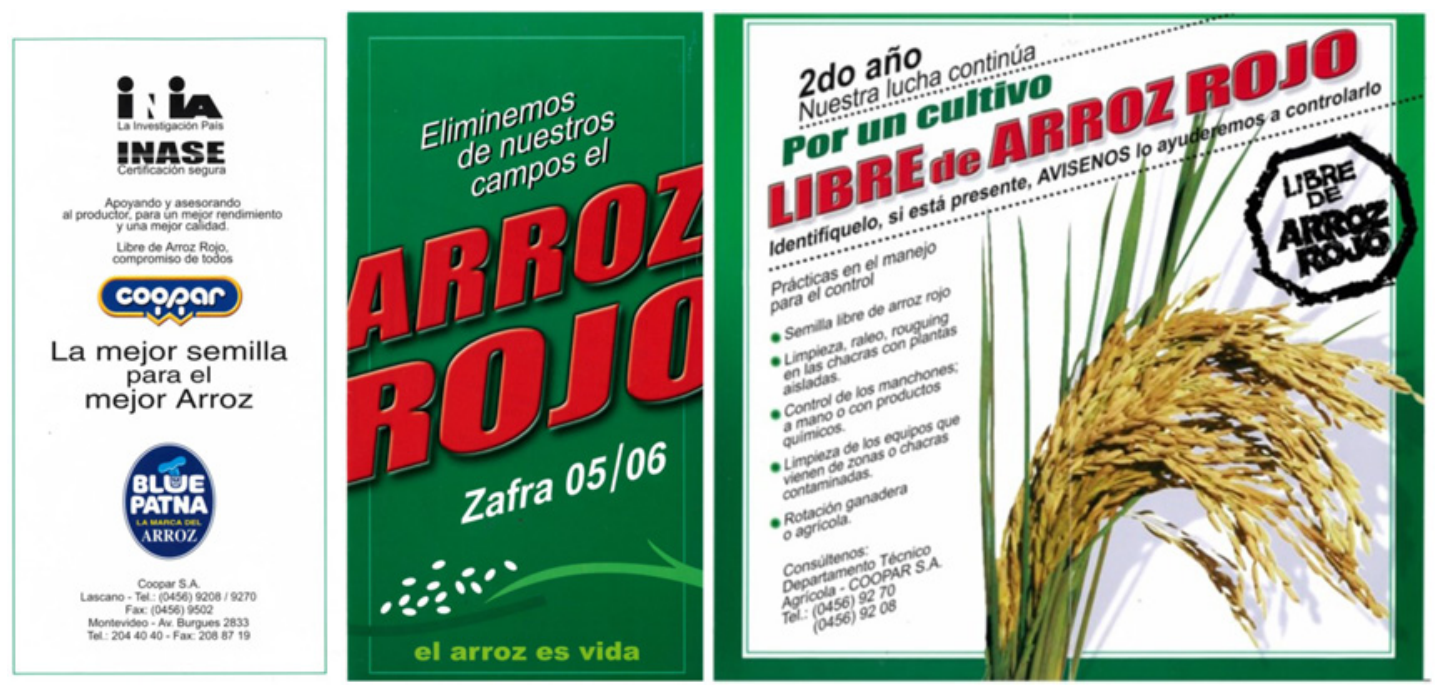

Figura 2. Díptico de difusión de COOPAR SA destinado a promover distintas prácticas culturales para reducir las poblaciones de plantas de arroz maleza de las chacras con infestación. Izq.: parte externa, Der.: parte interna (Quartino y Rovira, 2005). 
limitación, donde comenzó la domesticación del arroz cultivado, según lo indican los hallazgos arqueológicos recientes. La obtención de plantas anuales permitió el cultivo de manera repetida y el ejercicio de una presión de selección uniforme y sostenida para obtener panojas con más semillas, con envolturas de color paja, granos que se mantengan unidos al raquis y no se broten en la panoja, con floración más uniforme, sin dormancia o de corta duración entre la cosecha y la próxima siembra, y ausencia de pericarpio rojo. A ese conjunto de características se lo conoce como síndrome de domesticación. El esfuerzo invertido valía la pena porque se obtenía más alimento que recolectando semillas de las poblaciones del arroz salvaje. En la actualidad, cultivares parcialmente domesticados se usan en el oeste de India, siendo más precoces y uniformes a la floración, presentando un hábito erecto y aristas más cortas que el arroz salvaje (Vaughan et al., 2005).

Dos tipos genética y morfológicamente diferentes de arroces divergieron en distintos momentos y zonas geográficas, probablemente seleccionados desde poblaciones de arroces salvajes diferentes. El primero que fue seleccionado es el tipo japónica que se cultiva en la zona templada y en las tierras altas por encima de 1600 m sobre el nivel del mar de la zona tropical y posteriormente surgió el tipo de los arroces índica del cual derivan las variedades que se cultivan en la zona tropical de Asia y sur de China. Ambos tipos de arroces están compuestos por más de un subtipo que son genéticamente diferentes; mientras que en el tipo japónica se incluyen los subtipos: japónica templada, japónica tropical y aromáticos, en el tipo índica están los subtipos aus e índica ( $\mathrm{Li}$ y Olsen, 2020).

Con los avances recientes sobre el origen del arroz rojo, se acuñó el nombre de arroz maleza dejando de lado el termino arroz rojo reflejando el estado del arte del conocimiento sobre la maleza. Durante muchos años se pensó que era una especie anual congénere de Oryza y que estaba asociada al ancestro del arroz cultivado como 0 . rufipogon o la forma anual $O$. nivara; finalmente, se estableció que es conespecífica del arroz cultivado y es una forma con características de maleza derivada de aquel, denominándosela Oryza sativa f. spontanea Rosh. En la enorme mayoría de los casos tiene el pericarpio rojo, siendo la coloración variable en intensidad y uniformidad (Li y Olsen, 2020).

El proceso que origina una maleza a partir de una especie cultivada o durante su trayectoria de domesticación por el hombre a partir de una especie salvaje, se denomina de-domesticación. La selección natural opera con intensidad variable seleccionando caracteres que le permitan al biotipo adaptarse y dejar la mayor descendencia viable para sobrevivir en el agroecosistema del cultivo de arroz y su entorno más inmediato, no sobreviviendo afuera del ambiente del cultivo. Los caracteres asociados a las plantas salvajes, sin domesticación, como la dehiscencia elevada de las semillas de la panoja, la expresión de la dormancia secundaria en la semilla, las coloraciones negras u oscuras de las envolturas de la semilla con presencia de arista largas y la presencia de pigmentos derivados de la antocianina con coloraciones púrpuras en diferentes partes de la planta como la base de la vaina, nudos, bordes de la hoja, lámina de la hoja, apículo y pericarpio son conocidos como síndrome de adaptación (Qiu et al., 2017).

La de-domesticación no es simplemente el proceso inverso a la domesticación, sino que es la selección natural operando sobre distintos genes o grupos de genes en el genoma del arroz cultivado en los cuales operó o no la selección realizada por los incipientes agricultores durante el proceso de domesticación.Cuando comenzaron a divergir los primeros individuos de arroz maleza que se separan del arroz ancestral cultivado o desde variedades locales mejoradas más tardíamente, pasan por un cuello de botella en el tamaño efectivo de la población. Esto significa que efectivamente los individuos que se podrían cruzar entre sí son muy pocos, siendo ese grupo inicial de individuos el que fundara la nueva población de la maleza. La duración del cuello de 
botella se estimó en unos 150 años, siendo considerado corto comparado con el sufrido por el arroz cultivado cuando fue separado del arroz salvaje que se prolongó por unos 3000 años (Qiu et al., 2017).

En un estudio de los arroces maleza de cáscara negra y cáscara color paja de EE.UU. y color paja de China, se estableció que la divergencia relativa de aquellos con cáscara negra de los arroces del subtipo aus ocurrió más tempranamente que el arroz maleza común, con cáscara color paja, de los arroces del subtipo índica. El biotipo con cáscara color paja de EE.UU. divergió más temprano que aquel de China. El arroz maleza con cáscara negra presentaba mayor proporción de los alelos presentes en el ancestro salvaje o en arroces ancestrales más antiguos pertenecientes al subtipo aus que de las variedades de arroz mejoradas más recientemente. En cambio, los arroces malezas comunes mostraban mayor proporción de genes con alelos que provienen de las variedades de arroz mejoradas del subtipo índica. En orden cronológico, la divergencia de los distintos arroces maleza durante la trayectoria de la domesticación de los arroces cultivados ocurrió posteriormente a la divergencia aus-índica (Li et al., 2017).

\section{Características que facilitan su persistencia en el agroecosistema del arroz}

\section{Desgrane de las semillas}

La dehiscencia de las semillas es una característica evolucionaria que es vital para la sobrevivencia del arroz salvaje en el entorno natural y de los arroces maleza en el agroecosistema del cultivo. El gen Sh4 que codifica la dehiscencia de las semillas en el arroz salvaje presenta el alelo salvaje con un nucleótido T en una posición determinada que expresa alta dehiscencia; mientras que cuando es sustituido el nucleótido $T$ por $\mathrm{G}$ en las variedades del tipo índica, el fenotipo no muestra dehiscencia de las semillas. Sucede lo mismo en el gen qSH1 que codifica ese carácter en las variedades de arroz del tipo japónica templada.
En este caso la sustitución de un nucleótido $\mathrm{G}$ en el arroz salvaje por otro $\mathrm{T}$ en el gen reduce marcadamente la dehiscencia de semillas en este tipo de arroz. Existe consenso sobre que la selección en contra de la dehiscencia de semillas se realizó tempranamente en el proceso de domesticación dado que al incipiente agricultor le interesaba que no se cayeran al suelo las semillas para facilitar la colecta. Sin embargo, aunque los arroces maleza con cáscara negra de EE.UU. y los biotipos con cáscara color paja de EE.UU. y China portan el alelo seleccionado durante la domesticación en el gen Sh4 y qSH1, respectivamente, no perdieron la alta capacidad de dehiscencia de la semilla. Según los autores, estos hechos indican que el arroz maleza se originó del arroz ancestral cultivado dada la presencia de estos alelos, no obstante, la selección natural actúo sobre un gen u otro grupo de genes en otra parte de genoma durante el proceso de de-domesticación, recuperando la capacidad de dehiscencia de las semillas (Li et al., 2017).

En ese sentido, otros autores estudiaron la gran variabilidad existente en la dehiscencia de semillas en los arroces malezas de Río Grande del Sur, Brasil y demostraron que la expresión del gen OsCLP1 estaba asociado a alta dehiscencia de las semillas en la maleza, aunque no en el arroz cultivado Este gen tiene que ver con el mantenimiento de la integridad de la capa de absición entre el raquis y la inserción de la semilla. Además, en esta maleza se identificaron los genes OsXTH8 y OsCel9D que regulan la expresión de la síntesis y la degradación de la pared celular asociados a grados altos de dehiscencia de las semillas (Nunes et al., 2014).

\section{Color del pericarpio/dormancia de las semillas}

Este es un carácter muy importante porque su presencia está asociada a la expresión de dormancia secundaria en las semillas, existiendo un control pleiotrópico, es decir que cuando está presente el pericarpio rojo también presentarán las semillas dormancia secundaria (Gu et al., 2011). En Uruguay se determinó que la 
semilla del arroz maleza sobrevivió enterrada en el suelo hasta doce años (Pereira et al., 2013). El alelo funcional del gen Rc que otorga el color rojo al pericarpio se presenta en el arroz salvaje, variedades ancestrales y en los arroces maleza. En investigaciones recientes, se demostró que su presencia junto a otros genes que regulan la dormancia en la semilla tiene efecto sobre la longevidad en el suelo. La acumulación de genes que regulan la dormancia en la semilla incide en la persistencia de las poblaciones del arroz maleza en el agroecosistema (Pipatpongpinyo et al., 2020). La selección natural favorece el mantenimiento del pericarpio rojo seleccionando a favor de mantener el alelo funcional del gen Rc, lo que no quiere decir que no existan arroces maleza con pericarpio sin pigmentación, pero no van a perdurar en la población de la maleza porque no les ofrece una ventaja para la sobrevivencia de los individuos (ausencia síndrome de adaptación) (Li et al., 2017). Existen dos sitios en el genoma, uno ocupado por el gen Rc en el cromosoma 7 y otro que corresponde al gen $\mathrm{Rd}$ en el cromosoma 1 siendo la combinación de sus alelos lo que determinará la coloración del pericarpio. Cuando están presentes el alelo funcional del gen Rc, que es dominante sobre el alelo rc, domesticado y no funcional por presentar una supresión de 14-bp, y el alelo Rd el pericarpio es rojo como en $O$. rufipogon, arroces ancestrales y el arroz maleza; mientras que cuando está presente el alelo rc en los arroces del tipo japónica, pasado por hibridación selectiva a los arroces del tipo índica durante la domesticación, concomitantemente con el alelo $\mathrm{Rd}$ el pericarpio es incoloro. El alelo Rc en presencia del alelo rd presenta pericarpio de color marrón, en cambio el alelo Rc-s, domesticado, derivado de los arroces del subtipo aus, y el alelo Rd presentará un pericarpio con coloración levemente rojiza (Gross et al., 2010; Tong et al. 2021). El alelo funcional del gen Rc codifica una proteína bHLH que regula la síntesis de protoantocianidina determinando la pigmentación en el pericarpio (Sweeney et al., 2006).

\section{Color de la cáscara de la semilla}

Todas las especies salvajes de Oryza y los arroces maleza que tienen cubiertas de color negro en las semillas llevan el alelo funcional del gen Bh4 ubicado en el cromosoma 4. Ese alelo es dominante para esta característica, regulando su expresión a la madurez de la semilla, sin embargo, la ruta bioquímica aún no ha sido dilucidada. Algunos autores señalan que cuando se desgranan las semillas y caen al barro, el color oscuro puede otorgarle una ventaja adaptativa a la descendencia para que sobrevivan debido a que son menos detectadas por las aves que las consumen o por la presencia de mayor concentración de sustancias antioxidantes que desalientan el consumo. En los arroces cultivados del tipo índica el gen Bh4 presenta dos alelos, con pérdida de la función, que determinan el color paja de la cáscara de la semilla. Uno tiene una supresión de 22-bp y el otro una supresión de 1-bp en distintos sitios del gen Bh4 que están presentes en el $92 \%$ y $8 \%$ de los casos estudiados; respectivamente. En $1 \%$ de los casos el gen Bh4 portaba el alelo funcional asociado con la cáscara de color paja, lo que indicaría que la pérdida de función no es el único mecanismo que produce ese fenotipo y que podría haber otros genes u otros mecanismos involucrados. Un caso particular existe en los arroces del subtipo aus, la variedad Kasalath tiene cáscara color paja debido a la sustitución de un solo nucleótido por una mutación puntual en la secuencia del gen $B h 4$ resultando el alelo no funcional. Otros genes estarían involucrados en la regulación del color de las envolturas de la semilla. Por ejemplo, en los arroces del tipo japónica se insertó el alelo funcional del gen Bh4 y no se logró revertir el color de la cáscara mientras que eso fue posible en los arroces del tipo índica (Vigueira et al., 2013).

\section{El arroz maleza en otros países}

En China se estudiaron arroces maleza colectados, asociados al tipo japónica en el cultivo de arroz de distintas provincias como Liaoning y Ningxia (norte), Jiangsu (centro) y otros asociados al tipo índica 
Guangdong (sur). La diversidad genética, medida como la diversidad de nucleótidos $(\pi)$ en el genoma, fue menor en los arroces maleza estudiados que en los arroces cultivados en las provincias de Liaoning, Ningxia y Jiangsu; mientras que aquellos colectados en la provincia de Guangdong mostraron mayor diversidad que los arroces cultivados. En esta última provincia, ubicada en el sur de China, aún coexisten poblaciones de arroz salvaje, $O$. rufipogon, en la proximidad de las áreas cultivadas. Los autores de este trabajo estimaron que la divergencia de los arroces maleza de las variedades cultivadas localmente ocurrió en períodos de tiempo distintos y en múltiples eventos en cada provincia. La estimación de la fecha de divergencia se situó entre 1400 a 300 años atrás, existiendo una gran coincidencia con los registros históricos de los libros de agronomía chinos y la aparición de "Ludao» (arroz maleza) en los arrozales entre 1279 a 960 años atrás durante la dinastía Song (Qiu et al., 2017). En otro estudio reciente se determinó que el $38 \%$ de los arroces maleza actuales de las provincias de Jiangsu, Zhejiang y Guangdong del sur de China están emparentadas con Nianjing 11, una variedad muy popular que fue cultivada extensivamente cuando la producción de arroz se transformó de pequeñas empresas familiares a una producción más industrial en el siglo $X X$. Lo mismo sucedió en la provincia Liaoning del norte, donde 38 accesiones de arroz maleza estaban relacionados con la variedad tradicional Huk Zo de Corea (Qui et al., 2020).

Si bien no se ha cultivado arroz durante milenios, el caso de Italia es muy interesante porque el cultivo de arroz se ha realizado por 500 años y no existen parientes salvajes del género Oryza. Previo al 1800, se introducían semillas de variedades de grano largo y fino de la India que tenían alta diversidad genética. Probablemente se introdujo semilla contaminada con arroces maleza o eventualmente arroz salvaje o cruzado con la variedad, atento a que se ha detectado el alelo salvaje del gen Sh4 en baja proporción en los arroces maleza actuales. Los autores conceptualizan que existió una primera ola de dispersión de los arroces maleza asociada a las introducciones y una segunda ola se originó a partir del 1800 cuando se inició el programa de mejoramiento de arroz (Grimm et al., 2020). La similitud genética encontrada entre las variedades Bertone (1829), Ostiglia (1850) y Ranghino (1887) con algunas poblaciones actuales de los arroces maleza, indica que estas derivaron de las variedades liberadas a mediados del siglo XIX, debido a que no son más cultivadas desde hace mucho tiempo. La divergencia de individuos con características de maleza por de-domesticación es un proceso continuo y lo avala el hecho de que se detectó también otro grupo de arroces maleza muy asociado con la variedad Flipper (1997), contemporánea y del tipo japónica (Grimm et al., 2013; Qui et al., 2020). Antes de 1960 el arroz se trasplantaba y se desmalezaba manualmente, siendo la infestación del arroz maleza muy baja.Con la introducción de la siembra directa de arroz en el agua la infestación del arroz maleza se hizo más severa con los años. Actualmente, en la región arrocera del noroeste de Italia, se clasificaron cuatro grupos en función de la presencia de arista, la morfología y coloración de esta. Estos grupos son: sin aristas, con una arista menor a $2 \mathrm{~mm}$ (mucronato), con aristas largas mayor $2 \mathrm{~mm}$ que podían ser de color paja o negro. En los tres primeros grupos la coloración de la cáscara de la semilla era color paja, mientras que en el grupo con arista larga negra el $24,5 \%$ y el $2,4 \%$ mostraron las envolturas de color marrón y negro respectivamente (Grimm et al., 2013).

En EE.UU. similarmente a Italia, no existen poblaciones nativas de arroz salvaje ni otros parientes con genoma $A A$ compatibles para producir cruzamientos viables. Hace unos 170 años, se comenzó a cultivar arroz en el sureste y se documentó la presencia del arroz maleza como contaminante importado en la semilla de arroz en 1846. Actualmente se conocen dos grandes grupos de arroz maleza: el común con cáscara color paja sin aristas y aquel que tiene cáscara negra y aristas largas (Gealy et al., 2009; Gealy et al., 
2002). Un tercer grupo que es incipiente y está ganando visibilidad, es el que posee cáscara marrón y aristas. Los dos últimos grupos mencionados, con cáscara negra y el marrón, presentan mayor diversidad genética que el arroz maleza común. Los autores señalan que esto es debido a que el tipo con cáscara negra está más relacionado al arroz cultivado del subtipo aus en Bangladesh y del este de la India, mientras que el común está más relacionado a arroces del subtipo índica producidos en el este y sudeste asiático. Cuando se estudió la similitud genética con los arroces cultivados, los arroces maleza con cáscara negra y marrón se agruparon separados de los arroces cultivados y del grupo del arroz común. Sin embargo, en los distintos grupos aparecen mezclados individuos de los otros grupos indicando que se comparten alelos vía hibridación entre sí y eventualmente con los arroces cultivados, aunque sean autógamos (Shivrain et al., 2010).

Si bien en la América tropical existen especies silvestres del género Oryza, algunas de ellas con genoma AA compatible y arroz salvaje introducido como contaminante desde Asia (Lentini y Espinoza, 2005), en la América templada que incluye al estado de Río Grande del Sur, Brasil, las provincias de Santa Fe, Entre Ríos y Corrientes en Argentina, Chile, Uruguay y el suroeste de EE.UU., no se ha informado de la existencia ni de arroz salvaje ni parientes silvestres del género Oryza. En un reciente estudio en América Latina se colectaron 51 accesiones, 9 eran del subtipo índica, 4 aus y 38 de una supuesta mezcla de subtipos índicaaus. El origen de los arroces maleza mezcla fue el resultado de cruzamientos recientes entre subtipos índica y aus de la maleza. Estos presentaban diversidad genética más alta que los arroces maleza típicos índica y aus locales, y mayor grado de heterocigosis que los arroces maleza estudiados de otras partes del mundo. Después de que quedó disponible el arroz resistente a las imidazolinonas, se liberaron materiales en los países de América Latina. La mayor parte de las accesiones evaluadas provenían de Brasil y se detec- taron algunas de las tres mutaciones de la ALS usadas comercialmente en aquellos arroces resistentes. Los autores señalan que la hibridación ha jugado un papel relevante en la actual composición de las poblaciones en el campo, tanto entre los distintos tipos de arroz maleza así como con las variedades de arroz, básicamente del subtipo índica (Qiu et al., 2020).

En Uruguay, hace menos de 100 años que se cultiva el arroz y el arroz maleza fue introducido como contaminante de la semilla en las variedades introducidas. En un estudio conducido con marcadores AFLP se evaluó una muestra a nivel nacional de los biotipos colectados en las regiones donde el arroz maleza tiene más presencia. Se estableció que los arroces maleza negros y con aristas largas eran un grupo morfo y genéticamente distinto al que pertenecían los arroces maleza comunes con cáscara color paja y aristas ausentes o cortas en las semillas inferiores de la panoja. La cáscara negra y la presencia de largas aristas son características de plantas salvajes mientras que la coloración de color paja y la ausencia de aristas son características de domesticación que hacen, entre otros caracteres, que la maleza tienda a mimetizarse con el arroz cultivado. Un tercer grupo correspondió a los arroces cultivados, y finalmente, se detectó un cuarto grupo de individuos de arroz maleza producto de la hibridación con las variedades de arroz (Federici et al., 2001). Un biotipo colectado en Minas de Corrales se clasificó genéticamente como del subtipo aus, presentando cáscara de color paja con aristas largas (Qiu et al., 2020). La producción de semillas certificadas es un insumo vital para evitar la dispersión de la maleza a las áreas libres de la misma. Con el fin de apoyar el control de calidad de los lotes de semilla básica, se validó el uso de marcadores microsatélites del genoma del arroz. El uso de cuatro marcadores permitió clasificar correctamente el $95 \%$ de los arroces maleza y el $99 \%$ de las variedades de arroz evaluadas, además de discriminar los híbridos realizados de manera experimental (Garaycochea, 2007). 


\section{TECNOLOGÍA CLEARFIELD ${ }^{\circledR}$ EN ARROZ}

El arroz resistente a las imidazolinonas es producto de técnicas de mejoramiento tradicionales como la generación de mutaciones inducidas por agentes específicos. Las mutaciones puntuales generadas artificialmente sometiendo semilla de arroz a metanosulfonato de etilo (MSE) consisten en sustituciones de una guanina $(G)$ por una adenosina $(A)$ en tres posiciones diferentes de la secuencia nucleotídica del gen que codifica la ALS, que a su vez determinan distintas sustituciones de aminoácidos en la enzima ALS (Tabla 1) (Rosas et al., 2014).

En EE.UU. se patentó una línea de arroz resistente a imazetapir generada mediante el uso de MSE y seleccionada por aplicación de ese herbicida (Crougham et al., 1996). A partir de ese material, se obtuvieron las variedades de arroz resistente CL121 y CL141 (Louisiana State University, LSU) con la primera mutación, liberadas comercialmente en 2001. Asimismo, por el mismo método, se derivó otra línea del cultivar Cypress que fue la base para la creación de la variedad CL161 y el híbrido XL8 (RiceTec), iniciándose su comercialización en 2003 (Tan et al., 2005). En Brasil, el Instituto Riograndense del Arroz (IRGA) desarrolló la variedad IRGA $422 \mathrm{CL}$ resistente adaptada localmente por introgresión del gen con la primera mutación que codifica la enzima ALS, sustituyendo en la posición 654 serina por ácido glutámico $\left(\mathrm{Ser}_{654} \mathrm{Glu}\right.$ ) en la secuencia de aminoácidos de la proteína. En cambio, la empresa RiceTec utilizó la mutación encontrada en la segunda generación, que sustituye en la posición 653 serina por aspartato (Ser ${ }_{653}$ Asp) en los híbridos Avaxí CL, Inov CL y Sator CL (Lopes et al., 2004). En el mismo período, en el Instituto Nacional de Tecnología Agropecuaria (INTA) obtuvo una mutación distinta que promovía la sustitución en la posición 122 alanina por treonina ( $\mathrm{Ala}_{122} \mathrm{Thr}$ ), dando origen al cultivar INTA Puitá CL por mutagénesis sobre IRGA 417 (Livore, 2010).

Diez et al. (2013) valoró la actividad in vitro de la ALS frente al agregado independiente de imazapir e imazapic en materiales que portaban las distintas mutaciones en uso en el país (Tablas 2 y 3 ).

Tabla 1. Algunos materiales resistentes a las imidazolinonas que estuvieron o están disponibles en el Mercosur.

\begin{tabular}{|c|c|c|c|}
\hline $\begin{array}{l}\text { Materiales resistentes } \\
\text { a las imidazolinonas }\end{array}$ & Origen & $\begin{array}{l}\text { Posición de los } \\
\text { aminoácidos en la ALS }\end{array}$ & Estado \\
\hline IRGA $422 \mathrm{CL}$ & RGS, Brasil & $\mathrm{Ser}_{654} \mathrm{Glu}$ & Homocigota \\
\hline CL161 & Louisiana, EE. UU. & Ser $_{653}$ Asp & « \\
\hline INTA Puitá CL & Argentina & $\mathrm{Ala}_{122} \mathrm{Thr}$ & « \\
\hline Híbrido Avaxí CL & Brasil & $\operatorname{Ser}_{653}$ Asp & Heterocigota \\
\hline Híbrido Inov CL & Brasil & $\operatorname{Ser}_{653}$ Asp & « \\
\hline Híbrido Sator CL & Brasil & $\mathrm{Ala}_{122} \mathrm{Thr}$ & « \\
\hline INTA Gurí CL & Argentina & $\mathrm{Ala}_{122} \mathrm{Thr}$ & Homocigota \\
\hline CL212 & Uruguay & $\operatorname{Ser}_{653} A s p$ & « \\
\hline CL244 & Uruguay & Ser $_{653}$ Asp & « \\
\hline Titán & Brasil & $\mathrm{Ala}_{122} \mathrm{Thr}$ & Heterocigota \\
\hline Memby porá & Argentina & $\mathrm{Ala}_{122} \mathrm{Thr}$ & Homocigota \\
\hline CL1294 & Uruguay & $\operatorname{Ser}_{653}$ Asp & $"$ \\
\hline CL1202 & Uruguay & $\mathrm{Ala}_{122} \mathrm{Thr}$ & « \\
\hline
\end{tabular}


Tabla 2. Coeficientes obtenidos del ajuste del modelo log-logística de cuatro parámetros para las variedades e híbridos portadores de la mutación $\operatorname{Ser}_{653}$ Asp para cada herbicida considerado.

\begin{tabular}{|lcccccc|}
\hline Material & $\begin{array}{c}\text { Principio } \\
\text { activo }\end{array}$ & $\mathbf{I}_{50}(\mu \mathrm{M})^{1}$ & $\begin{array}{c}\text { Error } \\
\text { estándar }\end{array}$ & FR $^{2}$ & $\begin{array}{c}\text { Error } \\
\text { estándar }\end{array}$ & $\mathbf{p}$ \\
\hline INIA Olimar & imazapir & 7,65 & 0,41 & - & - & - \\
Inov CL & imazapir & 193,74 & 49,34 & 25,3 & 12,1 & 0,03 \\
Avaxi CL & imazapir & 245,93 & 29,00 & 32,1 & 15,3 & 0,04 \\
CL146 & imazapir & 544,21 & 119,96 & 71,1 & 45,5 & 0,01 \\
\hline INIA Olimar & imazapic & 3,77 & 0,17 & - & - & - \\
Inov CL & imazapic & 248,48 & 79,59 & 69,9 & 40,2 & 0,09 \\
Avaxi CL & imazapic & 196,21 & 40,84 & 52,1 & 24,4 & 0,06 \\
CL146 & imazapic & 602,68 & 176,07 & 159,9 & 55,4 & 0,04 \\
\hline
\end{tabular}

${ }^{1}=I_{50}$ es la concentración del herbicida que reduce en un $50 \%$ la actividad de la enzima ALS.

${ }^{2}=$ FR (factor de resistencia) del material de interés $/ I_{50}$ de INIA Olimar (testigo susceptible).

Tabla 3. Coeficientes obtenidos del ajuste del modelo log-logística de cuatro parámetros para las variedades e híbridos portadores de la mutación $\mathrm{Ala}_{122}$ Thr para cada herbicida considerado.

\begin{tabular}{|lcccccc|}
\hline Material & $\begin{array}{c}\text { Principio } \\
\text { activo }\end{array}$ & $\mathrm{I}_{50}(\mu \mathrm{M})^{1}$ & $\begin{array}{c}\text { Error } \\
\text { estándar }\end{array}$ & FR $^{2}$ & $\begin{array}{c}\text { Error } \\
\text { estándar }\end{array}$ & $\mathbf{p}$ \\
\hline INIA Olimar & imazapir & 7,65 & 0,41 & - & - & - \\
APSA CL & imazapir & 298,14 & 93,15 & 38,9 & 11,6 & 0,02 \\
Puitá INTA CL & imazapir & 638,64 & 152,92 & 80,5 & 20,3 & 0,04 \\
\hline INIA Olimar & imazapic & 3,77 & 0,17 & - & - & - \\
APSA CL & imazapic & 244,48 & 75,63 & 64,5 & 25,4 & 0,05 \\
Puitá INTA CL & imazapic & 678,57 & 190,21 & 179,9 & 55,4 & 0,03 \\
\hline
\end{tabular}

$1=I_{50}$ es la concentración del herbicida que reduce en un $50 \%$ la actividad de la enzima ALS.

${ }^{2}=$ FR (factor de resistencia) del material de interés// ${ }_{50}$ de INIA Olimar (testigo susceptible).

Si bien los distintos materiales no pueden compararse estrictamente ya que cuentan con base genética distinta, se observó que en los híbridos con un solo alelo que ofrece resistencia (heterocigota), independientemente del alelo considerado, alcanzaban un $I_{50}$ intermedio entre INIA Olimar (testigo susceptible) y las variedades de arroz con dos alelos de resistencia (homocigota). Estas últimas requerían más concentración de herbicida para lograr un $50 \%$ de inhibición en la actividad in vitro de la ALS. Los autores señalaron que la relación entre el alelo de resistencia y el alelo susceptible es de codominancia, ya que aparentemente se expresan ambos en los híbridos, aunque no se sabe la proporción; coexistirían enzimas sin mutación (sensible al herbicida) y enzima con mutación (no sensible al herbicida) resultando un fenotipo intermedio $\left(I_{50}\right)$.Este hecho está alineado con la recomendación práctica de aplicar dosis menores del herbicida y del coadyuvante asociados sobre el follaje en los híbridos disponibles a 
la fecha, comparado con las variedades resistentes.

\section{Familia de las imidazolinonas}

Esta familia de herbicidas fue descubierta y desarrollada a inicios de la década de 1980 por la empresa química American Cyanamid, posteriormente adquirida por la empresa BASF. Esta familia pertenece al modo de acción inhibidores de la ALS clasificado como grupo 2/B (WSSA, 2014). Está compuesta por varios principios activos como el imazapir, imazetapir, imazaquín, imazapic e imazamox, entre otros, con acción herbicida de amplio espectro, controlando gramíneas y malezas de hoja ancha anuales y perennes, y ciperáceas, especialmente en cultivos de soja, leguminosas para grano y forrajeras (Tan et al., 2005). En el caso particular del imazapir, como era un herbicida muy persistente, su uso inicial estuvo focalizado en el control de la vegetación en cultivos perennes como la caña de azúcar, palma de aceite, plantaciones de caucho, manejo de arbustivas en el bosque, limpieza de áreas industriales y vías férreas, etc. (Newhouse et al., 1991). En cambio, el imazapic mostró excelente selectividad en el cultivo de maní y en la caña de azúcar, donde era mayormente empleado debido a su persistencia (Anónimo b, BASF). Con el surgimiento de la tecnología Clearfield ${ }^{\circledR}$, la mezcla pre-formulada de imazapir + imazapic fue posible de usar de manera segura en el cultivo de arroz resistente para el control del arroz maleza y otras especies de interés (Anónimo, 2017, BASF).

\section{Estructura esquelética de las imidazolinonas asociadas al arroz resistente}

La estructura básica de la molécula de los herbicidas asociados a la tecnología Clearfield ${ }^{\circledR}$ es la misma. Esta presenta un grupo imidazolinona (- - ) con un enlace $=\mathrm{N}$ - que puede recibir un átomo de hidrógeno y protonarse $\left(\mathrm{H}^{+}\right)$y con un grupo $\mathrm{HN}$ que puede perder un átomo de hidrogeno ionizándose y además, tiene un anillo de piridina con un grupo carboxílico (- - -)

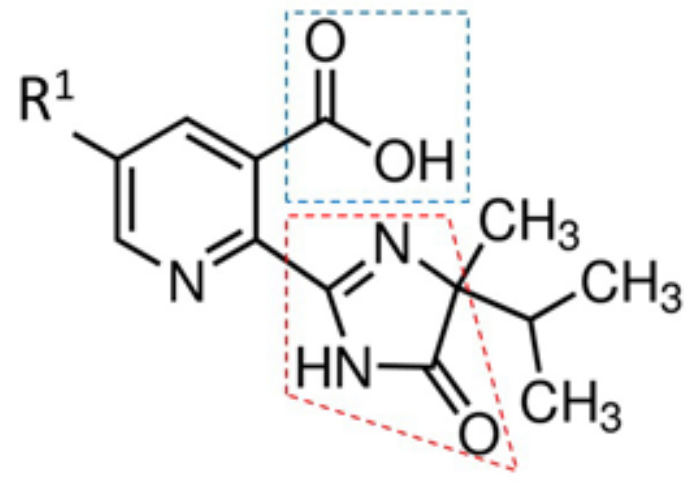

Figura 3. Esquema esquelético básico de los herbicidas usados en el arroz Clearfield $^{\circledR}$. Estos tienen un grupo imidazolinona (- - -) y grupo carboxílico (- - -). Tomada y modificada de Wepplo, 1991.

que puede también ionizarse (Figura 3 ). Cuando el radical $\mathrm{R}^{1}$ es ocupado por un hidrógeno $(\mathrm{H})$ el herbicida será el imazapir, en cambio, si la sustitución es por un grupo metilo $\left(\mathrm{CH}_{3}\right)$ el compuesto obtenido es el imazapic, y finalmente, si un grupo etilo $\left(\mathrm{C}_{2} \mathrm{H}_{5}\right)$ ocupa el sitio de $\mathrm{R}^{1}$, el herbicida será imazetapir (Wepplo, 1991).

\section{Modo de acción de las imidazolinonas}

Estos herbicidas son absorbidos por la planta por vía foliar y radicular, traslocados por xilema y floema y almacenados en los puntos de crecimiento. Alcanzan el tejido intervascular e ingresan a las células del parénquima. En los cloroplastos hacen contacto con la enzima ALS (también llamada acetohidroxiácido sintasa, AHAS; EC 2.2.1.6). A partir de los precursores piruvato, 2-ketobutirato y acetil-CoA, y mediante vías metabólicas cuyo primer paso en común es la acción de la ALS, ocurre la síntesis de valina, isoleucina y leucina. La biosíntesis de estos aminoácidos ramificados ocurre en los microorganismos y los vegetales, por lo que son esenciales para el crecimiento de los animales dado que no los pueden sintetizar y deben incluirlos en su dieta.

Cuando las imidazolinonas se unen a la ALS provocan la inhibición de su actividad ocurriendo el agotamiento de 
las reservas de aminoácidos de cadenas ramificadas, valina, isoleucina y leucina, con la consecuente detención del ciclo celular (Duggleby et al., 2008). La ALS vegetal es una proteína codificada en el núcleo y localizada en cloroplastos. Está compuesta por una subunidad regulatoria, que la hace sensible a la presencia de aminoácidos ramificados. El sitio de acción de estos herbicidas es el bloqueo del canal de acceso del sustrato sobre el que opera la enzima. En base a mutagénesis dirigida, se han identificado cinco sitios específicos de reconocimiento del herbicida o sitios de acople en la ALS cuyas secuencias aminoacídicas son conservadas. Esto quiere decir que esas secuencias han permanecido incambiadas durante la evolución a través de un largo período de tiempo. Un dominio puede ser una región de la proteína con un interés biológico funcional o estructural, por ejemplo el canal de acceso del sustrato. Los sitios de acople son A, C y D en el dominio alfa, el sitio $B$ en el dominio delta, y el sitio $E$ en el extremo C-terminal de la secuencia de aminoácidos (Shivrain, 2010).

\section{Comportamiento de las imidazolinonas en el agua y suelo}

Tanto el imazapir como el imazapic e imazetapir se comportan como un ácido débil en la solución del suelo, determinando el pH la dinámica de su comportamiento. La constante de ionización es el valor de $\mathrm{pH}$ al cual la molécula de herbicida se encuentra en equilibrio entre dos de sus formas que prevalecen a ese $\mathrm{pH}$ (Tabla 4). En la curva de titulación se relaciona el aumento en el $\mathrm{pH}$ con la composición de los distintos esta- dos del compuesto y se observan distintos puntos de inflexión. El primero se refiere al $p K_{1}$ que es cuando se protona el anillo de la imidazolinonas (incorpora un hidrógeno y queda con carga positiva), el $p K_{2}$ se presenta cuando el grupo carboxílico se ioniza (pierde un hidrógeno y la carga queda negativa), mientras que el último punto de inflexión, el $p K_{3}$, es debido a que se pierde un hidrógeno del grupo imidazolinona (HN), quedando con carga negativa ese grupo (Wepplo, 1991).

En los suelos de $\mathrm{pH}$ mayor a 5 se espera que una proporción muy alta del herbicida esté presente bajo su forma ionizada, con carga negativa en el grupo carboxilo, siendo menos retenido en la matriz del suelo y más soluble en agua. Sin embargo, en los suelos con $\mathrm{pH}$ por debajo de 5 (suelos más ácidos) la forma no ionizada, sin cargas, tendrá cierta proporción, sin ser mayoritaria, siendo muy relevante su papel dado que se comportará como un herbicida no iónico, uniéndose de manera reversible a la materia orgánica del suelo (Mangels, 1991). Al hacerse presente la forma no ionizada a $\mathrm{pH}$ más bajo, determinará que el herbicida sea menos soluble en agua y más lipofílico, es decir tendrá mayor afinidad por la materia orgánica del suelo. Las pérdidas por volatilización para estos tres compuestos serán negligibles debido a su muy baja presión de vapor (Wepplo, 1991).

La disipación de estos principios activos en el agua ocurre muy rápidamente. Esta característica se estima bajo condiciones de laboratorio en agua destilada sin partículas en suspensión que puedan interferir. El mecanismo principal de disipación es la fotolisis inducida por la

Tabla 4. Algunas propiedades químicas de los herbicidas usados en el arroz Clearfield ${ }^{\circledR}$.

\begin{tabular}{|c|c|c|c|c|c|}
\hline \multirow[t]{2}{*}{ Herbicidas } & \multicolumn{3}{|c|}{$\begin{array}{l}\text { Constante } \\
\text { de ionización }\end{array}$} & \multirow{2}{*}{$\begin{array}{c}\text { Solubilidad } \\
\text { en agua* } \\
\text { mg/l }\end{array}$} & \multirow{2}{*}{$\begin{array}{c}\text { Presión } \\
\text { de vapor } \\
\mathrm{Pa}\end{array}$} \\
\hline & $p K_{1}$ & $p K_{2}$ & $p K_{3}$ & & \\
\hline Imazapir & 1,9 & 3,6 & 11,0 & 11272 & $<1,3 \times 10^{-5}$ \\
\hline Imazapic & 2,0 & 3,9 & 11,1 & 2200 & $<1,3 \times 10^{-7}$ \\
\hline Imazetapir & 2,1 & 3,9 & - & 1400 & $1,3 \times 10^{-5}$ \\
\hline
\end{tabular}

${ }^{*}=$ medida a pH 7 y $25^{\circ} \mathrm{C}$. Herbicide Handbook, WSSA, Tenth Edition, 2014. 
Tabla 5. Vida media de las imidazolinonas y otros herbicidas usados en arroz Clearfield $^{\circledR}$ en las matrices agua y suelo.

\begin{tabular}{|lcc|}
\hline $\begin{array}{c}\text { Matriz } \\
\text { Herbicidas }\end{array}$ & $\begin{array}{c}\text { Agua destilada } \\
\text { días }\end{array}$ & $\begin{array}{c}\text { Suelo a campo } \\
\text { días }\end{array}$ \\
\hline Imazapir & $1-2$ & $25-142$ \\
Imazapic & sd & 120 \\
Imazetapir & $46 \mathrm{~h}$ & $60-90$ \\
Quinclorac & sd & 360 \\
Clomazone & sd & $16-36$ \\
Penoxulam & sd & $5-16$ \\
Bispiribac-sodio & sd & $<10$ \\
\hline
\end{tabular}

Herbicide Handbook, WSSA, Tenth Edition, 2014. sd=sin datos.

fracción ultravioleta de la radiación solar (Mangels, 1991). Sin embargo, en el suelo esos mecanismos de disipación no operan y estos herbicidas tienden a persistir más que otros herbicidas usados en el arroz, con la excepción del quinclorac, teniendo el potencial para afectar a los cultivos subsiguientes sensibles (Tabla 5 ).

Los residuos de las imidazolinonas se degradan vía microbiana en presencia de oxígeno (aerobiosis). Para que esto ocurra tienen que estar disponibles en la solución del suelo, así los microorganismos acceden a los mismos para metabolizarlos. El coeficiente de adsorción de Freundlich $\left(K_{t}\right)$ nos indica si los residuos están más o menos adheridos a la fase sólida o libre en la fase acuosa del suelo. Cuanto más elevado el valor, mayor la proporción de los residuos que estarán adheridos al suelo. Un ejemplo bien ilustrativo es el comportamiento del imazetapir en esa matriz. Este herbicida alcanzó un valor de $K_{t}$ de 232,22 y 41,59 en un suelo con un contenido de materia orgánica alta mientras que en uno de bajo contenido los valores obtenidos para el $K_{t}$ fueron de 12,53 y 2,83 cuando se ajustó el $\mathrm{pH}$ a 5 y a 6 respectivamente. Cuando el pH del suelo está en 5 , el imazetapir adsorbido aumenta, similarmente opera el contenido de materia orgánica entre suelos. En consecuencia, la disponibilidad de los residuos de las imidazolinonas en la solución del suelo regula la extensión de la degradación microbiana, mientras que una mayor adsorción aumentará la persistencia de estos herbicidas. La velocidad de la disipación de estos herbicidas es dependiente de la temperatura y la humedad del suelo. Pasar de temperaturas de 18 a $35^{\circ} \mathrm{C}$ y contenido de humedad desde marchitez permanente (-15 $\mathrm{kPa})$ a capacidad de campo $(-33 \mathrm{kPa})$ favorecen la rápida degradación. En ausencia de oxígeno (anaerobiosis) no se detectó una degradación significativa ni del imazapir ni tampoco del imazetapir por un período de incubación de dos meses, permaneciendo intacto estos herbicidas y contribuyendo a la persistencia en el suelo (Mangel, 1991).

En nuestro país se ofrece el herbicida conteniendo $52,5 \% \mathrm{p} / \mathrm{p}$ de imazapir + $17,5 \% \mathrm{p} / \mathrm{p}$ de imazapic, recomendándose dos aplicaciones de $140 \mathrm{~g} / \mathrm{ha}$ de KIFIX® con coadyuvante tensioactivo no iónico al $0,25 \%$. La primera en preemergencia y la segunda con el arroz entre 2 a 4 hojas en postemergencia temprana (Anónimo, BASF, 2017). La realización de la aplicación en preemergencia si hay poca humedad en superficie y no hay previstas precipitaciones en la semana siguiente a la aspersión debe ir acompañada de un baño para asegurar que el herbicida se active y quede disponible para la absorción por las semillas de las malezas germinando. En caso de existir arroz maleza nacido u otro tipo de vegetación, se aconseja mezclar en el tanque KIFIX® con 
un producto comercial en base a glifosato. Con respecto a la aplicación en postemergencia temprana, se debe tratar de aplicar con el arroz maleza preferentemente sin macollar y ajustar la dosis de KIFIX $®$ en función de la población de la maleza (Batalla y Fernández, 2007). El manejo de la inundación podría postergarse unos días más de lo habitual en aplicaciones en postemergencia temprana, sin embargo, para no perder eficacia de control se aconseja no demorar la inundación más allá de los 7 días después de la aplicación en postemergencia tardía (Avila et al., 2017). En el caso concreto del imazapir, existe información indicando que alcanza excelentes niveles de control de malezas perennes con dosis menores a temperatura más frescas que a temperaturas elevadas (Malefyt y Quakenbush, 1991).

\section{BIBLIOGRAFÍA}

Anónimo. 2017. Etiqueta KiFiK. BASF.

Anónimo a. n.d. 7 pasos para el control del arroz rojo y malezas díficiles. BASF. https://documents.basf.com/7ee3065b 4f4d6d5a6122d5209391560741fbdaa1/ Folleto\%20-\%20Clearfield.pdf

Anónimo b. 2020. Cadre $₫ 70$ DG, herbicida para caña de azúcar y maní. BASF. https://agriculture.basf.com/ar/es/ proteccion-decultivos-y-semillas/ productos/cadre-70-dg.html

Avila, L.A.; Senseman, S.A.; McCauley, G.N.; Chandler, J.M.; O'Barr, J. H. 2017. Effect of flood timing on red rice (Oryza sp.) control with imazethapyr applied at different dry-seeded rice growth stages. Weed Technology, 19(2), 476-480. https://doi.org/10.1614/WT04-181

Batalla, C.; Fernández, N. 2007. Eficiencia del imazapir y del imazapic aplicados sobre arroz Clearfield ${ }^{\circledR}$ en el control de malezas. Montevideo: Facultad de Agronomía. (UDELAR).

Crougham, T.P.; Utomo, H.S.; Sanders, D.E.; Braverman, M.P. 1996. Herbicideresistant rice offers potential solution to red rice problem. Louisiana Agriculture, 39(4), 10-12.
Delouche, J.C.; Burgos, N.R.; Gealy, D.R.; Martin, G.Z.D.S.; Labrada, R. 2007. Weedy rices - origin, biology, ecology and control. 156 p. (FAO Plant Production and Protection Paper, 188).

Diarra, A.; Smith, R.J.; Talbert, R.E. 1985. Red rice (Oryza sativa) control in drillsedeed rice (O. sativa). Weed Science, 33(5), 703-707. https://doi.org/10.1017/ S0043174500083120

DIEA/MGAP. 2009. Encuesta arrocera. Zafra 2008/2009. In: Estadisticas Agropecuarias (p. 26).

Diez, M.; Bonnecarrere, V.; Saldain, N.E. 2013. Evaluación in vitro de la actividad de la acetolactato sintasa ante los ingredientes activos del Kifix en arroces Clearfield. In INIA (Ed), Arroz-Soja Resultados Experimentales 2012-2013. Treinta y Tres: INIA, 2013. cap5, p. 6-8. (INIA Actividad de Difusión;713)

Duggleby, R.G.; McCourt, J.A.; Guddart, L.W. 2008. Structure and mechanism of inhibition of plant acetohydroxy cid synthase. Plant Physiology and Biochemistry 46(3): 309-24. https://doi. org/10.1016/j.plaphy.2007.12.004

Federici, M.T.; Vaughan, D.; Tomooka, N.; Kaga, A.; Wang, X.; Doi, K.; Francis, M.; Zorrilla, G.; Saldain, N. 2001. Analysis of Uruguayan weedy rice genetic diversity using AFLP molecular markers. Electronic Journal of Biotechnology 4(3). https://doi. org/10.2225/vol4-issue3-fulltext-3

Garaycochea, S. 2007. Clasificación asistida por marcadores moleculares para diferenciación de biotipos con características de maleza y cultivares comerciales de arroz. http://www.bib. fcien.edu.uy/files/etd/pasan/uy2412500.pdf

Gealy, D.; Agrama. H.; Eizenga, G. 2009. Exploring genetic and spatial structure of US weedy red rice (Oryza sativa) in relation to rice relatives worldwide. Weed Science, 57, 627-643. https://doi. org/10.1614/WS-09-018.1

Gealy, D.R.; Tai, T.H.; Sneller, C.H. 2002. Identification of red rice rice, and hybrids populations using microsatellite markers. Weed Science, 50, 333339. https://doi.org/10.1614/00431745(2002)050[0333:IORRRA]2.0.CO;2 
Gigena, N.; Moreira, A.L. 2002. Uso de hidracida maleica y glifosato en la supresión de la semillazón del arroz rojo (Oryza sp.) y su efecto en el rendimiento y calidad industrial de INIA Tacuarí (Oryza sativa). Montevideo:Facultad de Agronomía, UDELAR.

Grimm, A.; Fogliatto, S.; Nick, P.; Ferrero, A.; Vidotto, F. 2013. Microsatellite markers reveal multiple origins for Italian weedy rice. Ecology and Evolution 3(14):478698. https://doi.org/10.1002/ece3.848

Grimm, A,; Sahi, V.P.; Amann, H.; Vidotto, F.; Fogliatto, S.; Devos, K.M.; Ferrero, A.; Nick, P. 2020. Italian weedy rice - A case of de-domestication? Ecology and Evolution 10(15): 8449-8464. https:// doi.org/10.1002/ece3.6551

Gross, B.L.; Reagon, M.; Hsu, S.C.; Caicedo,A.L.; Jia, Y.; Olsen, K.M. 2010. Seeing red: the origin of grain pigmentation in US weedy rice. Molecular Ecology 19(16):3380-3393. https://doi. org/10.1111/j.1365-294X.2010.04707.x

Gu, X.Y.; Foley, M.E.; Horvath, D.P.; Anderson, J.V.; Feng, J.; Zhang, L.; Mowry C.; Ye, H.; Suttle, J.; Kadowaki, K.; Chen, Z. 2011. Association between seed dormancy and pericarp color is controlled by a pleiotropic gene that regulates abscisic acid and flavonoid synthesis in weedy red rice. Genetics, 189(4), 1515-1524. https://doi. org/10.1534/genetics.111.131169

Kwon, S.L.; Smith, R.J.; Talbert, R.E. 1992. Comparative growth and development of red rice (Oryza sativa) and rice (O. sativa). Weed Science, 40(1), 57-62. https://doi.org/10.1017/ S0043174500056952

Lentini, Z.; Espinoza, A.M. 2005. Coexistence of weedy rice and rice in tropical America -Gene flow and genetic diversity. In: Gressel, J. (Ed.), Crop ferality and volunteerism. BocaRaton: CRC Press; Taylor \& Francis Group. pp. 305-322.

Li, L; Li, Y.; Jia, Y.; Caicedo, A.L.; Olsen, K.M. 2017. Signatures of adaptation in the weedy rice genome. Nature Genetics, 49(5), 811-816. https://doi. org/10.1038/ng.3825

Li, L.F.; Olsen, K. 2020. Population genomics of weedy crop relatives: Insights from weedy rice. In: O. P. Rajora (Ed.). Population genomics: crop plants. Springer Nature Switzerland. p. 25.
Livore, A.B. 2010. Nueva variedad de arroz no transgénica resistente a herbicida, PUITA INTA CL. In: Torres, C. J.; Senigagliesi, C. (Eds.). INTA expone sus aportes al país. Buenos Aires: INTA. pp. 25-26.

Malefyt, T.; Quakenbush, L. 1991. Influence of environmental factors on thr biological activity of the imidazolinone herbicides. In: Shaner, D.L.; O'Connor, L. (Eds.). Theimidazolinone herbicides. Boca Raton: CRC Press. p. 289.

Mangels, G. 1991. Behavior of the imidazolinone herbicides in soil - A Review of the Literature. In: Shaner, D.L.; O'Connor, S.L. (Eds). The imidazolinone herbicides. Boca Raton: CRC Press. p. 191

MGAP. 1988. Comercialización arroz cáscara. Decreto $321 / 988$.

Newhouse, K.E.; Wang, T.; Anderson, P.C. 1991. Imidazolinone resistant crops. In: Shaner, D.L.; O'Connor, S.L. (Eds.). The imidazolinone herbicides, boca Raton: CRC Press, p. 139.

Nunes, A.L.; Delatorre, C.A.; Merotto, A. 2014. Gene expression related to seed shattering and the cell wall in cultivated and weedy rice. Plant Biology, 16(5), 888-896. https://doi.org/10.1111/ plb.12133

Pipatpongpinyo, W.; Korkmaz, V.; Wu, H.; Kena, A.; Ye, H.; Feng, J.; Gu, X.Y. 2020. Assembling seed dormancy genes into a system identified their effects on seedbank longetivity in weedy rice. Heredity, 124:135-145. https://doi. org/10.1038/s41437-019-0253-8

Qiu, J.; Jia, L.; Wu, D.; Weng, X.; Chen, L.; Sun, J.; Chen, M.; Mao, L.; Jiang, B.; Ye, C.; Turra, G.M.; Guo, L.; Ye, G.; Zhu, Q.; Imaizumi , T.; Song, B.; Scarabel, L.; Merotto Jr, A.; Olsen, K.M. 2020. Diverse genetic mechanisms underlie worldwideconvergent rice feralization. Genoma Biology, 21:70. https://doi.org/10.1186/s13059-02001980-x 
Qiu, J.; Zhou, Y.; Mao, L.; Ye, C.; Wang W.; Zhang, J.; Yu, Y.; Fu, F.; Wang, Y.; Qian, F.; Qi, T.; Wu, S.; Sultana, M.H.; Cao, Y.; Wang, Y.; Timko, M.P.; Ge, S.; Fan, L.; Lu, Y. 2017. Genomic variation associated with local adaptation of weedy rice during dedomestication. Nature Communications. art. num. 15323. https://doi.org/10.1038/ ncomms 15323

Rosas, J.E.; Bonnecarrère, V.; Pérez de Vida, F. 2014. One-step, codominant detection of imidazolinone resistance mutations in weedy rice (Oryza sativa L.). Electron J Biotechnol [Internet] 17(2):95-101. http://linkinghub.elsevier.com/retrieve/ pii/S0717345814000293

Shivrain, V.K.; Burgos, N.R.; Agrama, H.A.; Lawton-Rauh, A.; Lu, B.; Sales, M.A.; Boyett, V.; Gealy, D.R.; Moldenhauer, K.A.K. 2010. Genetic diversity of weedy red rice (Oryza sativa) in Arkansas, USA. Weed Research, 50(4), 289302. https://doi.org/10.1111/j.13653180.2010.00780.x

Smith, R.J. 1988. Weed thresholds in southern U.S. rice, Oryza sativa. Weed Technology, 2(3), 232-241. https://doi. org/10.1017/S0890037X00030505

Sweeney, M.T.; Thomson, M.J.; Pfeil, B.E.; MCCouch, S. 2006. Caught redhanded: Rc encodes a basic helix-loophelix protein conditioning red pericarp in rice. Plant Cell, 18(2), 283-294. https:// doi.org/10.1105/tpc. 105.038430

Tan, S.; Evans, R.R.; Dahmer, M.L.; Singh, B.K.; Sahner, D.L. 2005. Imidazolinonetolerant crops: history, current status and future. Pest Management Science, 61:246-257. https://doi.org/10.1002/ ps.993
Tong, J.; Han, Z.; Han, A. 2021. Genetic análisis and molecular mapping of $\mathrm{Rp}$, a mutant gene encoding red pericarp in rice (Oryza sativa L.). Czech Journal of Genetics and Plant Breeding 57(2):5157 https://doi.org/10.17221/70/2020CJGPB

Topolansky, E. 1975. El Arroz. Su cultivo y producción. Buenos Aires: Hemisferio Sur. 304 p.

Vaughan, D.A.; Sanchez, P.L.; Ushiki, J.; Kaga, A.; Tomooka, N. 2005. Asian Rice and Weedy Rice. Evolutionary Perspectives. In: Gressel, J. (Ed.). Crop ferality and volunteerism. Boca Raton: CRC Press; Taylor \& Francis. p. 257-273.

Vigueira, C.C.; Li, W.; Olsen, K. M. 2013. The role of Bh4 in parallel evolution of hull colour in domesticated and weedy rice. J. Evol. Biol., 26, 1738-1749.

Wepplo, P.J. 1991. Chemical and physical properties of the imidazolinones. In: Shaner, D.L.; O'Connor, S.L. (Eds.). The imidazolinone herbicides. Boca Raton: CRC Press. p. 289.

Zorrilla, G. 1992. Arroz rojo. Conózcalo y combátalo. Montevideo: INIA Uruguay. p. 19. (Boletín de Divulgación; 20). http:// www.ainfo.inia.uy/digital/bitstream/ item/2717/1/111219240807154749.pdf

Zorrilla, G.; Pereira, A.L.; Oxley, M.; Acevedo, A. 2011. Longevidad de semillas de variedades de arroz y de biotipos de arroz rojo y negro en el suelo. In INIA (Ed.), Arroz: Resultados Experimentales 2010-2011. Treinta y Tres: INIA 2011. Cap. 8 p.2-10. (INIA, Serie Actividades de Difusión; 651). 


\title{
2 - RECOMENDACIONES PARA UN MANEJO SUSTENTABLE DEL ARROZ RESISTENTE A IMIDAZOLINONAS Y HERRAMIENTAS DE APOYO DISPONIBLES
}

\author{
N.E. Saldain ${ }^{1}$, C. Marchesi $i^{2}$
}

PALABRAS CLAVE: arroz maleza, imazapir + imazapic, servicios, sistema

\section{INTRODUCCIÓN}

El uso de arroz resistente a imidazolinonas (IMIs) y su herbicida asociado, se recomienda en situaciones donde las poblaciones esperables de arroz maleza (AM) sean muy densas o con una distribución espacial muy dispersa, que hace muy difícil de eliminarlo manualmente o con la aplicación localizada de un herbicida total.

En Uruguay, a la fecha, el herbicida usado en este sistema es una mezcla preformulada de imazapir + imazapic (52,5 g/l $+17,5 \mathrm{~g} / \mathrm{l}$, respectivamente). Esta mezcla permite controlar de manera selectiva no sólo al AM, sino también a otras gramíneas anuales y perennes, malezas de hojas ancha y ciperáceas.

Se urge a no usar esta tecnología en chacras libres de AM o en chacras que se haya identificado de manera positiva o se tenga fundada sospecha de la existencia de individuos resultantes del cruzamiento entre el AM con el arroz cultivado resistente.

\section{RECOMENDACIONES DE USO}

La aplicación sistemática y esmerada de las prácticas de manejo indicadas por la empresa que ofrece esta tecnología, además también recomendadas por INIA, son indispensables para mantener la eficacia del control de las malezas en una chacra en particular en el tiempo.

Las recomendaciones generales son:

1. utilización en la siembra de únicamente semilla certificada;

2. realización de dos aplicaciones de la premezcla de imazapir + imazapic en las dosis y momentos recomendados en la etiqueta del herbicida, una en preemergencia (PRE) y otra en postemergencia temprana (POST), con V2-V4 hojas en el arroz;

3. en PRE, si no hay suficiente humedad en el suelo o ausencia de precipitaciones, bañar a la semana de la aplicación para activar el herbicida;

4. en POST, comenzar la inundación a los dos días posteriores de la aplicación del herbicida;

5. eliminación de las plantas de AM que escapen al herbicida, manualmente o con aplicaciones de precisión, quemando los restos extraídos en caso de eliminación manual;

6. realización de hasta dos cultivos consecutivos con variedades resistentes a IMIs;

7. inclusión de otro cultivo como la soja resistente al glifosato o pasturas sembradas para ganadería o cultivos de

\footnotetext{
${ }^{1}$ Néstor Saldain. Ing. Agr. M.Sc. INIA. Programa Nacional de Investigación en Producción de Arroz (hasta junio 2021). nsaldain56@gmail.com

${ }^{2}$ Claudia Marchesi. Ing. Agr. M.Sc. Ph.D. INIA. Programa Nacional de Investigación en Producción de Arroz.

cmarchesi@inia.org.uy
} 
cobertura que aseguran bajar la presión de selección de las IMIs sobre las poblaciones de malezas, atrasando el surgimiento de la resistencia al herbicida;

8. atención cuidadosa en la limpieza de tractores, cosechadoras y herramientas como las hojas niveladoras (landplane) y rastras de discos cuando salen de áreas con infestación de AM;

9. conservación de los caminos, auxiliares de riego y drenajes libre de AM.

Además, hay algunas especificaciones adicionales a las recomendaciones mencionadas, para el manejo de la tecnología en situaciones particulares, como:

El uso de arroz resistente a IMIs por primera vez en un sistema; se recomienda:

1. una aplicación en PRE de imazapir + imazapic seguida de otra en POST;

2. usar dosis de etiqueta para una infestación media de AM; en casos de infestación alta con manchones muy densos ajustar la dosis;

3. si ajusta la dosis, de preferencia hacerlo en la PRE;

4. si ajusta la dosis en POST, tiene más chance de dejar residuos remanentes del herbicida

Cuando se retorna a un potrero que tiene un año de descanso del arroz resistente a IMIs, se recomienda:

1. realizar laboreo de verano;

2. bajar gradualmente la intensidad de uso de variedades resistentes en los años siguientes, evitando repetir 2 cultivos consecutivos;

3. si es requerido ajustar dosis, seguir criterios mencionados arriba

El cultivo de arroz resistente a IMIs de segundo año o alternado con chacra anterior de variedad resistente se recomienda:

1. realizar laboreo de verano para evitar acumulación de residuos de los herbicidas;

2. es necesario incluir otros herbicidas para evitar resistencia del capín a las IMls;

3. en PRE, mezclar imazapir + imazapic con clomazone y/o glifosato (arroz emergido o no);
4. en POST, mezclar imazapir + imazapic con clomazone, propanil, florpirauxifen-benzil o quinclorac;

5. si es requerido ajustar dosis, seguir los criterios mencionados anteriormente;

6. inundación a partir de los dos días posteriores a la aspersión POST.

\section{¿QUÉ OTROS CULTIVOS PUEDO INCORPORAR AL SISTEMA?}

Las recomendaciones de qué cultivos se pueden incorporar en un sistema luego de haber utilizado arroz resistente a IMIs, va a depender del nivel acumulado y de la distribución vertical de los residuos del imazapir + imazapic y de la susceptibilidad de las especies a incluir. La acumulación de los residuos es un balance resultante entre las acciones que favorecen la persistencia y aquellas que contribuyen a su disipación.

A saber, favorecen la acumulación:

1. el uso reiterado de arroz resistente y el correspondiente herbicida;

2. la ausencia del laboreo o un laboreo muy superficial del suelo;

3. solo realizar aplicaciones en POST y a dosis muy elevadas;

4. precipitaciones voluminosas, riego o establecimiento de la inundación cercana a las aplicaciones del herbicida tanto en PRE como POST facilitan la incorporación al suelo;

5. el $\mathrm{pH}$ del suelo;

6. contenido de carbono orgánico del suelo elevado;

7. mayor profundidad del horizonte superficial;

Mientras que, la disipación de los residuos del herbicida es facilitada por:

1. la humedad del suelo a capacidad de campo, la temperatura y el contenido de oxígeno elevados estimulan la degradación por microrganismos del suelo;

2. el drenaje de las chacras y la ruptura de taipas inmediatamente después de la cosecha; 
3. el laboreo frecuente del suelo para traer los residuos del herbicida hacia la superficie;

4. el laboreo de verano previo a la siembra del arroz siguiente;

5. la fertilización fosfatada adecuada que favorezca el crecimiento de las leguminosas:

6. la siembra de mezclas forrajeras con trébol blanco y lotus;

7. un ajuste leve del $\mathrm{pH}$ cuando está por debajo de 5,2 por medio del encalado del suelo para reducir toxicidad por aluminio en las leguminosas sensibles;

8. la siembra de trébol persa al voleo temprano sobre el rastrojo de arroz.

En general, hasta donde se ha experimentado con las especies utilizadas en rotación con arroz resistentes a las IMis, el daño por los residuos de imazapir + imazapic no se traducen en una reducción de la población inicial de plantas y por ende no se ve afectada su implantación. El daño se aprecia en la reducción de la productividad en los cultivos siguientes sensibles y la magnitud del mismo está en función de la cantidad de residuos del herbicida acumulados en el horizonte superficial.

En suelos de textura arenosa, profundos, con bajos contenido de carbono orgánico y $\mathrm{pH}$ por debajo de 5,0 después de dos años de arroz resistente a IMIs usando dosis de etiqueta, valore que:

- si decide sembrar raigrás o trébol rojo solos o mezclados sobre el rastrojo, la pérdida de la materia seca producida puede alcanzar un $50 \%$;

- se puede sembrar una mezcla de trébol blanco y lotus (especies tolerantes) y raigrás (especie susceptible) sobre el rastrojo de arroz, pudiéndose reducir la productividad en un $20-25 \%$;

- no sembrar sorgo ni variedades convencionales de arroz durante dos años;

- si siembra soja, las plantas quedarán más bajas debido a menor número de nudos y entrenudos más cortos, además, tendrán menor diámetro de tallo estando los daños y la pérdida de ren- dimiento en función de la cantidad de residuos acumulados en el horizonte superficial presentes al momento de la siembra.

En suelos limosos o francos, poco profundos y de $\mathrm{pH}$ mayor a 5,0, después de dos años de arroz resistente a IMIs, y habiendo usado dosis de etiqueta valore que:

- si siembra raigrás solo sobre el rastrojo, en uno de cuatro años puede tener pérdidas de productividad del orden del $25 \%$;

- si siembra la mezcla de trébol blanco, lotus y raigrás sobre el rastrojo de arroz, en uno de cuatro años puede reducirse la productividad en el orden del $30 \%$;

- se puede sembrar trébol rojo y raigrás sobre rastrojo de arroz;

no se aconseja laborear inmediatamente a la cosecha del arroz y la siembra de pradera a fines del otoño porque no se permite una adecuada disipación de los residuos del herbicida traídos hacia la superficie desde el horizonte subsuperficial;

- el raigrás es severamente afectado;

- trébol blanco y lotus sufren daños leves que luego se recuperan (síntoma púrpura y/o rojizo en el borde de la lámina de los folíolos el primero y nervaduras en el envés de los foliolos en el segundo);

- no sembrar sorgo o variedades convencionales de arroz por un año;

- si siembra soja, las plantas quedarán más bajas por menor número de nudos, entrenudos más cortos y menor diámetro de tallo siendo pérdida de productividad en función de la acumulación de residuos presentes al momento de la siembra.

En suelos arcillosos con contenido alto de materia orgánica, profundos y de pH > 5,5, después de dos años de arroz resistente a IMIs y habiendo usado dosis de etiqueta valore que:

- se puede sembrar raigrás, trébol rojo, blanco o lotus directamente sobre el rastrojo de arroz; 
- se puede sembrar sorgo y arroz convencional al año siguiente;

- se recomienda aumentar la densidad de siembra entre un 10 a $20 \%$ para diluir los residuos entre más plántulas.

- si siembra soja, las plantas quedarán más bajas por menor número de nudos, entrenudos más cortos y menor diámetro de tallo, siendo la pérdida de productividad función de la acumulación de residuos presentes al momento de la siembra.

\section{HERRAMIENTAS DE APOYO DISPONIBLES}

Desde 2012 se cuenta en INIA con un servicio de detección de AM resistente a IMIs ${ }^{a}$ por medio de marcadores moleculares. El mismo ha procesado más de 500 muestras de AM identificando algo más de la mitad como tipos resistentes, detallándose la información en el capítulo 5 de esta publicación. Además, para la detección de resistencia en el capín se sabe la concentración del herbicida que separa biotipos susceptibles de resistentes, permitiendo establecer distintos niveles de resistencia cuando se emplea siguiendo el procedimiento protocolizado sobre semillas colectadas de individuos que escaparon al control.

Como existe la deriva de herbicida de chacras con arroces resistentes a las IMIs hacia variedades de arroz no resistentes u otros cultivos susceptibles, también ocurre así con la absorción de los residuos del herbicida acumulados en el suelo. Si bien los síntomas son una guía muy útil en la identificación del herbicida responsable del daño en la planta, a veces los mismos son confusos o poco claros. La determinación de los residuos de imazapir en planta es una herramienta objetiva que contribuye a la pesquisa del origen del problema y facilita la búsqueda de soluciones. El asesoramiento para la toma de muestras y la determinación analítica son realizadas por el Grupo de Análisis de Compuestos Traza, Departamento de Química del Litoral, CENUR del Litoral Norte, sede Paysandú. Universidad de la Repúblicab . a Servicio de detección de AM resistente a IMI, Laboratorio Biotecnología INIA Treinta y Tres, Ruta 8, Km 281, Tel: 44522023.
${ }^{\text {b } R u t a ~} 3$ km 363. Paysandú. Tel.: 47227950 int. 135. 


\section{3 - IMPORTANCIA DE LA SEMILLA CERTIFICADA EN LA CONTENCIÓN DEL ARROZ MALEZA}

A. L. Pereira ${ }^{1}$

PALABRAS CLAVE: arroz rojo, calidad de semilla, certificación, Oryza sativa

\section{INTRODUCCIÓN}

La semilla es un vehículo importante de propagación de arroz maleza (AM) en la cadena productiva del arroz en diversos países. Uruguay ha desarrollado por 50 años un programa de certificación de semillas que le ha permitido un efectivo control del AM, eliminando a la semilla como fuente relevante de contaminación de las chacras de arroz, evitando de esta forma su dispersión y mayor presencia. En el área sembrada con el cultivo de arroz en la zafra $2019-2020$ se usó semilla certificada en un $94 \%$ de la misma, manteniéndose en porcentajes superiores al 90\% desde el año 2005 (INASE, 2020). Cabe destacar que desde hace varios años el uso de semilla de variedades creadas en el Instituto Nacional de Investigación Agropecuaria es de más de $80 \%$ del área sembrada. Una de las grandes ventajas de utilizar semilla certificada en casi la totalidad del área de siembra es asegurar la pureza física y genética, evitando por lo tanto la diseminación de malezas en los cultivos a través de este medio. Como la semilla es la principal fuente de contaminación de nuevas áreas y la reintroducción en sitios sin presencia de maleza, esta medida es un control fundamental para mantener niveles bajos de infestación de AM y ha sido muy efectiva en Uruguay. Pero esto no siempre ha sido así y hubo cambios importantes en la presencia de la maleza en las chacras a partir del momento que se creó el Programa de Certificación de semillas de arroz. Este capítulo relata cómo funciona el Sistema Nacional para Producción de Semilla de
Arroz, cómo se ha logrado llegar a sembrar casi la totalidad del área con semilla certificada y cómo repercute este hecho en el control del AM.

\section{SISTEMA NACIONAL PARA PRODUCCIÓN DE SEMILLA DE ARROZ}

El sector arrocero uruguayo posee una fuerte integración de toda la cadena - productores, industria, investigación y Estado - que ha permitido el desarrollo de éste en un marco de acuerdos y seguridad para lograr los mejores resultados productivos. La cadena se encuentra integrada por la Asociación de Cultivadores de Arroz (ACA), la Gremial de Molinos Arroceros (GMA), Coopar, el Instituto Nacional de Semillas (INASE) y el Instituto Nacional de Investigación Agropecuaria (INIA). La producción de arroz es realizada mediante un contrato anual que define la obligación del productor a remitir su arroz a la industria que le provee la semilla. La industria provee asistencia técnica y financiera a sus productores, les proporciona la semilla certificada que van a utilizar y el costo de ésta se le descuenta al productor en el pago final del arroz obtenido. El asegurar buena calidad de la semilla utilizada por los productores disminuye los problemas de contaminación de chacras por esta vía, resultando beneficioso para todos los involucrados en la cadena productiva. Las excepciones a este sistema las constituyen algunos cultivares de calidades

\footnotetext{
${ }^{1}$ Ana Laura Pereira. Ing. Agr. D. Sc. INIA. Unidad de Semillas. apereira@inia.org.uy
} 


\section{Sistema Nacional para producción de semillas de arroz en Uruguay}

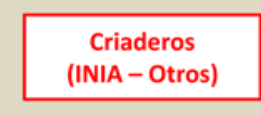

Mantenimiento de variedades y

primeras multiplicaciones

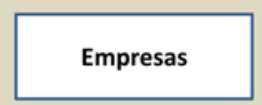

Multiplicación a gran escala y

comercialización

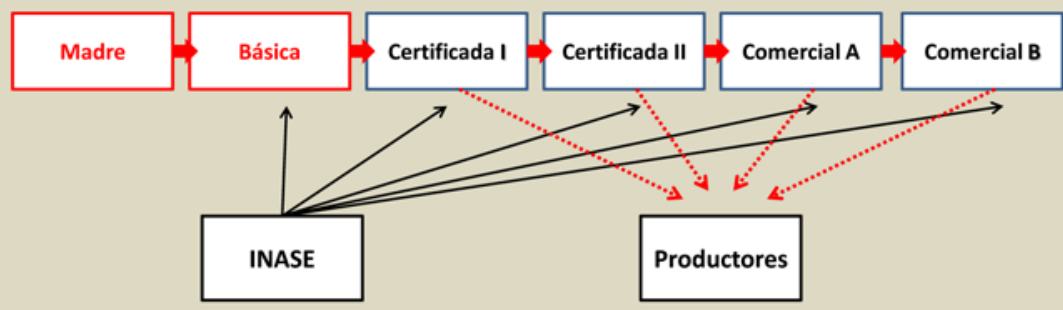

Figura 1. Esquema explicativo del Sistema Nacional para Producción de Semillas de Arroz en Uruguay, sus categorías de multiplicación y actores involucrados.

especiales producidos por las empresas en áreas muy reducidas y productores que no utilizan semilla certificada sino semilla de uso propio. Cabe aclarar que el arroz no es una especie de certificación obligatoria a nivel de la legislación vigente, si no que el sistema lo determina de esta forma.

La producción de semilla de arroz en Uruguay involucra varios actores que abastecen a los productores bajo un sistema de multiplicación generacional de semilla (Figura 1). Se inicia con pequeños volúmenes de alta pureza genética, sanitaria y fisiológica con sucesivas multiplicaciones que conformarán las distintas categorías de semilla.

Las categorías son producidas bajo el proceso de certificación, el cual se realiza siguiendo normas específicas de producción mediante controles de calidad en todas sus etapas, incluyendo el conocimiento del origen genético y el control de las generaciones.

Las semillas madre y básica son producidas por los criaderos, en su mayoría por el obtentor de las variedades o representantes del obtentor en el país (INIA y empresas). Las clases siguientes certificadas y comercial son producidas por las empresas arroceras que compran la semilla básica a INIA y demás empresas. Éstas seleccionan productores que cumplan con determinados requisitos para su multiplicación. La industria paga a los productores de semilla por la multiplicación de semillas un valor previamente acordado, en general el doble del valor del grano. Luego la distribuye entre todos los productores que remiten a su molino, asegurando así el abastecimiento de semilla necesaria para el área de producción y el control del uso de semilla certificada.

El Instituto Nacional de Semillas (INASE) actúa controlando todas las etapas de producción excepto la semilla madre que es de responsabilidad exclusiva del criadero.

Existen dos sistemas de certificación habilitados por INASE: el convencional y el acreditado. El sistema convencional de control es realizado directamente por los técnicos de INASE, quienes verifican el cumplimiento de los requisitos establecidos en los estándares específicos en cada una de las etapas de producción. Desde el año 2000, el sistema cuenta con un mecanismo de control realizado por las empresas. En este sistema las empresas se acreditan y sus técnicos 
realizan ese trabajo y son auditados por INASE en diferentes instancias. En la zafra 2020-2021 nueve empresas arroceras multiplican semilla certificada, de ellas tres producen bajo el esquema de certificación acreditada y el resto lo hace bajo el sistema convencional. Las empresas acreditadas manejan actualmente el $83 \%$ del área total de semilleros de arroz cultivados (Com. pers. Tarán, 2020).

\section{PRODUCCIÓN DE SEMILLA DE ARROZ}

El mantenimiento de un cultivar con sus características propias y su semilla pura, así como la obtención de los volúmenes necesarios para cubrir la demanda de los productores, requiere de sucesivas multiplicaciones controladas de semilla. A continuación, se describen las distintas etapas del control de generaciones de semilla de arroz:

1. semilla madre - primer volumen de semilla obtenida de una variedad sembrada normalmente por el método de panoja por hilera. Son pequeñas parcelas, que darán origen a la siembra del semillero de básica.

2. semilla básica (B) - producida a partir de semilla madre.

3. semilla certificada 1 (C1) - producida a partir de semilla básica

4. semilla certificada 2 (C2) - producida a partir de semilla certificada 1

5. semilla comercial A - producida a partir de semilla certificada 2

6. semilla comercial B - sin control generacional, pero debe cumplir los estándares correspondientes de comercialización.

La semilla madre es sembrada usando el método de multiplicación de panoja por hilera con la semilla remitida por el mejorador. La semilla también puede provenir de panojas seleccionadas de esta misma categoría del año anterior. En este método se seleccionan panojas de plantas sanas y que cumplan con la descripción varietal de la especie, con las que se siembran pequeñas parcelas. Todas las semillas provenientes de una panoja son sembradas en una hilera, y se realizan varias recorridas de observación en las distintas etapas de crecimiento del cultivo para identificar plantas atípicas. Eliminar tempranamente las plantas atípicas es muy importante para evitar que a través del proceso de de-domesticación puedan dar origen a biotipos de AM. En caso de identificarse alguna planta atípica, toda la hilera es eliminada, además de las dos hileras adyacentes a ambos lados. Este mecanismo asegura, además de la inexistencia de plantas atípicas, el control manual de cualquier maleza que haya escapado al control del herbicida, incluyendo el AM. Con la semilla proveniente de las panojas por hilera se siembra la semilla básica que dará origen a las siguientes multiplicaciones. Por el método y cuidados requeridos en la producción de esta semilla y su escala en cantidades mínimas, se obtiene la categoría más alta en pureza genética y física.

Las multiplicaciones de las sucesivas categorías se realizan siguiendo el estándar específico de arroz establecido por el INA$\mathrm{SE}$. Esta institución es quien se encarga de verificar el cumplimiento de los parámetros de campo y laboratorio exigidos.

En relación con los parámetros a nivel de campo que inciden favorablemente en el control de AM se encuentran la obligatoriedad del uso de rotaciones largas y la ausencia de panojas de esa maleza en la chacra. Se exigen seis años libres del cultivo de arroz en chacras para producción de semilla básica y $\mathrm{C} 1$ y cuatro años para semilla C2 y comercial.

Dos procedimientos son también fundamentales en la producción de semilla para evitar la presencia del AM:

- limpieza de maquinaria y herramientas: todos los implementos agrícolas utilizados en la producción de semillas deben estar correctamente limpios de forma de no contaminar nuevas áreas

- raleo manual: en las áreas de producción de semilla son realizadas varias recorridas por cuadrilla de operarios que van arrancando manualmente 
plantas atípicas y plantas consideradas con tolerancia cero (AM, entre otras). Generalmente, cuanto más alta la categoría de semilla (básica), mayor cantidad de raleos son realizados.

EI INASE realiza controles en la producción de la semilla básica y las categorías siguientes. Los técnicos realizan inspecciones en todas las etapas de producción de semilla para asegurar que se cumplan las normas establecidas. Por los estándares se exige al menos una inspección en la etapa de campo, pero lo habitual es que se realicen inspecciones en las etapas presiembra, siembra, floración y cosecha. En estas instancias se inspecciona el campo, la sembradora y cosechadora. Durante todas las etapas del procesamiento de la semilla también son realizadas inspecciones en la planta de semillas, lo que incluye secadores y máquinas de limpieza, clasificación y tratamiento de semillas. El objetivo de las inspecciones es asegurar, tanto en el campo como en la planta de procesamiento de semillas, la ausencia de plantas o semillas de otras especies, malezas y cultivares distintos al que se esté produciendo.

Todos los lotes de semilla producidos en el país de las diferentes categorías son muestreados por INASE para control de calidad en laboratorio y ensayos de postcontrol que es el último eslabón del proceso de certificación. Dentro de los parámetros de laboratorio definidos por INASE, el que incide directamente en el control del AM es el que define una tolerancia cero para las mismas, en todas las categorías de semillas. De esta forma se evita la comercialización de cualquier lote (volumen de hasta 30.000 $\mathrm{kg}$ ) al que se le encuentre al menos una semilla de arroz maleza.

En general, es muy poco frecuente la presencia de AM en los lotes en certificación muestreados por INASE. Esto es debido a que, además de todos los cuidados ya mencionados durante la etapa de producción, los lotes en los que se detecta AM en los controles internos de calidad de las empresas son descartados como semilla y destinados a la industria.

\section{RESULTADOS DE LA CREACIÓN Y MANTENIMIENTO DEL PROGRAMA DE CERTIFICACIÓN DE SEMILLAS DE ARROZ}

La creación del Programa de Certificación de Semillas de Arroz fue fundamental para el crecimiento del sector arrocero y la expansión del cultivo. El mismo inició la calificación de la semilla utilizada y el combate al AM que ya representaba un problema importante (FAO, 2007).

Con la creación de la Estación Experimental del Este (EEE) por el Ministerio de Ganadería Agricultura y Pesca (MGAP) en 1970, en el departamento de Treinta y Tres, se inició la certificación de semillas de arroz. El inicio de este proceso se da en el contexto de una situación comprometida de presencia de arroz maleza.

Según el informe publicado por FAO (2007), en Uruguay fueron cultivadas aproximadamente 26.800 ha de arroz en el año 1972. En ese momento, apenas $70 \%$ de la semilla utilizada por los productores era sometida a algún grado de procesamiento o limpieza. El 30\% restantes era destinada a la utilización por los propios productores sin ningún tipo de procesamiento. En ese año fue realizado un estudio que reveló que el $38 \%$ de los lotes de semilla estaban contaminados con semillas de AM. La situación no era homogénea, pues el $90 \%$ de los lotes de pequeños productores estaban contaminados, mientras que solo el $15 \%$ de los lotes provenientes de grandes empresas arroceras estaban en la misma situación. Para ese año y según los resultados presentados por Jorge (1972) indican que el AM estaba presente en casi toda el área del cultivo de arroz. La falta de pureza varietal y la contaminación de esta maleza fue afectando no solamente la producción de arroz, sino también la calidad del producto. Esta situación hizo priorizar el desarrollo de un sistema que asegurara el abastecimiento de semillas de calidad y pureza varietal (FAO, 2007).

En la Figura 2 se presenta la evolución de la proporción de semilla de arroz 


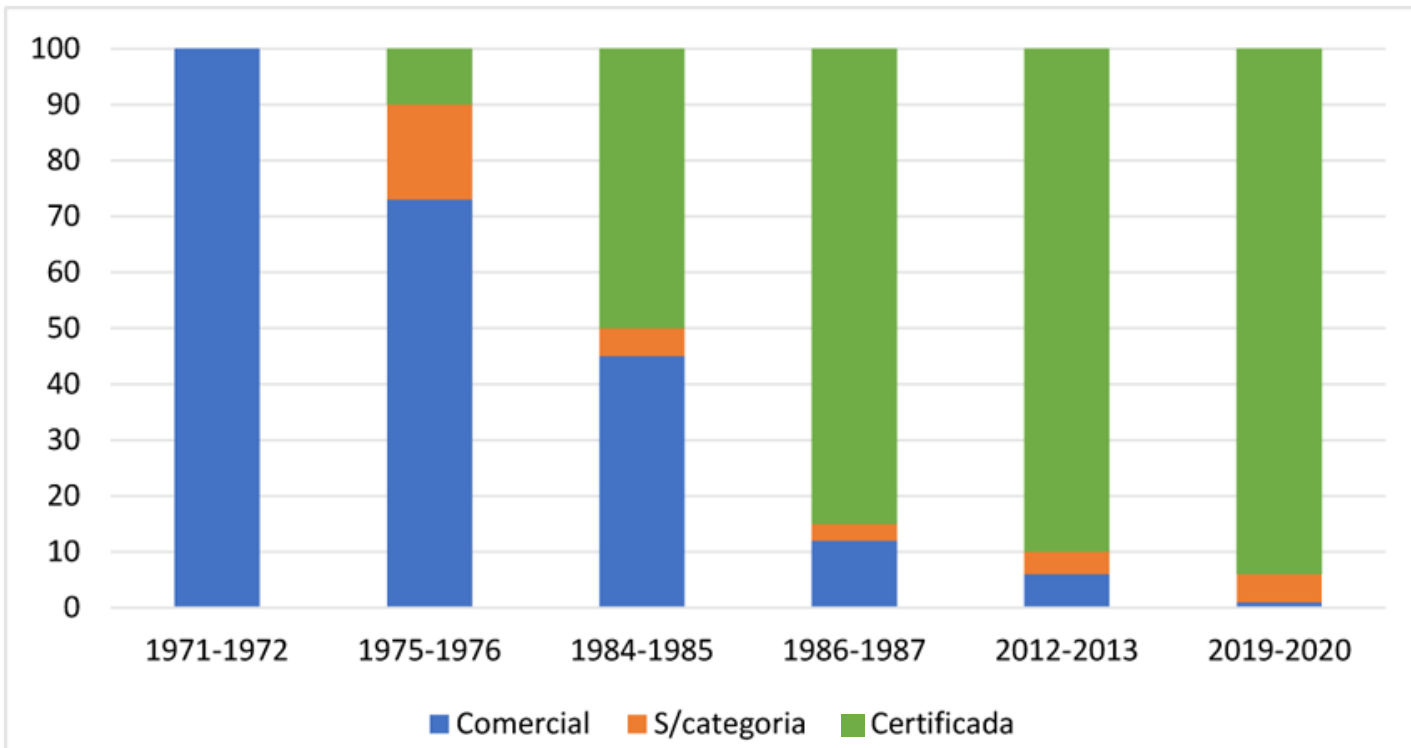

Figura 2. Evolución de la proporción de semilla de arroz certificada, comercial y sin categoría en Uruguay. Adaptado de Zorrilla y Jorge (1971 a 1987); Núñez (2012 a 2020).

certificada, comercial y sin categoría o de uso propio en diferentes zafras desde 1971-1972 hasta 2019-2020.

En la zafra 1984-1985, el cultivo de arroz ocupó un área de 80700 ha cultivadas, $48 \%$ de la misma fue cultivada con semilla certificada y la semilla comercial fue producida sobre estrictas reglamentaciones de control de calidad (Zorrilla y Acevedo, 1985). En ese año, los análisis de calidad de semilla mostraron que todos los lotes muestreados estaban libres de AM. El incremento en el uso de semilla certificada continuó hasta alcanzar más del $85 \%$ del área nacional cultivada en la zafra 19861987. En su informe, FAO (2007), afirma que el progreso realizado en establecer un sistema de calidad y el bajo uso de semilla propia por parte de los productores ha sido posible por el fuerte apoyo de la industria arrocera y su relación de cooperación con los productores de arroz.

En el año 1989 la Estación Experimental del Este pasa a formar parte del Instituto Nacional de Investigación Agropecuaria (INIA), que tenía entre sus objetivos la producción de semilla básica de arroz.

Desde ese momento hasta la actualidad la adopción de semillas certificada ha aumentado año a año llegando en la zafra $2019-2020$ a un $94 \%$.

\section{SEMILLA IMPORTADA}

La importación de semillas es muy variable cada año y representa una proporción muy baja del total de semilla utilizada en el país. En el año 2020 éste representó alrededor de $2 \%$ de la semilla total utilizada. El sector arrocero importa semilla de cultivares e híbridos con características de interés que no se encuentra en la genética nacional.

Sin embargo, hace algunos años comenzaron a detectarse lotes que entraban al país contaminados con AM. A partir de estos hechos, algunas empresas lograron la licencia de los cultivares de mayor interés para realizar la multiplicación de semillas en Uruguay con los respectivos controles del INASE.

\section{LAS FORTALEZAS DEL SISTEMA EN EL USO Y ADOPCIÓN DE SEMILLAS CERTIFICADAS}

\section{Situación en la región}

La tasa de utilización de semilla certificada para la siembra del cultivo de arroz en Uruguay es la mayor de la región. De todas formas, países vecinos han logrado aumentos importantes de 
áreas sembradas con semillas certificadas.

Como ejemplo puede mencionarse el caso del estado de Río Grande del Sur en Brasil, principal productor de arroz de riego en el país, donde pasaron de un uso de $19 \%$ del área sembrada con semilla certificada en la zafra 2006-2007 a 58\% en la zafra 2018-2019 (APASUL, 2019).

Además, se destacaron esfuerzos en aumentar la rigurosidad de la legislación para el comercio de semillas. Por la ley vigente en 1998 (Rio Grande del Sur, 1998) se permitía la presencia de dos granos de AM común (rojo) en muestras de $500 \mathrm{~g}$ de semillas, representativas de un lote de semillas. Para el año 2013 esto fue modificado, siendo considerado el AM común y $\mathrm{AM}$ negro de tolerancia 0 en las muestras de $500 \mathrm{~g}$ para la semilla certificada y permitido 1 grano de AM común en categorías comerciales (MAPA, 2013).

Algunos trabajos realizados en ese estado muestran la importancia del origen de la semilla en la propagación del AM (Marchesan et al., 2001; Bastiani et al., 2013). De hecho, Agostinetto et al. (2001) definieron que la utilización de semillas contaminadas era el principal mecanismo de dispersión de AM en los cultivos de arroz en RS. Marchesan et al. (2001) analizaron la calidad de la semilla utilizada para la siembra de la zafra 1997-1998 para un 25\% de los productores de Santa María, Brasil. Determinaron el origen de la semilla y cuantificaron la presencia de AM entre otros análisis. Los resultados indicaron que el $55 \%$ de los productores utilizaron semilla propia y solamente $10 \%$ utilizaron semilla certificada y/o básica. El 35\% restante compró la semilla en comercios o vecinos que no informaron su procedencia. Apenas un $17 \%$ de las muestras no presentaron AM y casi la mitad de las muestras (47\%) presentaron hasta dos semillas de AM por $500 \mathrm{~g}$ de semillas de arroz cultivado. Estas últimas fueron aptas para la comercialización por la legislación vigente. En promedio se encontraron 7,23 semillas de AM por muestra.

En un estudio donde se evaluó la calidad de lotes de semilla de arroz producida fuera del sistema de certificación, provenientes de 13 regiones del estado de Rio Grande del Sur en los años de 2006 a 2010 se evidenció la elevada incidencia de AM. En los diferentes años se encontró AM común entre un 70 y $100 \%$ de los lotes y el AM negro varió entre 15,2 a 47,6 \% de los lotes de semilla (Bastiani et al., 2013).

En el estado de Santa Catarina, el uso de semillas certificada es de un $75 \%$, siendo el estado con la mayor tasa de utilización de semilla certificada en Brasil.

En Colombia para la zafra 2018-2019 la información recabada por el FLAR (2019), indica un uso de semilla certificada de un $48 \%$.

Por otro lado, en Argentina no hay datos oficiales sobre el uso de semilla certificada para el cultivo de arroz, entretanto, Colazo et al. (com. pers.) utilizando información de INASE Argentina estimaron un porcentaje de uso de aproximadamente un $15 \%$. Sin embargo, datos del FLAR (2019) estiman un uso bastante mayor, de aproximadamente $55 \%$.

No cabe duda de que el uso de la semilla certificada de buena calidad es la primera medida para evitar la dispersión del arroz maleza y primera medida de control. Hay situaciones muy diversas en la adopción de semilla certificada entre los países y ésta se debe principalmente, entre otros factores, a la estrategia que cada uno de ellos ha desarrollado para fomentar el uso. Pueden mencionarse también las diferentes realidades en áreas, tecnologías de producción, así como la percepción de los productores de la importancia de adquirir semilla de buena calidad.

El éxito logrado en el caso de Uruguay demuestra la importancia de trabajar en conjunto con toda la cadena arrocera en el entendido que el beneficio de este trabajo repercute en todos los actores involucrados. Es importante destacar que, en los acuerdos logrados entre las partes, la semilla no es visualizada como un negocio en sí mismo, si no la forma de hacer llegar a todos los productores una semilla que garantice alcanzar el mejor producto final. 


\section{BIBLIOGRAFÍA}

Agostinetto, D.; Fleck, N.G.; Rizzardi M.A.; Merotto, A.; Vidal, R.A. 2001. Arroz Vermelho: ecofisiologia e estratégias de controle. Ciência Rural, Santa Maria, v31, n2, p. 341349. https://doi.org/10.1590/S010384782001000200026

Bastiani, J.; Andrade, F.; Cabrera, I.; Mertz, L.; Mattioni, N; Nunes, U. 2013. Levantamento da qualidade de sementes de arroz irrigado produzidas fora do sistema de certificação. Revista da FZVA, Uruguaiana, v.19, n1, p. 1019, 2013.

BRASIL. Ministério da Agricultura, Pecuária e Abastecimento Instruçâo. 2013. Normativa 45, de 17 de setembro de 2013. Diário Oficial da União, Brasília, $n^{\circ} 45$ de 17 de setembro de 2013, p.122.

Delouche, J.C.; Burgos, N.R.; Gealy, D.R.; Zorrilla, G.; Labrada, R. 2007. Weedy rices - origin, biology, ecology and control. Seed shattering and dormancy in weedy rices.(cap. 4). Rome: FAO. p. 45-62. FAO Plant production and protection paper; 188)
FLAR. 2019. Encuesta de monitoreo y seguimiento al sector Arrocero Latinoamericano (EMSAL). Observatorio del Arroz para América Latina.

Marchesan, E.; Menezes, N.L. de.; Siqueira, C. do A. 2001. Controle da qualidade das sementes de arroz irrigado utilizadas em Santa Maria/RS. Ciência Rural, Santa Maria, v.31, n.3, p. 375379. https://doi.org/10.1590/S010384782001000300002

Rio Grande do Sul. Secretaria de Agricultura e Abastecimento. Departamento de Produção Vegetal. CESM/RS.1998. Normas e padrões de produção de sementes para o Estado do Rio Grande do Sul. Porto Alegre: SAA/DPV, 1998. $156 \mathrm{p}$.

Tarán, C. 2019. Orgullo celeste. La certificación de semilla de arroz. Arroz (ACA), v.19, $\mathrm{n}^{\circ} .98$ p. $72-73$

Zorrilla, G.; Acevedo, A. 1985. Encuesta de semillas de arroz - año 1984. In: Resultados de la Experimentación Regional en Cultivos: Arroz - Soja, 1984 - 1985. Treinta y Tres: Estación Experimental del Este, CIAAB - MGA. p. $115-118$. 


\title{
4 - FLUJO GÉNICO DEL ARROZ CLEARFIELD ${ }^{\circledR}$ AL ARROZ MALEZA: ESTUDIO DE CASOS
}

\author{
J. E. Rosas ${ }^{1}$, F. Pérez de Vida², V. Bonnecarrère ${ }^{3}$, N. E. Saldain ${ }^{4}$
}

PALABRAS CLAVE: arroz rojo, cruzamientos, resistencia a herbicidas

\section{INTRODUCCIÓN}

La pertenencia del arroz cultivado (AC) y arroz maleza (AM) a la misma especie (Oryza sativa, genoma A diploide) posibilita el flujo de genes entre ambos. A pesar del carácter principalmente autógamo del arroz dado por su anatomía floral y la breve viabilidad de su polen, los eventos de fecundación cruzada entre AC y AM ocurren a frecuencias que pueden ir de $0,05 \%$ a más del 30\% (Chen et al., 2004; Jia et al., 2007). Un estudio de cruzamiento en condiciones experimentales entre las variedades Clearfield $^{\circledR}$ (CL) CL161 y CL121 y AM de cáscara pajiza concluyó que al menos 170 plantas resistentes por hectárea se generarían en un solo ciclo de cultivo (Shivrain et al., 2007). Por otra parte, las evaluaciones del riesgo de flujo de genes de resistencia en campos comerciales cultivados con cultivares CL en Luisiana, EE.UU., detectaron una tasa general del $0,17 \%$ (Zhang et al., 2006). Existen diversos factores que afectan las tasas de cruzamiento. Los cultivares pueden presentar diferentes tasas, encontrándose $0,003 \%$ para CL121, y $0,008 \%$ para CL161, con un mismo tipo de AM (Shivrain et al., 2007). El tipo de AM también puede determinar una variación en la tasa de cruzamiento, reportándose que el de cáscara negra presenta un rango hasta 10 veces mayor que el color paja (Shivrain et al., 2010b). Estas variaciones se asocian principalmente a floraciones simultáneas del AC y el AM (Niruntrayakul et al., 2009). Goulart et al. (2016) encontraron que las mutaciones de resistencia a imidazolinonas (IMI) en AM resistente cercano a cultivares $\mathrm{CL}$, son siempre las mismas que la presente en dicho cultivar, sugiriendo que el principal mecanismo de aparición de resistencia es el flujo de genes. El flujo génico también fue reportado como la principal fuente de resistencia a IMI en AM en EEUU (Shivrain et al., 2010a), Brasil (Roso et al., 2010), e Italia (Scarabel et al., 2012). El objetivo de este trabajo es evaluar la ocurrencia de flujo de genes de resistencia a IMI desde cultivos a AM en tres situaciones contrastantes de uso de la tecnología CL en Uruguay.

\section{MATERIALES Y MÉTODOS}

Las accesiones de AM estudiadas provienen de tres chacras arroceras representando situaciones contrastantes de uso de la tecnología CL.

Caso I: chacra ubicada al norte del departamento de Cerro Largo, con cuatro sectores con $0,1,2$ y 3 años de uso de $C L$ (sectores A, B, C y D, respectivamente). El área total estudiada fue de aproximadamente 30 ha, con topografía y suelo homogéneos.

\footnotetext{
1 Juan Rosas. Lic. M.Sc. Ph.D. INIA. Programa Nacional de Investigación en Producción de Arroz. jrosas@inia.org.uy ${ }^{2}$ Fernando Pérez de Vida. Ing. Agr. M.Sc. Ph.D. INIA. Programa Nacional de Investigación en Producción de Arroz. fperez@inia.org.uy

${ }^{3}$ Victoria Bonnecarrere. Lic. Bioq. Ing. Agr. M.Sc. Ph.D. INIA. Unidad de Biotecnología.

vbonnecarrere@inia.org.uy

${ }^{4}$ Néstor Saldain. Ing. Agr. M.Sc. INIA. Programa Nacional de Investigación en Producción de Arroz (hasta junio 2021) nsaldain56@gmail.com
} 
Tabla 1. Detalle de características de cada sector estudiado en el Caso I.

\begin{tabular}{|c|c|c|c|c|c|}
\hline Sector & $\begin{array}{l}\text { Superficie } \\
\text { (ha) }\end{array}$ & Año & $\begin{array}{l}\text { Aplicaciones } \\
\text { de herbicida }\end{array}$ & Cultivar & $\begin{array}{c}\text { Mutación de } \\
\text { resistencia a IMI }\end{array}$ \\
\hline \multirow{3}{*}{$A$} & \multirow{3}{*}{4} & 1 & 0 & INIA Olimar & Ninguna \\
\hline & & 2 & 0 & INIA Olimar & Ninguna \\
\hline & & 3 & 0 & INIA Olimar & Ninguna \\
\hline \multirow{3}{*}{$B$} & \multirow{3}{*}{8} & 1 & 0 & INIA Olimar & Ninguna \\
\hline & & 2 & 0 & INIA Olimar & Ninguna \\
\hline & & 3 & 2 & INTA Puitá-CL & Ala $_{122} \mathrm{Thr}$ \\
\hline \multirow{3}{*}{$\mathrm{C}$} & \multirow{3}{*}{9} & 1 & 0 & INIA Olimar & Ninguna \\
\hline & & 2 & 1 & INTA Puitá-CL & $\mathrm{Ala}_{122} \mathrm{Thr}$ \\
\hline & & 3 & 2 & INTA Puitá-CL & $\mathrm{Ala}_{122} \mathrm{Thr}$ \\
\hline \multirow{3}{*}{$\mathrm{D}$} & \multirow{3}{*}{8} & 1 & 1 & CL161 & Ser $_{653}$ Asp \\
\hline & & 2 & 1 & CL161+INTA Puitá-CL & Ser $_{653}$ Asp-Ala $_{122} \mathrm{Thr}$ \\
\hline & & 3 & 2 & INTA Puitá-CL & Ala $_{122}$ Thr \\
\hline
\end{tabular}

Los cultivares sembrados en cada sector y año, y sus mutaciones de resistencia a IMI se detallan en el cuadro 1.

Caso II: establecimiento en el ex EspiniIlar, Salto, sin historia previa de uso de $\mathrm{CL}$, en el que se relevaron en la zafra 2007-2008 tres sectores (E, F, y G) con cultivo de la variedad convencional El Paso 144. Las áreas $E$ y $F$ tuvieron en la zafra 2006-2007 híbrido CL de RiceTec, con mutación Ser $_{653}$ Asp, e INTA Puitá CL con mutación Ala ${ }_{122}$ Thr, respectivamente, mientras que en el área G se cultivó El Paso 144. El total del área muestreada en este caso fue de aproximadamente 40 ha.

Caso III: chacra en departamento de Treinta y Tres, con un único cultivo de CL161 en la zafra 2005-2006 y barbecho con laboreo de verano en zafra 2006-2007, para posterior implantación de un cultivo con la variedad convencional EI Paso 144 en la zafra 2007-2008, momento en que se realizó el muestreo de AM. Se relevó un área aproximada de 10 ha.

\section{Muestreos}

En los tres casos los muestreos se realizaron en la zafra 2007-2008, georreferenciándose puntos y colectándose plantas en 142 puntos en el Caso I, 75 puntos en el Caso II, y 50 puntos en el Caso III. En el Caso I los puntos se ubicaron 24 en el sector A (101 plantas), 29 en el sector B (74 plantas), 31 en el sector C (75 plantas), y 48 en el sector $D$ (90 plantas). En el caso II se muestrearon 25 puntos en las áreas $E, F$ y $G$. En los casos II y III la colecta de semillas se realizó en forma masal, mientras que en el caso I se cosechó una panoja de cada planta madre, manteniéndose las progenies identificadas y separadas.

La colecta de semillas se realizó en 4 instancias debido a la diversidad de tiempos de maduración en una misma planta madre, y entre distintas plantas. Se colocaron bolsas de papel cubriendo cada panoja a muestrear para evitar la pérdida de semillas por desgrane precoz (Figura 1).

\section{Aplicación de herbicida}

Se realizó una primera selección de plantas de AM por sobrevivencia a dosis letales de herbicida. Se sembró la semilla colectada en almacigueras conducidas en invernáculo. Por cada planta madre de AM se sembró la semilla de una panícula (aprox. 40 semillas) en una hilera de almaciguera, así como hileras con variedades testigo 


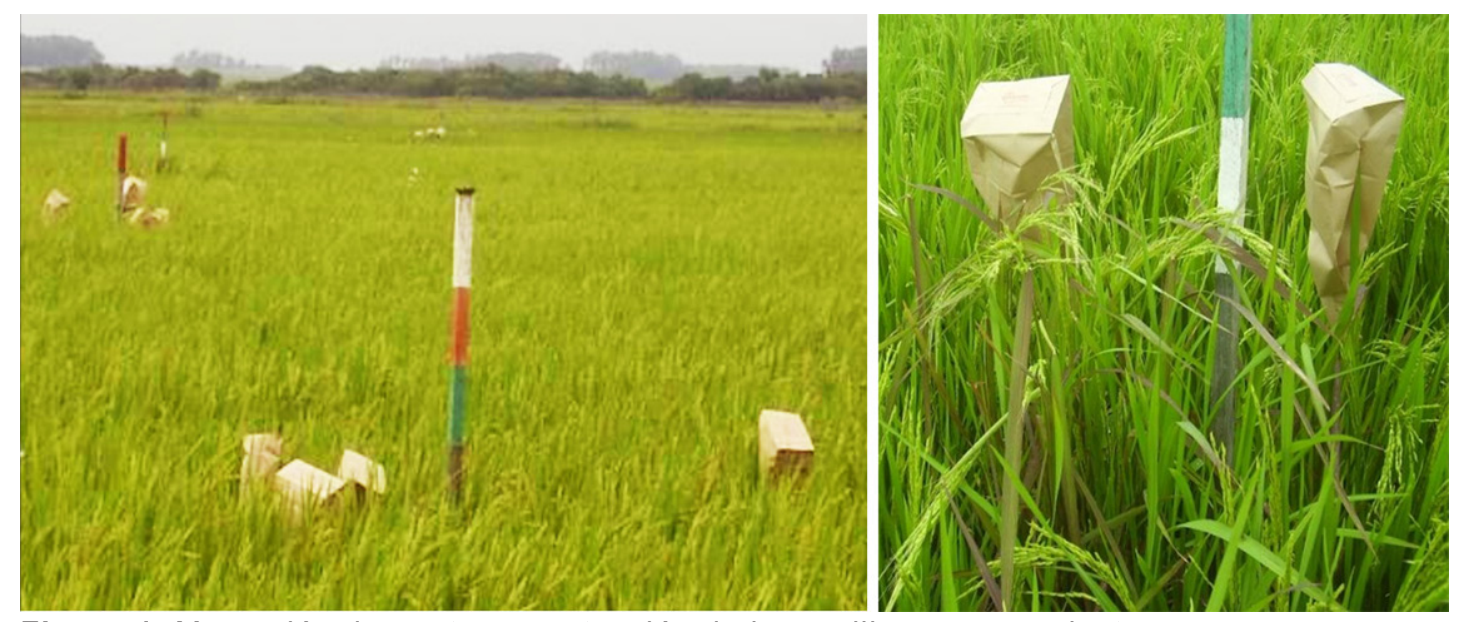

Figura 1. Marcación de puntos y protección de la semilla para su colecta.

susceptible (INIA Olimar) y resistente (INTA Puitá CL) en cada almaciguera. Se realizaron dos aplicaciones secuenciales de herbicida $\mathrm{Ki}+\mathrm{Fix}^{\circledR}$, BASF (imazapic $17,5 \% \mathrm{p} / \mathrm{p}$, imazapir $52,50 \% \mathrm{p} / \mathrm{p}+$ coadyuvante tensioactivo no iónico Plurafac ${ }^{\circledR}$ al $0,25 \%)$ a dosis letales (200 $\mathrm{g} / \mathrm{ha})$, a los 15 y 30 días postemergencia. Se conservaron a $-20^{\circ} \mathrm{C}$ muestras de tejido de una planta por cada hilera con más de $50 \%$ de sobrevivientes.

\section{Detección molecular de mutaciones de resistencia}

Para las plantas colectadas en el caso I, de cada planta madre cuya progenie tuviera más del $50 \%$ de plantas sobrevivientes se analizó un individuo sobre- viviente por técnicas moleculares, para determinar la presencia de mutaciones de resistencia. Se aisló ADN con el método CTAB, y se detectó la presencia de las mutaciones $\mathrm{Ser}_{653}$ Asp y $\mathrm{Ala}_{122}$ Thr con el método KASP (Rosas et al., 2014). Todas las plantas sobrevivientes a herbicida de los casos II y III fueron analizadas por estos marcadores.

\section{RESULTADOS Y DISCUSIÓN}

Caso I. Durante la identificación de puntos con presencia de AM, se observaron diferencias en la densidad de plantas $y$ de puntos en los distintos sectores, que fueron confirmadas por los datos de GPS. Los puntos del sector A que no
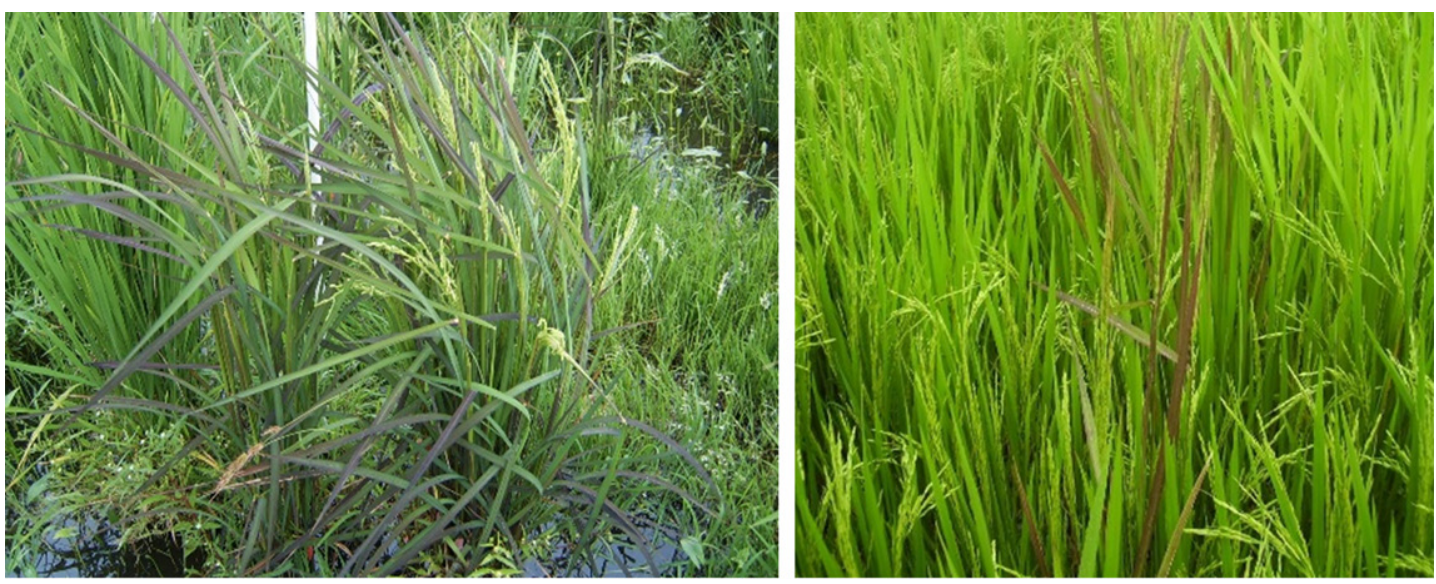

Figura 2. Ejemplos de variabilidad fenotípica observada en $A M$ de sectores $C$ y $D$, indicadora de poblaciones segregantes. Se observa en hojas y tallos pigmentación purpúrea sugestiva de hibridación con la variedad CL161 dado que tiene la base de la vaina con esa coloración. 
habían recibido tratamiento de herbicidas IMI, tendían a ser de mayor diámetro y con mayor cantidad de plantas, mientras que los sectores con más años de uso presentaban puntos con menos plantas. En cuanto a las características fenotípicas de los AM identificados, se observó una mayor diversidad en los sectores $C$ y $D$, encontrándose en este último gran variabilidad en la altura, color de hojas, forma y color de grano, presencia de arista, macollaje y pilosidad en hojas. Asimismo, se observó pigmentación en distintos tonos de púrpura en tallos y hojas de algunas plantas (Figura 2)

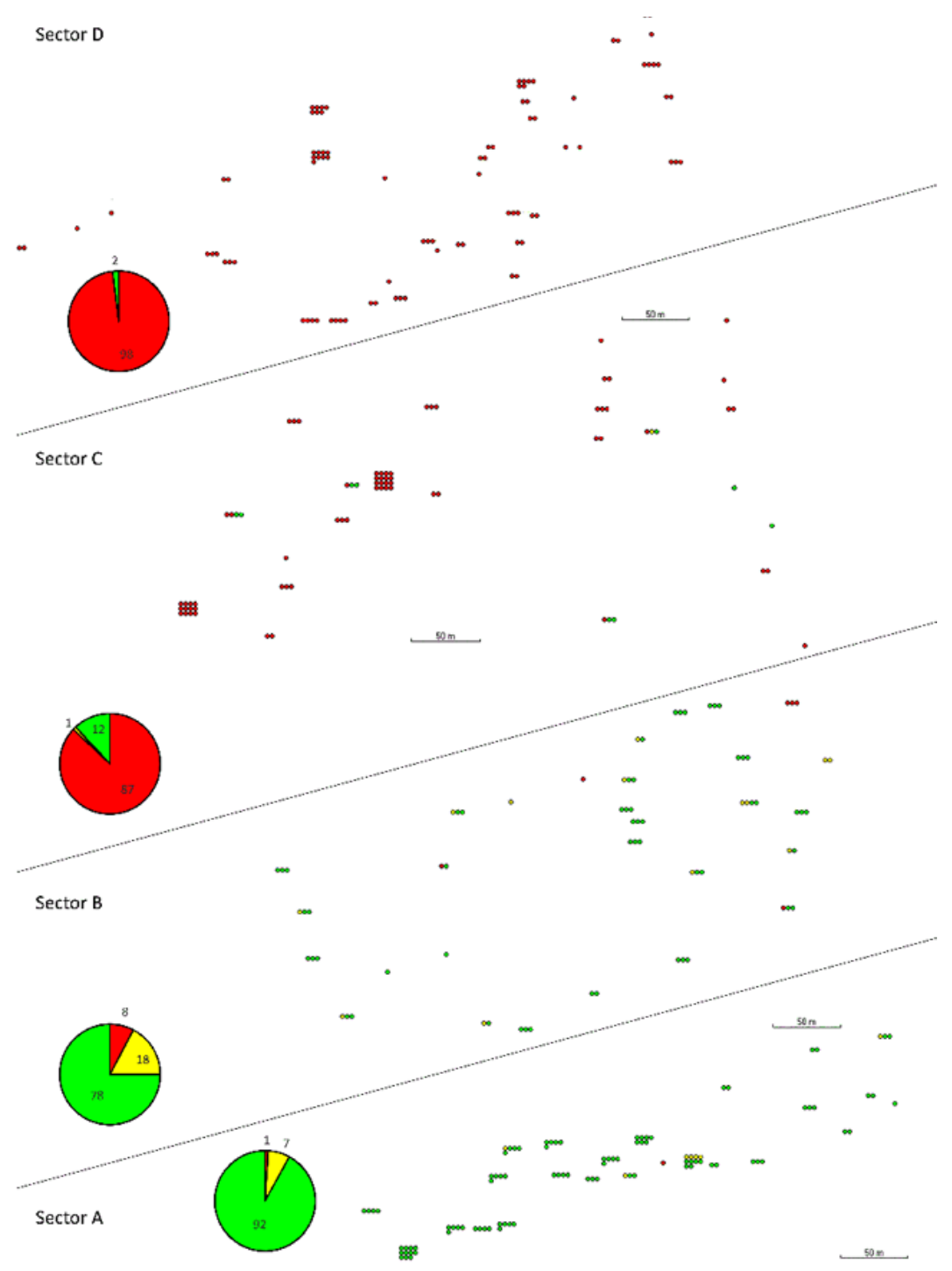

Figura 3. Distribución espacial de puntos muestreados y resultados de la aplicación de imidazolinonas en plantas de AM colectadas de los cuatro sectores del Caso I: sin uso de CL (A), con 1 año de uso (B), 2 años (C) y 3 años (D). Cada punto corresponde a un agrupamiento de individuos de AM (de 1 a 16, promedio 3,1). La progenie de cada individuo fue sometida a dosis letales de imidazolinonas. El color verde corresponde a una progenie totalmente susceptible (0 sobrevivientes); el amarillo a $<10 \%$ de plantas sobrevivientes; y el rojo a más del $50 \%$ de la progenie. De cada una de las progenies con más de $50 \%$ de sobrevivientes se tomó un individuo para determinar la presencia de las mutaciones de resistencia $\mathrm{Ala}_{122}$ Thr y $\mathrm{Ser}_{653}$ Asp por métodos moleculares. Los gráficos circulares muestran el porcentaje de puntos muestreados con cada tipo de progenie. 


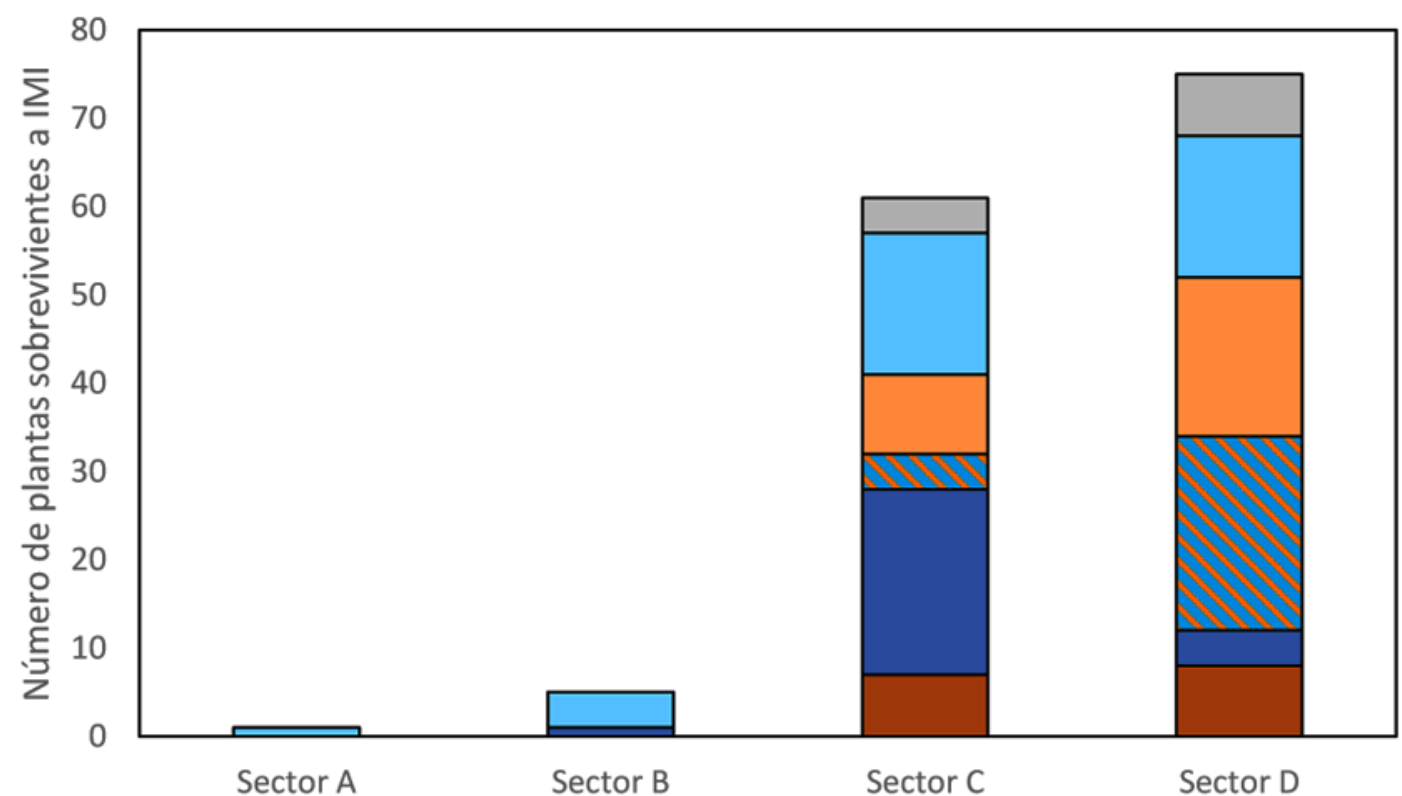

En la Figura 3 se muestra la distribución espacial de las plantas madre clasificadas de acuerdo con el porcentaje de plántulas sobrevivientes a la aplicación de herbicida en sus progenies, y su proporción en cada sector. Puede observarse la absoluta predominancia de plantas cuyas progenies fueron susceptibles a IMI en el sector $A$, y el progresivo aumento de plantas con progenies resistentes al herbicida a medida que se intensifica el uso del arroz $\mathrm{CL}$. Los dos únicos puntos con plantas resistentes en el sector $B$ se ubican a pocos metros del sector $C$, mientras que el único punto con plantas resistentes del sector A se encuentra a más de $300 \mathrm{~m}$ de los sectores con uso de CL.

El análisis por marcadores moleculares de las plantas sobrevivientes a IMI (Figura 4) mostró la ocurrencia de al menos dos eventos de flujo génico desde los cultivares $C L$ al $A M$, ya que fueron detectadas tanto la mutación $\mathrm{Ala}_{122} \mathrm{Thr}$ proveniente de la variedad INTA Puitá CL, como la
Ser $_{653}$ Asp proveniente de CL161. Asimismo, la presencia de plantas heterocigotas combinando ambas mutaciones implican un tercer evento de cruzamiento, probablemente entre plantas heterocigotas para $\operatorname{Ser}_{653} \mathrm{Asp}$, con el cultivar INTA Puitá CL. Este evento puede haber ocurrido en el sector $D$ y luego propagarse hacia el $\mathrm{B}$, o en ambos sectores en forma independiente. También se observó un impacto importante de la dispersión de semilla en la dinámica de la población del AM resistente a IMI, con dos plantas homocigotas para el alelo Ala $_{122}$ Thr en el sector $B$. Por ser un sector con sólo un año de uso de $C L$, no podrían haber ocurrido allí las dos generaciones necesarias para la obtención de individuos homocigotas. Por lo tanto, es muy probable que estas plantas sean producto de la dispersión de semilla desde el sector $D$.

Caso II. De los 75 puntos muestreados, solamente en tres se encontraron progenies sobrevivientes a la aplicación de dosis letales de IMI, dos de ellas 
provenientes del sector $\mathrm{E}, \mathrm{y}$ una del sector F. Las plantas sobrevivientes al herbicida fueron homocigotas resistentes para la mutación $\operatorname{Ser}_{653}$ Asp. Considerando que la chacra no tenía historia previa de cultivos resistentes a IMI, el origen de las plantas homocigotas resistentes podría atribuirse a dispersión de semilla de AM resistente a través de maquinaria $u$ otros medios, y/o al uso de semilla contaminada.

Caso III. En esta situación no se encontraron sobrevivientes a la aplicación de IMI en dosis recomendadas, en ninguna de las progenies de los 50 puntos estudiados. Este caso de mínima intensidad con un único año de uso de CL implica menos oportunidades de ocurrencia de cruzamientos, así como una baja presión de selección que pudiera haber favorecido la predominancia de individuos naturalmente resistentes que estuvieran presentes en muy baja frecuencia en el banco de semillas del suelo. Sin embargo, la ocurrencia de semillas de AM susceptible a IMI en el banco de suelo mantuvo la presencia de esta maleza en la zafra de muestreo, a pesar del uso de laboreos de verano para el control por mecanismos físicos de la maleza en la zafra 2006-2007.

\section{CONCLUSIONES}

En general se observa una relación entre la intensidad de uso de CL y la abundancia de AM resistente a IMI. Esto es particularmente claro en el Caso I, donde la proporción de plantas de AM resistente a IMI aumenta exponencialmente con los años de uso de CL. El Caso II es un ejemplo de la importancia que tienen los mecanismos de arrastre o traslado de semilla de maleza, probablemente mediante la maquinaria de cosecha, en la dispersión de las malezas resistentes. Por último, el Caso III muestra que en condiciones de baja intensidad de uso de CL y sin que haya presión de selección por el uso reiterado del mismo principio activo, no se genera AM resistente en cantidades detectables.

\section{BIBLIOGRAFÍA}

Chen LJ; Lee, DS; Song, ZP, Suh, H.S.; Lu, B.R. 2004. Gene Flow from Cultivated Rice (Oryza sativa) to its Weedy and Wild Relatives. Annals of Botany 93:6773. https://doi.org/10.1093/aob/mch006

Goulart, I. C. G. R.; Menezes, V. G.; Bortoly, E. D.; Kupas, V.; Merotto, A. 2016. Detecting gene flow from ALS-resistant hybrid and inbred rice to weedy rice using single plant pollen donors. Experimental Agriculture 52(2):237-250. https://doi. org/10.1017/S0014479715000058

Jia, S.; Wang, F.; Shi, L.; Yuan, Q.; Liu, W.; Liao, Y.; Li, S. Jin, W. Peng, H. 2007. Transgene flow to hybrid rice and its male-sterile lines. Transgenic Research 16:491-501. https://doi.org/10.1007/ s11248-006-9037-z

Niruntrayakul, S.; Rerkasem, B.; Jamjod, S. 2009. Crossability between cultivated rice (Oryza sativa) and common wild rice (O. rufipogon) and characterization of $\mathrm{F} 1$ and $\mathrm{F} 2$ populations. ScienceAsia 35:161-169. https://doi.org/10.2306/ scienceasia1513-1874.2009.35.161

Roso, A.C. Merotto Jr. A.; Delatorre C.A, Menezes V.G. 2010. Regional scale distribution of imidazolinone herbicideresistant alleles in red rice (Oryza sativa L.) determined through SNP markers. Field Crops Research 119:175-182. https://doi.org/10.1016/j.fcr.2010.07.006

Scarabel, L.; Cenghialta, C.: Manuello, D.; Sattin, M. 2012. Monitoring and Management of ImidazolinoneResistant Red Rice (Oryza sativa L., var. sylvatica) in Clearfield $^{\circledR}$ Italian Paddy Rice. Agronomy 2:371-383. https://doi. org/10.3390/agronomy2040371

Shivrain, V.K.; Burgos, N.R.; Anders, M.M. Rajguru, S.N.; Moore, J.; Sales, M.A. 2007. Gene flow between Clearfield ${ }^{\mathrm{TM}}$ rice and red rice. Crop Protection 26(3):349-356. https://doi. org/10.1016/j.cropro.2005.09.019

Shivrain, V.K.; Burgos, N.R.; Sales, M.A.: Kuk, Y.I. 2010a. Polymorphisms in the ALS gene of weedy rice (Oryza sativa L.) accessions with differential tolerance to imazethapyr. Crop Protection 29:336-341. https://doi.org/10.1016/j. cropro.2009.10.002 
Shivrain, V.K.; Burgos, N.R.; Scott, R.C.; Gbur Jr., E.E.; Estorninos Jr., L.E.; McClelland, M.R. 2010b. Diversity of weedy red rice (Oryza sativa L.) in Arkansas, U.S.A. in relation to weed management. Crop Prottection 29(7):721-730. https://doi. org/10.1016/j.cropro.2010.02.010
Zhang, W.; Linscombe, S.D.; Webster, E.; Tan, S.; Oard, J. 2006. Risk assessment of the transfer of imazethapyr herbicide tolerance from Clearfield rice to red rice (Oryza sativa). Euphytica 152:75-86. https://doi.org/10.1007/s10681-0069180-x 


\section{5 - MONITOREO DE MUTACIONES DE RESISTENCIA A IMIDAZOLINONAS EN ARROZ MALEZA}

J. E. Rosas ${ }^{1}$

PALABRAS CLAVE: marcadores moleculares, resistencia, Sistema Clearfield ${ }^{\circledR}$

\section{INTRODUCCIÓN}

Como se discutió en capítulos anteriores, el arroz maleza (AM) está considerado como una de las malezas más problemáticas del cultivo de arroz en Uruguay y en el mundo, por la dificultad que presenta su control y la potencialidad de dejar fuera del sistema a chacras con infestación severa (Delouche et al., 2007). La tecnología de arroz resistente a imidazolinonas (IMI) utilizada por ejemplo en Sistema Clearfield ${ }^{\circledR}$ (CL, BASF) o en el Full Page (FP, RiceTec) consiste en cultivares no transgénicos resistentes a estos herbicidas de acción total y amplio espectro, y es la herramienta más extendida para el control químico selectivo en el cultivo. La resistencia a IMI de los cultivares CL y FP está dada por mutaciones o polimorfismos de un solo nucleótido (SNP) en el gen que codifica para el sitio de acción de estos herbicidas, la enzima aceto lactato sintasa (ALS, también llamada aceto hidroxiácido sintasa, AHAS, EC 2.2.1.6). Existen tres mutaciones de resistencia a IMI presentes en cultivares CL reportadas a la fecha (Rosas et al., 2014). Las tres consisten en sustituciones de una guanina $(G)$ por una adenosina $(A)$ en las posiciones 1886, 1883 y 336 de la secuencia nucleotídica del gen ALS, y determinan cambios de los aminoácidos glicina por glutámico $\left(\mathrm{Gly}_{654} \mathrm{Glu}\right)$, serina por aspartato (Ser $\left.{ }_{653} \mathrm{Asp}\right)$, y alanina por treonina $\left(\mathrm{Ala}_{122} \mathrm{Thr}\right)$, respectivamente. Las mutaciones Gly ${ }_{654}$ Glu y Ser $_{653}$ Asp fueron obtenidas por la Universidad Estatal de Luisiana (EE.UU.) sometiendo a mutagénesis química a líneas y cultivares de tipo japónica tropical (Croughan, 1998), mientras que la mutación $\mathrm{Ala}_{122}$ Thr fue obtenida por el mismo método en INTA Concepción del Uruguay (Argentina) en líneas de tipo índica (Livore et al., 2007). En nuestro país la tecnología CL comenzó a utilizarse en arroz en 2004, existiendo a partir de ese entonces la disponibilidad de diversos cultivares con resistencia a IMI. Las variedades desarrolladas por INTA como Puitá CL, Gurí CL y Memby Porá CL y el híbrido de RiceTec Titán CL poseen la mutación Ala ${ }_{122} \mathrm{Thr}$, mientras que las variedades de INIA como CL212, CL244, y el híbrido de RiceTec Inov CL, poseen la mutación $\operatorname{Ser}_{653}$ Asp (Rosas et al., 2014). La mutación Gly ${ }_{654}$ Glu está presente en la variedad IRGA $422 \mathrm{CL}$, sembrada en la década pasada en Río Grande del Sur, Brasil.

Como se expone en capítulos anteriores, es posible la fecundación cruzada entre el arroz cultivado y el AM, dado que ambos pertenecen a la misma especie (Shivrain et al., 2009). Esto genera híbridos resistentes al herbicida que comprometen fuertemente la eficacia de su control químico (Flow et al., 2003). Las recomendaciones de uso de la tecnología CL en arroz buscan minimizar la ocurrencia de cruzamientos entre plantas de $\mathrm{AM}$ y el cultivo $\mathrm{CL}$, que puedan dar origen a AM resistente a IMI. Para ello se enfatiza en el uso de fórmulas, dosis y modo de aplicación adecuados que permitan el mayor

IJuan Rosas. Lic. M.Sc. Dr. Cs. Agrarias, INIA. Programa Nacional de Investigación en Producción de Arroz. jrosas@inia.org.uy 
control posible de la maleza y la realización de raleo manual (roguing) o aplicación localizada de herbicida con barra pulverizadora en los escapes de AM (BASF, 2016). Sin embargo, a pesar de estas recomendaciones se ha documentado la presencia de AM con mutaciones de resistencia a IMI en la mayoría de los países donde se cultiva arroz CL (Dauer et al., 2018; Merotto et al., 2016), incluyendo Uruguay (Rosas et al., 2013). Por ese motivo, se ha recomendado que el uso de la tecnología CL se acompañe del monitoreo de las poblaciones de AM para la identificación y control en forma temprana de AM con mutaciones de resistencia a IMI y para identificar los factores que afectan la aparición de esta resistencia (Scarabel et al., 2012). Uruguay fue pionero en ese monitoreo mediante el Servicio de Detección de Resistencia a Imidazolinonas en AM (SDRI) brindado por INIA desde la zafra 2011-2012. El servicio se ofrece a usuarios del sistema Clearfield $^{\circledR}$ y consiste en analizar plantas de AM provenientes de chacras con historia de uso de tecnología $C L$, para determinar si estas poseen alguna de las mutaciones de resistencia a IMI mencionadas anteriormente. Para su puesta en funcionamiento se contó con el apoyo de la Agencia Nacional de Investigación e Innovación (ANII, PR_SCT_2010_14). Actualmente es cofinanciado por BASF e INIA. Con el fin de apoyar las recomendaciones de uso de la tecnología en evidencia y datos locales, las muestras a analizar deben acompañarse de información sobre la intensidad de uso de $C L$ en la chacra de la que provienen. Para mantener la confidencialidad de los resultados esta información no identifica usuarios, sino que se utiliza únicamente con fines estadísticos.

Este trabajo presenta la información generada durante ocho años de funcionamiento del SDRI, analizándola con tres objetivos: 1) estimar la probabilidad de resistencia por cruzamientos entre AM y cultivares $C L$ en función de los años de uso de CL y su evolución durante el período analizado; 2) estudiar la presencia de plantas de AM resistentes en chacras en las que no hubo oportunidad de cruzamientos entre AM y el cultivo CL y 3) evaluar la dinámica del AM resistente cuando no hay selección por herbicida.

\section{MATERIALES Y MÉTODOS}

\section{Muestras analizadas en el SDRI y conjuntos de datos para análisis estadísticos}

Las 549 plantas de AM analizadas en este trabajo fueron recibidas por el SDRI desde 2011-2012 a 2019-2020. Provienen de 78 chacras, con una media de 7 , mínimo de 1 y un máximo de 66 plantas por chacra. Las chacras tuvieron un rango de entre 0 a 9 años de uso de CL (media 2 años, y se ubicaron en los departamentos de Artigas (30), Salto (5), Tacuarembó (2), Cerro Largo (27), Treinta y Tres (7) y Rocha (7). Las muestras fueron colectadas por los usuarios del servicio a inicio de floración, posteriormente a las aplicaciones de IMI y con identificación fenotípica de la planta como AM, georreferenciándose con GPS el punto de ubicación de las plantas muestreadas. Por cada planta a analizar, un fragmento de hoja nueva de unos $5 \mathrm{~cm}$ de largo se colocó en un tubo Falcon de $50 \mathrm{ml}$ conteniendo $15 \mathrm{ml}$ de sílica gel para conservación del tejido. Las muestras se enviaron al Laboratorio de Biotecnología de INIA Treinta y Tres para su análisis molecular.

\section{Análisis molecular}

Se extrajo el ADN a partir de tejido de cada planta colectada, mediante una modificación del método del CTAB (Dellaporta et al., 1983). Brevemente, en un tubo de $1,2 \mathrm{ml}$ se colocan $0,1 \mathrm{~g}$ de tejido y una bolita de acero de $3,97 \mathrm{~mm}$ de diámetro, agitándose intensamente por 1 minuto. Se agregan $500 \mu \mathrm{l}$ de CTAB al $10 \%$ con $0,2 \%$ de b-mercaptoetanol y se incuba por 20 minutos a $65^{\circ} \mathrm{C}$ agitando cada 5 minutos. Se agregan $500 \mu \mathrm{l}$ de cloroformo:alcohol isoamílico $24: 1 \mathrm{v} / \mathrm{v}$ y se mezcla por inversión. Se centrifugan los tubos por 20 minutos a $2100 \mathrm{~g}$. La fase acuosa se transfiere a un nuevo tubo y se agregan $300 \mu \mathrm{l}$ de isopropanol frío. Se incuba por 30 minutos a $4{ }^{\circ} \mathrm{C}$, centrifugándose 
a $2100 \mathrm{~g}$ por 5 minutos. Se realizan tres lavados con etanol al $70 \%$, tras lo cual el ADN aislado se resuspende en $100 \mu \mathrm{l}$ de agua bidestilada estéril. Se ajusta la concentración de ADN a $100 \mathrm{ng} / \mu \mathrm{l}$.

Las mutaciones Ala $_{122}$ Thr, Ser $_{653}$ Asp y Gly $_{654}$ Glu fueron detectados con el método «Kompetitive Allele-Specific PCR» (KASP, LGC Genomics) con la reacción descripta en Rosas et al. (2014). El genotipado por KASP permite la amplificación y detección en un único paso y en el mismo tubo, mediante la emisión de fluorescencia a una longitud de onda específica para cada uno de los dos alelos posibles en el locus analizado. La amplificación y detección por KASP se realizó en un termociclador PikoReal 96 PCR System (Thermo Scientific).

\section{Análisis estadístico}

\section{Conjuntos de datos}

Para los análisis estadísticos se dividieron los datos totales $(n=549)$ en tres grupos, que se corresponden con los tres objetivos de este trabajo: grupo de datos 1 , únicamente con datos de las plantas provenientes de chacras con cultivo CL en el momento de colecta y descartando las plantas resistentes que no pudieron originarse por cruzamientos ocurridos en la chacra muestreada ( $n=383$ ); grupo de datos 2 , con datos de plantas provenientes de chacras con menos de dos años de uso de CL en el momento de la colecta $(n=116)$ y grupo de datos 3 , con datos de plantas provenientes de chacras en las que no había $C L$ en el momento de la colecta $(n=115)$.

\section{Modelos}

Se ajustaron tres modelos de regresión logística ordinal, todos con el resultado del genotipado por KASP como variable de respuesta, codificado como 0 para homocigota susceptible (ausencia de mutación), 1 para heterocigota (mutación segregante) y 2 para homocigota resistente (mutación fijada). Para el objetivo 1 se estimaron los efectos de la intensidad de uso de CL, codificada como 1 (1 año de uso de CL), 2 (2 años de uso de CL) y 3 (3 o más años de uso de CL), del año en el que se colectaron las muestras como variable cuantitativa con valores de 2012 a 2019, y de la interacción entre ambas, en el grupo de datos 1 .

Para el objetivo 2 se estimaron los efectos del departamento de origen de la muestra (Artigas, Cerro Largo, Rocha, Salto, Tacuarembó, o Treinta y Tres), de la mutación identificada $\left(\mathrm{Ala}_{122} \mathrm{Thr}\right.$, Se$\mathrm{r}_{653}$ Asp, o $\mathrm{Gly}_{654} \mathrm{Glu}$ ), del tipo de cultivar (variedad o híbrido) y el tipo de antecesor más frecuente (arroz convencional, otros cultivos de verano, descanso), utilizando el grupo de datos 2.

Para el objetivo 3 , por un lado y utilizando el grupo de datos 3 , se estimó el efecto de la cantidad de años sin uso de $\mathrm{CL}$ inmediatamente anteriores al muestreo (de 1 a 4). Por otra parte y utilizando el total de los datos, se estimó el efecto de muestrear plantas de AM en chacras en las que en la zafra de colecta no se aplicaron IMI.

Los análisis se implementaron con el software estadístico R usando los paquetes MASS, Ime4, car, y effects.

\section{RESULTADOS}

Se encontraron efectos significativos ( $P$ $<0,05$ ) de la intensidad de uso de CL, de la zafra en la que se realizó la colecta y de la interacción entre ambas, sobre el nivel de resistencia encontrado en las plantas de AM analizadas. La figura 1 muestra las probabilidades de que las plantas muestreadas no tengan mutaciones de resistencia (homocigotas susceptibles), o tengan una copia del gen resistente (resistentes heterocigotas) o ambas copias (resistentes homocigotas). Con una intensidad de uso de CL baja (menos de 2 años), las probabilidades de tener plantas de AM resistentes se mantuvieron entre $23 \%$ y $24 \%$ durante el período analizado de 2012 a 2019. Sin embargo, en ese mismo período estas probabilidades pasaron de $34 \%$ a $54 \%$ en chacras con intensidad de uso de CL intermedia (2 años) y de $48 \%$ a $82 \%$ en chacras con intensidad de uso de CL alta (más de 2 años). 


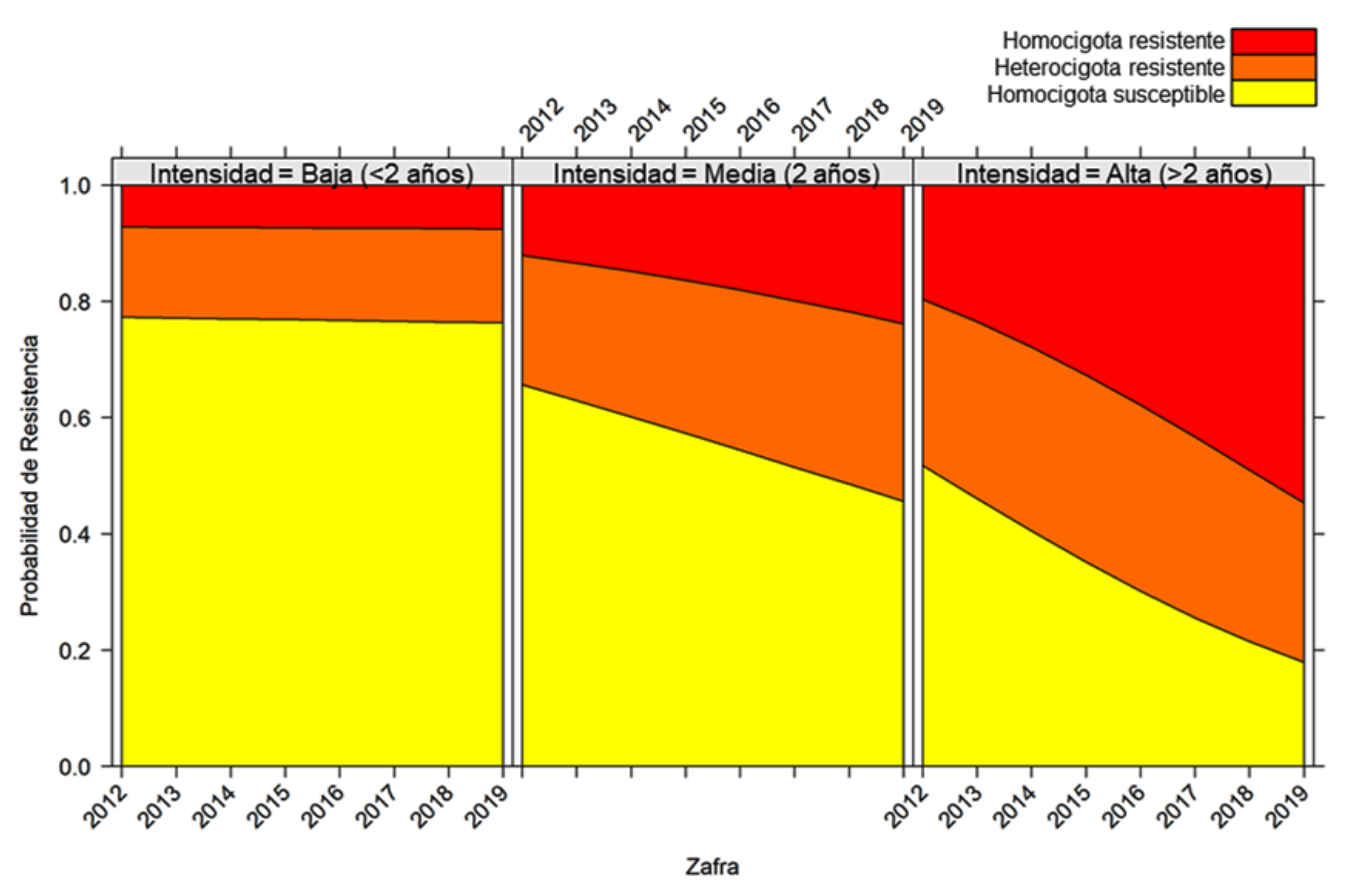

Figura 1. Evolución de la probabilidad de resistencia en plantas de AM a lo largo de las últimas 8 zafras en chacras con intensidad de uso de CL baja (menor a 2 años), media (2 años) y alta (más de 2 años).
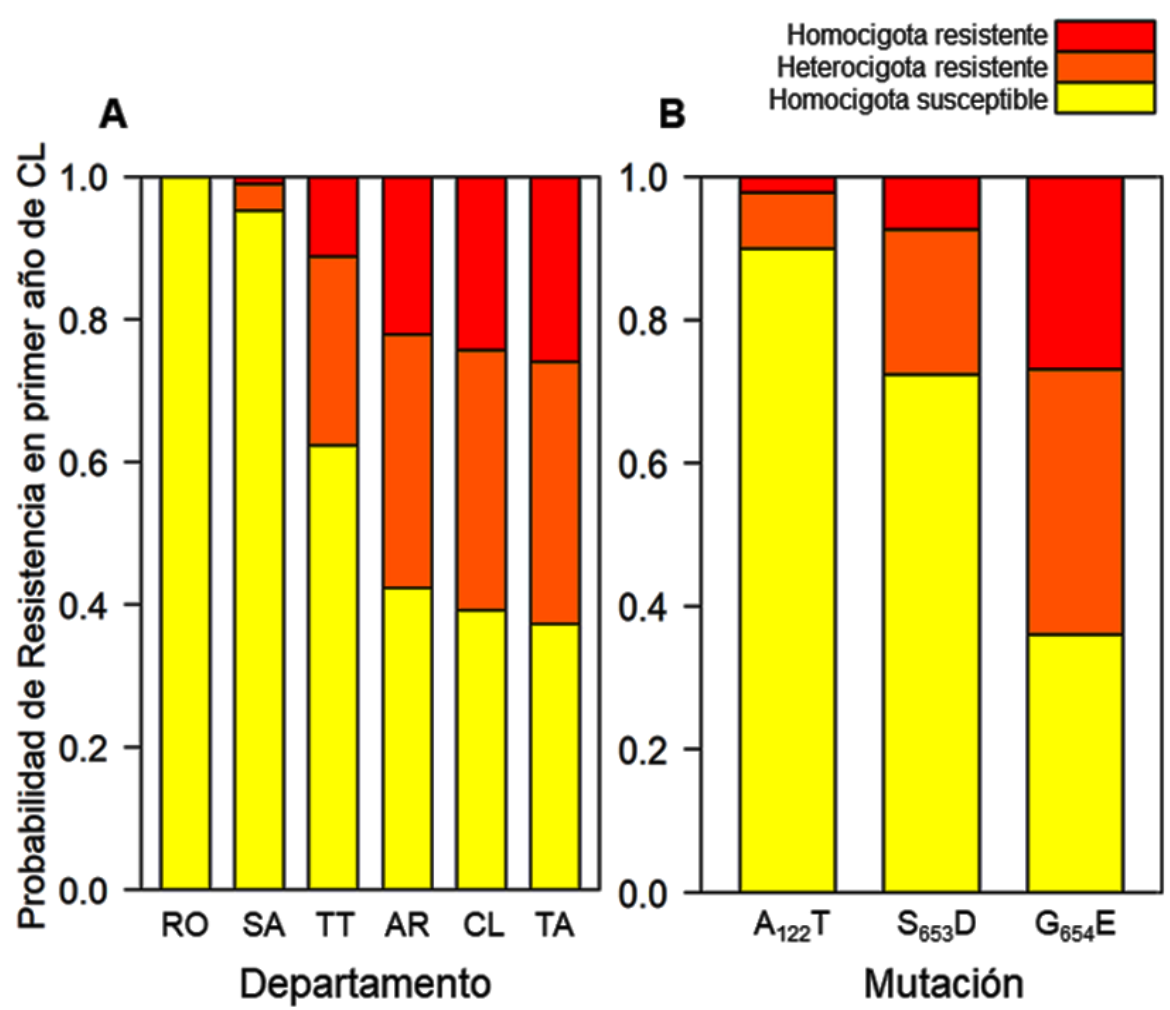

Figura 2. Probabilidades de resistencia en plantas de $A M$ colectadas al primer año de uso de $C L$, A) por Departamento AR: Artigas $(n=51), C L$ : Cerro Largo $(n=28), R O$ : Rocha $(n=7), S A$ : Salto $(n=5)$, TA: Tacuarembó $(n=4)$, TT: Treinta y Tres $(n=21) ; B)$ por mutación identificada $\operatorname{Ala}_{122} \operatorname{Thr}\left(A_{122} T, n=36\right)$, Ser ${ }_{653} \operatorname{Asp}\left(S_{653} D, n=71\right)$, Gly ${ }_{654}$ Glu $\left(G_{654} E, n=9\right)$. 
En cuanto a la presencia de AM resistente colectado de chacras con menos de dos años de uso de CL, es decir, que no pudo haberse originado por cruzamientos ocurridos en la chacra muestreada, se encontró un efecto significativo del departamento donde se obtuvo la muestra y de la mutación identificada. No fueron significativos los efectos de tipo de cultivar (variedad o híbrido) ni de tipo de antecesor más frecuente (arroz convencional, otros cultivos de verano, descanso). La figura 2 muestra las probabilidades de encontrar plantas sin mutaciones de resistencia, o heterocigotas y homocigotas resistentes. Se encontraron probabilidades bajas de este tipo de resistencias en los departamentos de Rocha y Salto, intermedias en Treinta y Tres (40\%) y altas (rondando el $60 \%$ ) en Artigas, Cerro Largo y Tacuarembó (Figura 2 A). Asimismo, la mutación Gly $_{654}$ Glu se encontró con mayor proporción que las demás en chacras con menos de dos años de uso de CL (Figura 2 B).

Finalmente, en lo que respecta a la dinámica de la población de AM resistente cuando no hay presión de selección por aplicación de IMIS no se encontró un efecto significativo de la cantidad de años desde el último uso de $C L$ en la probabilidad de encontrar plantas de AM resistentes. Sin embargo, la probabilidad de encontrar plantas resistentes en chacras donde no se aplicó IMI previamente al muestreo fue significativamente menor ( $24 \%$, con IC al $95 \%$ de 17 a $33 \%$ ) que en aquellas donde sí hubo selección por herbicida $(56 \%$, con IC al $95 \%$ de 51 a $61 \%$ ), independientemente de los demás factores de manejo e historia de la chacra.

\section{DISCUSIÓN Y CONCLUSIONES}

La probabilidad de resistencia por cruzamientos entre AM y cultivares $C L$ aumenta con la intensidad de uso de CL, y lo hace en forma cada vez más rápida. Si bien cuando la intensidad de uso de CL es baja (menos de dos años) la probabilidad de tener plantas de AM resistentes se ha mantenido igual en los últimos ocho años, sí hubo un aumento importante en chacras con dos o más años de uso de CL. La evidencia recogida en estas ocho zafras de monitoreo de poblaciones de AM en chacras con uso de $C L$ permite concluir que durante este período hubo un aumento del riesgo de resistencia en AM después del primer año de uso de $C L$. En otras palabras, el riesgo de tener AM resistente que anteriormente se asociaba a 3 o más años de uso de CL, hoy se tiene ya en el segundo año de CL. Una posible explicación a este fenómeno sería la creciente acumulación de alelos de resistencia en la población de arroz maleza, que haría cada vez más probable que una planta o semilla al azar posea dichos alelos. Serían necesarias más investigaciones para evaluar esta hipótesis, así como para confirmar si esta tendencia ocurre en forma general en todas las chacras con CL del país, o se limita a las de mayor intensidad que hacen uso del servicio.

Se comprobó también la presencia de AM resistente en chacras con menos de dos años de uso de CL. Estos hallazgos pueden explicarse o bien por un subregistro de la verdadera intensidad de uso de CL en la chacra muestreada, o bien por el origen de este AM resistente en forma externa a la chacra muestreada, y que llega a ella mediante el uso de semilla contaminada, o por arrastre o difusión por otros medios (maquinaria, cursos de agua y riego, animales, etc.). Estos hallazgos tienen una distribución geográfica bastante definida, estando asociados a localizaciones donde la ocurrencia de algunos de estos factores puede ser más frecuente. Se destaca también la presencia en proporciones significativas en AM resistentes encontrados en chacras con primer año de uso de $\mathrm{CL}$, de la mutación de primera generación Gly ${ }_{654}$ Glu, ausente en los cultivares $C L$ registrados en nuestro país, pero ampliamente difundida en los AM resistentes a IMI del estado de Río Grande del Sur (Roso et al., 2010).

La resistencia en AM proveniente de chacras que no tenían cultivo CL en el momento del muestreo no estuvo asociada a la cantidad de años transcurridos desde el último cultivo $C L$, lo que sugiere que la 
semilla de AM resistente se mantiene en el banco de semillas del suelo en forma similar a lo que ocurre con el AM susceptible. En otras palabras, la introgresión del gen de resistencia desde el cultivo CL no afecta significativamente la sobrevivencia de la maleza por varios años. En lo que hace a decisiones de manejo, esto puede ser interpretado como que una vez que se genera AM resistente en una chacra y éste logra producir semilla, ésta se mantendrá en la chacra por varios años, aún sin la presión de selección por uso de CL.

Finalmente, la observación de que es menos probable encontrar plantas resistentes en chacras en las que no se aplicó herbicida previo al muestreo, hace recomendable que los muestreos para monitorear la presencia de AM resistente se hagan preferentemente en chacras con uso de CL en el momento del muestreo.

En resumen, este trabajo presenta nueva evidencia que refuerza reportes previos de cruzamientos de AM con cultivo CL y que estos cruzamientos se incrementan con la intensidad de uso de CL. Además, por primera vez se observa que este incremento se está haciendo cada vez mayor con el paso de los años. La multiplicación y dispersión de AM resistente tiene un rol muy importante en las resistencias observadas en el primer año de uso de $C L$, debiendo reforzarse el apego a las recomendaciones de uso de semilla certificada, limpieza de maquinaria y demás buenas prácticas de uso de la tecnología que eviten que el AM resistente llegue o se genere en la chacra, ya que una vez que lo haga, podrá comprometer el control de malezas en los años subsiguientes.

\section{BIBLIOGRAFÍA}

BASF. 2016. "CLEARFIELD ${ }^{\circledR}$ En Arroz.» Revista Arroz 87:36-37.

Croughan, T.P. 1998. Herbicide resistance rice. (Patente de US No US5773704A) Louisiana State University and Agricultural and Mechanical College. p.1-10. https://patents.google.com/ patent/US5773704A/en
Dauer, J.; Hulting, A.; Carlson, D.; Mankin, L-: Harden, J.; Mallory-smith, C. 2018. Gene flow from single and stacked herbicide-resistant rice. Pest Management Science 74(2):348-55. https://doi.org/10.1002/ps.4711

Dellaporta, S.L.; Wood, J.; Hicks, J.B. 1983. A plant DNA minipreparation: Version II.» Plant Molecular Biology Reporter 1(4):19-21. https://doi.org/10.1007/ BF02712670

Delouche, J.C.;Burgos, N.R.; Gealy, D.R.; Zorrilla De San Martin, G.; Labrada. 2007. Weedy rices. Origin, biology, ecology and control. Roma (IT): FAO, 131 p. (FAO Plant Production and Protection Paper; 188)

Gealy, D.R.; Mitten, D.H.; Rutger, J.N. 2003. Gene flow between red rice (Oryza sativa) and herbicide-resistant rice (O. sativa): Implications for Weed Management. "Commentary." Weed Technology 17(3):627-45.

Livore, A.B.; Prina, A.R.; Birk, I.; Singh, B. 2007. Rice plant having increased torerance to midazolinone herbicides. (Patente de AR No.US 2007/0028318 A1) Instituto Nacional de Tecnología Agropecuaria, Argentina, p. 1-55 https://patentscope.wipo.int/search/en/ detail.jsf?docld=WO2005020673

Merotto, A.; Goulart, I.C.G.R.; Nunes, A.L.; Kalsing,A.; Markus, C.;Menezes, V.G.; Wander, A.E. 2016. Evolutionary and social consequences of introgression of nontransgenic herbicide resistance from rice to weedy rice in Brazil. Evolutionary Applications 9(7):837-46. https://doi. org/10.1111/eva.12387

Rosas, J. E.; Gómez, A.; Lago, F.; Macedo, I. 2013. Monitoreo de arroz rojo resistente a imidazolinonas en chacras con uso intensivo del sistema Clearfield ${ }^{\circledR}$.» In: Programa Nacional de Producción de Arroz; Jornada Anual Arroz-Soja, 2013, INIA Treinta y Tres. Arroz-soja: resultados experimentales 2012-2013. Treinta y Tres: INIA, 2013. cap. 5, p. 3-5 (INIA Serie Actividades de Difusión; 713)

Rosas, J.E.; Bonnecarrère, V.; Pérez de Vida, F. 2014. One-step, codominant detection of imidazolinone resistance mutations in weedy rice (Oryza sativa L.). Electronic Journal of Biotechnology, 17(2):95-101. https://doi.org/10.1016/j.ejbt.2014.02.003 
Roso, A.C.; Merotto Jr, A.; Delatorre, C.A.; Menezes, V.G. 2010. Regional scale distribution of imidazolinone herbicide-resistant alleles in red rice (Oryza sativa L.) determined through SNP markers. Field Crops Research 119(1):175-82. https://doi. org/10.1016/j.fcr.2010.07.006

Scarabel, L.; Cenghialta, C.; Manuello, D.; Sattin, M. 2012. Monitoring and management of imidazolinoneresistant red rice (Oryza sativa L., var. Sylvatica) in Clearfield ${ }^{\circledR}$ italian paddy rice. Agronomy 2(4):371-83. https://doi. org/10.3390/agronomy2040371
Shivrain, V.K.; Burgos, N.R.; Gealy, D.R.; Sales, M.A.; Smith; K.L. 2009. Gene flow from weedy red rice (Oryza sativa L.) to cultivated rice and fitness of hybrids. Pest Management Science 65(10):1124-29. https://doi. org/10.1002/ps.1802 


\section{6 - RESISTENCIA DE CAPINES A HERBICIDAS EN SISTEMAS DE PRODUCCIÓN DE ARROZ}

C. Marchesi ${ }^{1}$

PALABRAS CLAVE: Echinochloa sp., imidazolinonas, inhibidores de la ALS

\section{INTRODUCCIÓN}

Entre las diferentes formas de controlar malezas en un sistema de producción, el que más ha prevalecido en las últimas décadas es el control químico. No quedan dudas que dicho control presenta ventajas desde el punto de vista práctico y en muchos casos, económico. Otras opciones como el control mecánico, presenta costos elevados de energía y problemas ambientales como la erosión de suelos; el control cultural, requiere de mayor planificación y su eficiencia no siempre es elevada; el control biológico, también requiere de mayor planificación y tiempo de ejecución, además de que no es aplicable en todos los casos. La alta dependencia para con el control químico ha aparejado grandes problemas, como la aparición de malezas resistentes a los herbicidas.

La resistencia es la habilidad heredable de una planta de sobrevivir y reproducirse luego de haber sido expuesta a una dosis de herbicida que, en condiciones normales, hubiera sido letal para la especie (WSSA, 1998). Dentro de una población existen individuos con diferencias genéticas en distintas características,

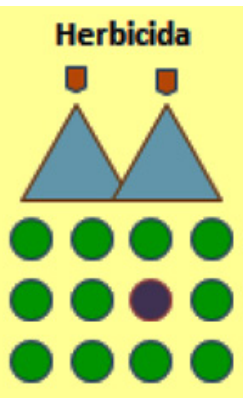

Cada vez más prevalecen los tipos resistentes en la población...

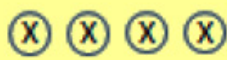

$\otimes \otimes$

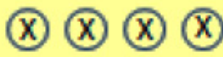

Resistente sobrevive y semilla...

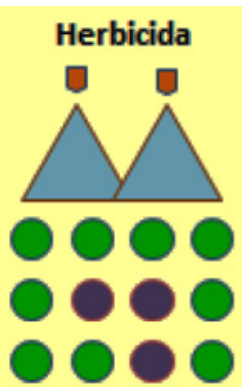

(1)

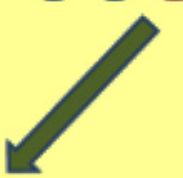

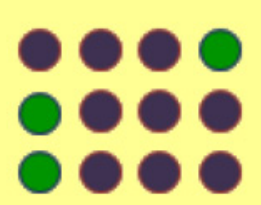

(X) Susceptiblecontrolado

Figura 1. Evolución de resistencia a herbicidas en una población de malezas, bajo presión de selección impartida por el uso de herbicidas.

\footnotetext{
${ }^{1}$ Claudia Marchesi. Ing. Agr. M.Sc. Ph.D. INIA. Programa Nacional de Investigación en Producción de Arroz. cmarchesi@inia.org.uy
} 
entre las cuales puede estar la habilidad de sobrevivir a un herbicida. Bajo presión de selección impartida por nuestras prácticas agronómicas, esos individuos -que conforman un biotipo- van prevaleciendo en la población, hasta hacerse mayoritarios, evolucionando de una población susceptible a una resistente a dicho herbicida (Figura 1) (Cousens y Mortimer, 1995; Gressel, 2002). Cuanto mayor sea la presión de selección ejercida, más rápidamente se dará esta evolución, ya que los sobrevivientes se corresponderán con el biotipo resistente en mayor proporción. La visualización de un problema de malezas resistentes generalmente se hace evidente cuando la proporción de plantas no controladas supera un $30 \%$ (Kogan y Perez, 2003).

La evolución de resistencia está asociada a muchos factores, unos dependientes de la especie de maleza en cuestión, otros del herbicida, así como del manejo agronómico que se realiza (o sea la presión de selección), e incluso del ambiente.

En cuanto a las características asociadas a la especie maleza, se destacan su biología, ecología, y genética. Por ejemplo, el ciclo de vida, la forma de reproducción, la capacidad de producción y longevidad de las semillas, el tamaño de la población, su capacidad colonizadora, la dormancia y germinación, la adaptabilidad ecológica, la genética de la resistencia, la frecuencia original de mutaciones resistentes y el modo de herencia. La probabilidad de ocurrencia de mutaciones resistentes y la chance de ser seleccionadas está muy asociada al tamaño de la población susceptible; cuanto mayor la población, mayor será la oportunidad de seleccionar un tipo resistente (Jasieniuk et al., 1996; Preston y Powles, 2002). Las especies que tienen mayor habilidad colonizadora son más proclives a responder ante presión de selección (Gressel, 2002). La dormancia prolongada y germinación no uniforme enlentece la evolución de resistencia cuando se usan herbicidas no residuales, ya que los nuevos mutantes se diluyen en la población al haber continuas emergencias de tipos susceptibles desde el banco de semillas del suelo. Por el contrario, la evolución de tipos resistentes se ve favorecida en esta misma especie si se utilizan herbicidas residuales, ya que más individuos se ven expuestos a dosis letales y subletales por un período mayor (Gressel y Segel, 1982). Existen diferencias importantes en el modo de herencia; los genes nucleares se diseminan vía polen, mientras que los citoplasmáticos solo vía semilla. Muchos genes con efecto aditivo pequeño, o un gen único, y diferencias en la dominancia de alelos (recesivos, parcialmente o completamente dominantes), va a modelar en forma diferente la evolución de la resistencia (Jasieniuk et al., 1996).

Respecto a las características del herbicida, la presión de selección ejercida por los herbicidas es la más importante en determinar la evolución de resistencia (Gressel y Segel, 1982; Jasieniuk et al., 1996). La misma dependerá de su toxicidad, de las dosis usadas y del modo de acción, su efecto residual y la frecuencia de uso. Las imidazolinonas (IMIs) -inhibidores de la acetolactato-sintasa (ALS)- se absorben vía radical y foliar y se mueven por apoplasto y simplasto. Son herbicidas de amplio espectro, de una alta eficiencia con muy bajas dosis, escaso riesgo de daño, y menor carga ambiental que muchos otros herbicidas; se degradan en el suelo, y no se acumulan en organismos no objetivo. Estas características los hacen muy atractivos para su uso, que generalmente se torna excesivo (Tranel y Wright, 2002).

Respecto al manejo agronómico que también determina la presión de selección, se destacan el uso de rotaciones de cultivos, de modo que éstas desfavorezcan el establecimiento de las mismas especies de malezas una y otra vez, y permitan una mayor diversidad de opciones de herbicidas a utilizar, a la vez que puedan reducir el uso de herbicidas (Beckie y Gill, 2006; Blackshaw et al., 2008; Powles et al., 1997). También se sugiere el uso de cultivos competitivos, así como estrategias de fertilización y manejo del riego tendientes a lograr 
mejores cultivos que compitan y reduzcan la presencia de malezas (Beckie y Gill, 2006; Blackshaw et al., 2008). Además, el control mecánico puede utilizarse para la promoción de germinaciones tempranas y posterior eliminación de plántulas en el barbecho antes de la siembra del cultivo, reduciendo así el banco de semillas presente (Gill y Holmes, 1997), o también el enterrar semillas para reducir su posterior germinación (Moss, 1997). También se han probado los cambios en los sistemas de cultivo para arroz, rotando la siembra en agua con siembras en seco (Fischer y Valverde, 2005; Linquist et al., 2008; Brim-DeForest et al., 2017), la rotación y mezcla de productos de diferente modo de acción y la limpieza de maquinaria para evitar la dispersión de semilla resistente (Beckie, 2007; Diggle y Neve, 2001; Legere et al., 2000).

En cuanto al ambiente, las diferencias pueden estar dadas por la región misma, ya que la presencia de biotipos resistentes puede facilitar su dispersión por viento, aves o el movimiento del agua de riego (Tsuji et al., 2003; Kogan y Perez, 2003)

La predicción de la aparición y diseminación de la resistencia es posible a través de modelos matemáticos de creciente complejidad (Gressel y Segel, 1982; Maxwell et al., 1990; Gardner et al., 1998; Diggle y Neve, 2001). Los modelos permiten establecer la importancia relativa de los diversos factores que determinan la evolución hacia la resistencia. Ayudan al entendimiento y predicción de dicha evolución, y pueden auxiliar en el diseño y evaluación de la eficacia de diferentes estrategias para enlentecer la aparición de biotipos resistentes y que no solo se reaccione luego de la aparición del problema en la realidad. Son una herramienta útil, pero de difícil aplicación. Su principal utilidad es la de ayudar a orientar la investigación y explorar opciones de manejo. Para que los modelos sean ajustados a la realidad, se necesita información de parámetros biológicos y ecológicos de la población, tales como el porcentaje inicial de individuos resistentes, los años de uso de herbicidas, la adaptabilidad ecológica de los biotipos resistentes y susceptibles, la vida media del banco de semillas, el coeficiente de selección del herbicida, la dinámica de poblaciones, el tipo de herencia, la dinámica espacial de plantas afectando el flujo de genes y la dispersión de la resistencia. En general, concluyen en tres acciones: reducir la presión de selección, rotar herbicidas e integrar medidas de control diferente (Fischer y Valverde, 2005). Desarrollos más recientes demuestran que se pueden aplicar modelos aún sin tener toda la información requerida inicialmente y que los resultados se adecúan a lo observado en el campo (Neve et al., 2010). Los factores más relevantes para cambiar el resultado de la modelación implicaron a la presión de selección, que se interrumpe al utilizar modos de acción diferentes, y el tamaño de la población de malezas, muy relevante para casos como el de Amaranthus spp. Otros autores reportan una mayor eficacia en la mezcla de herbicidas de diferente modo de acción, pero con similar espectro de control de malezas, que la rotación de modos de acción dentro del ciclo del cultivo (Norsworthy et al., 2012). Otro factor relevante a tener en cuenta en la evolución de resistencia es la dosis utilizada. Los modelos han predicho que altas presiones de selección dadas por dosis altas de herbicidas, resultan en un rápido aumento de la frecuencia de alelos $\mathrm{R}$ en la población, cuando la misma está dada por un solo gen dominante (monogénica). Sin embargo, también se sugiere que dosis bajas resultan rápidamente en problemas de resistencia cuando la misma está determinada por varios genes de efecto menor (poligénica). Se sugiere entonces encarar un manejo alternado en cuanto a las dosis a utilizar, si se sabe que la resistencia está causada por ambos tipos de genes (Renton et al., 2014). Una aproximación diferente es la que han planteado recientemente Moss et al., 2019, en la que se confecciona una "matriz de riesgo de resistencia», basado en toda la información ya relevada a nivel global (Figura 2). Se tiene en cuenta el riesgo inherente de cada herbicida, 


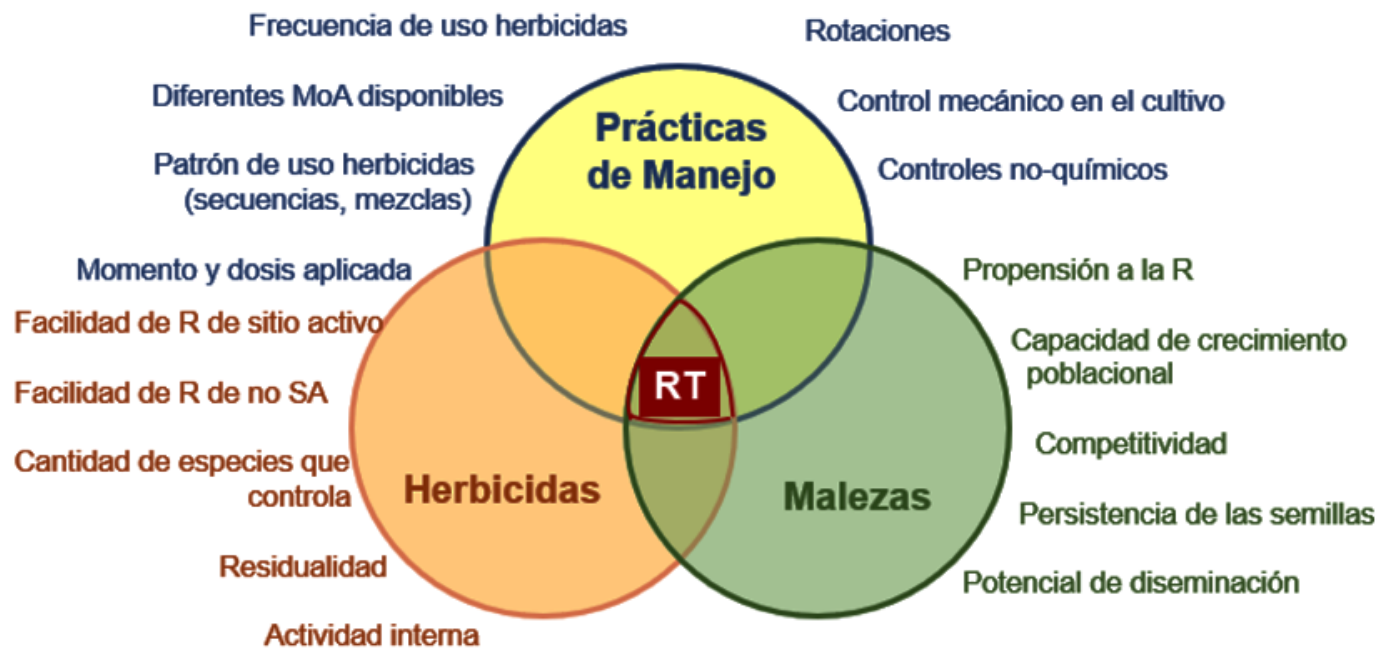

Figura 2. Principales factores de riesgo para la evolución de resistencia, y sus componentes.

de cada maleza y la agronomía que se aplica en el sistema de producción, y se construye como un semáforo, indicando dicho riesgo. Esta aproximación cuantitativa es más robusta y realista y de más fácil aplicación.

Existen diferentes mecanismos de resistencia, relacionados al sitio de acción ( (no de sitio activo) (Gressel, 2002; Powles y $\mathrm{Yu}, 2010)$. El sitio de acción de los herbicidas es, en general, una proteína específica -enzima-, con un rol determinado en el funcionamiento de la planta. Este mecanismo por el cual el herbicida no puede actuar en el sitio de acción generalmente se da porque ha habido una mutación en dicha proteína y la molécula herbicida no encaja (Pang et al., 2002; Tranel y Wright, 2002). Este tipo de resistencia es común en algunos modos de acción ya que existen varias mutaciones que le pueden conferir resistencia, haciendo relativamente fácil la selección de resistencia en estos biotipos. Por ejemplo, los inhibidores de la ALS y los de la acetil- Coenzima A- carboxilasa (ACCasa), con al menos 6 sitios de la enzima que pueden mutar y conferir resistencia (Délye, 2005; Tranel y Wright, 2002). La existencia de tantas posibles mutaciones hace que la resistencia a estos herbicidas sea abundante y rápida de seleccionar. Este mecanismo de resistencia también puede estar dado por una sobreexpresión de la enzima o de su actividad, dada por efectos postranscripcionales, reguladores de expresión, o por herencia poligénica (por ejemplo, en algunos casos de Lolium, Conyza o Amaranthus resistente a glifosato) (Powles y Yu, 2010). Dentro de los mecanismos que no involucran al sitio activo, el más conocido es la resistencia metabólica, donde el herbicida es desactivado dentro de la planta y no ejerce su acción. Los mecanismos enzimáticos involucrados en este proceso de degradación son variados, incluyendo las isoenzimas citocromo P450 monooxigenasas, y las glutatión-S-transferasas (Yuan et al., 2007). Normalmente están involucradas en la defensa de las plantas ante estreses bióticos y abióticos. Dentro de los mecanismos que no involucran los sitios de acción, también se encuentra impedimentos en la absorción o translocación de la molécula (Powles y Preston, 2006; Powles y Yu, 2010) y compartimentación en la célula (secuestro), en que el herbicida es aislado en una vacuola (Jori et al., 2007; Yasuor et al., 2008).

Se pueden clasificar tipos de resistencia, como la resistencia cruzada y la 
múltiple (Kogan y Perez, 2003). Resistencia cruzada es cuando un mecanismo fisiológico de resistencia le confiere la misma a varias moléculas, dentro o no de un mismo modo de acción. Puede ser de sitio activo, y en ese caso es dentro de un mismo modo de acción (por ejemplo, un cambio en la configuración de la enzima ALS, hace que tanto las sulfonilureas como las triazolpirimidinas -penoxsulam- hayan perdido eficacia). También puede ser de no-sitio activo, cuando el mecanismo trasciende modos de acción, como en el caso de un metabolismo acrecentado (por ejemplo, Lolium sp. degrada herbicidas inhibidores de la ALS y ACCasa por un incremento de metabolismo relacionado con las $\mathrm{P} 450$ ) (Beckie y Tardif, 2012). Resistencia múltiple, cuando varios eventos diferentes y secuenciales se dan en la misma población, haciendo a los individuos resistentes a diferentes modos de acción. Se asocia al uso frecuente de varios modos de acción, durante mucho tiempo, como en Lolium rigidum en Australia, resistente a glifosato, paraquat y ACCasa (Yu et al., 2007), o de Echinochloa crus-galli y E. colona a propanil, quinclorac, y cyhalofop en USA (Rouse et al., 2017)

\section{HERBICIDAS INHIBIDORES DE LA ALS}

Los inhibidores de la enzima ALS impiden la síntesis de algunos aminoácidos esenciales para la planta (valina, leucina e isoleucina), por lo que su mortalidad es muy elevada (alta eficiencia). Si bien las plantas sensibles demoran unas 2 semanas en morir, la detención del crecimiento se da en unas pocas horas luego de la absorción del herbicida. Los síntomas incluyen crecimiento atrofiado, clorosis intervenal, a veces venas rojizas, necrosis de hojas y puntos de crecimiento. La enzima ALS se codifica en el núcleo y se localiza en el cloroplasto (Kogan y Perez, 2003). Tiene al menos 8 sitios donde puede ocurrir una mutación que resulte en resistencia (Tranel y Wright, 2002; Beckie y Tardif, 2012), lo que hace que esta familia de herbicidas esté catalogada como de «alto riesgo de evolución de tipos resistentes». Hay reportadas 165 especies de malezas resistentes a estos herbicidas a nivel mundial, con varios casos de cada una (Heap, 2020). Hay reportes de que simplemente tres aplicaciones de inhibidores de ALS pueden inducir la evolución de tipos resistentes (Powles et al., 1997). A su vez, como fue mencionado anteriormente, su inocuidad para los organismos no objetivo y su alta efectividad con muy bajas dosis facilitan su manejo y rápida adopción, siendo en general herbicidas «económicos». Dentro de la familia hay cinco grupos (Tabla 1) y cada mutación descubierta a la fecha le confiere resistencia a uno o varios de los grupos, siendo en muchos casos, cruzadas. Los patrones más conocidos de resistencia cruzada se dan entre los grupos de sulfonilureas y triazolpirimidinas $\left({ }^{*} 1\right)$, y entre las IMIs y los piridinilbenzoatos $\left({ }^{*} 2\right)$. La mayoría de las mutaciones conocidas

Tabla 1. Moléculas de inhibidores de la ALS clasificadas según su química (grupo) y patrones de resistencia cruzada más comunes.

\begin{tabular}{|lcc|}
\hline Grupos & Moléculas & Resistencia cruzada \\
\hline Sulfonilureas & Pyrazosulfurón, metsulfurón, & ${ }^{*} 1$ \\
Imidazolinonas & Imazapir, imazapic & ${ }^{*}$ \\
Triazolpirimidinas & Penoxsulam & ${ }^{*} 2$ \\
Piridinilbenzoatos & Bispiribac & \\
Sulfonilamino- & Flucarbazone (no se usa en arroz) & \\
carboniltriazolinonas & & \\
\hline
\end{tabular}


pueden conferirle resistencia de las malezas a las IMIs (Beckie y Tardif, 2012).

\section{MALEZAS PROBLEMA EN SISTEMAS ARROCEROS}

Se han reportado más de 160 casos de malezas resistentes a herbicidas en arroz en el mundo incluyendo gramíneas, hojas anchas y ciperáceas, y considerando varios modos de acción. Dentro de las principales malezas en sistemas arroceros de Uruguay, los capines (Echinochloa spp.) y el arroz maleza -AM- (Oryza sativa) son los más relevantes. Este capítulo se centra en el tema del capín.

El complejo de las Echinochloa spp. es de los más importantes en haber generado resistencia a herbicidas. Pertenecen a la familia de las Poaceae; son gramíneas que se encuentran en todo el mundo, tanto en zonas templadas como tropicales. Son malezas de tipo C4 que generan una alta competencia y de alta prolificidad. Varias especies están citadas como las malezas más importantes del arroz y otros cultivos en diferentes sistemas de producción, lo que demuestra su gran plasticidad (Barrett y Wilson, 1981a, 1981b; Holm et al., 1977; Vidotto et al., 2007; Yabuno, 1966). Además, son altamente polimórficas (Michael, 1983) y algunas de sus especies se cruzan, lo que hace más difícil su reconocimiento correcto (Norris, 1996; Pratley et al., 2008; Vidotto et al., 2007; Yabuno, 1966). Echinochloa crus-galli es la maleza más común y abundante de este grupo, tiene morfología variable y se adapta muy bien a condiciones húmedas. Se encuentra tanto en taipas como en partes bajas de los campos, pero no germina bajo el agua (Barrett y Seaman, 1980).

Existen reportes de Echinochloa spp. resistentes a inhibidores de la ALS en 18 países, en muchos casos asociados al uso inadecuado de la tecnología Clearfield $^{\circledR}$. Para E. crus-galli hay reportados en el mundo 34 casos de resistencia relacionados al cultivo de arroz, resistentes a 7 modos de acción (a auxinas sintéticas, ej. quinclorac; a cloroacetamidas, ej. butaclor; a tiocarbamatos ej. molinate; a amidas, ej. propanil; a ACCasas, ej. cyhalofop; a inhibidores de ALS, ej. imazapir + imazapic, nicosulfurón, penoxsulam, y a inhibidores de DOXP, ej. clomazone). Existen además reportes de Echinochloa spp. resistentes presentes en otros cultivos y otras malezas resistentes presentes en arroz (Heap, 2020).

Echinochloa crus-galli presenta problemas en sistemas de producción similares al de Uruguay, como Brasil, Argentina y EE.UU. En Arkansas, hay biotipos resistentes ampliamente distribuidos, y en expansión, a herbicidas como IMIs, propanil, quinclorac, cyhalofop y algunos casos de resistencia múltiple (Rouse et al., 2017). En Brasil, biotipos resistentes a IMIs, quinclorac, y múltiple (Andres et al., 2013), así como a quinclorac, penoxsulam y cyhalofop (Eberhardt et al., 2016). En Argentina también están muy extendidos los biotipos resistentes a inhibidores de la ALS (Metzler et al., 2018). En todos estos casos, se los asocia a sistemas sin rotaciones o con rotación con otros cultivos, pero no con fase de pasturas. En algunos casos hay rotación de arroz con soja, lo que es beneficioso desde muchos puntos de vista (facilidad de rastrojo, uso de otros herbicidas), pero por otro lado aumenta la problemática de exposición a glifosato, siendo que ya hay referencias de Echinochloa spp. resistentes a glifosato en situaciones muy próximas al arroz (García y Marques, com. pers.). Además, en dicha rotación se producen cambios en las malezas predominantes, que pueden ser beneficiosos o muy problemáticos, según se están observando mayores presencias de Amaranthus spp. (yuyos colorados) en las taipas o Conyza spp. (yerba carnicera) que requieren de una atención especial. Ambas malezas han generado problemas de resistencia en gran cantidad de ocasiones, complejizando mucho el control. 


\section{MALEZAS RESISTENTES EN SISTEMAS ARROCEROS DE URUGUAY}

Parte de la producción de arroz en Uruguay se realiza bajo un sistema de rotaciones con pasturas, lo que le imprime un bajo impacto ambiental, entre otros beneficios. Específicamente esto se refiere al mayor cuidado del recurso suelo y su fertilidad, al menor uso de agroquímicos en el tiempo, a la menor presión que se ejerce sobre el ambiente y un menor consumo de energía (Macedo et al., 2020; Pittelkow et al., 2016).

Sistemas más intensivos (sin rotación arroz-pasturas o en rotaciones cortas con retornos de corto plazo) conducirían a un mayor uso de agroquímicos en el tiempo (en este caso, de herbicidas). Esta tendencia al monocultivo estaría continuamente propiciando el establecimiento del mismo tipo de malezas adaptadas al sistema, lo cual resultaría en un aumento de sus poblaciones. Es sabido que el contar con una mayor población de malezas aumenta la probabilidad de encontrar mutantes que puedan ser resistentes a diversos químicos. Estos sistemas más intensivos, tanto por inducir una mayor presencia de cierto tipo de malezas, así como por utilizar más herbicidas, implicarían una mayor presión de selección sobre las poblaciones de malezas existentes, lo cual está asociado a un incremento en la probabilidad de seleccionar biotipos con niveles de resistencia (sistemas más riesgosos) (Fischer y Valverde, 2005). Un acortamiento del periodo de pasturas en la rotación llevaría a un aumento del período de cultivo y por consiguiente mayor uso de herbicidas, entre otros cambios. Por otro lado, el uso del herbicida total glifosato ha aumentado significativamente, así como también las dosis utilizadas para controlar varias malezas durante los barbechos. El uso intensivo de solo glifosato también ha generado resistencia de malezas, destacándose algunas situaciones muy cercanas (Lolium multiflorum, Conyza spp., Digitaria insularis, Chloris spp, Eleusine indica y Amaranthus spp. en Brasil, Sorghum halepense, L. multiflorum, Conyza spp., E. colona, Brassica spp., Amaranthus spp., D. insularis, E. indica y otras en Argentina (AAPRESIDREM). En Uruguay, relevamientos recientes están constatando la presencia de $L$. multiflorum, Amaranthus spp., Conyza spp. y E. colona resistente a glifosato en el litoral del país y L. multiflorum también en la zona Este (Felix y Urioste, 2016; García y Marques com.pers.)

Además de la situación de intensificación en general, la inclusión de tecnología de arroz resistente a IMIs (no transgénico) ha propiciado un incremento del uso de inhibidores de la ALS, herbicidas calificados como de alto riesgo, la cual actualmente es la mayor responsable de casos de resistencia de malezas en varios cultivos en todo el mundo. La tecnología de arroz resistente a IMIs, como el sistema Clearfield ${ }^{\circledR}$ (BASF) y hoy en día, también Full Page (RiceTec), se creó para el control de AM, pero además es muy buena controlando otras malezas como las Echinochloa spp. La preocupación se da ya que, como se menciona más arriba, las mutaciones en la enzima ALS son "comunes» encontrarlas en la naturaleza, por lo que es probable que el AM u otras malezas la consigan con relativamente poca exposición a los herbicidas en cuestión (además de por flujo de genes RR de las mismas variedades $C L$ al $A M$ ). Si se excede en el uso de dichas tecnologías, o sea, uso reiterado del mismo principio activo sin otras medidas de manejo complementarias, se estaría seleccionando a favor de tipos con resistencia a esos herbicidas y las mismas se perderían, quedando obsoleta la herramienta más efectiva para control de AM.

A partir del año 2000, aproximadamente, se comenzaron a recibir consultas y apreciaciones de técnicos del sector arrocero, acerca de la falta de control del herbicida quinclorac sobre Echinochloa crusgalli, lo que ameritó las colectas y pruebas de confirmación de resistencia. Además, la aparición y el aumento de uso de tecnologías Clearfield ${ }^{\circledR}$, hizo que se incremente el uso de inhibidores de la ALS, familia 


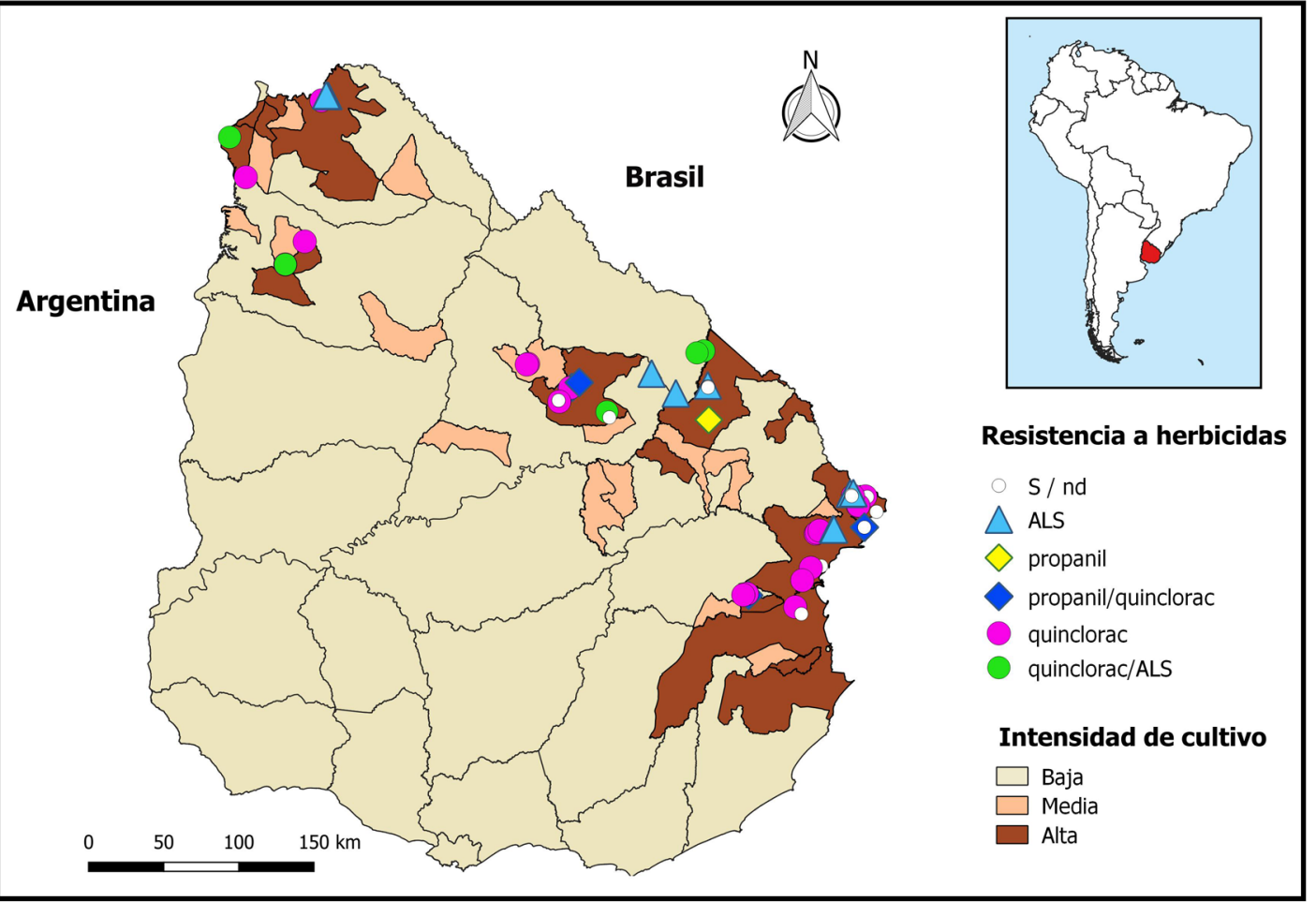

Figura 3. Distribución de los biotipos de Echinochloa crus-galli con resistencia a los diferentes herbicidas en uso en arroz. Se incluye la información de la intensidad de uso arrocero del área en cuestión (color más oscuro, mayor intensidad).

que ya estaba siendo utilizada en gran proporción del área arrocera. Se realizó un estudio a nivel nacional para evaluar la presencia de biotipos de Echinochloa crus-galli resistentes a herbicidas. Más de 40 muestras, la mayoría colectadas entre 2006 y 2018, y provenientes de las regiones Este y Centro Norte fueron evaluadas siguiendo el protocolo de confirmación definido por la HRAC ((Herbicide Resistance Action Committee). Los herbicidas utilizados incluyeron propanil, quinclorac, clomazone, bispyribac-sodium, penoxsulam, imazapyr + imazapic, profoxidim y cyhalofop. La mayoría de los biotipos evaluados (35) resultaron resistentes a quinclorac. También se confirmó resistencia a propanil en al menos 7 biotipos, 12 a imazapyr + imazapic, y 3 a penoxsulam. Cinco biotipos mostraron resistencia múltiple a propanil y quinclorac y 1 resistencia a quinclorac, penoxsulam e imazapyr + imazapic (Figura 3). No hubo confirmación de resistencia a clomazone, bispyribacsodium, cyhalofop o profoxidim (Marchesi y Saldain, 2019).

Dentro de ese trabajo, interesa resaltar un caso en donde se evaluaron biotipos de capín colectados en la situación descripta por Rosas et al (Cuadro 1, Cap.4). En la misma conviven varias chacras contiguas con distinta historia de aplicaciones del herbicida asociado a la tecnología CL. En esta situación, se detectó un biotipo $\mathrm{E} 3 \mathrm{CL}$, colectado en escapes de un área que había sido tratada con IMIs cuatro veces en tres años continuos de arroz CL, cuyo $\mathrm{GR}_{50}$ fue 1,8 la dosis de etiqueta (98 g i.a./ha). Por otro lado, los biotipos EOCL (sin historia de arroz CL), y E1CL y E2CL (con una y dos aplicaciones del herbicida, respectivamente) murieron con la mínima dosis usada en la evaluación. Además, se estudió la resistencia cruzada a otros inhibidores de la ALS como penoxsulam y bispiribac, no detectándose problemas 
de control para estos herbicidas (Saldain y Sosa, 2012, 2016).

La evaluación de mecanismos de resistencia en los casos confirmados no se ha culminado, habiendo casos más característicos de lo que sería resistencia por metabolismo (caso de $E$. crus-galli resistente a los 3 herbicidas IMIs, quinclorac y penoxsulam) y otros de sitio activo ( $E$. crus-galli resistente a quinclorac, Saldain y Sosa, 2016; Diez et al., 2020). Otros estudios locales indican también la ausencia de mutaciones en la enzima ALS reportadas a nivel mundial en capines provenientes de sistemas con uso intensivo de CL (Bonecarrere et al., 2016). Por otro lado, el uso de inhibidores de las monooxigenasa $\mathrm{P} 450$ revierten la resistencia en algunos biotipos como el E3CL, denotando resistencia de tipo metabólica (Saldain y Sosa, 2016), pero no ocurre lo mismo en otros biotipos. Queda pendiente establecer qué otro mecanismo de tipo metabólico se encuentra presente en estos biotipos locales.

\section{ESTRATEGIAS PARA REDUCIR EL RIESGO DE EVOLUCIÓN A BIOTIPOS RESISTENTES}

Además del esfuerzo que se realiza para encontrar soluciones a la problemática de resistencia en malezas ya instalada, es de vital importancia considerar estrategias para reducir el riesgo de evolución de más biotipos resistentes. Dichas estrategias se basan fundamentalmente en dos principios: 1. reducir la presión de selección y 2 . evitar la dispersión de individuos resistentes.

Las prácticas que se pueden recomendar en este sentido incluyen la rotación de cultivos o sistemas de producción (Beckie y Gill, 2006; Blackshaw et al., 2008; Bourgeois et al., 1997; Gill y Holmes, 1997; Powles et al., 1997; Opena et al., 2019), la rotación y uso de mezclas de herbicidas (Beckie, 2007; Bourgeois et al., 1997; Fischer y Valverde, 2005; Legere et al., 2000) y técnicas de control cultural -no químicode las malezas (Beckie, 2006; Blackshaw et al. 2008; Bourgeois y Morrison, 1997; Fischer y Valverde, 2005; Gill y Holmes, 1997). Por otro lado, también se enfatiza en reducir los individuos sobrevivientes, para disminuir la producción de semillas de los mismos (Diggle y Neve, 2001; Legere et al., 2000), y destruir las semillas remanentes de malezas mediante dispositivos que se anexan a equipos de cosecha (seed harvester or destructor) (Somerville et al., 2018; Walsh et al., 2012).

\section{BIBLIOGRAFÍA}

Andres, A.; Theisen, G.; Concenco, G.; Galon, L. 2013. Weed resistance to herbicides in rice fields in Southern Brazil. In: Price, A.J.; Kelton, J.A.(eds). Herbicides - current research and case studies in use. Croatia: Intech. pp. 3-26. https://doi.org/10.5772/55947

Barrett, S.C.H.,; Seaman, D.E. 1980. The weed flora of californian rice fields. Aquatic Botany, 9: 351-376. https:// doi.org/10.1016/0304-3770(80)90036-4

Barrett, S.C.H.; Wilson, B.F. 1981 a. Colonizing ability in the Echinochloa crus-galli complex (barnyard grass). II. Seed biology. Canadian Journal of Botany, 61(2): 556-562. https://doi. org/10.1139/b83-063

Barrett, S.C.H.; Wilson, B.F. 1981 b. Colonizing ability in the Echinochloa crus-galli complex (Barnyardgrass) .l. Variation in life history. Canadian Journal of Botany, 59: 1844-1860. https://doi.org/10.1139/b81-245

Beckie, H.J. 2006. Herbicide-resistant weeds: management tactics and practices. Weed Technology, 20(03): 793-814. https://doi.org/10.1614/wt-05-084r1.1

Beckie, H.J. 2007. Beneficial management practices to Combat herbicide-resistant Grass weeds in the Northern Great Plains. Weed Technology, 21(2): 290299. https://doi.org/10.1614/wt-06083.1

Beckie, H.J.; Gill, G. 2006. Strategies for managing herbicide-resistant weeds. In H. Singh, D. R. Batish, \& R. K. Kohli (Eds.), Handbook of sustainable weed management. New York: Food Products Press. pp. 581-625. 
Beckie, H.J.; Tardif, F.J. 2012. Herbicide cross resistance in weeds. Crop Protection, 35: 15-28. https://doi.org/10.1016/j. cropro.2011.12.018

Blackshaw, R.E.; Harker, K.N.; Smith, E.G.; Beckie, H.J.; O'Donovan, J.T. 2008. Ongoing development of integrated weed management systems on the canadian prairies. Weed Science, 56(1): 146-150. https://doi.org/10.1614/ws07-038.1

Bonnecarrère, V.; Iriarte, W.; Saldain, N. 2016. La resistencia que expresa el biotipo de capín E3CL al Kifix, ¿a qué mecanismo es debida? In INIA (Ed.), Resultados Experimentales de Arroz 2015-2016. Treinta y Tres: INIA. p. 18-19. (INIA Serie Actividades de Difusión 765)

Bourgeois, L.; Kenkel, N.C.; Morrison, I.N. 1997. Characterization of crossresistance patterns in Acetyl-CoA Carboxylase inhibitor resistant wild oat (Avena fatua). Weed Science, 45(6): 750-755. https://doi.org/10.1017/ S0043174500088925

Brim-DeForest, W.B.; Al-khatib, K.; Linquist, B.A.; Fischer, A.J. 2017. Weed community dynamics and system productivity in alternative irrigation systems in California rice. Weed Science, 65: 177-188. https://doi. org/10.1614/WS-D-16-00064.1

Cousens, R.; Mortimer, M. 1995. Dynamics of weed population. Cambridge: University Press. 332 p. https://doi.org/10.1017/ CBO9780511608629

Délye, C. 2005. Weed resistance to acetyl coenzyme A carboxylase inhibitors: an update. Weed Science, 53: 728-746. https://doi.org/10.1614/WS-04-203R.1

Diez, M.; Sainz, M.; Saldain, N.; Marchesi, C.; Bonnecarrère, V.; Diaz, P. 2020. Limited induction of ethylene and cyanide synthesis are observed in Quinclorac- resistant barnyardgrass (Echinochloa crus-galli) in Uruguay. Weed Science, 68(4):348-357. https:// doi.org/doi:10.1017/wsc.2020.32

Diggle, A.; Neve, P. 2001. The population dynamics and genetics of herbicide resistance-a modelling approach. In: Powles, S.B.; Shaner, D. (Eds.), Herbicide resistance and world grains. New York: CRC Press. p. 61-99.
Eberhardt, D.S.; Oliveira Neto, A.M.; Noldin, J.A.; Vanti, R.M. 2016. Barnyardgrass with multiple resistance to synthetic auxin, ALS and ACCase inhibitors. Planta Daninha, 34(4):823832. https://doi.org/10.1590/s010083582016340400023

Felix, E.; Urioste, S. 2016. Primer reporte de resistencia a glifosato en poblaciones de Lolium multiflorum Lam en Uruguay, y susceptibilidad de éstas a herbicidas inhibidores de las ACCasa. Montevideo: UDELAR.

Fischer, A.J.; Valverde, B.E. 2005. Evolución de resistencia a herbicidas, diagnóstico y manejo en malezas de arroz. In: Rios, A. (Ed.). Seminario-Taller Iberoamericano: resistencia a herbicidas y cultivos transgénicos. Colonia del Sacramento: INIA; FAO; FAGRO.

Gill, G.S.; Holmes, J.E. 1997. Efficacy of cultural control methods for combating herbicide-resistant Lolium rigidum. Pesticide Science, 51: 352-358.

Gressel, J. 2002. Molecular biology of weed control. London: Taylor \& Francis. 504 p.

Gressel, J.; Segel, L.A. 1982. Interrelating factors controlling the rate of appearance of resistance: the outlook for the future. In: LeBaron, H.; Gressel, J. (Eds.), Herbicide resistance in plants. New York: John Wiley \& Sons. p. 325-347.

Heap, I.M. 2020. The international survey of herbicide resistant weeds. Retrieved March 31, 2020, from www.weedscience.org

Holm, L.; Pucknett, D.; Pancho, J.; Heberger, J. 1977. The world's worst weeds : distribution and biology. Honolulu, HI: University Press of Hawaii. 609 p.

HRAC https://www.hracglobal.com/

Jasieniuk, M.; Brule-babel, A.L.; Morrison, I.N. 1996. The evolution and genetics of herbicide resistance in weeds. Weed Science, 44(1): 176-193. https://doi. org/10.1017/S0043174500093747

Jori, B.; Sóos, V.; Szego, D.; Páldi, E.; Szigeti, Z.; Rácz, I.; Lásztity, D. 2007. Role of transporters in Paraquat resistance of horseweed Conyza canadensis (L.) Cronq . Pesticide Biochemistry and Physiology, 88, 57-65. https://doi. org/10.1016/j.pestbp.2006.08.013 
Kogan, M.; Perez J., A. 2003. Herbicidas. Fundamentos fisiológicos y bioquímicos del modo de acción. Santiago de Chile: Universidad Católica de Chile.

Légère, A.; Beckie, H.; Stevenson, F.; Thomas, A. 2000. Survey of management practices affecting the occurance of wild oat (Avena fatua) resistant to acetyl CoA carboxilase inhibitors. Weed Technology, 14(2): 366376. https://doi.org/10.1614/0890-037X(2 000)014[0366:SOMPAT]2.0.CO;2

Linquist, B.; Fischer, A.J.; Godfrey, L.; Greer, C.; Hill, J.; Koffer, K.; Moeching, M.; Mutters, R.; van Kessel, C. (2008). Minimun tillage could benefit California rice farmers. California Agriculture, 62(1):24-29.

Macedo, I.; Carrasco-Letelier, L.; Velasco, J.I.; Siri-Prieto, G.; Terra, J. A. 2020. Intensification alternatives to rice-pasture systems: energy use efficiency. In: Andres, A. Scivittaro, W. (Eds.), International Temperate Rice Conference (7./ :2020. Pelotas, Brazil) Pelotas: Embrapa.p. 18-19.

Marchesi, C.; Saldain, N. 2019. First report of herbicide-resistant Echinochloa crus galli in uruguayan rice fields. Agronomy, 9, 790-809. https://doi.org/10.3390/ agronomy 9120790

Metzler, M.; Rampoldi, A.; Dellaferrera, I. 2018. Alerta rojo: Echinochloa crus-galli «capín arroz», resistente a glifosato e imidazolinonas en la Provincia de Entre Ríos. Buenos Aires: INTA.

Michael, P. 1983. Taxonomy and distribution of Echinochloa species with special reference to their occurance as weeds of rice. In IRRI (Ed.), Weed control in rice. Phillipines: IRRI. p. 291-306.

Moss, S. 1997. Strategies for the prevention and control of herbicide resistance in annual grass weeds. In: De Prado, R.; Jorrin, j. García Torres, L. (Eds.), Weed and crop resistance to herbicides. London: Kluwer Academic. p. 225-252.

Moss, S.; Ulber, L.; Hoed, I. d. 2019. A herbicide resistance risk matrix. Crop Protection, 115: 13-19. https://doi. org/10.1016/j.cropro.2018.09.005
Neve, P.; Norsworthy, J.K.; Smith, K.L.; Zelaya, I.A. 2010. Modelling evolution and management of glyphosate resistance in Amaranthus palmeri. Weed Research, (51):99-112. https://doi. org/10.1111/j.1365-3180.2010.00838.x

Norris, R.F. 1996. Morphological and phenological variation in barnyardgrass (Echinochloa crus-galli) in California. Weed Science, 44(4): 804-814. https:// doi.org/10.1017/S0043174500094753

Norsworthy, J.K.; Ward, S.M.; Shaw, D.R.; Llewellyn, R.S.; Nichols, R.L.; Webster, T.M., Bradley, K.W.; Frisvold; G.; Powles, S.B-; Barrett, M. 2012. Reducing the risks of herbicide resistance: best management practices and recommendations. Weed Science, 60(1): 31-62. https://doi. org/10.1614/WS-D-11-00155.1

Opena, J.; Pratley, J.; Mccormick, J.; Wu, H.; Lemerle, D. 2019. Pasture legumes offer promise to control barnyard grass in delayed permanent water systems in rice. In: Pratley, J. E. (Ed.). Proceedings of the 19th Australian Society of Agronomy Conference. Wagga-Wagga: Australian Society of Agronomy. p. 1-4.

Pang, S.S.; Duggleby, R.G.; Guddat, L.W. 2002. Crystal structure of yeast acetohydroxyacid synthase: A target of herbicidal inhibitors. Journal of Molecular Biology, 317(2): 249-269. https://doi.org/10.1006/jmbi.2001.5419

Pittelkow, C.M.; Zorrilla, G.; Terra, J.; Riccetto, S.; Macedo, I.; Bonilla, C.; Roel, A. 2016. Sustainability of rice intensification in Uruguay from 1993 to 2013. Global Food Security, 9, 10-18. https://doi. org/10.1016/j.gfs.2016.05.003

Powles, S.B.; Preston, C. 2006. Evolved glyphosate resistance in plants: biochemical and genetic basis of resistance. Weed Technology, 20(2): 282-289. https://doi. org/10.1614/WT-04-142R.1

Powles, S.B.; Preston, C.; Bryan, I.B.; Jutsum, A.R. 1997. Herbicide resistance: Impact and management. Advances in Agronomy, 58, 57-93.

Powles, S.B.; Yu, Q. 2010. Evolution in action/ : plants resistant to herbicides. Annual Review in Plant Biology, 61, 317-347. https://doi.org/10.1146/ annurev-arplant-042809-112119 
Pratley, J.E.; Broster, J.C.; Michael, P. 2008. Echinochloa spp. in Australian rice fields - species distribution and resistance status. Australian Journal of Agricultural Research, 59, 639-645.

Preston, C.; Powles, S. 2002. Evolution of herbicide resistance in weeds: initial frequency of target-site based resistance to acetolactate synthase inhibiting herbicides in Lolium rigidum. Heredity, 88:8-13. https://doi. org/10.1038/sj.hdy.6800004

Renton, M.; Busi, R.; Neve, P.; Thornby, D.; Vila-Aiub, M. 2014. Herbicide resistance modelling/ : past, present and future. Pest Management Science, 70(9): 1394-1404. https://doi.org/10.1002/ps.3773

Rouse, C.E.; Roma-Burgos, N.; Norsworthy, J.K.; Tseng, T.M.; Starkey, C.E.; Scott, R.C. 2017. Echinochloa resistance to herbicides continues to increase in Arkansas rice fields. Weed Technology, 32(1):34-44. https://doi.org/10.1017/ wet.2017.82

Saldain, N.; Sosa, B. 2012. Susceptibilidad de los biotipos de capín colectados en sitios con distinta intensidad de uso del arroz Clearfield ${ }^{\circledR}$ al Kifix®. In INIA (Ed.), Resultados Experimentales de Arroz 2011-2012. Treinta y Tres: INIA. p. 18-21. (INIA Serie Actividades de Difusión; 686)

Saldain, N.; Sosa, B. 2016. ¿Qué papel juega la resistencia metabólica en la expresión de la resistencia a Quinclorac y a Kifix en algunos biotipos de capín de la zona este de Uruguay? In: INIA (Ed.), Resultados Experimentales de Arroz 2015-2016. Treinta y Tres: INIA. p. 15-17 (INIA Serie Actividades de Difusión; 765).

Somerville, G.; Powles, S.; Walsh, M.; Renton, M. 2018. Modeling the impact of harvest weed seed control on herbicide-resistance evolution. Weed Science, 66(3):395-403. https://doi.org/10.1017/wsc.2018.9

Tranel, P.J.; Wright, T.R. 2002. Review resistance of weeds to ALS-inhibiting herbicides/: what have we learned/ ? Weed Science, 50(6):700-712. ht tps://doi.org/10.1614/00431745(2002)050[0700:RROWTA]2.0.CO;2
Tsuji, R.; Fischer, A.J.; Yoshino, M.; Hill, J.E.; Roel, A.; Yamasue, Y. 2003. Herbicide-resistant late watergrass (Echinochloa phyllopogon): similarity in morphological and amplified fragment length polymorphism traits. Weed Science, 51(5):740-747. https://doi. org/10.1614/P2002-143

Vidotto, F.; Tesio, F.; Tabacchi, M.; Ferrero, A. 2007. Herbicide sensitivity of Echinochloa spp . accessions in italian rice fields. Crop Protection, 26(3):285293. https://doi.org/10.1016/j. cropro.2005.07.016

Walsh, M. J.; Harrington, R.B.; Powles, S.B. 2012. Harrington Seed Destructor/ : A new nonchemical weed control tool for global grain crops. Crop Science, 52(3):1343-1347. https://doi. org/10.2135/cropsci2011.11.0608

WSSA. 1998. Technology Notes. Weed Technology, 12(4):789-790.

Yabuno, T. 1966. Biosystematic study of genus Echinochloa. Japanese Journal of Botany, 19, 277.

Yasuor, H.; Tenbrook, P.L.; Tjeerdema, R.S.; Fischer, A.J. 2008. Responses to clomazone and 5-ketoclomazone by Echinochloa phyllopogon resistant to multiple herbicides in Californian rice fields. Pest Management Science, 64(10):1031-1039. https://doi. org/10.1002/ps.1604

Yu, Q.; Cairns, A.; Powles, S. 2007. Glyphosate, paraquat and ACCase multiple herbicide resistance evolved in a Lolium rigidum biotype. Planta, 225(2):499-513. https://doi.org/10.1007/ s00425-006-0364-3

Yuan, J. S.; Tranel, P. J.; Stewart Jr, C.N. 2007. Non-target-site herbicide resistance: a family business. Trends in Plant Science, 12(1):6-13. https:// doi.org/10.1016/j.tplants.2006.11.001 


\section{7 - DISIPACIÓN DE LOS \\ RESIDUOS REMANENTES DE LAS \\ IMIDAZOLINONAS Y SU INCIDENCIA \\ EN LOS CULTIVOS SIGUIENTES}

N.E. Saldain ${ }^{1}$

PALABRAS CLAVE: degradación microbiana, persistencia, toxicidad imazapir e imazapic

\section{GENERALIDADES DE LAS IMIDAZOLINONAS}

Las imidazolinonas se comportan como un ácido débil en la solución del suelo, siendo el $\mathrm{pH}$ el determinante de su dinámica. En sus moléculas presentan un anillo del grupo imidazolinona que tiene radicales metil e isopropil en el carbono de la posición 4 (núcleo común a la familia), mientras que en el carbono 2 de ese grupo se unen estructuras en anillo de benceno, piridina o quinolina (Anderson, 1996). Estos herbicidas muestran varias constantes de disociación relacionadas a los grupos funcionales según el $\mathrm{pH}$ de la solución (Capítulo 1, Figura 4, Tabla 4). Estas propiedades hacen que en solución estos herbicidas se encuentren como una mezcla de moléculas con carga positiva (Figura 1, «1»), sin carga (Figura 1, «2»), con ambas cargas simultáneamente (Figura 1, «3»), o con carga negativa (Figura 1, «4»).

Mangels (1991) mostró como la composición de las formas químicas varía en función del pH de la solución (Figura 2). En todos los suelos estudiados las imidazolinonas presentaron una adsorción muy<smiles>CC(C)C1(C)N=C(c2ncccc2C(=O)O)NC1=O</smiles>

1<smiles>CC(C)C1(C)N=C(c2ncccc2C(=O)O)NC1=O</smiles>

2<smiles>CC(C)C1(C)NC(c2ncccc2C(=O)[O-])NC1=O</smiles>

3<smiles>CC(C)C1(C)N=C(c2ncccc2C(=O)[O-])NC1=O</smiles>

4<smiles>CC(C)C1(C)N=C(c2ncccc2C(=O)[O-])NC1=O</smiles>

5

Figura 1. Distintas formas químicas de las imidazolinonas en la solución acuosa (tomada de Mangels, 1991).

${ }^{1}$ Néstor Saldain. Ing. Agr. M.Sc. INIA. Programa Nacional de Investigación en Producción de Arroz (hasta junio 2021). nsaldain56@gmail.com 


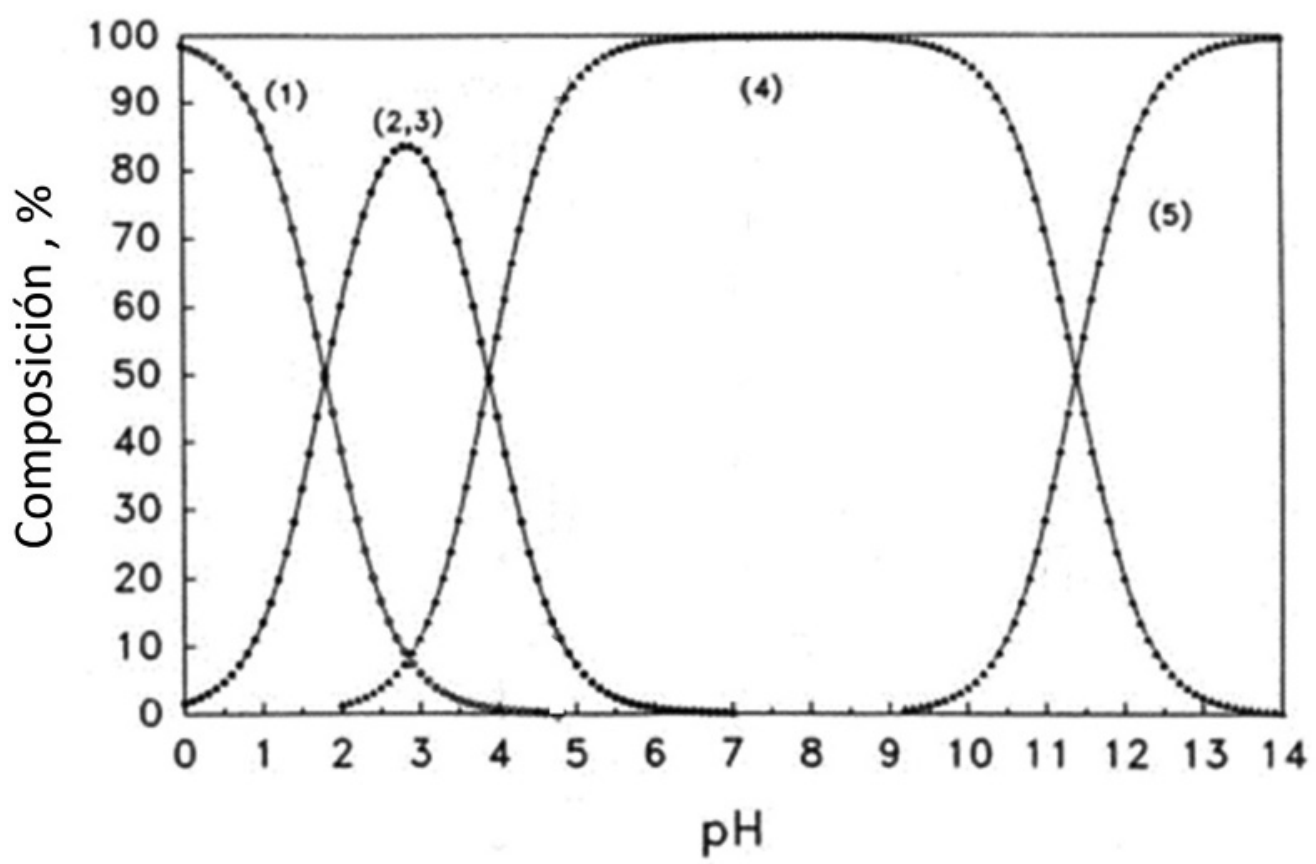

Figura 2. Efecto del pH de la solución acuosa en la composición de distintas formas químicas (tomada de Mangels, 1991).

débil a pH mayores que 6 y en el rango de $\mathrm{pH}$ de 3 a 6 , la adsorción aumenta significativamente cuando el $\mathrm{pH}$ es más ácido (Figura 3). Además, señaló el hecho de que pequeñas reducciones en el $\mathrm{pH}$ del orden de 0,2 a 0,4 unidades por debajo de 5,5 pueden duplicar el coeficiente de adsorción o distribución (Kd), debido a que aumenta significativamente la cantidad de la forma química «2», que está en equilibrio con la forma « $3 »$, reteniéndose en los coloides de la materia orgánica

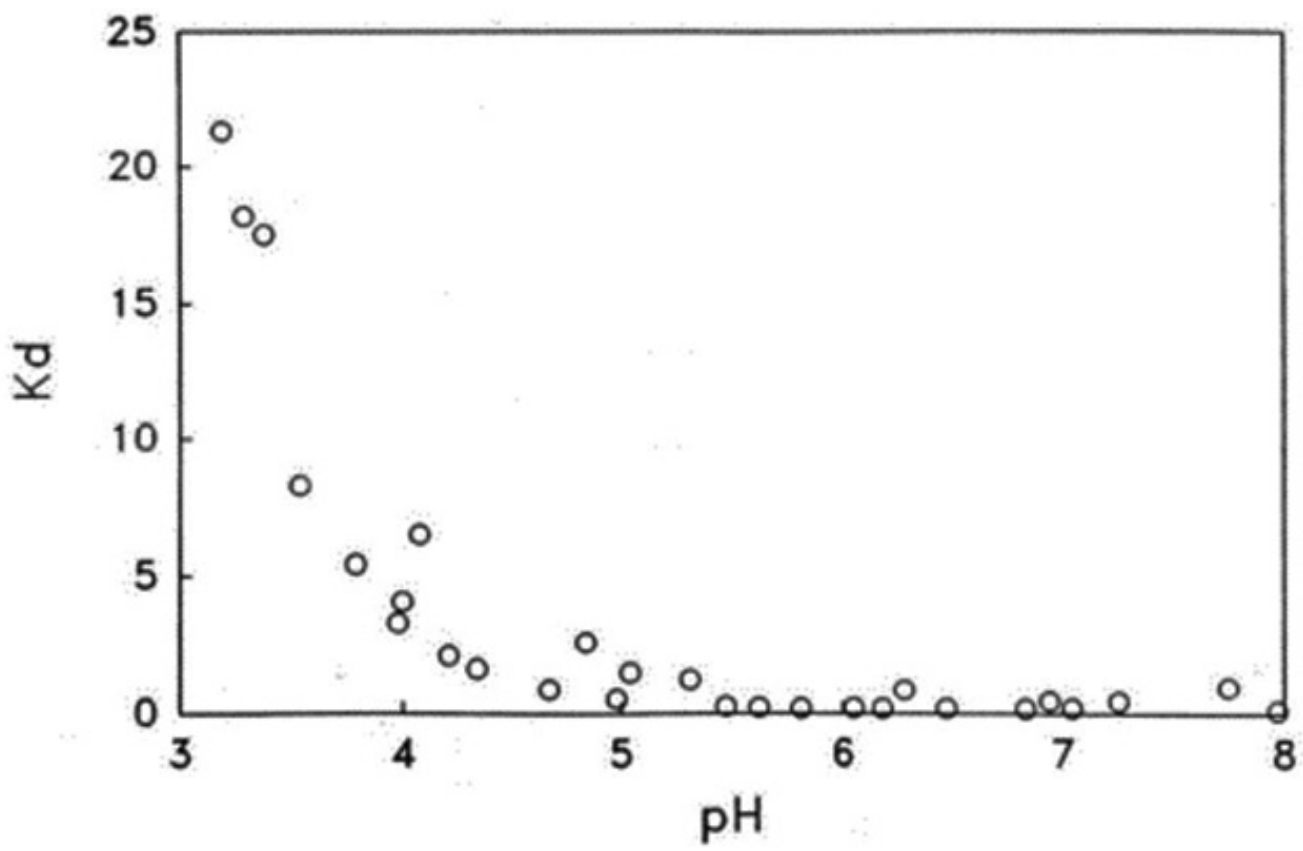

Figura 3. Efecto del pH en el coeficiente de distribución (Kd) entre la matriz coloidal del suelo y el agua (tomada de Mangels, 1991). 
del suelo. Al aumentar la polaridad de las imidazolinonas debido a que está disociado el grupo carboxilo (COO-), se incrementa su solubilidad en agua, siendo muy débilmente retenido en el suelo o repelido, quedando disponible los residuos en la solución del suelo para la metabolización por los microorganismos y eventualmente, para la lixiviación hacia horizontes más profundos.

El autor señala que a pH entre 5 y 9 predomina la forma química «4», mientras que cuando se reduce el $\mathrm{pH}$ por debajo de 5 aumenta en mayor proporción la forma «2». Esta forma «2» no tiene cargas, no está disociada, por lo que tiene un comportamiento similar a los herbicidas no iónicos en el suelo, estando su adsorción en función del contenido de materia orgánica. Por otro lado, la forma «4» que tiene carga negativa, grupo carboxilo disociado, se unirá muy débilmente a la materia orgánica del suelo o puede ser repelida por las cargas negativas de ésta y la fracción arcilla, y se podría unir bien a ciertos minerales (Mangels, 1991). Uno de esos minerales es la hematita, compuesta por óxidos de hierro que se presentan como cationes (cargas positivas) en los suelos agrícolas con $\mathrm{pH}$ entre 5,5 y 6,5 , mostrando gran capacidad de adsorción (Helling, 2005).

\section{DINÁMICA DEL PH EN EL SUELO BAJO INUNDACIÓN}

En el país, los suelos arroceros presentan un rango de $\mathrm{pH}$ en el horizonte superficial entre 4,8 y 6,5 , correspondiendo los más ácidos a suelos de contenido bajo de materia orgánica, con menor proporción de arcilla y más arena, mientras que aquellos de $\mathrm{pH}$ más elevados tienen mayor proporción de materia orgánica, limo y arcilla. Por lo tanto, es esperable que la forma química «4» del herbicida domine en la mayoría de los casos, con cierta proporción creciente de la forma química «2» en suelos con pH entre 4,8 a 5,2 , indicando una mayor proporción adsorbida al suelo.

Rabuffetti y Deambrosi (2017) explican que el agua de la inundación al entrar al suelo ocupa el espacio poroso, reduciendo el contenido de oxígeno a nulo entre uno a tres días posteriores. La disminución del contenido de oxígeno en el suelo al inundar es más drástica aún, cuando éste está seco, porque se promueve la oxidación de la materia orgánica que consume rápidamente el oxígeno disponible. Sin embargo, el agua de inundación encima de la superficie del suelo contiene oxígeno proveniente de la atmosfera. En los suelos inundados existe una capa con mayor presencia de oxígeno entre la superficie del suelo y un $\mathrm{cm}$ de profundidad, donde ocurren procesos de oxidación.

Las propiedades fisicoquímicas del suelo se modifican cuando éste se inunda. Por ejemplo, el $\mathrm{pH}$ desciende hasta un mínimo en los primeros días y se recupera posteriormente hasta alcanzar un valor comprendido entre 6,7 y 7,2, aproximadamente a las cuatro a seis semanas. En general, el pH aumenta con la inundación cuando se parte de un valor más ácido (excepto cuando el contenido de hierro es bajo) y disminuye hacia la neutralidad cuando se parte de un $\mathrm{pH}$ más elevado. Además, los suelos con alto contenido de materia orgánica y hierro reducible tienden a un $\mathrm{pH}$ de 6,5 de manera rápida, mientras que en los suelos ácidos con bajo contenido de materia orgánica y hierro, el pH crecerá muy lentamente y no superará el valor de 5 , incluso aunque la inundación dure varios meses. Un alto contenido de materia orgánica contribuye a la caída rápida del $\mathrm{pH}$, especialmente en los suelos sódicos y calcáreos, sin embargo, las temperaturas bajas y la presencia de nitratos disminuye la velocidad en el cambio en el pH (Rabuffetti y Deambrosi, 2017).

Otra propiedad fisicoquímica de interés es la concentración de iones o fuerza iónica en la solución de suelo. Rabuffetti y Deambrosi (2017) señalan que en los suelos ácidos y levemente ácidos ocurre la reducción de compuestos de hierro $\left(\mathrm{Fe}^{+3}\right.$ a $\left.\mathrm{Fe}^{+2}\right)$ y de manganeso $\left(\mathrm{Mn}^{+4} \mathrm{a} \mathrm{Mn}^{+2}\right)$ de formas insolubles a más solubles. Estos desplazan a otros cationes del complejo de intercambio, siendo los responsables del aumento de los cationes en 
la solución del suelo; en cambio, en los suelos de $\mathrm{pH}$ neutro o levemente alcalinos, el calcio $\left(\mathrm{Ca}^{+2}\right)$ y el magnesio $\left(\mathrm{Mg}^{+2}\right)$ de la solución del suelo contribuyen significativamente a la fuerza iónica.

\section{¿CÓMO SE COMPORTAN LOS RESIDUOS DE LAS IMIDAZOLINONAS EN EL PERFIL DEL SUELO INUNDADO?}

Se detectaron distintos perfiles de distribución de los residuos remanentes del herbicida en la profundidad de suelo, según se haya realizado laboreo o siembra directa. Kraemer et al. (2009), trabajaron sobre suelo con y sin laboreo luego de dos arroces Clearfield (CL) seguido de un arroz no CL y determinaron luego de la cosecha de este último que el imazetapir lixivió hasta $20 \mathrm{~cm}$ de profundidad a los 540 días después de aplicado (DDA), alcanzando una concentración de $0,8 \mu \mathrm{g} / \mathrm{kg}(0,8 \mathrm{ppb})$ (Figura 4). En la siembra convencional la concentración de este herbicida se distribuyó uniformemente hasta los $15 \mathrm{~cm}$ de profundidad en el perfil del suelo, mientras que bajo siembra directa la concentración en los primeros $5 \mathrm{~cm}$ fue menor que en la siembra convencional, acumulándose imazetapir entre los 5 a $15 \mathrm{~cm}$.
En otra experiencia usando lisímetros, con un suelo típico de la Depresión Central, RS, sin historia de arroz $\mathrm{CL}$, con $\mathrm{pH}$ $4,8 \pm 0,2$ y una saturación en aluminio de $12,9 \pm 4,2 \%$ en el perfil, Refatti et al. (2014) detectaron que al aumentar el pH del suelo a través del encalado se promovió una mayor disponibilidad de los residuos del imazetapir y el imazapic y a su vez mayor lixiviación en el perfil del suelo. Así como el herbicida se mueve hacia horizontes subsuperficiales acompañando el frente de humedecimiento durante los 90100 días de inundación del arroz, Bundt et al. (2013) demostraron que la mezcla de imazetapir + imazapic también asciende con el agua por capilaridad. Este transporte es un proceso lento que no ocurre en el cultivo de arroz sino en el barbecho comprendido entre dos zafras consecutivas (150 días). La cantidad de residuos del herbicida que será transportado por este mecanismo dependerá de cuán cerca esté de la superficie la napa colgada y de la evaporación del agua desde el suelo.

Con la misma metodología, Bundt et al. (2015) detectaron que, en un suelo superficial seguido de una capa impermeable, como un horizonte $B$ textural típico de la mayoría de los suelos arroceros, los residuos se acumularán por encima de

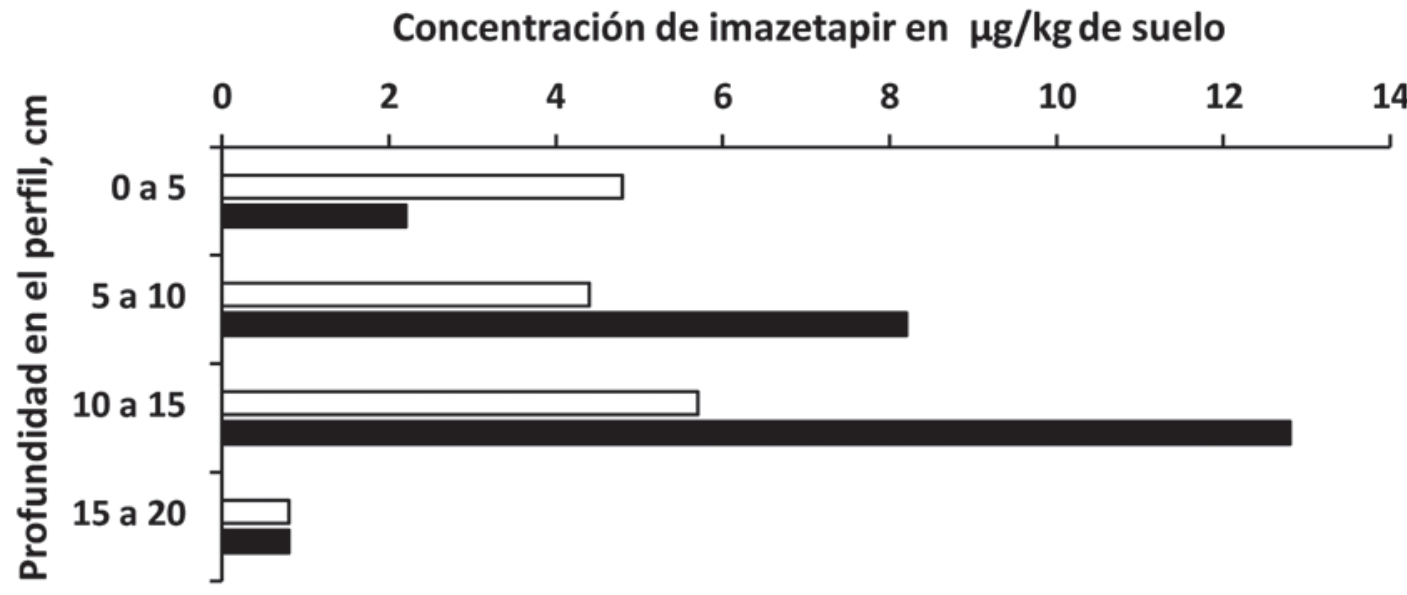

\section{$\square$ Siembra convencional $\square$ Siembra directa}

Figura 4. Distribución de la concentración de imazetapir $(\mu \mathrm{g} / \mathrm{kg})$ en los distintos horizontes en el perfil del suelo muestreado después de haber cultivado dos años seguidos arroz CL y un año arroz no CL bajo siembra convencional con laboreo y en siembra directa (adaptada de Kramer et al., 2009). 
esa capa siendo el daño mayor en el arroz no CL. Por el contrario, en un suelo con mayor espesor del horizonte superficial los residuos herbicidas lixiviarán durante la inundación, distribuyéndose en un mayor volumen de suelo por lo que bajará la concentración de los residuos redundando en un menor daño en el arroz no CL. Estos autores señalan que cuanto más espesor tengan los horizontes superficiales y subsuperficiales explorables por las raíces, se observarán síntomas de daño leves dada la menor absorción de residuos en las etapas iniciales de desarrollo del arroz no CL; en una etapa posterior cuando las raíces exploren los horizontes más profundos, se expresarán en mayor medida los síntomas de daño. Asumiendo que las raíces realmente absorban los residuos, la expresión de síntomas de daño y su severidad estarán en función del grado de desarrollo del cultivo, de la dilución que se haga de los residuos en la materia seca producida y de la capacidad de detoxificación. El 50\% de los suelos donde se cultiva arroz en Río Grande del Sur tienen pH menor a 5, por
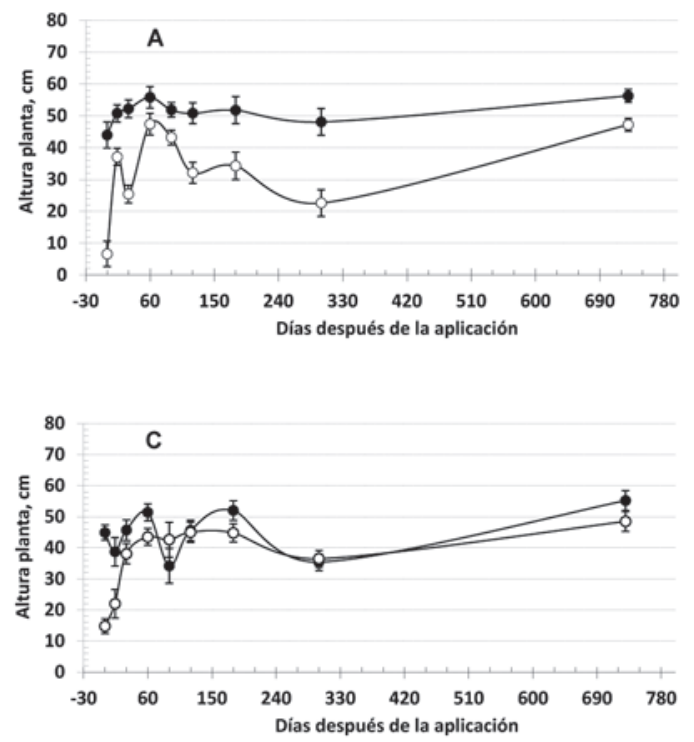

lo que se espera que una buena proporción de los residuos queden adsorbidos a los coloides del suelo persistiendo más tiempo y en consecuencia afectando a los cultivos susceptibles siguientes. La gran mayoría de los suelos donde se cultiva arroz son planosoles que desarrollan una napa colgada que está presente la mayor parte del año, siendo una característica que contribuye a la persistencia de los residuos de las imidazolinonas.

Saldain et al. (2014a) estudiaron la persistencia de los residuos de la mezcla de imazapir + imazapic en el suelo de la secuencia arroz CL seguido de raigrás sembrado al voleo sobre el rastrojo de arroz $\mathrm{CL}$ y posteriormente por arroz no $\mathrm{CL}$ en siembra directa. Para contextualizar, se asume que la inundación es de 90-100 días en el cultivo de arroz y la siembra de especies forrajeras sobre el rastrojo comienza un poco antes de los 120 días después de la aplicación (DDA). Entre este momento y los 180 DDA es cuando las plántulas de las especies forrajeras se implantarán y realizarán su crecimiento inicial, mientras que alrededor de los 300
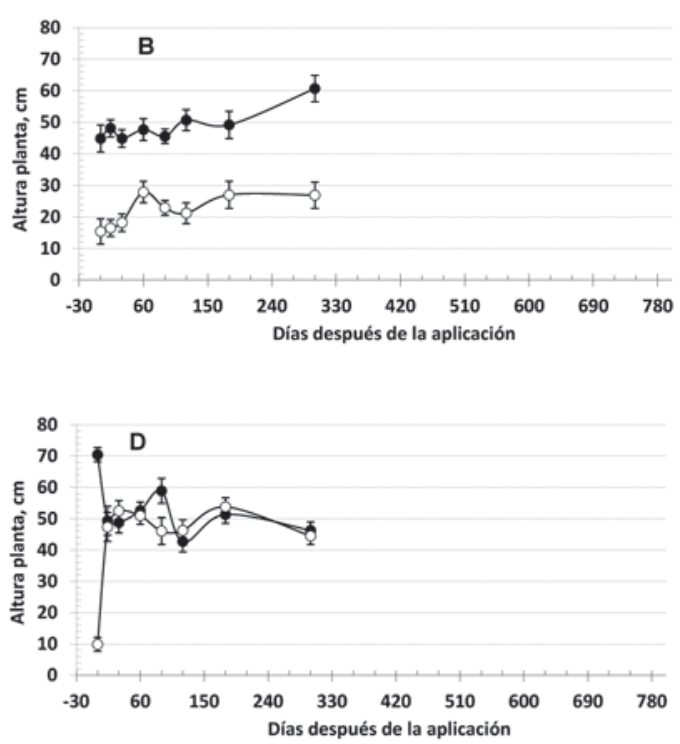

Figura 5. Altura de la planta del sorgo forrajero $(\mathrm{cm})$ a las 4 SDS de los tratamientos $(\bullet)$ sin imazapir + imazapic y (O) con 110 + $37 \mathrm{~g}$ a.e./ha de imazapir + imazapic correspondiente a los muestreos en el horizonte de $0-10 \mathrm{~cm}$ estudiados en función del sitio y del año de recolección. A: Río Branco 2008-2009; B: Río Branco 2009-2010; C: UEPL 2008-2009; D: UEPL 2009-2010. Los círculos representan la media \pm error estándar $(n=6), 4 S D S=$ cuatro semanas después de la siembra, UEPL=Unidad Experimental Paso de La Laguna, Treinta y Tres. 
DDA, se comenzará a sembrar arroz no $\mathrm{CL}$, soja y sorgo.

Se monitoreó la presencia de los residuos en el suelo de las parcelas que no habían sido tratadas con imidazolinonas y las tratadas con $110+37 \mathrm{~g}$ a.e./ha de imazapir + imazapic en el cultivo del arroz CL y el barbecho posterior, con un bioensayo sembrando sorgo forrajero como especie indicadora. En general, se observó que las máximas diferencias de altura de la planta de sorgo forrajero ocurrieron entre los tratamientos en las fechas de muestreo más cercanas a la aplicación de la mezcla imazapir + imazapic en postemergencia temprana (Figura 5), registrándose muerte de plántulas en ese momento y a los 14 días DDA, en ambos suelos.

En el horizonte de $0-10 \mathrm{~cm}$, las diferencias significativas observadas en la altura en todos los momentos muestreados indican que existieron residuos disponibles y con actividad biológica en ambos años en Río Branco (Figuras 5A y 5B). Sin embargo, se aprecia una fase rápida de disipación de los residuos atento al creci-
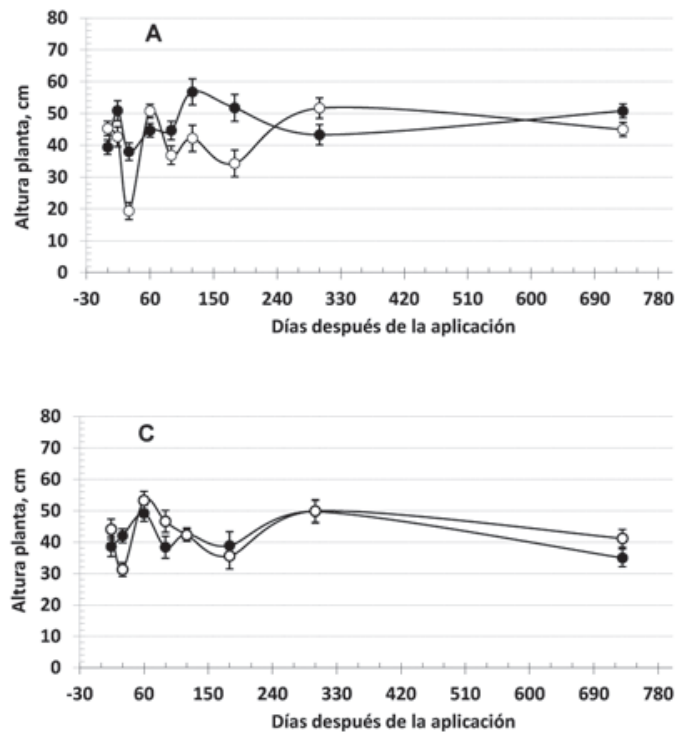

miento del sorgo forrajero y después habría más disponibilidad de residuos entre 120 y 180 DDA; algo más aumentaría a los 300 DDA probablemente por el ascenso de residuos en la entre zafra en el año 2008-2009, mientras que la fase rápida es mucho menos pronunciada en el año 2009-2010. En cambio, el comportamiento de los residuos es bien contrastante con aquellos en la UEPL (Figuras 5C y 5D). Se observaron diferencias en altura significativas entre el día de la aplicación y los 60 DDA, y puntualmente a los 180 DDA en el año 2008-2009, mientras que los residuos se disiparon muy rápido en el año 20092010 , dado que se apreciaron diferencias significativas en el día de la aplicación y a los 90 DDA. Además, en ambos sitios se evaluó la persistencia hasta los 730 DDA en el año 2008-2009, constatándose que persisten siendo la diferencia de altura escasa, lo que indicaría que es una concentración de residuos muy pequeña en Río Branco y despreciable en la UEPL.

En el horizonte de 10-20 cm (Figura 6), se observa una reducción significativa en el crecimiento de la planta de sorgo forrajero a
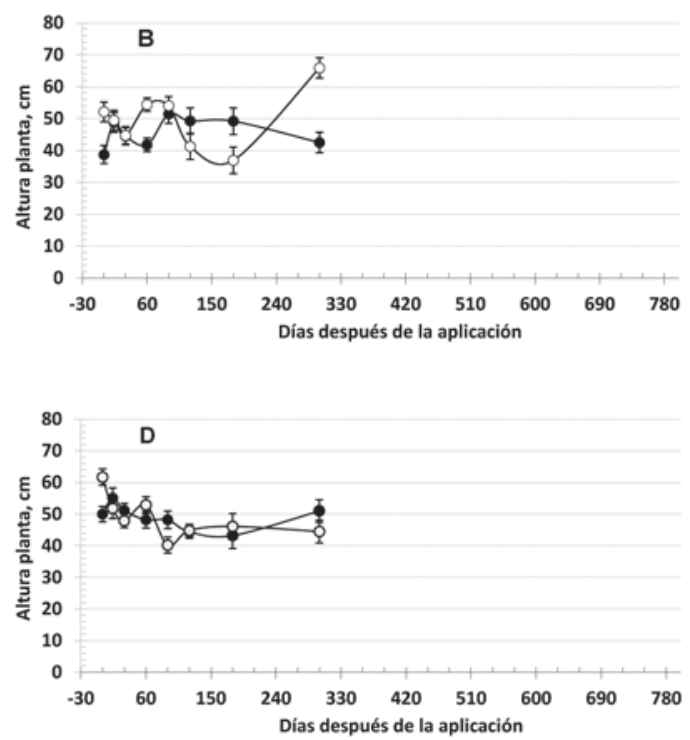

Figura 6. Altura de la planta del sorgo forrajero $(\mathrm{cm})$ a las 5SDS de los tratamientos (•) sin imazapir + imazapic y $(\mathrm{O})$ con $110+37 \mathrm{~g}$ a.e./ha de imazapir + imazapic correspondiente a los muestreos de 10-20 cm estudiados en función del sitio y año de recolección. A: Río Branco 2008-2009; B: Río Branco 2009-2010; C: UEPL 2008-2009; D: UEPL 2009-2010. Los círculos representan la media \pm error estándar $(n=6), 5 S D S=$ cinco semanas después de la siembra, UEPL=Unidad Experimental Paso de La Laguna, Treinta y Tres. 
los 120 y 180 DDA, indicando la presencia de residuos asociada a la lixiviación que promueve el frente de humedecimiento cuando avanza la inundación en los suelos de Río Branco (Figuras 6A y 6B), mientras que no se detectó inhibición en el horizonte subsuperficial del suelo de la UEPL (Figuras $6 \mathrm{C}$ y $6 \mathrm{D}$ ). A los $300 \mathrm{DDA}$, tampoco se detectó inhibición en la altura de la planta indicadora en ninguno de los sitios.

\section{DISIPACIÓN DE LOS RESIDUOS DE LAS IMIDAZOLINONAS EN EL AGUA DE RIEGO}

En general la disipación de las imidazolinonas en el agua y suelo está basada en mecanismos que pueden operar en ambas matrices o que pueden actuar preferentemente en una u otra. En consecuencia, la eficacia de los mecanismos involucrados en la disipación de los residuos determinará la persistencia de éstos (Ramezani, 2007). Las imidazolinonas son herbicidas cuyas moléculas no son simétricas porque su estructura no se superpone a su imagen especular (herbicidas quirales). Gehrke et al. (2021) explicaron que un átomo de carbono ubicado en la posición 4 en el anillo del grupo imidazolinona es asimétrico. Por lo tanto, presenta cuatro enlaces distintos provocando variaciones en la molécula denominadas enantiómeros ópticos, que tienen las mismas propiedades físicas y químicas. Este hecho hace que el compuesto se presente bajo forma de R-enantiómeros y L-enantiómeros según hacia donde desvían la luz incidente. Ramezani (2007) agregó que los mecanismos de disipación de estos herbicidas a través de la degradación microbiana y la catálisis enzimática del suelo podrían tener preferencia por un enantiómero dejando al otro sin modificarse, con la consiguiente acumulación e impacto en el ambiente. Se ha demostrado que el R-enantiómero del imazapir tiene más capacidad inhibitoria que el L-enantiómero (Hsiao et al., 2014). Generalmente, las formulaciones de herbicidas quirales se presentan como una mezcla racémica, componiéndose la mezcla por $50 \%$ de cada enantiómero debido a lo costoso de la separación del enantiómero de menor actividad herbicida (Ramezani, 2007). Estos autores mencionaron que los pesticidas que presentan radicales carboxilos $(\mathrm{COOH})$ tienden a tener degradación por hidrólisis. No obstante, encontraron que tanto imazaquín, imazetapir, así como el imazapir presentaron una degradación despreciable por hidrólisis en solución acuosa ajustadas a distintos $\mathrm{pH}$.

Otro mecanismo de disipación estudiado fue la fotólisis o foto degradación en solución acuosa debido a la fracción ultravioleta (UV) de la radiación solar que deriva los residuos en otros compuestos sin actividad herbicida. Ramezani (2007) trabajó al inicio del uso de las imidazolinonas en colza en el sur de Australia, zona ubicada en una latitud similar a la de Uruguay, donde la incidencia de la radiación ultravioleta (UV) es alta a muy alta entre noviembre y marzo. En condiciones de campo, la vida media en el agua puede estar afectada por el $\mathrm{pH}$, el contenido de carbono orgánico y la temperatura, siendo la magnitud del efecto específico para cada compuesto. El imazapir aumentó su vida media en el agua en 1,8 días con la presencia de ácidos húmicos en una relación 1:1 (imazapir: ácidos húmicos) comparado con aquella en el agua destilada ( 9,8 días), mientras que el imazetapir necesitó más concentración de ácidos húmicos para alargar significativamente la vida media. Los autores señalan que los ácidos húmicos tienen la capacidad de absorber la radiación ultravioleta actuando como una pantalla solar protegiendo al herbicida considerado (Ramezani et al., 2008). Otros autores reportaron vidas medias en soluciones acuosas (agua destilada) de 1,3 a 2,3 días; 3 a 4,5 horas y 57 horas para el imazapir, imazapic y el imazetapir, respectivamente (Mallipudi et al., 1991; Mangels, 1991; Harir et al., 2007; Espy et al., 2011). La vida media del imazapic en medio acuoso se redujo de 3 h 30 min a 2 h 5 min con un aumento de la temperatura de 30 a $40{ }^{\circ} \mathrm{C}$ (Espy et al., 2011). En general en estos herbicidas la tasa de disipación en el agua no cambia 
con el pH mayor a 5, manteniéndose la vida media específica. Los días más frescos, con menor intensidad de luz por nubes de gran espesor y mayor contenido de carbono orgánico natural en el agua, prolongan la vida media de estos herbicidas (Espy et al., 2011); además, la turbidez del agua opera de manera similar (Ramezani et al., 2008; Avila et al., 2006).

En condiciones de campo en Uruguay, Umpiérrez et al. (2014) monitorearon la evolución de la concentración de residuos de imazapir e imazapic en el agua de riego a partir del primer día después de la inundación (DDI) hasta los $42 \mathrm{DDI}$ en las parcelas tratadas con $110+37 \mathrm{~g}$ a.e. /ha en postemergencia (Tablas 1 y 2). En Río Branco, no se detectó imazapir en el año 2008-2009, persistiendo hasta los 7 DDI en a el año 2009-2010, mientras que se encontró imazapic a los 1 y 35 DDI para el año 2008-2009 y 2009-2010, respectivamente. En la UEPL, se disipó rápidamente el imazapir ya que se detectó únicamente en 1 DDI en el año 2007-2008 mientras que la persistencia del imazapic fue de 42, 28 y 14 DDI para los años 2007-2008, 2008-2009 y 2009-2010, respectivamente. El imazapir se disipó más rápidamente en el agua de inundación sobre el suelo franco limoso de la UEPL que sobre el agua en el suelo franco a franco arenoso de Río Branco. En cambio, el imazapic persistió más, aunque fue más variable, mostrando una persistencia media de $24 \pm 17$ días estando alineados con aquellos de 23,5 \pm 11,2 días obtenidos por Zanella et al. (2011). Estos datos son muy importantes para evitar drenar antes de ese período y reducir el transporte de agua con residuos de las imidazolinonas a las aguas superficiales. El límite de cuantificación del equipamiento ( $L O Q)$ no permitió estimar concentraciones inferiores a 10 $\mu \mathrm{g} / \mathrm{L}$ por lo que no se pudo calcular la vida media. Zanella et al. (2011) encontraron que la vida media del imazapic fue 10,6 \pm 5,1 días y para el imazetapir fue 4,4 \pm 1,9 días en el agua de inundación. Schreiber et al. (2017) determinaron que la vida media del imazapic y del imazapir fueron de 3, 5 y 6 y 11 días para las parcelas regadas por inundación continua y para aquellas regadas con inundación intermitente, respectivamente.

Al comienzo del uso del arroz CL, existía la inquietud entre técnicos y productores sobre qué pasaba si escapes de agua de inundación de una chacra con arroz CL entraban en una chacra sembrada con

Tabla 1. Evolución de la concentración ( $\mu \mathrm{g} / \mathrm{l}, \mathrm{ppb})$ del imazapir e imazapic en el agua de inundación del arroz Clearfield ${ }^{\circledR}$. Río Branco, 2008-2009 y 2009-2010.

\begin{tabular}{|ccccc|}
\hline Año & \multicolumn{2}{c}{$2008-2009$} & \multicolumn{2}{c|}{ 2009-2010 } \\
DDI & imazapir & imazapic & imazapir & imazapic \\
\hline 1 & nd & $<10^{(2 / 3)}$ & $<10$ & nd \\
3 & nd & nd & $<10$ & nd \\
7 & nd & nd & $<10^{(2 / 3)}$ & nd \\
14 & nd & nd & nd & $<10$ \\
21 & nd & nd & nd & $17,5^{(1 / 3)} y<10^{(1 / 3)}$ \\
28 & nd & nd & nd & $<10^{(1 / 3)}$ \\
35 & $*$ & $*$ & nd & $<10^{(1 / 3)}$ \\
42 & $*$ & $*$ & nd & nd \\
\hline
\end{tabular}

DDI=días después de la inundación, * =precipitaciones mayores a $100 \mathrm{~mm} /$ día que provocaron desborde del agua, $n d=$ no detectado, ()$=$ =entre paréntesis número de muestras con la concentración de residuos detectada en tres repeticiones. LOD (Límite de Detección) $=1 \mu \mathrm{g} / \mathrm{l}$. LOQ (Límite de Cuantificación o Concentración) = $10 \mu \mathrm{g} / \mathrm{l}$. 
Tabla 2. Evolución de la concentración $(\mu \mathrm{g} / \mathrm{L}, \mathrm{ppb})$ de los principios activos imazapir e imazapic en el agua de inundación del arroz Clearfield ${ }^{\circledR}$. UEPL, 2007-2008, 2008-2009 y 2009-2010.

\begin{tabular}{|ccccccc|}
\hline Año & \multicolumn{2}{c}{$2007-2008$} & \multicolumn{2}{c}{$2008-2009$} & \multicolumn{2}{c|}{$2009-2010$} \\
DDI & imazapir & imazapic & imazapir & imazapic & imazapir & imazapic \\
\hline 1 & $<10$ & $<10^{(2 / 3)}$ & nd & $<10^{(1 / 3)}$ & nd & 78,5 \\
3 & nd & nd & nd & nd & nd & 56,3 \\
7 & nd & $<10^{(2 / 3)}$ & nd & $<10^{(1 / 3)}$ & nd & $<10^{(1 / 3)}$ \\
14 & nd & nd & nd & nd & nd & $<10^{(1 / 3)}$ \\
21 & nd & nd & nd & nd & nd & nd \\
28 & nd & nd & nd & $<10^{(1 / 3)}$ & nd & nd \\
35 & nd & nd & nd & nd & nd & nd \\
42 & nd & $<10^{(2 / 3)}$ & nd & nd & nd & nd \\
\hline
\end{tabular}

DDI=días después de la inundación, nd=no detectado, () =entre paréntesis número de muestras con la concentración de residuos detectada en tres repeticiones. LOD (Límite de Detección) = $1 \mu \mathrm{g} / \mathrm{l}, \mathrm{LOQ}$ (Límite de Cuantificación o Concentración) = $10 \mu \mathrm{g} / \mathrm{l}$

otra variedad de arroz no CL. De modo que, en cada momento de colecta de agua para la determinación analítica de residuos, se colectó un duplicado para valorar si los residuos presentes afectaban el crecimiento de la plántula de la variedad El Paso 144. Se evaluó por medio de un bioensayo con semillas y no se detectó ningún efecto adverso tanto en el largo de las raíces y su forma, así como en el largo de la parte área de las plántulas (Saldain et al., 2015).

\section{DISIPACIÓN DE LAS IMIDAZOLINONAS EN EL SUELO}

Helling (2005) valoró que la ventaja económica principal del uso de herbicidas residuales es la obtención de un control de malezas más prolongado en el tiempo para un cultivo. Este hecho beneficioso para el agricultor tiene dos contrapesos a considerar: el efecto de los residuos con actividad biológica sobre los cultivos siguientes en la rotación, y el transporte de residuos por el agua de lluvia hacia aguas superficiales o subterráneas (acuíferos). Este último aspecto, sí bien es de interés, especialmente para suelos agrícolas no arroceros ubicados en la zona de recarga de acuíferos locales, no será abordado atento a que escapa al objetivo de esta publicación. Por otro lado, tampoco se incluye el tema de la volatilización ya que se considera despreciable, según Shaner (2014).

Respecto a los mecanismos de disipación como la degradación microbiana y la foto degradación, son muy relevantes para reducir la cantidad de los residuos de herbicidas en el suelo para un contexto del cultivo de arroz y sus rotaciones. Los factores que regulan la adsorción y la desorción de los residuos a los coloides del suelo determinarán la cantidad disponible de residuos en la solución de este para que operen los procesos de disipación. Entre estos factores se encuentran el $\mathrm{pH}$ del suelo, contenido de materia orgánica y humedad del suelo, la temperatura y en sentido amplio la textura, incluyéndose la composición mineral del suelo (Helling, 2005).

Trabajando con ocho suelos diferentes, Wang y Liu (1999) determinaron que el porcentaje de imazapir adsorbido a los coloides del suelo aumenta con la temperatura, sugiriendo que es un fenómeno endotérmico. Constataron, además, que aumentó con el contenido de materia orgánica y con la reducción en el pH del suelo. En cuanto a la desorción del imazapir, encontraron un 
coeficiente de correlación de -0,971 con el contenido de materia orgánica indicando que a menor materia orgánica más cantidad de imazapir será desorbido y estará disponible en la solución del suelo. En suelos arroceros tropicales con pH entre 5,2 a 6,4, Yavari et al. (2020) asociaron la mayor adsorción del imazapic y el imazapir a los mayores contenidos de carbono orgánico y de arcilla, y una fuerte correlación negativa entre los contenidos de carbono orgánico y de arcilla y la cantidad de imazapic e imazapir desorbido, en concordancia con Wang y Liu (1999). Mangels (1991) destacó que el efecto de retención del imazetapir y del imazaquín aumenta con el alto contenido de materia orgánica o arcilla y es solamente significativo en suelos de $\mathrm{pH}$ bajos. En el mismo sentido, Gehrke et al. (2021) lo generalizan para las imidazolinonas y explica que el comportamiento es debido a que la fracción hidrofóbica de los coloides del suelo atraen al herbicida. Su et al. (2019) encontraron que la adsorción del imazapic fue muy significativa en un suelo con altos contenidos de arcilla y limo $(69,1 \%)$. Los autores destacan que tanto la fracción arcilla como la fracción limo tienen mucha superficie de adsorción lo que aumenta su capacidad de retener al imazapic.

Helling (2005) señaló menor disponibilidad de los herbicidas en la solución cuando se reduce el contenido de agua en el suelo. Mangels (1991) sostiene que la alternancia de ciclos de secado y humedecimiento de corta duración aumentó la adsorción del imazapir. La mayor adsorción obtenida por el secado temporal fue atribuido a la reducción de la película de agua que rodea las partículas de suelo, lo cual concentra el herbicida cerca de la superficie de adsorción. Este fenómeno es maximizado cuando el suelo se seca hasta el $25 \%$ del contenido de agua correspondiente a capacidad de campo.

Gehrke et al. (2021) agruparon la vida media de las imidazolinonas según hubiesen sido determinadas en suelos esterilizados o en suelos sin esterilización, siendo mucho más corta en los últimos, destacán- dose la relevancia de la degradación aeróbica debido a los microorganismos naturales del suelo como mecanismo de disipación.

Wang et al. (2006) estudiaron la degradación microbiana aeróbica y anaeróbica del imazapir en cuatro suelos bajo condiciones de oscuridad por 60 días. La degradación aeróbica por los microorganismos nativos ocurrió a una tasa constante para cada suelo durante el período considerado, habiéndose reducido la concentración del herbicida en $82 \%$ para un suelo de $\mathrm{pH} 5,3$, y de $59 \%$ para un suelo de $\mathrm{pH} 8,8$, siendo la vida media de 26 y 44 días, respectivamente. Los autores explican que la hidrólisis y la adsorción del imazapir es aumentada en suelos con pH bajos y podría explicar la disipación más completa observada en el suelo de $\mathrm{pH}$ menor. En cuanto a la degradación anaeróbica del imazapir observada se ajustó a un modelo de dos fases. Una fase rápida que mostraba una vida media de 10 días para el suelo de $\mathrm{pH} 5,3$ y 4 días para el suelo de $\mathrm{pH} 8,8$, mientras que la segunda fase era de disipación muy lenta. Los autores destacan que en promedio la degradación ocurrió seis veces más rápido en la fase inicial debido a la actividad de los microorganismos nativos en un ambiente anaeróbico y que solo detectaron un efecto leve del $\mathrm{pH}$ del suelo en la disipación. Sin embargo, Gehrke et al. (2021) señalan que existe un déficit de información sobre la persistencia y degradación anaeróbica de las imidazolinonas en las condiciones de un suelo bajo la producción de arroz, con inundación de forma permanente por 100 días. Como regla general se asume que en un ambiente anaeróbico la tasa de degradación de los herbicidas es más lenta, con algunas excepciones (Helling, 2005). En condiciones de campo, Junkes et al. (2019) determinaron que la vida media del imazapir fue de 182 días cuando se manejó la inundación continua y de 42 días cuando se usó la inundación intermitente en el cultivo de arroz. Para el imazapic no se estimó la vida media por falta de un ajuste del modelo en la inundación continua y fue de 96 días en la inundación intermitente. Además, observaron que la concentración de los residuos para ambos herbicidas a los 
184 DDA quedaron por debajo del límite de detección en las parcelas con inundación intermitente.

Su et al. (2019) concluyeron que el imazapic se degrada principalmente por la acción de microorganismos aeróbicos nativos del suelo. Al aumentar la temperatura aumenta la población de microorganismos y su actividad acelerando la degradación. Esto se ve reflejado en la vida media del imazapic que pasó de 99 a 139 y 193 días cuando fue expuesto a 35,25 y $15^{\circ} \mathrm{C}$, respectivamente. Con la humedad del suelo, se detectó un comportamiento similar. Cuando el suelo tiene poca humedad en torno al $15 \%$, la vida media del imazapic fue de 231 días mientras que, con $90 \%$ de humedad la vida media se redujo a 96 días. Cuando se acoplan la temperatura y humedad adecuada, la degradación ocurre muy rápido siempre que haya oxígeno disponible. Este comportamiento también fue observado para imazaquín e imazetapir, con el agregado que por encima del $75 \%$ de la capacidad de campo tendía a disminuir la producción de ${ }^{14} \mathrm{CO}_{2}$ significando menor degradación aeróbica, especialmente en el imazetapir (Flint y Witt, 1997). Esta situación se puede presentar cuando se hace una aplicación preemergente y ocurren precipitaciones superiores a $30 \mathrm{~mm}$ o hay que bañar porque el suelo está seco. Ahí el herbicida se activa por la humedad y degrada rápidamente por la combinación con la temperatura elevada, reduciéndose la dosis en el suelo; por ende, el control de malezas es menor debido a la acción residual reducida del herbicida.

En los suelos estudiados, Su et al. (2019) encontraron que la tasa de degradación microbiana aeróbica del imazapic fue mayor en el suelo con $\mathrm{pH}$ de 8 que a pH de $7 \mathrm{y}$ luego a pH 6. La vida media siguió el orden inverso con 139 días a $\mathrm{pH}$ de 8, 147 días a $\mathrm{pH} 7$ y de 154 días a $\mathrm{pH} 6$. El contenido de materia orgánica condicionó la tasa de degradación microbiana. Cuando estuvo entre valores de 0,55 a $1,0 \%$, la vida media se ubicó en el rango de 139-128 días, mientras que cuando el contenido de la materia orgánica se situó en el rango de 2,5 a 4,0\%, las correspondientes vidas medias fueron de 158 y 165 días, siendo mayores, lo que según los autores indicaba una menor tasa de degradación microbiana. Contrariamente, Gehrke et al. (2021) señalaron que no detectaron una relación específica entre la degradación microbiana aeróbica y el contenido de materia orgánica, ya que si bien esta favorece mayor actividad microbiana también favorece una mayor adsorción.

Aichele y Penner (2005) realizaron estudios de adsorción y desorción en situaciones controladas en el tiempo, de los herbicidas imazamox, imazetapir e imazaquin. Detectaron que el porcentaje de herbicida marcado con carbono radioactivo ${ }^{14} \mathrm{C}$ encontrado en la solución del suelo fue en orden decreciente imazamox > imazetapir > imazaquín, siendo más elevada a $\mathrm{pH} 7$ que a $\mathrm{pH} 5$ para todos los herbicidas. En el caso particular del imazetapir una proporción más alta del herbicida retirado de los coloides (desorbido) fue obtenida a $\mathrm{pH} 7$ que a $\mathrm{pH} 5$, confirmándose información previa que establecía que a $\mathrm{pH}$ menores que 6 , aumentaba la adsorción del imazetapir y del imazaquín.

El otro mecanismo de disipación de interés es la degradación abiótica debida a la radiación ultravioleta (UV) que ocurre en el suelo. Ramezani et al. (2008) evaluó la foto-degradación de las imidazolinonas en la superficie del suelo y constataron que ocurrió solamente en presencia de luz, siendo estos herbicidas estables en la oscuridad. Como estos herbicidas son estables a la hidrólisis, los autores adjudican a la foto-degradación el principal mecanismo de disipación de los herbicidas en esta situación. La tasa de degradación en la superficie del suelo fue más lenta que en el agua, presentando vidas medias mayores (Tabla 3). Las diferencias en la tasa de foto degradación en la superficie del suelo puede deberse a las diferencias en solubilidad en agua entre las tres imidazolinonas estudiadas. Dicha solubilidad es mayor para el imazapir > imazetapir > imazquín y a mayor solubilidad en agua, mayor es la penetración en el suelo quedando fuera del alcance de la radiación solar. Existe evidencia de que la radiación solar alcanza una profundidad entre 0,2 y 
Tabla 3. Cinética de la foto degradación del imazapir, imazetapir e imazaquín tanto en agua como en la superficie del suelo $(n=3)$.

\begin{tabular}{|lcccc|}
\hline Herbicida & \multicolumn{2}{c}{ En agua deionizada } & \multicolumn{2}{c|}{ En superficie del suelo } \\
& $\begin{array}{c}\boldsymbol{k} \\
\text { (/días) }\end{array}$ & $\begin{array}{c}\boldsymbol{t}_{1 / 2} \\
\text { (días) }\end{array}$ & $\begin{array}{c}\boldsymbol{k} \\
\text { (/días) }\end{array}$ & $\begin{array}{c}\boldsymbol{t}_{1 / 2} \\
\text { (días) }\end{array}$ \\
\hline Imazapir & 0,075 & 9,1 & 0,022 & 30,9 \\
Imazetapir & 0,07 & 9,8 & 0,028 & 24,6 \\
Imazaquín & 0,369 & 1,8 & 0,045 & 15,3 \\
\hline
\end{tabular}

$k=$ tasa de foto degradación $\mathrm{y}_{1 / 2}=$ vida media obtenidas del modelo de reacción de primer orden ajustado por Ramezani et al. (2008).

$0,3 \mathrm{~mm}$ pudiendo llegar a más de $0,7 \mathrm{~mm}$ en un suelo secado al aire.

Este mecanismo de disipación actúa en el suelo cuando en las aplicaciones en preemergencia en el arroz CL el suelo esté seco y se demora en realizar un baño por una semana o 10 días. Si el suelo está seco y bañar es impostergable para que germine el arroz, se recomienda realizar la aplicación en preemergencia después del baño cuando el agua se resuma. Con humedad en el suelo y debido a la solubilidad alta del imazapir y la buena solubilidad del imazapic, quedarán bajo la superficie del suelo, no operando este mecanismo de disipación.

\section{EFECTO DE LAS IMIDAZOLINONAS EN LOS CULTIVOS SIGUIENTES}

\section{Susceptibilidad de las especies forrajeras a los residuos remanentes del imazapir + imazapic}

La siembra de raigrás solo o una gramínea (raigrás o festuca) en mezcla con trébol blanco y lotus sobre el rastrojo de arroz, implica romper las taipas anticipadamente y drenar la chacra para luego distribuir las semillas. De acuerdo con las últimas encuestas arroceras correspondientes al período 2015-2019 (DIEA), la siembra de pasturas sobre el rastrojo de arroz ha estado en el orden de las $53 \mathrm{mil}$ ha, lo que representa un $58 \%$ del arroz de salida de cada año, entendido como aquel rastrojo que no retorna inmediatamente a la producción de arroz.

Cuando se evalúa la susceptibilidad de los cultivos siguientes a los residuos de los herbicidas hay que tener en cuenta varios factores, entre ellos el tipo de suelo (Tabla 4) y cómo interactúan la fecha de siembra, la especie forrajera y el nivel de residuos remanente generado a través de las dosis aplicadas en postemergencia (Tabla 5, Saldain et al., sin publicar). En un planosol arenoso de Río Branco (RB), el raigrás sembrado una semana después de la cosecha (SDC) correspondiente a los 130 DDA, redujo la productividad ante la presencia creciente de residuos frente al testigo sin aplicación de imidazolinonas, mientras que no se detectó ninguna diferencia en la siembra a las 5 SDC (165 DDA). Los residuos remanentes debido a la dosis más

Tabla 4. Características del suelo utilizado en Río Branco y en la UEPL para la evaluación de la susceptibilidad de las distintas especies a los residuos de imazapir + imazapic en el suelo.

\begin{tabular}{|lccccccc|}
\hline Sitio & $\begin{array}{c}\text { Año } \\
\text { siembra CL }\end{array}$ & $\begin{array}{c}\text { Profundidad } \\
\text { muestra }\end{array}$ & pH & C.org. \% & Arena $\%$ & Limo \% & Arcilla \% \\
\hline Río Branco & $2008-2009$ & $0-10 \mathrm{~cm}$ & 5,4 & 1 & 70 & 9 & 21 \\
UEPL & $2005-2006$ & $0-10 \mathrm{~cm}$ & 5,3 & 1,3 & 36 & 51 & 13 \\
\hline
\end{tabular}

Análisis de suelos realizados en el Laboratorio de Suelos, Plantas y Agua de INIA La Estanzuela. \%M.O.=\%C.org. x 1,72. 
Tabla 5. Materia seca producida a los 180 días después de la siembra (DDS) sobre el rastrojo de arroz Clearfield por especies forrajeras seleccionadas en un suelo de Río Branco, 2008-2009.

\begin{tabular}{|c|c|c|c|c|}
\hline \multirow{2}{*}{$\begin{array}{l}\text { Especie forrajera: } \\
\text { Dosis de } \\
\text { imazapir + imazapic } \\
\text { g a.e./ha }\end{array}$} & \multicolumn{2}{|c|}{$\begin{array}{l}\text { Raigrás cv INIA Cetus } \\
\text { Fecha de siembra }\end{array}$} & \multicolumn{2}{|c|}{$\begin{array}{l}\text { Lotus cv San Gabriel } \\
\text { Fecha de siembra }\end{array}$} \\
\hline & $\begin{array}{l}1 \mathrm{SDC} \\
\mathrm{kg} / \mathrm{ha}\end{array}$ & $\begin{array}{l}5 \text { SDC } \\
\text { kg/ha }\end{array}$ & $\begin{array}{l}1 \text { SDC } \\
\mathrm{kg} / \mathrm{ha}\end{array}$ & $\begin{array}{l}5 \text { SDC } \\
\mathrm{kg} / \mathrm{ha}\end{array}$ \\
\hline 0 & $3046 a$ & $2239 a$ & $507 a$ & $2133 a$ \\
\hline $110+37$ & $2069 b$ & $1766 a$ & $324 a$ & $1949 a$ \\
\hline $220+74$ & $1677 \mathrm{~b}$ & 1971 a & $242 a$ & $1135 a$ \\
\hline
\end{tabular}

Las medias seguidas por la misma letra dentro de cada columna no difieren significativamente entre sí según la prueba de la Mínima Diferencia Significativa al $5 \%, \mathrm{SDC}=$ semana(s) después de la cosecha. Tomado de Saldain et al (sin publicar).

baja del herbicida empleada permitieron que el raigrás sembrado 1 SDC produjera una cantidad de forraje similar a aquel sembrado a las 5 SDC. Se destaca que no existieron diferencias causadas por los residuos en la población inicial de plantas de raigrás ni en el peso seco de las mismas a los 90 DDS (datos no mostrados).

Pinto et al. (2009b) señalaron que en la sucesión con arroz CL el raigrás debe ser sembrado después de los 180 DDA para evitar efectos adversos, sin embargo, no presentó datos que avalen esa conclusión. En cambio, en el lotus si bien es superior la productividad cuando se siembra 5 SDC comparado con 1 SDC (Tabla 5), no disminuyó significativamente la productividad por efecto de la persistencia de los residuos de imazapir + imazapic en el suelo en ninguna fecha de siembra. Por otro lado, en un suelo brunosol franco de la UEPL, donde se usó un rango de fecha de siembra más estrecho entre 1 SDC (145 DDA) y 3 SDC (160 DDA), los mismos tratamientos herbicidas no afectaron ninguna de las variables estudiadas (datos no mostrados), indicando que los residuos remanentes de los herbicidas fueron más bajos que en el suelo arenoso de RB.

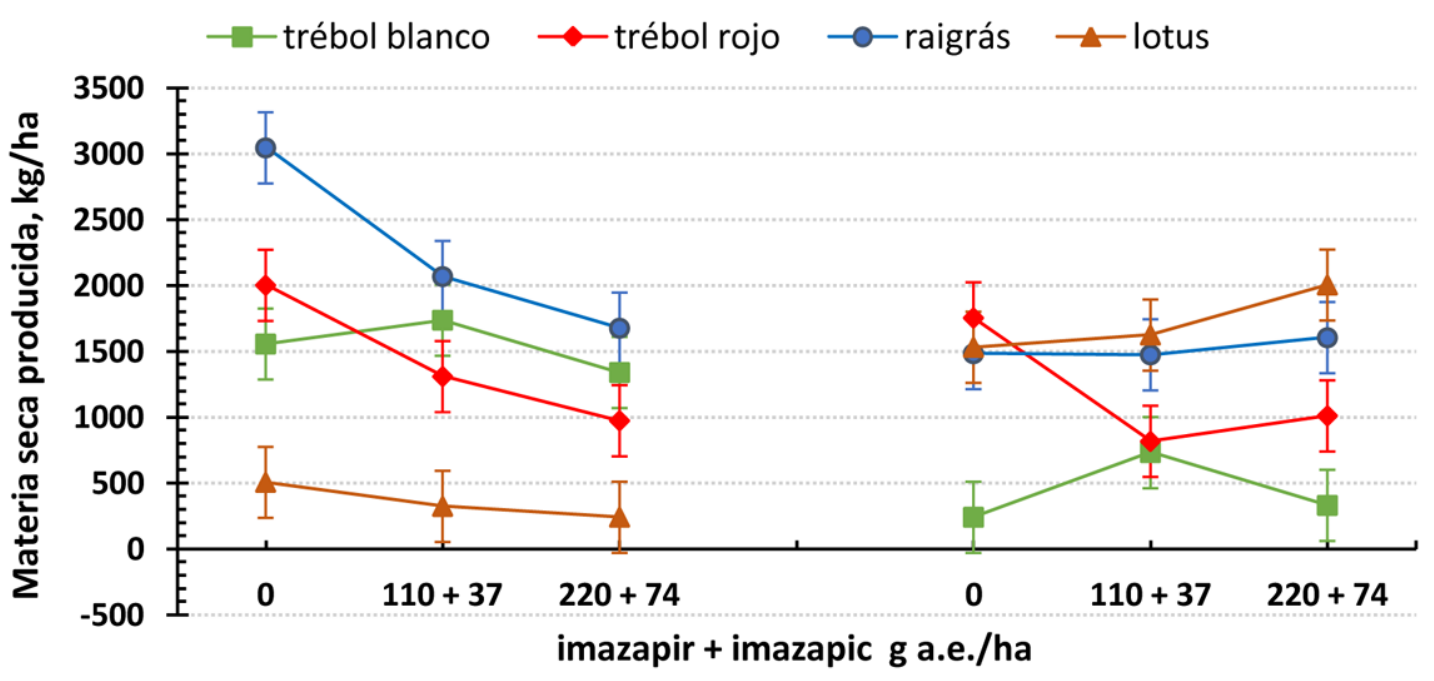

Figura 7. Materia seca producida $(\mathrm{kg} / \mathrm{ha})$ por cada especie forrajera a los 180 días después de la siembra sobre el rastrojo del arroz Clearfield con dosis crecientes de imazapir + imazapic en postemergencia aplicadas en el cultivo. Izq. Río Branco, 2008-2009, Der. Unidad Experimental Paso de La Laguna (UEPL), 2005-2006. 
En el mismo suelo de RB, se evaluaron raigrás, trébol blanco, trébol rojo y lotus sembrados puros a la 1 SDC (130 DDA), mientras que en el suelo de la UEPL se estudiaron las mismas especies sembradas a 1 SDC (145 DDA). Saldain et al. (2012) observaron que las especies forrajeras evaluadas se implantaron bien y el crecimiento inicial a los 90 DDS transcurrió sin ser afectado por los residuos de los herbicidas (datos no mostrados). Sin embargo, la materia seca producida de forraje a los 180 DDS se redujo para el raigrás y el trébol rojo en el suelo de RB, pero no en el de UEPL (Figura 7). El trébol blanco, así como el lotus no fueron afectados en ninguno de los dos sitios. Aunque no se cuantificaron los residuos de imazapir + imazapic en los suelos, una misma dosis de herbicida en combinación con las condiciones ambientales después de la cosecha del arroz y las características del suelo generó aparentemente distintas cantidades de residuos disponibles para interferir con las especies sembradas.

A la dosis de etiqueta o mayores del imazetapir + imazapic, Pinto et al. (2009b) determinaron reducciones en la altura de la planta y la productividad del forraje producido por el raigrás. Los autores determinaron en un suelo planosol de Capao do Leao (RS) reducciones de la productividad de forraje del raigrás del orden de los 1788,2456 y 3754 kg/ha con respecto al testigo sembrado después de uno, dos y tres años seguidos de arroz CL. Además, mencionan que en los planosoles francos de la Planicie Costera Externa, RS, los residuos del imazetapir + imazapic persisten en años con precipi- taciones bajas en el invierno y primavera, pudiéndose acumular si se hace un uso repetido del arroz CL. Santos et al. (2014) confirmaron que la aplicación de imazetapir + imazapic o imazapir + imazapic con dosis de etiqueta o mayores afectaron la altura y productividad del raigrás siendo la última mezcla más persistente y fuerte el efecto en la forrajera.

\section{Efecto de los residuos del imazapir + imazapic sobre la productividad inicial de la pastura}

La rotación del arroz con pasturas sembradas compuesta de varias especies es una práctica común en el país, realizándose en alrededor de un $58 \%$ del rastrojo de arroz que se deja de cultivar. Saldain et al. (2014b) estudiaron cómo afectaban la productividad inicial de la pastura sembrada los distintos tratamientos de imazapir + imazapic y el manejo del riego en el arroz $C L$, sobre un suelo solod de la UEPL (Tabla 6). La pastura sembrada fue la mezcla estándar usada de raigrás, trébol blanco y lotus.

Se detectó una interacción significativa entre el año de siembra del arroz y los tratamientos de herbicida en la producción de forraje de la mezcla de especies a los 180 DDS. Se destaca el hecho de que $147+49$ g a.e./ha de imazapir + imazapic redujo significativamente la productividad de forraje frente al testigo sin aplicación en el año 2005-2006 y frente al tratamiento recomendado donde se aplica la mitad de la dosis en preemergencia y la otra mitad en postemergencia. Este hecho no ocurrió en el año 2008-2009 y

Tabla 6. Características fisicoquímicas y textura del solod melánico en los distintos sitios de la Unidad Experimental Paso de La Laguna (UEPL).

\begin{tabular}{|ccccccc|}
\hline Año & \multicolumn{5}{c}{ Características del suelo } & Clase \\
siembra CL & pH & C.org. \% & Arena \% & Limo \% & Arcilla \% & textural \\
\hline $2005-2006$ & 5,6 & 1,06 & 36 & 51 & 13 & limo arenoso \\
$2006-2007$ & 6,4 & 0,91 & 26 & 45 & 29 & franca \\
$2008-2009$ & 5,4 & 1,88 & 28 & 45 & 27 & franca \\
\hline
\end{tabular}

Análisis de suelos realizados en el Laboratorio de Suelos, Plantas y Agua de INIA La Estanzuela. \%M.O.=\%C.org. x 1,72. 
Tabla 7. Materia seca producida por la pradera a los 180 días después de la siembra debido a la interacción año por tratamiento herbicida en la Unidad Experimental Paso de La Laguna (UEPL).

\begin{tabular}{|c|c|c|c|c|c|c|}
\hline \multirow{2}{*}{$\begin{array}{c}\text { Año } \\
\text { siembra CL }\end{array}$} & \multicolumn{6}{|c|}{ Dosis de imazapir + imazapic, g a.e./ha } \\
\hline & $\begin{array}{c}0 \\
\mathrm{~kg} / \mathrm{ha}\end{array}$ & & $\begin{array}{l}73,5+24,5^{*} \\
\mathrm{~kg} / \mathrm{ha}\end{array}$ & $\begin{array}{c}110+37 \\
\mathrm{~kg} / \mathrm{ha}\end{array}$ & $\begin{array}{l}147+49 \\
\mathrm{~kg} / \mathrm{ha}\end{array}$ & $\begin{array}{c}73,5+24,5 / 73,5+24,5^{* \star} \\
\mathrm{kg} / \mathrm{ha}\end{array}$ \\
\hline $2005-2006$ & 3073 a & & $2725 b$ & $2838 a$ & 2769 b & $2819 a$ \\
\hline 2006-2007 & 974 & c & 1094 bc & 1467 a & $1311 a b$ & 1022 bc \\
\hline 2008-2009 & 2958 a & & $2860 \mathrm{a}$ & $2762 \mathrm{a}$ & $2722 \mathrm{a}$ & 2995 a \\
\hline
\end{tabular}

${ }^{*}=$ tratamientos aplicados en postemergencia temprana, ${ }^{* *}=$ tratamientos aplicados en preemergencia seguida de aplicación en postemergencia temprana. Las medias seguidas por la misma letra no difieren significativamente según la prueba de la Mínima Diferencia Significativa (MDS) al 5\% dentro de la misma fila (año).

Tabla 8. Materia seca producida por las malezas a los 180 días después de la siembra debido a la interacción año por tratamiento herbicida en la Unidad Experimental Paso de La Laguna (UEPL).

\begin{tabular}{|c|c|c|c|c|c|}
\hline \multirow{2}{*}{$\begin{array}{c}\text { Año } \\
\text { siembra CL }\end{array}$} & \multicolumn{5}{|c|}{ Dosis de imazapir + imazapic, g a.e./ha } \\
\hline & $\begin{array}{c}0 \\
\mathrm{~kg} / \mathrm{ha}\end{array}$ & $\begin{array}{l}73,5+24,5^{*} \\
\mathrm{~kg} / \mathrm{ha}\end{array}$ & $\begin{array}{c}110+37 \\
\mathrm{~kg} / \mathrm{ha}\end{array}$ & $\begin{array}{c}147+49 \\
\mathrm{~kg} / \mathrm{ha}\end{array}$ & $\begin{array}{c}73,5+24,5 / 73,5+24,5^{* *} \\
\mathrm{~kg} / \mathrm{ha}\end{array}$ \\
\hline $2005-2006$ & $424 a$ & $425 a$ & $350 \mathrm{~b}$ & $340 \mathrm{~b}$ & $330 \mathrm{~b}$ \\
\hline $2006-2007$ & $77 a$ & $66 a$ & $48 a$ & $105 a$ & $47 a$ \\
\hline 2008-2009 & $2 \mathrm{a}$ & $0 \mathrm{a}$ & $31 \mathrm{a}$ & 5 a & $9 a$ \\
\hline
\end{tabular}

${ }^{*}=$ tratamientos aplicados en postemergencia temprana, ${ }^{* *}=$ tratamientos aplicados en preemergencia seguida de aplicación en postemergencia temprana. Las medias seguidas por la misma letra no difieren significativamente según la prueba de la Mínima Diferencia Significativa (MDS) al 5\% dentro de la misma fila (año).

tampoco en el 2006-2007 (Tabla 7). En el año 2005-2006, se aprecia un efecto de control de las malezas en las parcelas tratadas a partir de la dosis de $110+37 \mathrm{~g}$ a.e./ha o mayor, y contrariamente, la presencia de malezas fue muy escasa en el año 2008-2009 (Tabla 8). Además, se comprobó que aplicar la dosis de $147+49 \mathrm{~g}$ a.e./ha en postemergencia temprana o dividirla en preemergencia y postemergencia temprana, redujo significativamente la producción de materia seca de las malezas, siendo menor que en testigo en el año 2005-2006 y que no se repite en los otros años. El año 20062007, la producción de forraje fue mucho menor que en los otros años debido a ausencia de precipitaciones en la primavera y las diferencias observadas no se asociaron al crecimiento de las malezas presentes en las parcelas.

Otra interacción significativa encontrada para la producción de forraje en la mezcla de especies sembradas fue entre años de siembra del arroz CL y el manejo del riego. Sin embargo, esta interacción no fue relevante para la presencia de malezas (datos no mostrados). En los manejos del riego que incluyeron inundación a los 3 y 7 días después de la aplicación (DDA) o baños semanales antes de la inundación a los 21 DDA, se redujo significativamente la productividad de la pastura comparada con la inundación a los 21 DDA sin baños semanales en el año 2005-2006, sin embargo, este hecho no se presentó en los otros años evaluados (Tabla 9). Ese año fue el que llovió menos antes de la inundación a los $21 \mathrm{DDA}, 23,5 \mathrm{~mm} /$ día a los 6 DDA, mientras los otros años presentaron precipitaciones de $50 \mathrm{~mm} /$ día a los 2 DDA y $43 \mathrm{~mm} /$ día a los 8 DDA para los años 2006-2007 y 2008-2009, respectivamente. En el 2005-2006, los tratamientos con inundación temprana y el hecho de bañar cada semana antes de la inundación a los 21 
Tabla 9. Materia seca producida por la pradera a los 180 días después de la siembra debido a la interacción año por manejo del riego en la Unidad Experimental Paso de La Laguna (UEPL).

\begin{tabular}{|clccc|}
\hline Manejo del riego & \multicolumn{4}{c|}{ Inundación, días después de la aplicación (DDA) } \\
Año siembra CL & $\begin{array}{c}\text { 3 DDA } \\
\text { kg/ha }\end{array}$ & $\begin{array}{c}\text { 7 DDA } \\
\text { kg/ha }\end{array}$ & $\begin{array}{c}\text { 21 DDA c/baños* } \\
\text { kg/ha }\end{array}$ & $\begin{array}{c}\text { 21 DDA s/baños** } \\
\text { kg/ha }\end{array}$ \\
\hline $2005-2006$ & $2517 \mathrm{~b}$ & $2287 \mathrm{~b}$ & $2871 \mathrm{~b}$ & $3652 \mathrm{a}$ \\
$2006-2007$ & $1215 \mathrm{a}$ & $1134 \mathrm{a}$ & $1202 \mathrm{a}$ & $1144 \mathrm{a}$ \\
$2008-2009$ & $2870 \mathrm{a}$ & $2983 \mathrm{a}$ & $2958 \mathrm{a}$ & $2625 \mathrm{a}$ \\
\hline
\end{tabular}

${ }^{*}=$ con baños semanales previo a la inundación, ${ }^{* *}=\sin$ baños semanales previo a la inundación. Las medias seguidas por la misma letra no difieren significativamente según la prueba de la Mínima Diferencia Significativa (MDS) al $5 \%$ dentro de la misma fila (año).

DDA contribuyó a preservar el herbicida en el suelo retardando la disipación, quedando un remanente de residuos en suelo para afectar al raigrás, la especie más susceptible de las utilizadas. A los 21 DDA sin baños semanales, si bien no se determinó que mecanismos de disipación operaron, probablemente, la foto degradación en la superficie del suelo y la degradación microbiana contribuyeron a que existieran menos residuos remanentes.

En el arroz CL del año 2008-2009 en un suelo de RB (Tabla 4), se instalaron parcelas con la mezcla forrajera comentada con anterioridad, a 1 y 5 SDC. La producción de forraje a los 180 DDS para el tratamiento de $110+37 \mathrm{~g}$ a.e./ha de imazapir + imazapic no fue significativamente menor a la del testigo sin aplicación de imidazolinonas, en cambio, la dosis doble evaluada redujo la productividad (Tabla 10).

Este hecho mostró que la siembra de una especie susceptible como el raigrás en mezcla con dos especies tolerantes a los residuos del imazapir + imazapic como el trébol blanco y el lotus, favorece a la productividad de la mezcla cuando está presente un nivel intermedio de residuos en el suelo. Con un nivel más alto, la producción inicial de forraje se reduce alrededor de un $20 \%$. Souto et al. (2013) destacaron que el suelo con vegetación respira más que el suelo sin vegetación y que el suelo de la rizosfera proveniente de leguminosas presentó más actividad respiratoria que aquel del raigrás y el arroz CL. La combinación de trébol blanco + lotus y la soja, entre otras especies evaluadas, estimularon la tasa de degradación de la población microbiana nativa metabolizando en promedio un 91, 92 y 93\% del imazetapir, imazapic e imazapir agregado al suelo de rizosfera bajo condiciones ideales de temperatura y humedad, respectivamente. También, cuando se duplicó la dosis de etiqueta del imazetapir y el imazapic en el suelo de la rizosfera del

Tabla 10. Materia seca producida por las especies a los 180 días después de la siembra (DDS) promedio de siembra a 1 y 5 SDC de la pradera con dosis de imazapir + imazapic. Río Branco, 2008-2009.

\begin{tabular}{|cc|}
\hline $\begin{array}{c}\text { Dosis de } \\
\text { imazap }+ \text { imazapic } \\
\text { g a.e./ha }\end{array}$ & $\begin{array}{c}\text { Materia seca producida } \\
\text { a los } 180 \text { DDS } \\
\text { kg/ha }\end{array}$ \\
\hline 0 & 1878 a \\
$110+37$ & 1879 a \\
$220+74$ & 1498 b \\
\hline
\end{tabular}

SDC=semanas después de la cosecha. Las medias seguidas por la misma letra no difieren significativamente según la prueba de la Mínima Diferencia Significativa (MDS) al $5 \%$ dentro. 
raigrás, trébol blanco + lotus y de la soja aumentaron la tasa de respiración. Sin embargo, para el imazapir al duplicar la dosis, la respiración del suelo de rizosfera disminuyó para las especies mencionadas. Ese hecho indica que el imazapir fue más tóxico para las poblaciones microbianas nativas que las otras imidazolinonas evaluadas.

\section{Efecto de los residuos del imazapir + imazapic en la secuencia arroz $C L$, raigrás, arroz no $C L$ y/o sorgo forrajero bajo siembra directa}

Saldain et al. (2014c) condujeron esta secuencia de cultivos en un suelo planosol de RB y en un solod de la UEPL en años consecutivos con ensayos independientes (Tabla 11).

En RB, se observa la existencia de residuos remanentes con actividad biológica a los 120 y 180 DDA tanto en el horizonte superficial como en el subsuperficial (Figuras $5 \mathrm{~A}$ y $6 \mathrm{~A}$ ). En este sitio la siembra del raigrás fue realizada a los 140 DDA lo que indica que el raigrás creció absorbiendo residuos disponibles en la solución del suelo. Sin embargo, en la UEPL se detectaron solamente residuos con actividad biológica a los 180 DDA en el horizonte superficial pero no en el subsuperficial (Figuras $5 \mathrm{C}$ y $6 C)$. El raigrás fue sembrado a los 149 DDA lo que indica que absorbió los residuos disponibles provocando la respuesta obtenida.

Tabla 11. Características de los suelos usados para los estudios de secuencia de cultivos.

\begin{tabular}{|ccccccc|}
\hline $\begin{array}{c}\text { Sitio } \\
\text { Año siembra CL }\end{array}$ & $\begin{array}{c}\text { Profundidad } \\
\text { muestra }\end{array}$ & pH & C.org. \% & Arena \% & Limo \% & Arcilla \% \\
\hline Río Branco & & & & & \\
$2008-2009$ & $0-10 \mathrm{~cm}$ & $5,6 \pm 0,1$ & $1,2 \pm 0,1$ & $47 \pm 1$ & $32 \pm 2$ & $21 \pm 2$ \\
& $10-20 \mathrm{~cm}$ & $5,9 \pm 0,1$ & $0,7 \pm 0,1$ & $50 \pm 4$ & $29 \pm 1$ & $21 \pm 3$ \\
$2009-2010$ & $0-10 \mathrm{~cm}$ & $5,4 \pm 0,1$ & $0,8 \pm 0,2$ & $49 \pm 3$ & $34 \pm 1$ & $17 \pm 3$ \\
& $10-20 \mathrm{~cm}$ & $5,8 \pm 0,2$ & $0,6 \pm 0,1$ & $49 \pm 4$ & $33 \pm 2$ & $19 \pm 4$ \\
\hline UEPL & & & & & & \\
$2008-2009$ & $0-10 \mathrm{~cm}$ & $5,4 \pm 0,1$ & $1,8 \pm 0,1$ & $30 \pm 2$ & $46 \pm 3$ & $24 \pm 1$ \\
& $10-20 \mathrm{~cm}$ & $6,1 \pm 0,1$ & $1,1 \pm 0,1$ & $29 \pm 3$ & $43 \pm 3$ & $27 \pm 1$ \\
$2009-2010$ & $0-10 \mathrm{~cm}$ & $5,2 \pm 0,1$ & $1,0 \pm 0,2$ & $27 \pm 1$ & $46 \pm 2$ & $26 \pm 1$ \\
& $10-20 \mathrm{~cm}$ & $5,6 \pm 0,2$ & $1,3 \pm 0.3$ & $27 \pm 1$ & $45 \pm 1$ & $28 \pm 1$ \\
\hline
\end{tabular}

Análisis de suelos realizados en el Laboratorio de Suelos, Plantas y Agua de INIA La Estanzuela. \%M.O.=\%C.org. x 1,72.

Tabla 12. Resultados promedios obtenidos para densidad y crecimiento inicial de las plantas a los 90 días después de la siembra (DDS) y altura de la planta al corte del raigrás cv. LE 284 respecto a las dosis de imazapir + imazapic en ambos sitios evaluados.

\begin{tabular}{|c|c|c|c|c|c|c|}
\hline \multirow{3}{*}{$\begin{array}{c}\text { Imazapir + } \\
\text { imazapic } \\
\text { g a.e./ha } \\
0\end{array}$} & \multicolumn{2}{|c|}{ Población } & \multicolumn{2}{|c|}{ Tamaño planta (peso seco) } & \multicolumn{2}{|c|}{ Altura planta al corte } \\
\hline & $\begin{array}{r}\text { UEPL' } \\
\text { pla }\end{array}$ & $\begin{array}{l}\text { Río Branco } \\
\text { tas } / \mathrm{m}^{2}\end{array}$ & \multicolumn{2}{|c|}{$\mathrm{g} / 10$ plantas } & cm/planta & $\begin{array}{l}\text { Río Branco } \\
\text { nta }\end{array}$ \\
\hline & 401 & 466 & 2,3 & 2,1 & 73 & $82 \mathrm{a}$ \\
\hline $110+37$ & 349 & 475 & 2,8 & 1,4 & 71 & $75 \mathrm{~b}$ \\
\hline $220+74$ & 394 & 497 & 2,8 & 1,8 & 70 & $73 \mathrm{~b}$ \\
\hline
\end{tabular}

${ }^{1}=$ Medias de tres ensayos independientes conducidos en la Unidad Experimental Paso de La Laguna.

2=Medias de dos ensayos independientes conducidos en el año 2008-2009, no se evaluó el ensayo del 2009-2010. Las medias seguidas por la misma letra no difieren significativamente según la prueba de la Mínima Diferencia Significativa (MDS) al $5 \%$ dentro de la misma columna.. 
Tabla 13. Productividad del raigrás cv. LE 284 a los 180 después de la siembra debido a la interacción entre las dosis de imazapir + imazapic y el año de siembra arroz CL/sitio.

\begin{tabular}{|c|c|c|c|c|}
\hline \multirow{2}{*}{$\begin{array}{c}\text { Imazapir + } \\
\text { imazapic } \\
\text { g a.e./ha }\end{array}$} & \multicolumn{3}{|c|}{ Unidad Experimental Paso de La Laguna (UEPL) } & Río Branco \\
\hline & $\begin{array}{c}2007-2008 \\
\mathrm{~kg} / \mathrm{ha}\end{array}$ & $\begin{array}{c}2008-2009 \\
\mathrm{~kg} / \mathrm{ha}\end{array}$ & $\begin{array}{c}2009-2010 \\
\mathrm{~kg} / \mathrm{ha}\end{array}$ & $\begin{array}{c}2008-2009^{1} \\
\mathrm{~kg} / \mathrm{ha}\end{array}$ \\
\hline 0 & $1043 a$ & $3281 a$ & $1866 \mathrm{a}$ & 3797 a \\
\hline $110+37$ & $921 \mathrm{a}$ & $2571 b$ & $2146 a$ & $2932 b$ \\
\hline $220+74$ & 1085 a & $2692 b$ & 2248 a & $2918 b$ \\
\hline
\end{tabular}

${ }^{1}=$ Medias corresponden a dos ensayos independientes y contiguos en 2008-2009. Las medias seguidas por la misma letra no difieren significativamente según la prueba de la Mínima Diferencia Significativa (MDS) al 5\% dentro de la misma columna.

Esta respuesta contrastó con la ausencia de reducción de la producción de forraje en el raigrás sembrado a los 131 DDA en el año 2009-2010, donde no se detectaron residuos remanentes con actividad biológica (Figuras 5D y 6D). Esto indicaría que probablemente existieron condiciones de menores precipitaciones y temperaturas más bajas durante el crecimiento del raigrás que favorecieron la persistencia de los re- siduos del herbicida en ambos sitios en el año 2008-2009.

Dos meses antes de la siembra del arroz no CL y del sorgo forrajero se finalizó el raigrás, sembrándose directamente en el rastrojo muerto y seco. No se detectaron interacciones entre las dosis del herbicida y el año de siembra arroz CL/sitio, ni de las dosis evaluadas de imazapir + imazapic para el arroz no CL o

Tabla 14. Resultados obtenidos con EI Paso 144 en la Unidad Experimental Paso de La Laguna (UEPL) y con INIA Olimar en Río Branco.

\begin{tabular}{|c|c|c|c|c|c|c|c|c|}
\hline \multirow{3}{*}{$\begin{array}{c}\text { Imazapir + } \\
\text { imazapic } \\
\text { g a.e./ha }\end{array}$} & \multirow{2}{*}{\multicolumn{2}{|c|}{$\begin{array}{l}\text { Población plantas } \\
\text { UEPL Río Branco }{ }^{2} \\
\text { plantas } / \mathrm{m}^{2}\end{array}$}} & \multirow{2}{*}{\multicolumn{2}{|c|}{$\begin{array}{c}\text { Población panojas } \\
\text { UEPL Río Branco } \\
\text { panojas } / \mathrm{m}^{2}\end{array}$}} & \multicolumn{2}{|c|}{ Altura planta cosecha } & \multirow{2}{*}{\multicolumn{2}{|c|}{$\begin{array}{l}\text { Rendimiento arroz } \\
\text { UEPL Río Branco } \\
\text { kg/ha }\end{array}$}} \\
\hline & & & & & UEPL & $\begin{array}{l}\text { Río Branco } \\
\mathrm{cm} / \text { planta }\end{array}$ & & \\
\hline & $178 a$ & & $510 a$ & & $80 a$ & & & \\
\hline $110+37$ & $202 a$ & $257 a$ & $522 \mathrm{a}$ & & 82 & 72 & $7128 a$ & $5511 a$ \\
\hline $220+74$ & $186 \mathrm{a}$ & $240 \mathrm{a}$ & $487 \mathrm{a}$ & 533 a & $82 \mathrm{a}$ & $73 a$ & $6735 a$ & $5275 a$ \\
\hline
\end{tabular}

$1=$ Promedio de tres ensayos en 2007-2008, 2008-2009 y 2009-2010.

${ }^{2}=$ Promedio de dos ensayos en 2008-2009 y 2009-2010. Las medias seguidas por la misma letra no difieren significativamente entre sí según la prueba de Tukey al $5 \%$.

Tabla 15. Efecto de la mezcla de imazetapir + imazapic asperjada en IRGA $422 \mathrm{CL}$ en el año 2004-2005 en el cultivo siguiente de IRGA 417 sembrado a los 371 días después de la aplicación. Santa María, 2005-2006.

\begin{tabular}{|c|c|c|c|c|c|c|}
\hline $\begin{array}{c}\text { Imazetapir + imazapic } \\
\text { g a.e./ha }\end{array}$ & $\begin{array}{l}\text { Población } \\
\text { de plantas } \\
\text { plantas } / \mathrm{m}^{2}\end{array}$ & $\begin{array}{c}\text { Macollaje }^{\mathrm{E}} \\
\text { tallos/planta }\end{array}$ & $\begin{array}{l}\text { Población } \\
\text { de panojas } \\
\text { panojas } / \mathrm{m}^{2}\end{array}$ & $\begin{array}{c}\text { Tamaño } \\
\text { panoja } \\
\text { granos/panoja }\end{array}$ & $\begin{array}{l}\text { Peso de } \\
1000 \\
\text { granos, g }\end{array}$ & $\begin{array}{c}\text { Rendimien- } \\
\text { to arroz } \\
\text { kg/ha }\end{array}$ \\
\hline 0 & $295 a$ & $4,5 \mathrm{a}$ & $648 a$ & $79 a$ & $27 \mathrm{a}$ & 8928 a \\
\hline $52,5+17,5^{\mathrm{A}} / / 52,5+17,5^{\mathrm{B}}$ & $191 b$ & $1,8 \quad b$ & $358 b$ & $73 \mathrm{~b}$ & $23 \mathrm{~b}$ & $5262 b$ \\
\hline $70+25^{c}$ & $199 \mathrm{~b}$ & $1,6 \mathrm{~b}$ & $338 \mathrm{~b}$ & $72 \mathrm{~b}$ & $22 b$ & 3989 b \\
\hline $70+25^{D}$ & $171 \mathrm{~b}$ & $1,5 \mathrm{~b}$ & $303 \mathrm{~b}$ & $71 \mathrm{~b}$ & $23 b$ & $4158 b$ \\
\hline
\end{tabular}

$\mathrm{A}=$ premergencia seguida por $^{\mathrm{B}}=$ postemergencia, ${ }^{\mathrm{C}}=$ solo en preemergencia, ${ }^{\mathrm{D}}=$ solo en postemergencia, ${ }^{\mathrm{E}}=$ registrado $\mathrm{a}$ los 29 días después de la emergencia (DDE). Las medias seguidas por la misma letra no difieren significativamente entre sí según la prueba de Tukey al 5\%. Adaptado de Marchesan et al., 2010. 
para el sorgo forrajero siguientes (Tablas 14 y 15). La siembra de EI Paso 144 fue realizada a los 333,342 y 328 DDA en la UEPL, y para INIA Olimar a los 374 y 288 en RB para los años 2007-2008, 20082009 y 2009-2010, y para los años 20082009 y 2009-2010, respectivamente. A los 300 DDA no se detectaron residuos con actividad biológica que pudieran interferir con el cultivo siguiente a la dosis de 110 + $37 \mathrm{~g}$ a.e./ha de imazapir + imazapic en la UEPL (Figuras 5C, 5D, 6C y 6D), mientras tanto, se detectaron residuos en el horizonte superficial (Figuras $5 \mathrm{~A}$ y $5 \mathrm{~B}$ ) pero no en el horizonte subsuperficial en RB (Figura 6A y 6B). No se observaron efectos adversos en el arroz sin tolerancia tanto en la UEPL como en RB, aunque en este último sitio se observó en INIA Olimar un atraso leve en el inicio de la floración en el año 2008-2009. Ese comportamiento está asociado a la ausencia de residuos remanentes detectables del herbicida en la UEPL, así como el bajo nivel de residuos remanentes detectados en RB.

En condiciones de campo se ha reportado menor altura en INIA Olimar sembrada en directa después de un arroz CL. Marchesan et al. (2010) trabajando con IRGA 417 en siembra directa sin laboreo, sobre un raigrás antecedido por IRGA $422 \mathrm{CL}$ sobre un planosol $(\mathrm{pH} \mathrm{4,5}$, carbono orgánico $0,7 \%$ y arcilla $17 \%$ ), señalaron que el $\mathrm{pH}$ bajo determinó que más herbicida permaneciera adsorbido a los coloides del suelo, evitando estar disponible para la degradación por la población microbiana que mostró menos actividad dado las temperaturas frías. El hecho de que aún antes de la inundación se observaron síntomas de daño en las plántulas de arroz y posteriormente muerte de ellas, indica la existencia de un nivel de residuos remanentes alto, reduciéndose la población en un $35 \%$ a los 10 días después de la emergencia (DDE), y los tallos/planta a los 29 DDE por efecto del herbicida. Posteriormente, los tallos/planta se recuperaron a los 49 DDE (datos no mostrados), sin embargo, disminuyó el número y tamaño de panojas, y resultaron granos más livianos. Las plantas fueron algo más bajas (datos no mostrados) y se obtuvieron menores rendimientos de arroz (Tabla 15).

Sobre esa situación, se sembró raigrás enseguida de la cosecha y a los 705 DDA se realizó siembra directa nuevamente de IRGA 417. La dosis de etiqueta aplicada sola en postemergencia fue el único tratamiento que afectó la población de plantas, sin embargo, no se tradujo en pérdida de rendimiento del IRGA 417 ni en sus componentes, lo que indicaría que los residuos remanentes estaban fuera del umbral que provocara daños severos (Tabla 16).

Andres et al. (2011) trabajaron también

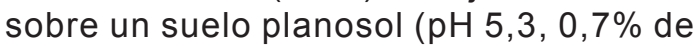
carbono orgánico y $22 \%$ de arcilla) para estudiar el efecto de las dosis de imazetapir + imazapic aplicadas en el arroz tolerante en el cultivo siguiente de arroz no $\mathrm{CL}$. En este caso no se sembró raigrás en los rastrojos de arroz, dejándose que

Tabla 16. Efecto de la mezcla de imazetapir + imazapic asperjada en IRGA $422 \mathrm{CL}$ en el año 2004-2005 en el cultivo siguiente de IRGA 417 sembrado a los 705 días después de la aplicación. Santa María, 2006-2007.

\begin{tabular}{|c|c|c|c|c|c|c|}
\hline $\begin{array}{c}\text { Imazetapir + imazapic } \\
\text { g a.e./ha }\end{array}$ & $\begin{array}{l}\text { Población } \\
\text { de plantas } \\
\text { plantas } / \mathrm{m}^{2}\end{array}$ & $\begin{array}{l}\text { Macollaje }^{\mathrm{E}} \\
\text { tallos } / \mathrm{m}^{2}\end{array}$ & $\begin{array}{l}\text { Población } \\
\text { de panojas } \\
\text { panojas } / \mathrm{m}^{2}\end{array}$ & $\begin{array}{c}\text { Tamaño } \\
\text { panoja } \\
\text { granos/panoja }\end{array}$ & $\begin{array}{l}\text { Peso de } \\
1000 \\
\text { granos, g }\end{array}$ & $\begin{array}{c}\text { Rendimien- } \\
\text { to arroz } \\
\text { kg/ha }\end{array}$ \\
\hline 0 & $281 \mathrm{a}$ & $1,7 \mathrm{a}$ & $249 a$ & 68 a & $27,5 \mathrm{a}$ & 4450 a \\
\hline $52,5+17,5^{\mathrm{A}} / / 52,5+17,5^{\mathrm{B}}$ & $234 a b$ & $2,0 \mathrm{a}$ & $273 a$ & $71 \mathrm{a}$ & 26,9 a & 3887 a \\
\hline $70+25^{c}$ & $240 a b$ & $1,9 \mathrm{a}$ & $142 \mathrm{a}$ & 59 a & $26,1 \mathrm{a}$ & 3736 a \\
\hline $70+25^{D}$ & $195 \mathrm{~b}$ & $2,3 \mathrm{a}$ & $219 a$ & $64 \mathrm{a}$ & $26,8 \mathrm{a}$ & 3725 a \\
\hline
\end{tabular}

$\mathrm{A}=$ premergencia seguida por ${ }^{\mathrm{B}}=$ postemergencia, ${ }^{\mathrm{C}}=$ solo en preemergencia, ${ }^{\mathrm{D}}=$ solo en postemergencia, ${ }^{\mathrm{E}}=$ registrado a los 29 días después de la emergencia (DDE). Las medias seguidas por la misma letra no difieren significativamente entre sí según la prueba de Tukey al 5\%. Adaptado de Marchesan et al., 2010. 
Tabla 17. Efecto del imazetapir + imazapic aplicado en postemergencia de IRGA 422 CL en 2006-2007 sobre el arroz no CL siguiente sembrado a los 335 DDA en 2007-2008 y a los 710 DDA en 2008-2009. Capao de Leao, RS.

\begin{tabular}{|c|c|c|c|c|}
\hline \multirow{2}{*}{$\begin{array}{c}\text { Imazetapir + imazapic } \\
\text { g a.e./ha }\end{array}$} & \multicolumn{2}{|c|}{ BRS Querencia a 335 DDA $^{2}$} & \multicolumn{2}{|c|}{ BRS Querencia a 710 DDA } \\
\hline & $\begin{array}{c}\text { Daño } 35 \text { DDE }^{1} \\
\%\end{array}$ & $\begin{array}{l}\text { Rendimiento } \\
\text { kg/ha }\end{array}$ & $\begin{array}{c}\text { Daño } 35 \text { DDE } \\
\%\end{array}$ & $\begin{array}{c}\text { Rendimiento } \\
\text { kg/ha }\end{array}$ \\
\hline 0 & $0 \mathrm{a}$ & $6443 a$ & $0 \mathrm{a}$ & $6835 a$ \\
\hline $75+25$ & $66 \mathrm{~b}$ & $3813 b$ & $10 \mathrm{~b}$ & 7276 a \\
\hline $150+50$ & 83 & $3261 \mathrm{~b}$ & $19 b$ & $7215 a$ \\
\hline
\end{tabular}

${ }^{1}=$ días después de la emergencia, ${ }^{2}=$ días después de la aplicación. Las medias seguidas por la misma letra no difieren significativamente entre sí según la prueba de la Mínima Diferencia Significativa al 5\%. Adaptado de Andres et al, 2011.

Tabla 18. Efecto del imazetapir + imazapic aplicado en postemergencia de BRS Señuelo CL en 2007-2008 sobre el arroz no CL siguiente sembrado a los 339 DDA en 2008-2009 y a los 702 DDA en 2009-2010. Capao de Leao, RS.

\begin{tabular}{|c|c|c|c|c|}
\hline \multirow{2}{*}{$\begin{array}{c}\text { Imazetapir + imazapic } \\
\text { g a.e./ha }\end{array}$} & \multicolumn{2}{|c|}{ BRS Querencia a 339 DDA $^{2}$} & \multicolumn{2}{|c|}{ BRS Querencia a 702 DDA } \\
\hline & $\begin{array}{c}\text { Daño } 42 \text { DDE }^{1} \\
\%\end{array}$ & $\begin{array}{l}\text { Rendimiento } \\
\text { kg/ha }\end{array}$ & $\begin{array}{c}\text { Daño } 34 \text { DDE } \\
\%\end{array}$ & $\begin{array}{c}\text { Rendimiento } \\
\text { kg/ha }\end{array}$ \\
\hline 0 & $0 \mathrm{a}$ & $6405 a$ & $0 \mathrm{a}$ & 5886 a \\
\hline $75+25$ & $28 \mathrm{~b}$ & $5524 \quad b$ & $19 \mathrm{~b}$ & $5424 a b$ \\
\hline $150+50$ & $66 \mathrm{c}$ & 4499 b & 23 & 5114 \\
\hline
\end{tabular}

${ }^{1}=$ días después de la emergencia, ${ }^{2}=$ días después de la aplicación. Las medias seguidas por la misma letra no difieren significativamente entre sí según la prueba de la Mínima Diferencia Significativa al 5\%. Adaptado de Andres et al., 2011

retornara la vegetación espontánea en el barbecho cuya cobertura fue disminuida por los residuos del herbicida. Los autores concluyeron que se necesitan un intervalo de 2 años para realizar una siembra segura en ese tipo de suelo predominante en la región del sureste de Río Grande del Sur (Tablas 17 y 18).

En Río Branco, Saldain et al. (2014c) estudiaron el efecto en el sorgo forrajero sembrado a los 396 y 312 DDA del herbicida para los años 2008-2009 y 2009-2010, respectivamente. Aunque es una especie muy sensible frente a los residuos de estos herbicidas, los residuos disponibles (Figura $5 \mathrm{~A}$ y $5 \mathrm{~B}$ ) no alcanzaron el umbral que induce pérdidas de plantas y de productividad del sorgo forrajero (Tabla 19).

Ávila et al. (2009) estudiaron el efecto de la aplicación de la premezcla de imazetapir + imazapic en IRGA $422 \mathrm{CL}$ sobre el sorgo forrajero sembrado posteriormente en Santa María. Al contrario de lo anteriormente reportado, a los 360 DDA encontraron toxicidad severa en las plántulas del sorgo persistiendo hasta los $35 \mathrm{DDE}$, lo que redujo significativamente la productividad. A pesar de detectar efectos adversos en las plántulas a los 710 DDA estas se recuperaron rápidamente y no se afectó la productividad (Tabla 20). En el mismo sentido, Pinto et al. (2009a) encontraron que en un suelo planosol ( $\mathrm{pH} 5$, carbono orgánico de $0,7 \%$ y arcilla $15,4 \%$ ) la dosis de etiqueta de imazetapir + imazapic (75 g e.a. + 25 g e.a./ha) y el doble, aplicados en postemergencia en el arroz $C L$, redujeron la población de plantas de sorgo granífero. A partir de los 7 días después de la emergencia (DDE), observaron síntomas de daño en las plántulas de sorgo, ocurriendo muerte de plantas entre los 42 a 70 DDE. La población de plantas disminuyó entre un 21 a $31 \%$ en las parcelas tratadas con la dosis de etiqueta con respecto al testigo 
Tabla 19. Resultados obtenidos frente a los residuos remanentes de imazapir + imazapic generados en el suelo con el sorgo forrajero (cv. Talisman en 2009 y cv. ACA 764 en 2010) en Río Branco*.

\begin{tabular}{|cccc|}
\hline $\begin{array}{c}\text { Imazapir + imazapic } \\
\text { g a.e./ha }\end{array}$ & $\begin{array}{c}\text { Población } \\
\text { plantas } \\
\text { plantas/m² }\end{array}$ & $\begin{array}{c}\text { Altura } \\
\text { planta } \\
\text { cm/planta }\end{array}$ & $\begin{array}{c}\text { Materia seca } \\
\text { producida en 180 DDS } \\
\text { t/ha }\end{array}$ \\
\hline 0 & $31 \mathrm{~b}$ & $193 \mathrm{a}$ & $9,11 \mathrm{a}$ \\
$110+37$ & $38 \mathrm{ab}$ & $194 \mathrm{a}$ & $9,22 \mathrm{a}$ \\
$220+74$ & $42 \mathrm{a}$ & $193 \mathrm{a}$ & $9,91 \mathrm{a}$ \\
\hline
\end{tabular}

"=Promedio de dos ensayos en 2008-2009 y 2009-2010. Las medias seguidas por la misma letra no difieren significativamente entre sí según la prueba de la Mínima Diferencia Significativa al $5 \%$.

Tabla 20. Efecto de la aplicación de imazetapir + imazapic en IRGA $422 \mathrm{CL}$ (2006-2007) en el sorgo forrajero sembrado en dos momentos. Santa María, 2007-2008 y 2008-2009.

sin tratar, mientras que las pérdidas se duplicaron al usar la dosis doble. Además, ese efecto adverso se tradujo en la reducción significativa de la materia seca total producida al inicio de la floración, así como en la productividad del grano. A la dosis de etiqueta, los residuos de imazetapir + imazapic remanentes en el suelo redujeron ambas variables en un $38 \%$, mientras que cuando se duplicó la dosis la reducción fue el doble. Los autores señalan que existe evidencia experimental de que cantidades pequeñas de imazapic son suficientes para provocar daño en los cultivos siguientes, y que, además, este principio activo produce sinergias cuando se lo mezcla con otras imidazolinonas.

Aunque no hay una compresión cabal de cómo opera el raigrás en cuanto a la disipación, cuando se finaliza el raigrás en la preparación de la cama de siembra en directa, los restos secos se descomponen y los residuos remanentes del herbicida podrían ser metabolizados por la población microbiana, dependiendo de las condiciones ambientales. Souto et al. (2013) establecieron que el suelo de la rizosfera del raigrás cuando se lo compara con un suelo sin vegetación contribuyó a la disipación por estímulo a la población microbiana, aunque en mucho menor medida que lo hace la rizosfera de las leguminosas evaluadas.

\section{Efecto de los residuos remanentes del imazapir + imazapic en arroz no CL bajo siembra convencional}

Saldain (2010) evaluó el efecto de la residualidad de estos herbicidas sobre la productividad de distintas variedades de arroz. Se incluyeron arroces tipo índica como las variedades INIA Olimar, EI Paso 144 y Puitá INTA CL, de tipo tropical japónica como INIA Tacuarí y CL 161 y tipo japónica templada, la variedad EEA 404. En el año 2005-2006, se sembró CL161 en 


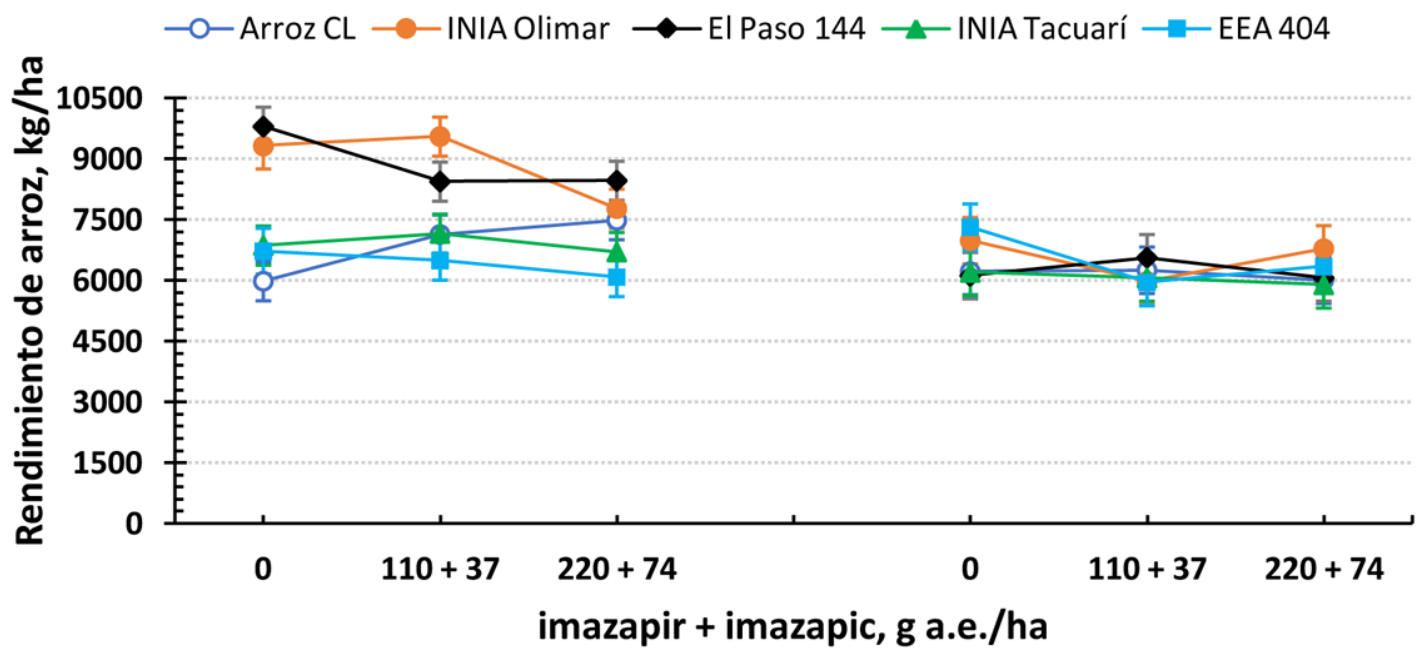

Figura 8. Rendimiento de arroz (kg/ha) frente a dosis crecientes de la premezcla de imazapir + imazapic aplicada en postemergencia al arroz CL el año anterior en la Unidad Experimental Paso de La Laguna. Izq. Siembra 2006-2007 (304 DDA), Der. Siembra 2007-2008 (332 DDA). DDA=días después de la aplicación.

un suelo brunosol ( $\mathrm{pH} 5,3,0,8 \%$ de carbono orgánico y $23 \%$ de arcilla), mientras que en el año 2006-2007 se utilizó Puitá INTA CL en un brunosol $(\mathrm{pH} 5,5,0,7 \%$ de carbono orgánico y $31 \%$ de arcilla). En ambos años previo a la siembra de las variedades de arroz no CL se hizo un laboreo superficial con excéntrica liviana (dos pasadas) sobre el rastrojo del arroz $\mathrm{CL}$, sin nivelar, sembrándose las variedades previo pasada de rodillo. En el año 2006-2007, la siembra se realizó a los 304 DDA y se observó un comportamiento diferencial entre INIA Olimar y EI Paso 144; mientras la primera parece tolerar bien los residuos remanentes dejados por la dosis intermedia, EI Paso144 redujo su rendimiento comparado con el testigo sin imidazolinonas. Las otras variedades no fueron afectadas, salvo INIA Tacuarí que atrasó seis días el inicio de floración con el aumento de la dosis. Cuando se repitió el ensayo de manera independiente en el año 2006-2007, la siembra se realizó a los 332 DDA y los residuos remanentes ese año no indujeron ninguna respuesta adversa ni pérdida de rendimiento de arroz en ninguna de las variedades evaluadas (Figura 8).

\section{Efecto de los residuos remanentes del imazapir + imazapic sobre la soja siguiente}

En el país, no se ha evaluado este aspecto de los residuos remanentes del herbicida sobre el crecimiento y productividad de la soja, pero sí hay información de Río Grande del Sur, BR.

Ulguim et al. (2019) trabajaron sobre un gleysol $(\mathrm{pH} 5,3,0,99 \%$ de carbono orgánico y $17 \%$ de arcilla), con dosis que incluyeron desde la de etiqueta hasta ocho veces la misma para simular escenarios contrastantes. Detectaron que la tasa de emisión de nudos se retrasa y los grados acumulados necesarios para obtener un nudo nuevo en soja aumenta a partir de la dosis doble, lo que indica retraso del crecimiento; también el número de ramas por planta, la altura de planta, el número de chauchas por planta y el número de nudos al estado de R8 disminuyen con el uso de la dosis de etiqueta. Al afectarse a algunos de los componentes del rendimiento, la productividad de grano se redujo al aumentar las dosis (Figura 9).

Oliveira et al. (2019) encontraron resultados divergentes con los anteriores autores en cuanto a la respuesta de la soja. Sobre un suelo planosol $\mathrm{pH} 5,8,1,2 \%$ de carbono 


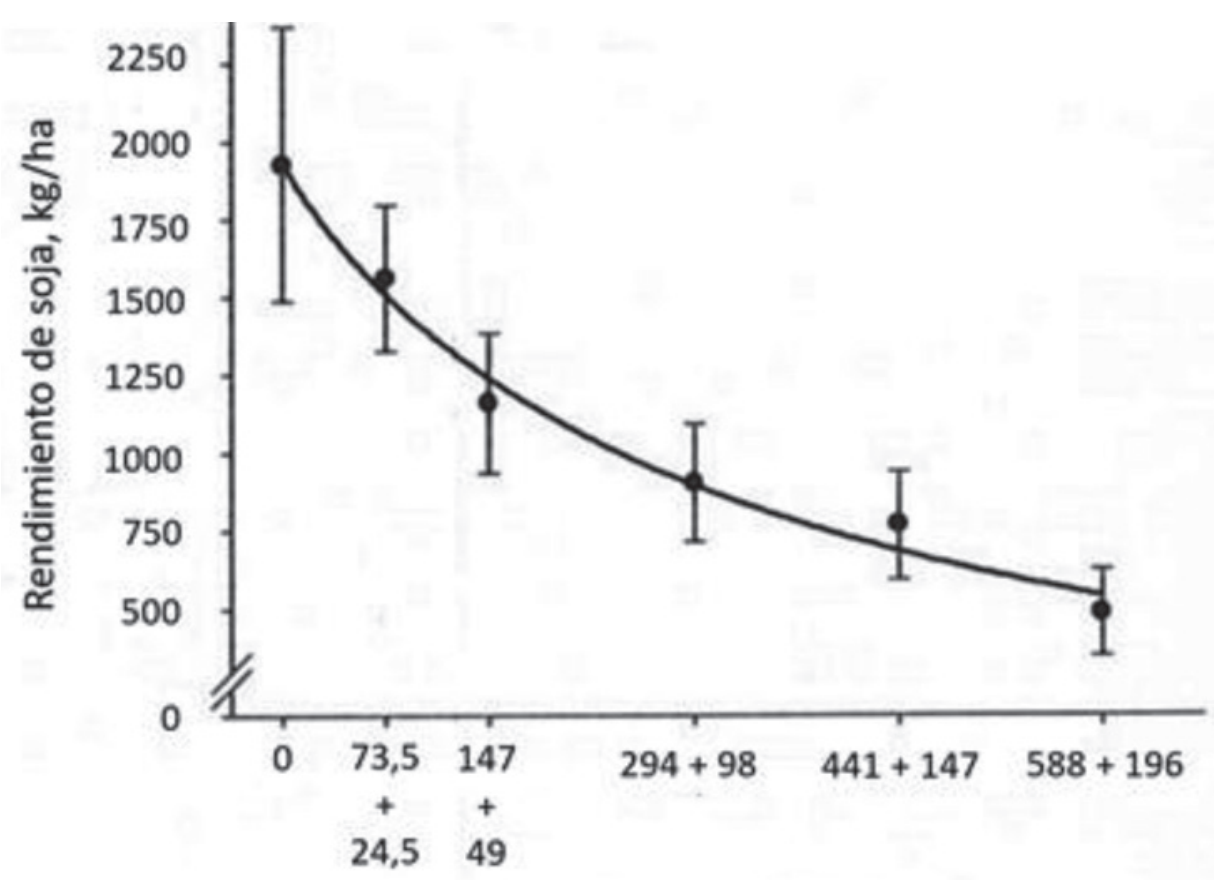

Imazapir + imazapic, g a.e./ha

Figura 9. Respuesta en el rendimiento de soja (kg/ha) siguiente a los residuos remanentes dejados por el uso de dosis crecientes de imazapir + imazapic aplicadas en postemergencia en el arroz CL en 2014-2015. Santa Maria, 2015-2016 (Adaptado de Ulguim et al., 2019).

orgánico y $25 \%$ de arcilla), se sembró raigrás sobre el rastrojo de arroz CL a los 129 DDA, seguido posteriormente por una soja a los 359 DDA del imazapir + imazapic, no encontrándose relación entre las dosis del herbicida y el rendimiento de la oleaginosa. Sin embargo, en los estados fenológicos V3 y R1 algunos atributos de la soja fueron afectados por las dosis de imazapir + imazapic evaluadas con respecto al testigo, cuando la humedad de suelo superó el $70 \%$ de la capacidad de campo y en presencia de raigrás que fue afectado por el herbicida, recuperándose la soja sin afectar el rendimiento (Tablas 21 y 22). Además, detectaron un comportamiento diferencial debido a la cobertura de raigrás y la humedad del suelo en el barbecho que afectó el rendimiento de la oleaginosa (Tabla 22).

.Los autores señalan que el menor rendimiento de soja observado cuando fue sembrada sobre el raigrás crecido bajo condiciones de suelo seco podría estar explicado por un ascenso tardío del herbicida por capilaridad en las parcelas tratadas

Tabla 21. Características de la soja en estado vegetativo y reproductivo afectadas por la presencia de cobertura en el barbecho para el nivel de humedad del suelo mayor a $70 \%$ de la capacidad de campo. Santa María, 2016-2017.

\begin{tabular}{|cccc|}
\hline $\begin{array}{c}\text { Cobertura en la } \\
\text { entre zafra }\end{array}$ & $\begin{array}{c}\text { Volumen radicular } \\
\text { estado V3 } \\
\text { cm } 3 \text { /planta }\end{array}$ & $\begin{array}{c}\text { Altura de planta } \\
\text { estado R1 } \\
\text { cm/planta }\end{array}$ & $\begin{array}{c}\text { Materia seca del tallo } \\
\text { estado R1 } \\
\text { g/planta }\end{array}$ \\
\hline Con raigrás* & 0,66 b & 43,5 b & 10,4 b \\
Sin raigrás & 0,82 a & 46,2 a & 12,6 a \\
\hline
\end{tabular}

=promedio de las tres dosis empleadas. Las medias seguidas por la misma letra no difieren significativamente entre sí según la prueba de la Mínima Diferencia Significativa al 5\%. Adaptado de Oliveira et al., 2019. 
Tabla 22. Efecto de la cobertura y la humedad del suelo en el barbecho el rendimiento de soja. Santa María, 2016-2017.

\begin{tabular}{|ccc|}
\hline $\begin{array}{c}\text { Cobertura en la } \\
\text { entre zafra }\end{array}$ & $\begin{array}{c}\text { Rendimiento en grano de la soja } \\
\text { Humedad suelo }>\text { a } 70 \%\end{array} \begin{array}{c}\text { CC } \\
\text { kg/ha }\end{array}$ \\
\hline Con raigrás & $3733 \mathrm{a}$ & $3406 \mathrm{~b}$ \\
Sin raigrás & $3869 \mathrm{a}$ & $3765 \mathrm{a}$ \\
\hline
\end{tabular}

*=promedio de las tres dosis evaluadas, ${ }^{* *}=$ capacidad de campo. Las medias seguidas por la misma letra no difieren significativamente entre sí dentro de la columna según la prueba de la Mínima Diferencia Significativa al 5\%. Adaptado de Oliveira et al., 2019

dado que afectó muy levemente al raigrás y a la soja en el crecimiento vegetativo inicial. Dicho herbicida disponible fue absorbido por la soja más tardíamente afectando su rendimiento. Además, proponen que la elevada producción de raigrás $(6000 \mathrm{~kg} / \mathrm{ha})$ en las parcelas sin imidazolinonas podría promover la inmovilización de nitrógeno dada la alta relación $\mathrm{C} / \mathrm{N}$ cuando se descomponen los restos del raigrás, deprimiendo el rendimiento.

\section{¿CÓMO MITIGAR LOS EFECTOS NO DESEADOS DE LOS RESIDUOS REMANENTES DE LOS HERBICIDAS?}

Es claro establecer que la mitigación empieza con las decisiones que se toman cuando se hace el arroz CL, incluyendo saber cómo es el suelo por utilizar. El foco debe de estar en dejar la menor cantidad de residuos de los herbicidas para los cultivos siguientes. Para ello, hay que evitar repetir el arroz CL por más de dos años seguidos y siempre dividir las aplicaciones en premergencia y postemergencia temprana. Si la situación indica aumentar la dosis por elevado enmalezamiento, el aumento deberá ser preferentemente mayor en la dosis en preemergencia que tendrá más tiempo para disiparse; el aumento de dosis deberá ser menor si es necesario realizar la aplicación en postemergencia temprana. No se recomienda poner el doble de la dosis en una aplicación ya que aumenta la cantidad de residuos remanentes en esa situación. Otra medida de manejo posible sería atrasar la inundación hasta una semana si se observa que hay humedad en el suelo, para ayudar a que se disipe algo del herbicida por degradación microbiana.

A pesar de usar todas estas estrategias, siempre quedan residuos remanentes, por lo que es recomendable romper taipas y drenar la chacra enseguida de la cosecha del arroz para facilitar la aeración de la superficie del suelo. Esta aeración combinada con la humedad y la temperatura adecuadas en el otoño hará que funcione la degradación microbiana, contribuyendo a la disipación de los residuos ubicados más cerca de la superficie. La mayoría de los suelos aptos para el cultivo del arroz presentan una napa colgada permanente, aumentando su espesor en el invierno y siendo menor en el verano. Está demostrado que quedan residuos ubicados más profundos en el suelo que para ser disipados hay que traerlos a la superficie por medio de laboreo, o eventualmente emplear especies que los consuman y los trasladen hacia el horizonte superficial del suelo. Hay que tener en cuenta que se pueden producir pérdidas de productividad en el raigrás y en el trébol rojo, mientras que especies el trébol blanco, lotus y la soja estimulan a la población microbiana nativa del suelo de la rizosfera para acelerar su degradación dentro de ciertos rangos de concentración del imazapir + imazapic.

Gehrke et al. (2021) señalaron que al aumentar moderadamente la materia orgánica del suelo trae un aumento de la población microbiana, lo que mejora la capacidad de degradación metabólica. Todo lo que se haga para favorecer esa característica mejorará la capacidad del suelo de detoxificar los residuos, como la siembra de mezclas de forrajeras incluyendo gramíneas y leguminosas como el trébol blanco y el 
lotus, además de otras leguminosas anuales adaptadas al ambiente de las tierras bajas. Ellos también proponen usar el encalado de los suelos más ácidos para favorecer la disponibilidad de estos herbicidas y de esa manera los microorganismos puedan acceder a los residuos y metabolizarlos.

En resumen, la principal estrategia es evitar la acumulación excesiva de residuos en el suelo ya que nos reduce las opciones productivas y aumenta los costos de producción.

\section{BIBLIOGRAFÍA}

Aichele, T.M.; Penner, D. 2005. Adsorption, desorption, and degradation of imidazolinones in soil. Weed Technology, 19(1):154-159. https://doi.org/10.1614/ WT-04-057R

Anderson, W. P. 1996. Weed science: principles and applications. Anderson, W.P. (Ed.); 3a. ed. West Publishing Company. 789 p.

Andres, A.; Avila, L. A.; Theisen, G.; Saldain, N. 2011. Carryover of imazethapyr + imazapic to natural winter pasture and to nontolerant rice. XIV Symposium in Pesticide Chemistry Pesticides in the Environment: Fate, Modelling and Risk Mitigation.

Avila, L.A.; Cassol, G.V.; Marchezan, E.; Cezimbra, D. M.; Filho, G.R.; Saldain, N. 2009. Compartamento do sorgo forrageiro semeado um o dois anos após a aplicacao da mistura formulada da imazethapyr e imazapic. In SOSBAI \& UFRGS (Eds.), VI Congresso Brasileiro de Arroz Irrigado. IRGA.

Avila, Luis A.; Massey, J.H.; Senseman, S.A.; Armbrust, K.L.; Lancaster, S.R.; Mccauley, G.N.; Chandler, J.M. 2006. Imazethapyr aqueous photolysis, reaction quantum yield, and hydroxyl radical rate constant. Journal of Agricultural and Food Chemistry, 54(7):2635-9. https://doi. org/10.1021/jf052214b

Bundt, A.D.C.; Avila, L.A.; Agostinetto, D.; Nohatto, M.A.; Vargas, H.C. 2015. Carryover of imazethapyr + imazapic on ryegrass and non-tolerante rice as affected by thickness of soil profile. Planta Daninha, 33(2):357364. https://doi.org/10.1590/010083582015000200022
Bundt, A.D.C.; Avila, L.A.; Pinto, J.J.O.; Santos, T.T.; Agostinetto, D.; Martins, K. 2013. Transporte ascendente da mistura formulada de imazethapyr e imazapic em resposta à profundidade do lençol freático. Ciência Rural, 43(9):15971604. https://doi.org/10.1590/S010384782013005000111

Espy, R.; Pelton, E.; Opseth, A.; Kasprisin, J.; Nienow, A.M. 2011. Photodegradation of the herbicide imazethapyr in aqueous solution: Effects of wavelength, $\mathrm{pH}$, and natural organic matter (NOM) and analysis of photoproducts. Journal of Agricultural and Food Chemitry, 59, 7277-7285. https://doi.org/10.1021/ jf200573g

Flint, J. L.; Witt, W.W. 1997. Microbial degradation of imazaquin and imazethapyr. Weed Science, 45(4): 586-591. https://doi.org/10.1017/ S004317450008886X

Gehrke, V. R.; Fipke, M.V.; Avila, L.A.; Camargo, E. R. 2021. Understanding the opportunities to mitigate carryover of imidazolinone herbicides in lowland rice. Agriculture, 11(4):299-316. https:// doi.org/10.3390/agriculture11040299

Harir, M.; Gaspar, A.; Frommberger, M.; Lucio, M.; El Azzouzi, M.; Martens, D.; Kettrup, A.; Schmitt-Kopplin, P.H. 2007. Photolysis pathway of imazapic in aqueous solution: ultrahigh resolution mass spectrometry analysis of intermediates. Journal of Agricultural and Food Chemitry, 55(24):9936-9943. https://doi.org/10.1021/jf0720279

Helling, C. S. 2005. The science of soil residual herbicides. In: van Acker, R.C. (Ed.), Soil residual herbicides: science and management. SainteAnne-de-Bellevue: Canadian Weed Science Society - Société canadienne de malherbologie. p. 3-22.

Hsiao, Y. L., Wang, Y. S., \& Yen, J. H. 2014. Enantioselective effects of herbicide imazapyr on Arabidopsis thaliana. Journal of Environmental Science and Health, Part B, 49(9): 646-653. https://doi.org/10.108 0/03601234.2014.922404 
Junkes, G. V.; Camargo, E. R.; Avila, L. A.; Kemmerich, M.; Gehrke, R. 2019. Manejo intermitente da irrigaçao favorece a dissipaçao da mistura imazapyr + imazapic em solos de várzea . In: EPAGRI (Ed.), XI Congresso Brasileiro de Arroz Irrigado Inovaçao e desenvolvimento. Camboriú: SOSBAI. p. 103-103.

Kraemer, A. F.; Marchesan, E.; Grohs, M.; Avila, L. A.; Oliveira, S.L.M.; Zanella, R.; Sachet, P. F. M.; Sarzi, G M.S. 2009. Lixiviação do imazethapyr em solo de várzea sob dois sistemas de manejo. Ciência Rural, 39(6):16601666. https://doi.org/10.1590/S010384782009005000119

Mallipudi, N.M.; Stout, S.J.; Dacunha, A.R.; Lee, A. 1991. Photolysis of imazapyr (AC 243997) herbicide in aqueous media. Journal of Agricultural and Food Chemistry, 39(2):412-417. https://doi. org/10.1021/jf00002a038

Mangels, G. 1991. Behavior of Imidazolinone Herbicides in Soil - A Review of the Literature. In: Shaner, D.L.; O'Connor, S.L. (Eds). The Imidazoline herbicide, pp. 191-209). Boca Raton: CRC Press, Inc.

Marchesan, E.; Dos Santos, F. M.; Grohs, M.; De Avila, L. A.; Machado, S.L.O.; Senseman, S.A.; Massoni, P.F.S.; Sartori, G.M.S. 2010. Carryover of Imazethapyr and Imazapic to Nontolerant Rice. Weed Technology, 24(1). https:// doi.org/10.1614/WT-08-153.1

Oliveira, M. L.; Marchesan, E.; Soares, C. F.; Farias, J. G.; Ulguim, A. da R.; Fleck, A.G.; Coelho, L.L. 2019. Persistence of imazapyr+imazapic in irrigated rice area and effect on soybean due to soil moisture and phytoremediation in the off-season. Bragantia, 78(3). https:// doi.org/10.1590/1678-4499.20190074

Pinto, J.J.O.; Noldin, J.A.; Rosenthal, M.D.; Pinho, C.F.; Rossi, F.; Machado, A.; Piveta, L.; Galon, L. 2009a. Atividade residual de (imazethapyr+imazapic) sobre azevém anual (Lolium multiflorum), semeado em sucessâo ao arroz irrigado, sistema Clearfield. Planta Daninha, 27(3): 609 613. https://doi.org/10.1590/ s0100-83582009000300023
Pinto, J.J.O.; Noldin, J.A.; Pinho, C.F.; Rossi, F.; Galon, L.; Almeida, G. F. 2009b. Actividade residual de (imazetahpyr + imazapic) para sorgo granífero (Sorghum bicolor) semeado em rotaçao com o arroz irrigado. Planta Daninha, 27:1015 1024. https://doi.org/10.1590/S010083582009000500015

Rabuffetti, A.; Deambrosi, E. 2017. Dinámica de nutrientes en suelos inundados. In: Rabuffetti, A. (Ed.). La Fertilidad del suelo y su manejo. Volumen II. Montevideo: Editorial Hemisferio Sur. p. 679-736.

Ramezani, M.; Oliver, D.P.; Kookans, R.S.; Gill, G.; Preston, C. 2008. Abiotic degradation (photodegradation and hydrolysis) of imidazolinone herbicides. Journal of Environmental Science and Health Part B, 43(2):105-112. https:// doi.org/10.1080/03601230701794968

Ramezani, M. 2007. Environmental Fate of Imidazolinone Herbicides and their antiomers in soil and water. South Australia: The University of Adelaide. 177 p.

Refatti, J. P.; Avila, L. A.; Agostinetto, D.; Manica, R.B.; Das Cas; A.B.; Balbé, D.E. 2014. Efeito da calagem na lixiviaçiao de imazethapyr e imazapyr em solo de cultivo de arroz irrigado. Ciência Rural, 44(6);1008-1014. https://doi.org/10.1590/ s0103-84782014000600009

Saldain, N.E. 2010. Efecto del imazapir + imazapic aplicados en el arroz Clearfield sobre las variedades de arroz sin resistencia a las imidazolinonas. In: Filippini, J. M. A. (Ed.), Sustentabilidade socioambiental da bacia da Lagoa Mirim. Pelotas: EMBRAPA Clima Temperado, 2010 p. 163-170.

Saldain, N.E.; Bermúdez, R.; Serrón, N.; López, A.; Sosa, B. 2014b. Efecto de la dosis de Kifit y del manejo del riego en la productividad inicial de la pradera subsiguiente. En: INIA Treinta y Tres. ArrozSoja:Resultados Experimentales 20132014. Treinta y Tres: INIA Treinta y Tres. cap. 5. p. 11-13. (INIA Serie Actividades de Difusión; 735)

Saldain, N.E.; Bermúdez, R.; Serrón, N.; Sosa, B. 2012. Efecto del Kifix (Imazapir + Imazapic) asperjado en el arroz clearfield sobre las plantas forrajeras subsiguientes en el Este del Uruguay. In: INIA Treinta y Tres. Arroz: resultados experimentales 2011-2012. Treinta y Tres: INIA, 2012. cap. 5 p.32-37. (INIA Serie Actividades de Difusión; 686) 
Saldain, N.E.; López, A.; Sosa, B. 2014c. Efecto del Kifix asperjado en el arroz clearfield sobre el raigrás subsiguiente seguido por arroz sin resistencia (no clearfield) o sorgo forrajero en siembra directa. En: INIA Treinta y Tres. Arroz-Soja: Resultados Experimentales 2013-2014. Treinta y Tres: INIA. cap. 5. p. 14-16. (INIA Serie Actividades de Difusión; 735)

Saldain, N.E.; López, A.; Sosa, B. 2014a. Persistencia y actividad biológica del Kifix en suelos arroceros en el Este del Uruguay. En: INIA Treinta y Tres. Arroz-Soja: Resultados Experimentales 2013-2014. Treinta y Tres: INIA. cap. 5. p. 17-19. (INIA Serie Actividades de Difusión; 735)

Saldain, N.E.; Oxley, M.; López, A.; Sosa, B. 2015. Bioensayo con semillas de el Paso 144 del agua de inundación proveniente de parcelas tratadas con y sin Kifix. In:INIA Treinta y Tres. Resultados experimentales 2014-2015. Treinta y Tres: INIA, 2015. cap. 2, p. 16-18. (INIA, Serie Actividades de Difusión; 748)

Santos, L. O.; Pinto, J.J.O.; Piveta, L.B.; Noldin, J.A., Galon, L.; Concenço, G. 2014. Carryover effect of imidazolinone herbicides for crops following rice. American Journal of Plant Sciences, 05(08):1049-1058. https:// doi.org/10.4236/ajps.2014.58117

Schreiber, F.; Scherner, A.; Massey, J.H.; Zanella, R.; Avila, L.A. 2017. Dissipatioin of clomazone, imazapyr and imazapic herbicides in paffy water under two rice flood managements regimes. Weed Technology, 31(2):330-340. https://doi. org/10.1017/wet.2017.5

Shaner, D. L. (Ed.). 2014. Herbicide Handbook (Tenth). Lawrence, KS : Weed Science Society of America.

Souto, K. M.; Jacques, R.J.S.; Avila, L.A.; Machado, S.L.O.; Zanella, R.; Reffatti, J.P. 2013. Biodegradation of the herbicides imazethapyr and imazapic in rhizosphere soil of six plants species. Ciência Rural, 43(10):1790-1796. https://doi.org/10.1590/ S0103-84782013001000010

Su, W.; Hao, H.; Ding, M.; Wu, R.; Xu, H.; Xue, F.; Shen, C.; Sun, L.; Lou, C. 2019. Adsorption and degradation of imazapic in soils under different environmental conditions. PLOS ONE 14(7): e0219462 https://doi. org/10.1371/journal.pone.0219462
Ulguim, A.R.; Carlos, F.S.; Zanon, A.J.; Ogoshi, C.; Bexaira, K.P.; Silva, P.R.F. 2019. Is increasing doses of imazapyr + imazapic detrimental to the main crop rotation alternatives to flooded rice? Planta Daninha, 37: e019217913 https://doi.org/10.1590/ s0100-83582019370100148

Umpiérrez, E.; Villagrán, V.; López, A.; Sosa, B.; Saldain, N. 2014. Disipación del Kifix ${ }^{\circledR}$ en el agua de inundación del arroz Clearfield ${ }^{\circledR}$.In: INIA Treinta y Tres. Arroz-Soja:Resultados Experimentales 2013-2014. Treinta y Tres: INIA Treinta y Tres. cap. 5. p. 20-22 (INIA Serie Actividades de Difusión; 735)

Wang, Q.; Liu, W. 1999. Correlation of imazapyr adsorption and desorption with soil properties. Soil Science, 164(6):411-416.

Wang, X.; Wang, H.; Fan, D. 2006. Degradation and metabolism of imazapyr in soils under aerobic and anaerobic conditions. International Journal of Environmental Analytical Chemistry, 86(8):541-551. https://doi. org/10.1080/03067310500410730

Yavari, S.: Sapari, N.B.; Malakahmad, A.; Razali, M.A. Bin; Gervais, T.S.; Yavari, S. 2020. Adsorption-Desorption Behavior of Polar Imidazolinone Herbicides in Tropical Paddy Fields Soils. Bulletin of Environmental Contamination and Toxicology, 104(1):121-127. https:// doi.org/10.1007/s00128-019-02759-y

Zanella, R.; Adaime, A.B.; Peixoto, S.C.; Friggi, C.A.; Prestes, O.D.; Machado, S.L.O.; Marchezan, E.; Avila, L.A.; Primel, E.G. 2011. Herbicide persistence in rice paddy water in Southern Brazil. In: Hasaneen; M.N.A. (Ed.), Herbicides mechanisms and mode of action. InTech. p. 204. https:// doi.org/10.5772/32727 


\title{
8 - EL USO SOSTENIBLE DEL ARROZ RESISTENTE A IMIDAZOLINONAS INCLUYE ROTACIONES
}

\author{
N.E. Saldain ${ }^{1}$, C. Marchesi ${ }^{2}$, J. Rosas ${ }^{3}$, A. L. Pereira ${ }^{4}$
}

PALABRAS CLAVE: acumulación residuos herbicidas, malezas resistentes ALS, rotaciones

\section{INTRODUCCIÓN}

El sistema de producción de arroz Clearfield ${ }^{\circledR}(C L)$ es la combinación del cultivo con resistencia a imidazolinonas y el uso de dos integrantes de esa familia de herbicidas, imazapir e imazapic, para el control selectivo del arroz maleza (AM) y un amplio espectro de otras malezas.

La empresa BASF recomienda sembrar hasta dos años seguidos de arroz CL aplicando la dosis estándar de 73,5 $+24,5 \mathrm{~g}$ a.e./ha de imazapir + imazapic en preemergencia, seguido de una dosis igual en postemergencia temprana para el control eficaz de infestaciones medias del AM. Además, se destaca como complemento de lo anterior que la inundación se realice a partir de las $72 \mathrm{~h}$ de esta última aplicación. Estas recomendaciones buscan preservar la vida útil de la tecnología en términos de eficacia de control del herbicida asociado, especialmente, en el control del AM.

La introducción del arroz CL en el país ocurrió en un contexto favorable a la sostenibilidad de la tecnología. Por un lado, la existencia de un sistema de producción de semillas certificadas robusto e integrado y por otro, apenas $31 \%$ del área arrocera presentaba infestación de AM siendo muy variable en términos de densidad de plantas y área afectada. La adopción de la tecnología favoreció la obtención de elevadas productividades en las chacras que presentaban muy altas infestaciones de arroz maleza y además permitió el retorno a la producción del cereal de otras áreas que habían tenido una larga historia del cultivo. Al concentrar el uso del arroz CL en las áreas mencionadas, especialmente las que tenían poblaciones más altas de la maleza, se manifestaron a lo largo de los años diversos eventos que comprometen la sostenibilidad de la tecnología.

\section{¿Qué pasó con las poblaciones del arroz maleza?}

La frecuencia del uso de la tecnología condiciona los resultados obtenidos en el control de la maleza en el mediano plazo, como se ilustra en dos chacras ubicadas alambrado por medio (Figura 1). En una de ellas se realizaron dos cultivos de arroz CL, uno de soja y dos de arroz convencional, alternando entre cultivos con un año de barbecho, mientras que en la otra chacra se cultivaron cinco arroces CL alternando entre cultivos con un año de barbecho (5 años de cultivo en 10 años en ambas chacras). En la primera situación, la infestación de arroz maleza es aún muy abundante y susceptible por lo que la tecnología CL se mantiene eficaz en el control de la maleza. Sin embargo, se ve que a pesar de solo haber

\footnotetext{
${ }^{1}$ Néstor Saldain. Ing. Agr. M.Sc. INIA. Programa Nacional de Investigación en Producción de Arroz (hasta junio 2021). nsaldain56@gmail.com

${ }^{2}$ Claudia Marchesi. Ing. Agr. M.Sc. Ph.D. INIA. Programa Nacional de Investigación en Producción de Arroz. cmarchesi@inia.org.uy

${ }^{3}$ Juan Rosas. Lic. M.Sc. Dr. Cs. Agrarias, INIA. Programa Nacional de Investigación en Producción de Arroz. jrosas@inia.org.uy

${ }^{4}$ Ana Laura Pereira. Ing. Agr. D. Sc. INIA. Unidad de Semillas. apereira@inia.org.uy
} 


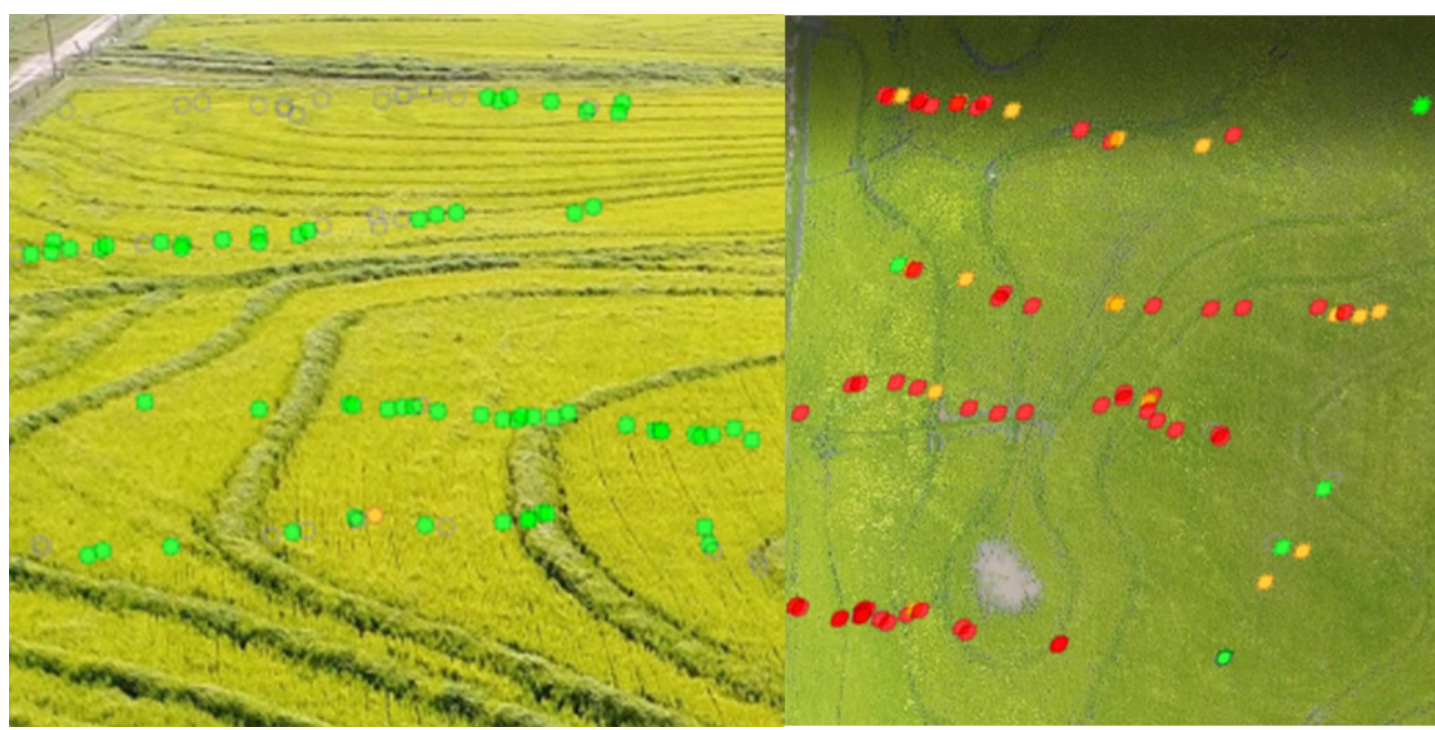

Figura 1. Susceptibilidad del AM a la mezcla preformulada de imazapir + imazapic, y mutaciones de resistencia en dos chacras con historia contrastante. Río Branco, 2017-2018. Izq.: población abundante de AM susceptible que sobresale sobre el arroz en el cuadro y en la taipa. Der.: población menos abundante del AM resistente al herbicida que se distingue por su color verde claro. Los puntos representan la ubicación de plantas analizadas para presencia de mutaciones de resistencia al herbicida. Círculos verdes= homocigotas susceptibles, naranjas $=$ heterocigotos resistentes, rojos =homocigotas resistentes, vacíos $=$ no analizado. N.E. Saldain, J. Rosas y B. Sosa (sin publicar).

cultivado dos años arroz Clearfield ${ }^{\circledR}$ se detectó una planta que porta la mutación de resistencia al herbicida. Por otro lado, en la segunda chacra donde se hibridó tempranamente la maleza con el arroz CL y se siguió cultivando el mismo se fueron seleccionado las plantas resistentes, siendo prácticamente todo lo muestreado resistente al herbicida tanto en individuos heterocigotas como homocigotas. En esta situación, la tecnología CL ya no es útil por lo que se hace necesario bajar la población resistente por otros medios.

\section{¿Qué pasó con las poblaciones de capín?}

Por otro lado, el uso muy frecuente de la tecnología CL acarrea problemas de resistencia a los herbicidas inhibidores de la ALS de otras malezas muy importantes del sistema arrocero, como lo son las Echinochloas y las ciperáceas. Esto complejiza mucho más el control de malezas en general, encarece enormemente la producción y reduce rendimientos en muy alta proporción.
El uso recurrente de la tecnología Clearfield ${ }^{\circledR}$ durante varios años, trae aparejado el rápido surgimiento de Echinochloas (capines) resistentes. Después de tres años seguidos de arroz CL se observan distintos escapes de capín en grupos pequeños en el área tratada, mientras que en una chacra donde se alternaron años de arroz CL y años de barbecho durante un período de 10 años, se aprecia que existen menos grupos con diámetro muy grande debido a las abundantes plantas de capín cuyo fenotipo es muy similar entre sí, habiéndose confirmado resistencia en ambos casos, especialmente con alto nivel de resistencia en la última situación relatada (Figura 2).

\section{¿Qué pasó con la acumulación de los residuos de imazapir + imazapic?}

Otro aspecto relevante cuando se usa reiteradamente el arroz resistente a las imidazolinonas es lo relativo a la acumulación de residuos de los herbicidas en el perfil del suelo. Los estudios realizados, con un solo año de aplicación de la mezcla preformulada de imazapir + imazapic, 


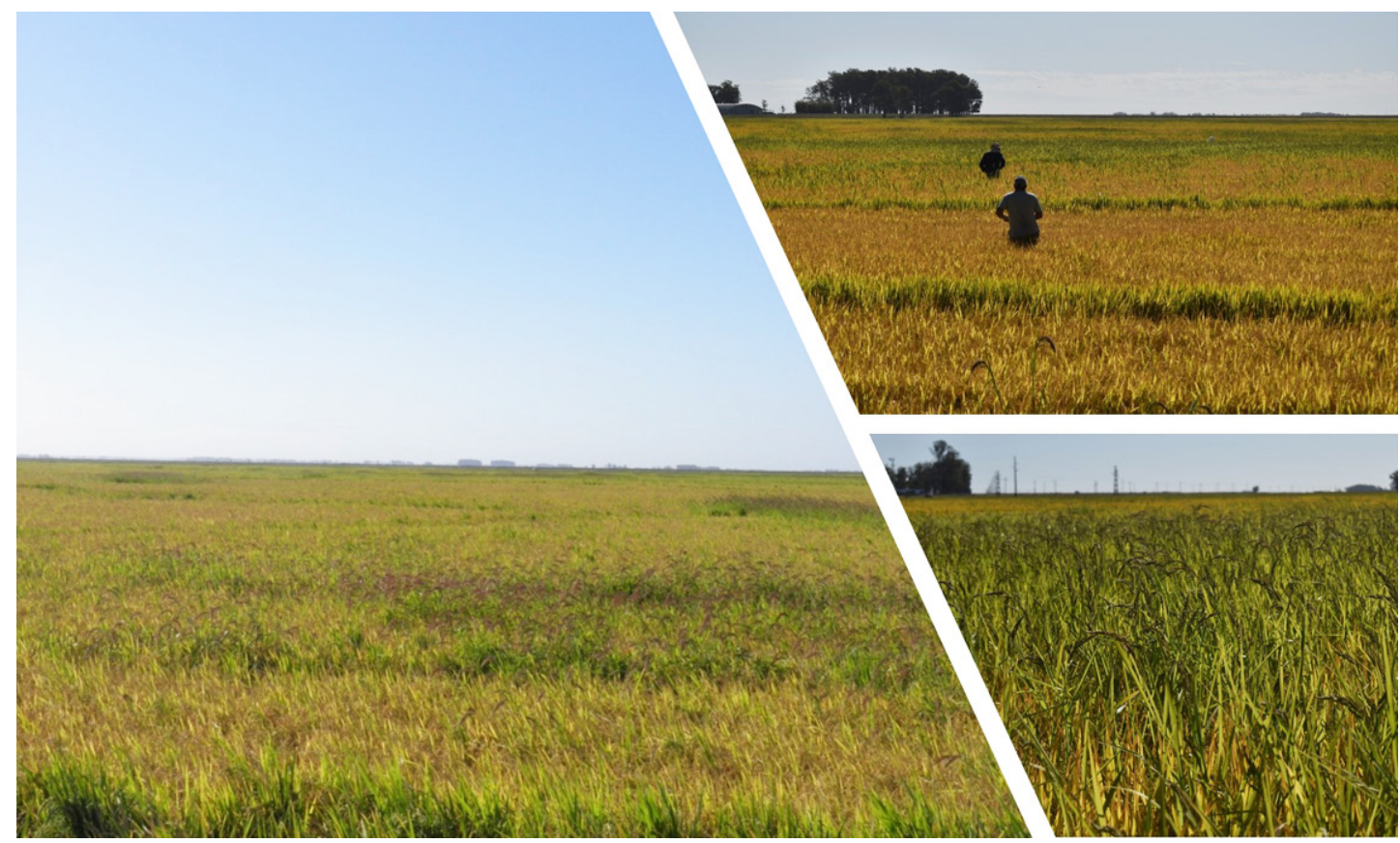

Figura 2. Escapes de capín al control de la aplicación de la mezcla preformulada de imazapir + imazapic en dos situaciones distintas. Izq.: escapes pequeños y dispersos en el área tratada después de tres años seguidos de arroz Clearfield ${ }^{\circledR}$, Der. superior: escapes de capín abundantes en una chacra con 5 años de arroz Clearfield ${ }^{\circledR}$ alternando con un año de barbecho, Der. inferior: muy llamativa la gran uniformidad de las plantas de capín en su aspecto y ciclo dentro de ese grupo.

indican que todas las especies estudiadas en ausencia de laboreo se implantan bien sin afectación de la población inicial. Sin embargo, el crecimiento es afectado dependiendo la magnitud de la reducción del nivel de residuos disponible en el suelo. De las especies estudiadas, el sorgo forrajero es muy sensible porque su productividad se afecta aún a los 10 meses de aplicado el último herbicida con imazapir + imazapic. En este caso particular, en un suelo arenoso, profundo, $\mathrm{pH}$ de 5,0 y con materia orgánica baja, después de dos años de arroz Clearfield ${ }^{\circledR}$ a las dosis recomendadas por BASF, con una pasada de la hoja niveladora para romper las taipas sin laboreo, se sembró el sorgo forrajero directamente. Se aprecia la diferencia en el crecimiento y el atraso en el ciclo de éste cuando se compara el cuadro con el sitio donde estaba la base de la taipa, donde no llegó el herbicida (Figura 3).

Las especies forrajeras sembradas sin laboreo directamente sobre el rastrojo de arroz CL después de la cosecha se han implantado sin problemas y el crecimiento hasta los 90 días después de la siembra no fue afectado. El efecto adverso fue observado en la productividad en el raigrás y el trébol rojo a los 180 días después de la siembra. La magnitud de la reducción dependerá de la cantidad de residuos del herbicida acumulados en los horizontes superficiales del suelo. Los factores que determinarán la magnitud de la acumulación serán la frecuencia del arroz CL, la realización de laboreo de verano y su profundidad entre arroces $C L$, las dosis del herbicida usadas con mucho énfasis en la empleada en postemergencia, cuando se realiza la inundación, los contenidos de materia orgánica y arcilla, y el pH del suelo.

\section{¿Qué pasó con la deriva de los herbicidas?}

Si bien este un aspecto que no se desarrolló en los capítulos anteriores, es necesario realizar algunos comentarios. 


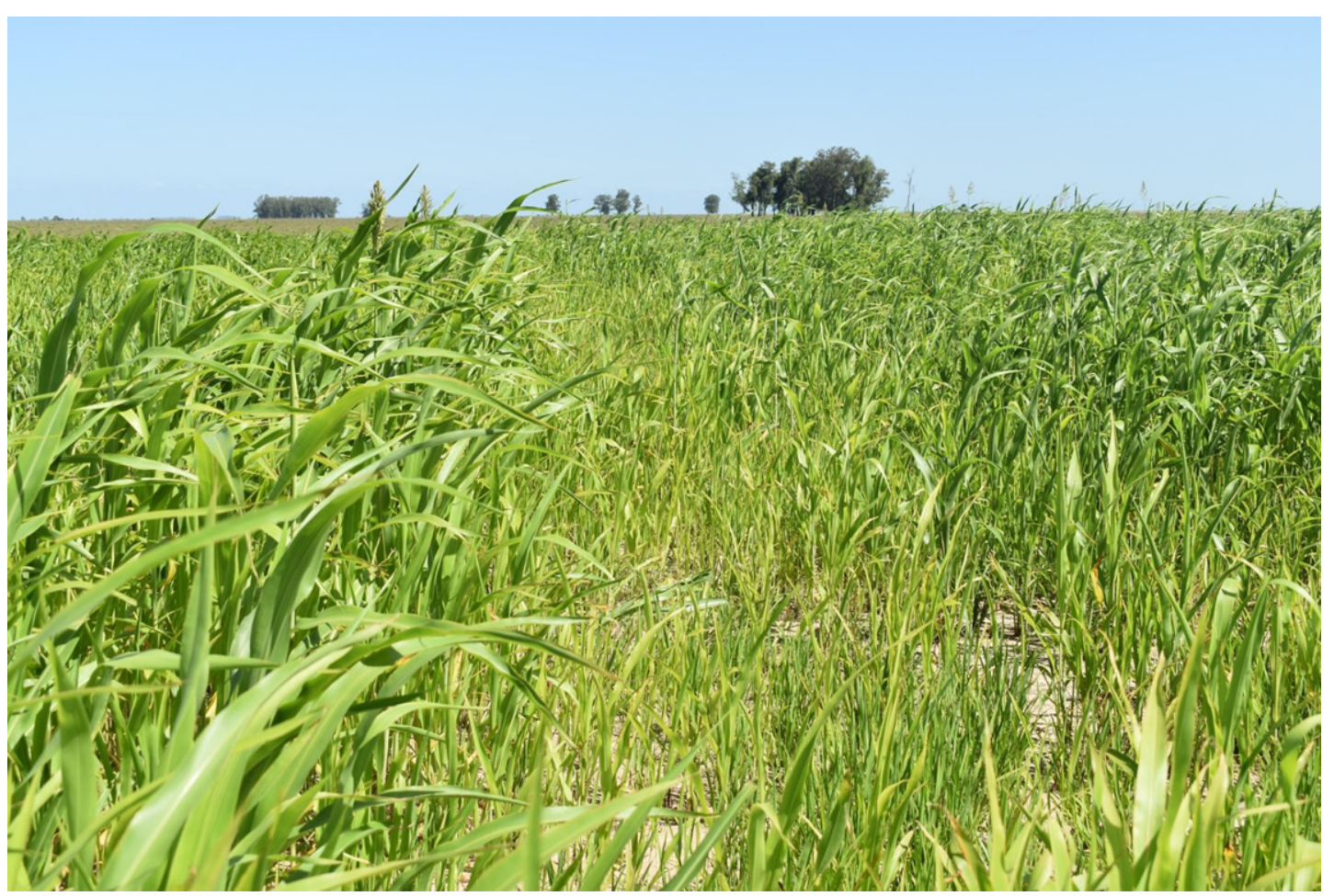

Figura 3. Sorgo forrajero afectado por los residuos de la mezcla de imazapir + Imazapic. Este de Cerro Largo, 2016-2017.

La deriva de herbicida fue frecuente cuando fue creciendo el área del arroz $\mathrm{CL}$ hacia el arroz convencional, observándose distintos daños (Hensly et al., 2012; Leiva y Zaldúa, 2016). Esto obligó a organizarse de tal manera de evitar que quedaran áreas con variedades convencionales rodeadas de arroz CL.

La promoción de siembras tempranas en el arroz para lograr mayor productividad y la recuperación del precio de la soja han estimulado el uso de este último cultivo en rotación con arroz en suelos arroceros típicos. Estos hechos junto a otros dibujan un escenario propenso a que se produzcan eventos de deriva de los herbicidas de un cultivo hacia el otro dado su proximidad (Saldain y Deambrosi, 2005; Saldain, 2007; Hensley et al., 2013). Las aplicaciones de herbicidas en el arroz, con temperaturas subóptimas para su crecimiento, provoca más frecuentemente fitotoxicidad en el mismo, mientras que la soja en estado vegetativo con pocas hojas verdaderas queda muy expuesta a recibir deriva de los herbici- das inhibidores de la ALS usados en el arroz que producen daño severo (Walker, 2018). Este factor adicional agrega más variabilidad a los rendimientos de soja en secano que, además, puede llegar a sufrir en el mismo año tanto sequía como excesos de agua en períodos críticos para el cultivo.

\section{¿Qué pasa cuando en el apuro no se leen las etiquetas de los herbicidas a utilizar?}

Uno de los atributos entre varios que tiene la producción de arroz en Uruguay es que hace un uso de insecticidas muy reducido, aunque existe en algunos actores una práctica arraigada de mezclar herbicidas con insecticidas en el afán de prevenir la aparición de plagas y reducir costos, práctica que no está respaldada por la evidencia. No se aconseja usar insecticidas organofosforados aplicados a la semilla, en tratamiento del suelo o mezclado en el tanque con el herbicida preformulado de imazapir + imazapic 
como lo establece la etiqueta del producto. Cuando esto ocurre, se pueden producir daños muy severos en la planta de arroz, con elevadas probabilidades de reducción de la productividad.

\section{¿Qué estrategias se deben de usar para minimizar los efectos no deseados?}

Una opción para retrasar la evolución de malezas resistentes a imidazolinonas es rotar con cultivos como la soja dado que permite usar herbicidas con principios activos no usados en el cultivo de arroz.Otra es el uso de las tecnologías de arroz resistente a los inhibidores de la ACCasa que estará disponible en el corto plazo (RiceTec, BASF). Ambas opciones implican tratar toda el área con nuevos principios activos y/o sus mezclas. Hay una tercera opción que se puede usar para controlar escapes, confirmados o no que sean resistentes y que no necesita aplicaciones generalizadas en el área problema. Está operando en el país la aplicación dirigida por medio de drones aplicadores (UAV). Estos equipos generan planes de vuelo y de aplicación referenciados que nos permite retornar a los mismos sitios con precisión menor al centímetro cuando se cultive arroz nuevamente, otro cultivo, en el barbecho o se practique eventualmente la falsa siembra. Como el área tratada será muy pequeña, se podría aplicar herbicidas que, aunque dañen al arroz como por ejemplo glifosato + graminicida, reducirán la producción de semillas viables del arroz maleza o el capín, evitando cargar de semillas frescas al banco del suelo.

Para minimizar la acumulación de los residuos del imazapir + imazapic el primer factor a considerar es bajar la intensidad de uso del arroz CL. Lo segundo, si la historia del cultivo, el tipo de suelo y la ausencia de laboreo indican que se espera acumulación de residuos, se puede sembrar una pradera multi-especies con mayor proporción de trébol blanco y lotus que lo habitual, agregando una gramínea anual o perenne enseguida de la cosecha y previa ruptura de taipas y realización de drenajes. Si la cantidad de residuos del herbicida acumulados es muy alta puede haber una reducción de la productividad inicial de la pastura del orden del $25 \%$. Si se alterna arroz CL y un año de barbecho se recomienda pasarse al laboreo de verano, y se puede sembrar trébol persa en líneas en el otoño temprano dado que crece bien en presencia de los residuos y colabora con aportar de nitrógeno para el arroz siguiente.

\section{CONCLUSIÓN}

En resumen, queda claro que el arroz $C L$ tuvo y tiene un importante papel a jugar en el control del arroz maleza y otras especies en las rotaciones con arroz en el país. Asimismo, ignorar las recomendaciones de uso de la tecnología posibilita que se presenten problemas aún más complejos de resolver, para los cuales la tecnología no fue creada, que necesitan nuevas soluciones con costos incrementales.

Esto subraya la necesidad de involucrar a todos los actores de la cadena productiva en un uso responsable de la tecnología en combinación con otras opciones de arroz resistente a herbicidas, rotación de pasturas y/o cultivos, y la aplicación sitio-específica con drones.

\section{BIBLIOGRAFÍA}

Hensley, J. B.; Webster, E.P.; Blouin, D.C.; Harrell, D.L.; Bond, J. A.. 2013. Response of rice to Idrift rates of glyphosate applied at low carrier volumes. Weed Technology, 27(2):257262. https://doi.org/10.1614/WT-D-1200061.1

Hensly, J.B.; Webster, E.P.; Blouin, D.C.; HarrelI, D.L.; Bond, J.A. 2012. Impact of drift rates of imazethapyr and low carrier volume on on-Clearfield rice. Weed Technology, 26(2):236-242. https://doi.org/DOI: 10.1614/WT-D-1100128.1 
Leiva, F.; Zaldúa, F. 2016. Efecto de deriva de herbicida (imazapir + imazapic) en arroz no Clearfield. Montevideo: UDELAR, FAGRO.

Saldain, N.E.; Deambrosi, E. 2005. Efectos de simulación de deriva del glifosato en EI Paso 144. In: INIA Treinta y Tres. Arroz: resultados experimentales 2004-2005. Treinta y Tres: INIA. cap. 8, p. 25-29. (INIA Serie Actividades de Difusión; 418)
Saldain, N. 2007. Efectos de simulación de deriva del glifosato en El Paso 144. In INIA Treinta y Tres. Arroz: resultados experimentales 2006-2007. Treinta y Tres: INIA. cap. 5 p. 19-24. (INIA Serie Actividades de Difusión; 502)

Walker, D. C. 2018. Utilizing enhanced acetolactate-synthase tolerant soybean to mitigate off-target deposition of penoxulam and bispyribac-sodium. Mississippi: Mississippi State University. $61 \mathrm{p}$. 
INIA Dirección Nacional

Avenida Italia 6201,

Ed. Los Guayabos,

Parque Tecnológico LATU.

Montevideo

Tel.: 26056021

inia@inia.org.uy

INIA La Estanzuela Ruta 50, Km 11

Colonia

Tel.: 59845748000

Fax: 59845748012

iniale@le.inia.org.uy

INIA Las Brujas

Ruta 48, Km 10

Canelones

Tel.: 59823677641

Fax: 59823677609

inia_lb@lb.inia.org.uy

INIA Salto Grande

Camino al Terrible

Salto

Tel.: 59847335156

Fax: 59847329624

inia_sg@sg.inia.org.uy

INIA Tacuarembó

Ruta 5, Km 386

Tacuarembó

Tel.: 59846322407

Fax: 59846323969

iniatbo@tb.inia.org.uy

INIA Treinta y Tres

Ruta 8, Km 281

Treinta y Tres

Tel.: 59844522023

Fax: 59844525701

iniatt@tyt.inia.org.uy

www.inia.uy 